Jana Menegassi del Favero

\title{
Ictiofauna de ambientes praiais da barra sul do sistema costeiro Cananéia-Iguape, São Paulo
}

\begin{abstract}
Dissertação apresentada ao Instituto Oceanográfico da Universidade de São Paulo, como parte dos requisitos para obtenção do título de Mestre em Ciências, área de Oceanografia Biológica.
\end{abstract}

Orientadora: Profa. Dra. June Ferraz Dias

São Paulo 


\title{
Ictiofauna de ambientes praiais da barra sul do sistema costeiro Cananéia-Iguape, São Paulo
}

\author{
Jana Menegassi del Favero
}

Dissertação apresentada ao Instituto Oceanográfico da Universidade de São Paulo, como parte dos requisitos para obtenção do título de Mestre em Ciências, área de Oceanografia Biológica.

Julgada em

Prof. Dr.

Conceito

Prof. Dr.

Conceito

Prof. Dr.

Conceito 
ÍNDICE

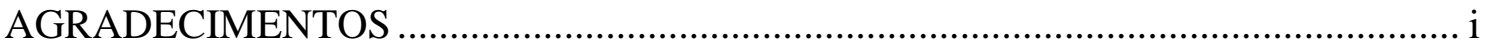

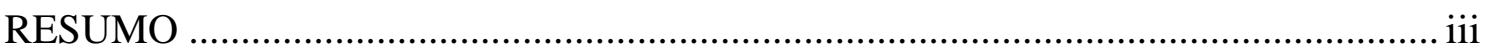

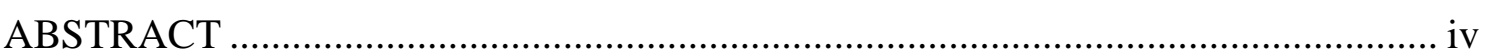

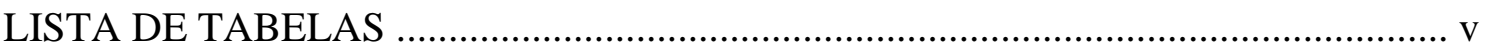

LISTA DE FIGURAS …………………………………................................... vii

Capítulo 1

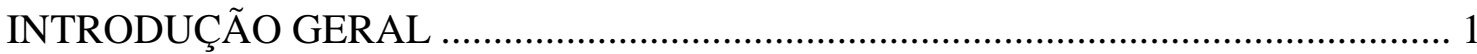

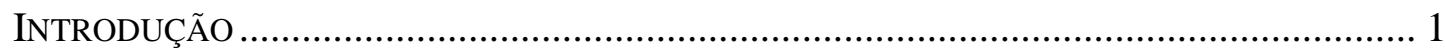

OBJETIVO GERAL E HIPÓTESES DE TRABALHO ………………................................... 4

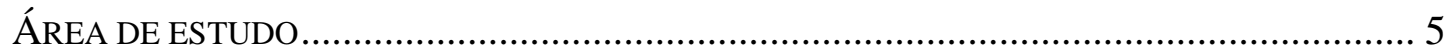

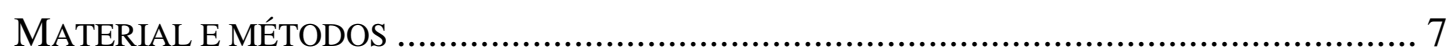

Locais de amostragem e variáveis ambientais....................................................... 7

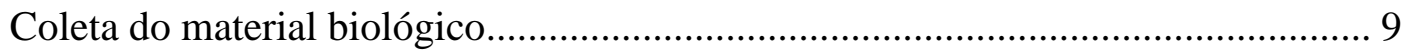

Tomada de dados dos exemplares .................................................................... 9

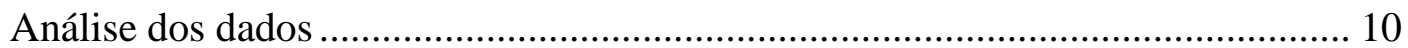

Capítulo 2

ASPECTOS ESTRUTURAIS DA ICTIOFAUNA DE AMBIENTES PRAIAIS DA

BARRA SUL DO SISTEMA COSTEIRO CANANÉIA-IGUAPE: VARIAÇÕES DE

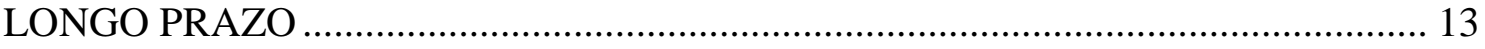

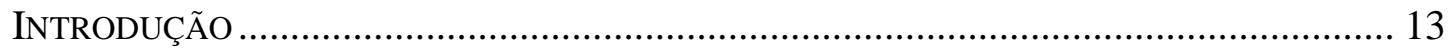

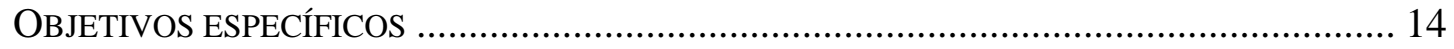

MÉTODO DE COLETA E TOMADA DOS DADOS …………………............................... 15

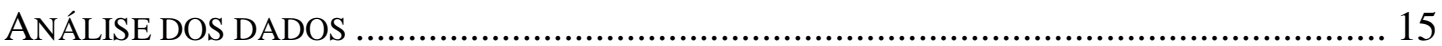

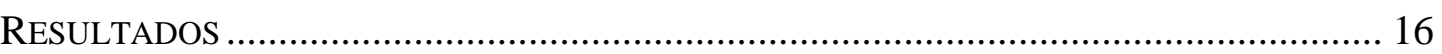

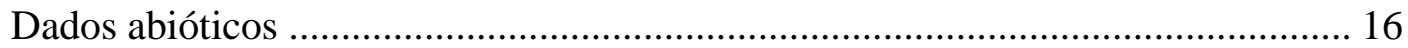

Composição da ictiofauna ……………………………………………………..... 17

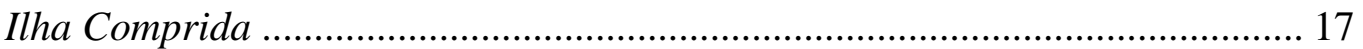

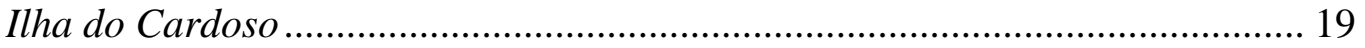

Variações na composição e estruturação da ictiofauna .............................................. 21

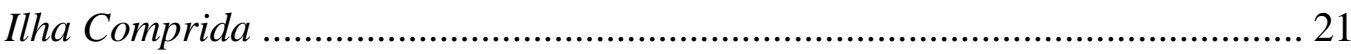

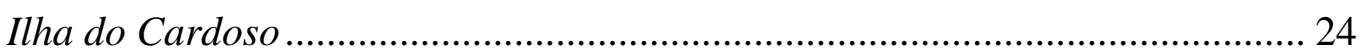

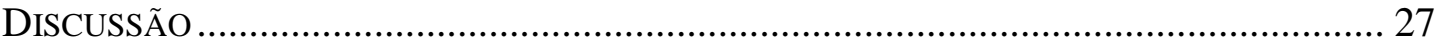


Capítulo 3

ASPECTOS ESTRUTURAIS DA ICTIOFAUNA DE AMBIENTES PRAIAIS DA BARRA SUL DO SISTEMA COSTEIRO CANANÉIA-IGUAPE: VARIAÇÕES DE

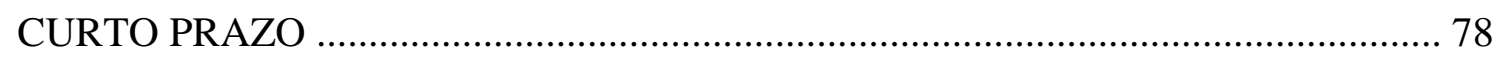

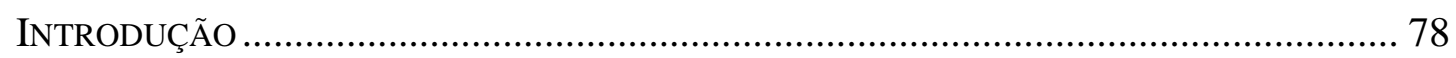

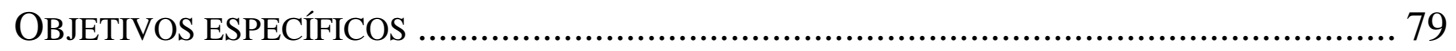

MÉTODO DE COLETA E TOMADA DOS DADOS ............................................................. 79

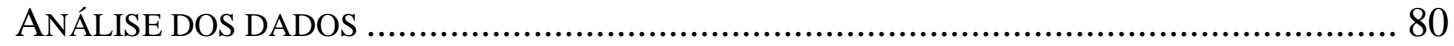

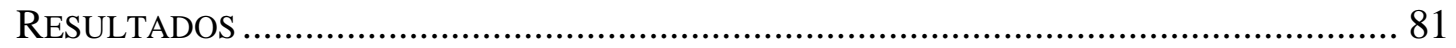

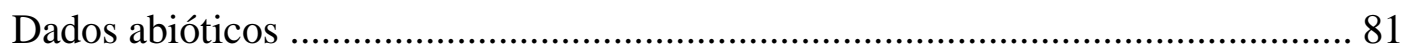

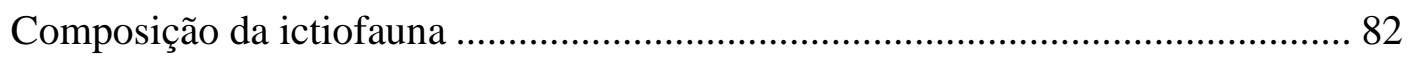

Variações na composição e estruturação da ictiofauna ........................................ 83

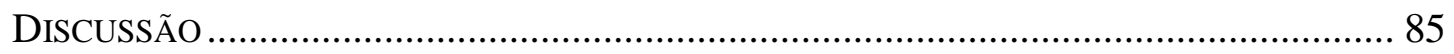

Capítulo 4

PADRÕES DE RECRUTAMENTO DA ICTIOFAUNA EM ÁREAS RASAS DE PRAIAS ARENOSAS DA BARRA SUL DO SISTEMA COSTEIRO CANANÉIA-

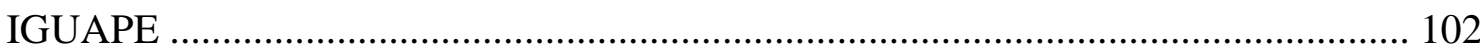

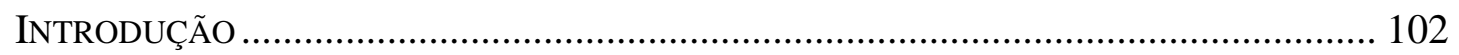

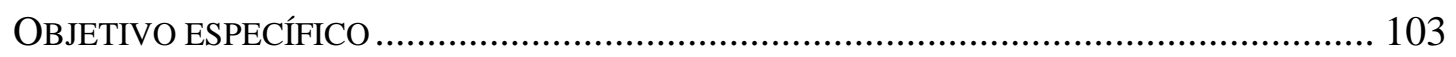

MÉTODO DE COLETA E TOMADA DOS DADOS ........................................................... 103

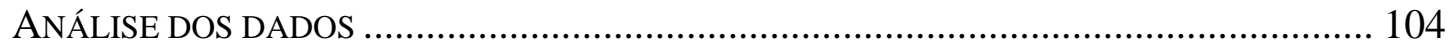

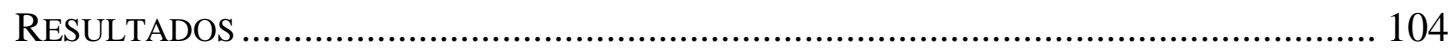

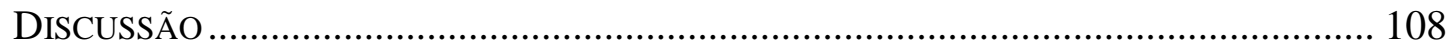

SUMÁRIO DOS RESULTADOS OBTIDOS …....................................................... 137

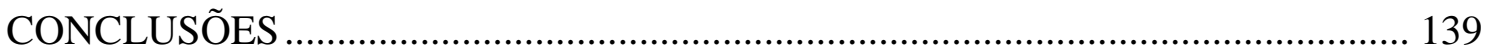

SUGESTÕES PARA TRABALHOS FUTUROS .................................................... 140

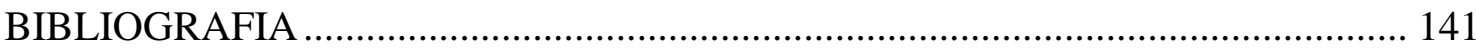




\section{AGRADECIMENTOS}

Primeiramente a Profa June Ferraz Dias, por ter aberto as portas de seu laboratório, fazendo possível a migração tão sonhada de água doce para marinha. Sua orientação e correção segura, estímulos e amizade foram imprescindíveis para a realização deste trabalho.

Ao CNPq pela bolsa concedida.

Ao Instituto Oceanográfico pelo uso de suas instalações. Principalmente pelo uso da base de pesquisa "João de Paiva Carvalho", localizada em Cananéia. Guardo com carinho os dias passados na base triando ou em praias coletando, dias esses que foram muito mais divertidos e produtivos graças a todos os seus funcionários. Impossível não agradecer em especial: Amaury, Ricardo (grande contador de piadas), Clovinho (além de "piloteiro" era também companheiro na cervejinha), Humberto, Chico e Seu João, por estarem sempre de bom humor quer faça sol quer faça chuva!

Aos funcionários do IO/USP, quer seja da biblioteca, secretaria, motoristas etc, vocês em muito ajudaram e talvez nem saibam. Especialmente ao Válter Miyagi por me socorrer sempre que o computador pifava (ou eu!).

A todos os alunos de graduação que me ajudaram no trabalho de campo. Especialmente à Bárbara, Augusto e Natasha que, além de me aturarem vários dias em Cananéia, muito me ajudaram em São Paulo.

Aos meus professores das disciplinas cursadas, que em muito contribuíram para meu crescimento profissional, em especial ao Eduardo Tavares Paes, que ajudou com a análise dos dados.

Aos professores José Lima de Figueiredo e Naércio Menezes, por me receber sempre muito bem no Museu de Zoologia e me ajudar na identificação dos exemplares.

Ao atual diretor do Instituto Oceanográfico, Michel Michaelovitch, por ter "fugido" da diretoria e me dar algumas aulas particulares, além das referências sugeridas.

Ao prof. Vicente Gomes, pela supervisão no programa PAE.

Ao prof. Mario Katsuragawa, pelas diversas ajudas com identificação de larvas, referências e por fim, por ter-me "contratado". Tem sido uma grande honra trabalhar com você!

À técnica, amiga, massagista, médica, psicóloga, Maria de Lourdes Zani- 
Teixeira. Impossível lembrar e citar todas as ajudas prestadas quer seja na identificação das larvas, ajuda nos programas de computador, até mesmo como psicóloga para desabafos, arrumar remédios para dor e assim vai... Sou muito feliz por ter tido (e ter) você no meu caminho.

À técnica Helcy e todo pessoal do Laboratório de Recrutamento e Reprodução de organismos marinhos. Carinhosamente aos amigos Tassilda, Isita, Rigueleto, Miguelits, Frango, Diego, Tati, Kenji, Eudriano e Válter André. Inúmeras foram as ajudas e risadas cedidas...

Ao pessoal do meu segundo laboratório: Cláudia, Márcio (Bãr) (que além de amigos tentaram e muito identificar as larvas), Renatinha, Camila, Aninha e Pedro. E a todos os agregados que frequentam o laboratório para apreciar o cafezinho MK. Nada melhor que uma fuga do trabalho e um bom papo!

A todos os amigos conquistados e re-conquistados desde a minha mudança a São Paulo. Principalmente à Mariana Copede que em muito me ajudou na minha chegada, e às queridas Rutita, Martita, Carolzita e Dani!

Aos velhos e eternos amigos das mais diversas turmas que são presentes em minha vida. Infelizmente não há espaço para citar cada um de vocês aqui, mas vocês sabem o tão importantes são para mim! Em especial a turma que vive enquanto os outros lêem, esta aqui é a prova concreta disso, pois mesmo acompanhando vocês consegui terminar esse trabalho, rs. E também a turma de Biologia-UFLA (2007), vocês são os melhores!

À minha família, de perto e de longe, em especial aos meus irmãos, por literalmente terem salvado minha vida no começo do mestrado, e meus pais, que continuam acreditando e incentivando meus sonhos e loucuras. Amo vocês!

Ao meu noivo Sandro, por além das inúmeras ajudas no que se refere o trabalho, na formatação, mapas, xerox, etc, de muito ajudou não perdendo a paciência nos dias de estresse, cozinhando e cuidando de mim. Impossível descrever o que você significa na minha vida em um único parágrafo. Te amo.

A todos que de alguma forma contribuíram para a realização deste trabalho.

E por fim aos anjos, por guiarem e iluminarem meu caminho

Muito obrigada! 


\section{RESUMO}

O objetivo deste estudo foi analisar as variações de curta e longa escala temporal na composição e na estrutura da ictiofauna de ambientes praiais e entender os padrões de recrutamento das principais espécies. Seis praias do sistema costeiro Cananéia-Iguape foram amostradas com uma rede de picaré. As amostragens foram realizadas mensalmente de dezembro de 2008 a janeiro de 2010 para as análises de longa escala e a cada dois dias durante um mês de verão para as análises de curto tempo. Independente do foco na variabilidade de curta ou de longa escala, muitas das características da comunidade de peixes permaneceram as mesmas: a predominância de exemplares juvenis, a presença de poucas espécies dominantes e constantes, a alta abundância de Trachinotus e Mugil, e as variações dos índices ecológicos em cada praia ou maré estudada. A influência da temperatura na estrutura da comunidade foi significativa nos estudos de longa escala, mostrando a importância das variações sazonais e do recrutamento nos padrões da comunidade. Juvenis de T. carolinus recrutam ao longo do ano, enquanto T. goodei e Menticirrhus littoralis foram recrutados durante a primavera. $M$. curema e $M$. hospes recrutaram durante o verão, enquanto $M$. liza foi recrutou durante o inverno. Este estudo ressaltou a importância ecológica e econômica da zona rasa de ambientes praias, pois muitas das espécies analisadas na área são importantes recursos pesqueiros para a região.

Palavras-chave: ictiofauna, zona de surfe, sistema costeiro Cananéia-Iguape, recrutamento, fatores ambientais. 


\section{ABSTRACT}

The aim of this study was to analyze short and long-term temporal variations in ichthyofauna composition and structure from sandy beaches and to understand recruitment patterns of the main species. Six beaches of the coastal system CananéiaIguape were sampled using a beach seine. The samples were conducted monthly from December 2008 to January 2010 for a long-term analysis, or every other day during a summer month, for a short-term analysis. Regardless the focus in short or long-term variability, most characteristics of the fish community remained the same: the juvenile fish's predominance, the presence few dominant and constant species, the high Trachinotus and Mugil abundance, and the variation of the ecological indexes on each beach and tide studied. The influence of the temperature in the community structure was significant only in the long-term study, showing the seasonal variation and the recruitment importance on the community patterns. T. carolinus juveniles' recruit all over the year, while T. goodei and Menticirrhus littoralis recruit during spring. $M$. curema and $M$. hospes recruit during summer, while $M$. liza recruit during winter. The present study highlighted the ecological and economic importance of sandy beach shallow zone, as many species analyzed are regional important fishery resources.

Keywords: ichthyofauna, surf zone, costal system Cananéia-Iguape, recruitment, environmental variables. 


\section{LISTA DE TABELAS}

Tabela 2.1. Frequencia relativa (\%) dos indivíduos da ictiofauna ao longo dos meses amostrados nas praias da Ilha Comprida, contribuição total e constância de ocorrência $(\mathrm{C})$.

Tabela 2.2. Peso total (g) das oito espécies da ictiofauna com maiores contribuições relativas (\%) da amostragem realizada nas praias da Ilha Comprida.

Tabela 2.3. Médias de comprimento padrão ( $\mathrm{mm}$ ) e do peso $(\mathrm{g})$ das espécies da ictiofauna, em ordem alfabética, amostrados nas praias da Ilha Comprida, com seus valores mínimo, máximo e desvio padrão.

Tabela 2.4. Frequência relativa (\%) dos indivíduos da ictiofauna ao longo dos meses amostrados nas praias Ilha do Cardoso, contribuição total, e constância de ocorrência $(\mathrm{C})$

Tabela 2.5. Peso total (g) das quatro espécies da ictiofauna com maiores contribuições relativas (\%) da amostragem realizada nas praias da Ilha do Cardoso

Tabela 2.6. Médias de comprimento padrão $(\mathrm{mm})$ e do peso $(\mathrm{g})$ das espécies da ictiofauna, em ordem alfabética, amostrados nas praias da Ilha do Cardoso, com seus valores mínimo, máximo e desvio padrão.

Tabela 2.7. Frequência relativa (\%) das espécies da ictiofauna amostrados nas diferentes praias da Ilha Comprida.

Tabela 2.8. Índices ecológicos calculados para a ictiofauna capturada durante a maré alta e baixa das diferentes praias da Ilha Comprida 
Tabela 2.9. Índices ecológicos calculados para a ictiofauna capturada durante os meses frios e quentes das praias da Ilha Comprida.

Tabela 2.10. Correlação das variáveis significativas para a explicação da estrutura da ictiofauna das praias Ilha Comprida com os quatro primeiros eixos e resumo estatístico dos dados

Tabela 2.11. Freqüência relativa (\%) das espécies da ictiofauna amostrados na diferentes praias da Ilha do Cardoso.

Tabela 2.12. Índices ecológicos calculados para a ictiofauna capturada durante maré alta e baixa das diferentes praias da Ilha do Cardoso.

Tabela 2.13. Índices ecológicos calculados para a ictiofauna capturada durante os meses frios e quentes agrupados na Ilha do Cardoso.

Tabela 2.14. Correlação das variáveis significativas para a explicação da estrutura da ictiofauna da Ilha do Cardoso com os quatro primeiros eixos e resumo estatístico dos dados.

Tabela 2.15. Tamanho de rede e de malha utilizadas em diferentes estudos relativos à ictiofauna de zona de surfe em praias.

Tabela 3.1. Abundância (\%), constância de ocorrência (C), comprimento total máximo (Max CT) e mínimo (min CT) medido e o máximo obtido na literatura, em milímetros, de cada espécie amostrada na Ilha Comprida entre 23 de janeiro de 2009 e 18 de fevereiro de 2009

Tabela 3.2. Índices descritores de comunidade durante o verão de 2009 nas diferentes praias amostradas da Ilha Comprida, e valor do teste de BOOTSTRAP (Boot P) com $95 \%$ de confiança. 
Tabela 3.3. Índices descritores de comunidade durante o verão de 2009 na maré baixa e alta da Ilha Comprida, e valor do teste de BOOTSTRAP (Boot P) com $95 \%$ de confiança

Tabela 3.4. Sumário da Análise de Correspondência Canônica (CCA) sobre a abundância de espécies de peixes amostrados na Ilha Comprida durante o verão de 2009.

Tabela 3.5. Estudos selecionados sobre a ictiofauna da zona de surfe de praias arenosas amostrados com diferentes esforços em diversos locais e por diferentes tipos de arrasto de praia

Tabela 4.1. Frequência relativa mensal e total (\%) das espécies amostradas na barra sul do sistema costeiro Cananéia-Iguape de fevereiro de 2009 a janeiro de 2010, e o local em que elas foram obtidas.

Tabela 4.2. Ocorrência das espécies mais abundantes no presente estudo amostradas em outras regiões do sistema costeiro Cananéia-Iguape, e a arte de pesca utilizada na amostragem das mesmas 


\section{LISTA DE FIGURAS}

Figura 1.1. Imagem de satélite ilustrando a América do Sul e em destaque o Sistema Costeiro Cananéia- Iguape, localizado no litoral sul do estado de São Paulo, Brasil

Figura 1.2 Praias Abrigadas (A), Intermediárias (I) e Expostas (E) amostradas na Ilha Comprida (1) e na Ilha do Cardoso (2), localizadas na barra sul do sistema costeiro Cananéia-Iguape, São Paulo, Brasil

Figura 2.1. Variações de temperatura média medida na zona de surfe de praias arenosas da Ilha Comprida entre dezembro de 2008 e janeiro de 2010

Figura 2.2. Variações de temperatura média medida na zona de surfe de praias arenosas da Ilha do Cardoso entre fevereiro de 2009 e janeiro de 2010

Figura 2.3. Variações de temperatura média medida na zona de surfe de diferentes praias arenosas da Ilha Comprida entre dezembro de 2008 e janeiro de 2010 .

Figura 2.4. Variações de temperatura média medida na zona de surfe de diferentes praias arenosas da Ilha do Cardoso entre fevereiro de 2009 e janeiro de 2010 .

Figura 2.5. Variações de temperatura média medida durante a maré alta e baixa na zona de surfe de praias arenosas da Ilha Comprida de dezembro de 2008 a janeiro de 2010

Figura 2.6. Variações de temperatura média medida durante a maré alta e baixa na zona de surfe de praias arenosas da Ilha do Cardoso de fevereiro de 2008 a janeiro de 2010 
Figura 2.7. Variações de salinidade média medida na zona de surfe de diferentes praias arenosas da Ilha do Cardoso entre fevereiro de 2009 e janeiro de 2010 .

Figura 2.8. Variações de salinidade média medida na zona de surfe de diferentes praias arenosas da Ilha Comprida entre dezembro de 2008 e janeiro de 2010.

Figura 2.9. Variações de salinidade média medida na zona de surfe de praias arenosas da Ilha Comprida entre dezembro de 2008 e janeiro de 2010

Figura 2.10. Variações de salinidade média medida na zona de surfe de praias arenosas da Ilha do Cardoso entre fevereiro de 2010 e janeiro de 2010

Figura 2.11. Variações de temperatura média medida durante a maré alta e baixa na zona de surfe de praias arenosas da Ilha Comprida de dezembro de 2008 a janeiro de 2010

Figura 2.12. Variações de temperatura média medida durante a maré alta e baixa na zona de surfe de praias arenosas da Ilha do Cardoso de fevereiro de 2009 a janeiro de 2010.

Figura 2.13. Distribuição dos dados mensais dos fatores abióticos mensurados nas três praias e nas diferentes marés amostradas entre dezembro de 2008 e janeiro de 2010 na Ilha Comprida obtida pela análise de escalonamento multidimensional não métrico $M D S$.

Figura 2.14. Distribuição dos dados mensais dos fatores abióticos mensurados nas três praias e nas diferentes marés amostradas entre fevereiro de 2009 e janeiro de 2010 na Ilha do Cardoso obtida pela análise de escalonamento multidimensional não métrico $M D S$. 
Figura 2.15. Distribuição de frequência das classes de comprimento padrão dos exemplares da ictiofauna obtidos nas praias da Ilha Comprida.

Figura 2.16. Distribuição de frequência das classes de comprimento padrão dos exemplares da ictiofauna capturados nas praias da Ilha do Cardoso.

Figura 2.17. Distribuição de frequência das classes de comprimento padrão, em milímetros, dos exemplares de peixes obtidos nas diferentes praias da Ilha Comprida.

Figura 2.18. Distribuição de frequência das classes de comprimento padrão, em milímetros, dos exemplares de peixes obtidos nas praias da Ilha Comprida durante diferentes marés.

Figura 2.19. Número de indivíduos da ictiofauna capturados por praia ao longo dos meses amostrados na Ilha Comprida de dezembro de 2008 a janeiro de 2010 .

Figura 2.20. Peso total da ictiofauna obtido por praia ao longo dos meses amostrados na Ilha Comprida de dezembro de 2008 a janeiro de 2010.

Figura 2.21. Número de espécies da ictiofauna identificados por praia ao longo dos meses amostrados na Ilha Comprida de dezembro de 2008 a janeiro de 2010

Figura 2.22. Variação mensal dos índices ecológicos calculados com dados de ictiofauna obtidos nas praias da Ilha Comprida de dezembro de 2008 a janeiro de 2010.

Figura 2.23. Dendograma resultante da análise de agrupamento realizada com dados de ocorrência numérica mensal da ictiofauna, transformados por raiz quadrada, obtidos em praias da Ilha Comprida de dezembro de 2008 a janeiro de 2010. 
Figura 2.24. Diagrama de ordenação (biplot) da Análise de Correspondência Canônica incluindo as espécies da ictiofauna amostradas mensalmente entre dezembro de 2008 e janeiro de 2010 nas diferentes praias da Ilha Comprida e as variáveis abióticas significativas (representadas por vetores).

Figura 2.25. Distribuição de frequência das classes de comprimento padrão, em milímetros, dos exemplares de peixes obtidos nas diferentes praias da Ilha do Cardoso

Figura 2.26. Distribuição de frequência das classes de comprimento padrão, em milímetros, dos exemplares de peixes obtidos nas praias da Ilha do Cardoso durante as diferentes marés.

Figura 2.27. Número de indivíduos da ictiofauna capturados por praia ao longo do ano de coleta nas praias da Ilha do Cardoso de fevereiro de 2009 a janeiro de 2010 .

Figura 2.28. Peso total da ictiofauna obtido por praia ao longo do ano de coleta nas praias da Ilha do Cardoso de fevereiro de 2009 a janeiro de 2010.

Figura 2.29. Número de exemplares da ictiofauna identificados em nível específico ou de gênero por praia ao longo do ano de coleta nas praias da Ilha do Cardoso de fevereiro de 2009 a janeiro de 2010

Figura 2.30. Variação mensal dos índices ecológicos calculados com dados obtidos nas praias da Ilha do Cardoso de fevereiro de 2009 a janeiro de $2010 \ldots .$.

Figura 2.31. Dendograma resultante da análise de agrupamento realizada com dados de ocorrência numérica mensal da ictiofauna, transformados por raiz quadrada, obtidos em praias da Ilha do Cardoso de fevereiro de 2009 a janeiro de 2010 
Figura 2.32. Diagrama de ordenação (biplot) da Análise de Correspondência Canônica incluindo as espécies da ictiofauna amostradas mensalmente entre fevereiro de 2009 a janeiro de 2010 nas diferentes praias da Ilha do Cardoso e as variáveis abióticas significativas (representadas por vetores)

Figura 3.1. Variações de temperatura média medida na zona de surfe de praias arenosas da Ilha Comprida de 23 de janeiro de 2009 a 18 de fevereiro de 2009.. 94

Figura 3.2. Variações de temperatura média medida durante a maré alta e baixa na zona de surfe de praias arenosas da Ilha Comprida de 23 de janeiro de 2009 a 18 de fevereiro de 2009

Figura 3.3. Variações de temperatura média medida na zona de surfe de diferentes praias da Ilha Comprida entre 23 de janeiro de 2009 e 18 de fevereiro de 2009 .

Figura 3.4. Variações de salinidade média medida na zona de surfe de praias arenosas da Ilha Comprida de 23 de janeiro de 2009 a 18 de fevereiro de 2009... 96

Figura 3.5. Variações de salinidade média medida durante a maré alta e baixa na zona de surfe de praias arenosas da Ilha Comprida de 23 de janeiro de 2009 a 18 de fevereiro de 2009

Figura 3.6. Variações de salinidade média medida na zona de surfe de diferentes praias da Ilha Comprida entre 23 de janeiro de 2009 e 18 de fevereiro de 2009.

Figura 3.7. Classes de comprimento padrão, em milímetros, de todos os exemplares amostrados na zona de surfe de praias da Ilha Comprida entre 23 de janeiro de 2009 e 18 de fevereiro de 2009. 
Figura 3.8. Diagrama de ordenação da Análise de Correspondência Canônica incluindo as espécies amostradas durante o verão de 2009 na Ilha Comprida e as variáveis abióticas significativas, representadas por vetores

Figura 3.9. Valores de $T$ value com o círculo de Van Dobben em vermelho representando a praia abrigada e o em azul a praia exposta. As espécies que estão com seus vetores representados dentro do círculo correlacionam-se com o mesmo

Figura 3.10. Valores de $T$ value com o círculo de Van Dobben em vermelho representando a maré alta e o em azul a maré baixa. As espécies que estão com seus vetores representados dentro do círculo correlacionam-se com o mesmo.....

Figura 3.11. Valores de $T$ value com o círculo de Van Dobben em vermelho representando as fases de quadratura e o em azul a de sizígia. As espécies que estão com seus vetores representados dentro do círculo correlacionam-se com o mesmo

Figura 4.1. Variação de temperatura média mensal medida na zona de surfe de praias arenosas da barra sul do Sistema Costeiro Cananéia-Iguape de fevereiro de 2009 a janeiro de 2010.

Figura 4.2. Variação de salinidade média mensal medida na zona de surfe de praias arenosas da barra sul do Sistema Costeiro Cananéia-Iguape de fevereiro de 2009 a janeiro de 2010 .

Figura 4.3. Dendograma resultante da análise de agrupamento da abundância total nos meses de coleta realizada com dados de ocorrência numérica mensal, transformados por Hellinger. 
Figura 4.4. Dendograma resultante da análise de agrupamento das espécies realizada com dados de ocorrência numérica mensal, transformados por Hellinger.

Figura 4.5. Frequência de classes de comprimento padrão para Trachinotus goodei amostrados na zona de surfe de praias arenosas da barra sul do sistema costeiro Cananéia Iguape entre fevereiro de 2009 e janeiro de 2010.

Figura 4.6. Frequência de classes de comprimento padrão para Trachinotus carolinus amostrados na zona de surfe de praias arenosas da barra sul do sistema costeiro Cananéia Iguape entre fevereiro de 2009 e janeiro de 2010 .........

Figura 4.7. Frequência de classes de comprimento padrão para Oligoplites saliens amostrados na zona de surfe de praias arenosas da barra sul do sistema costeiro Cananéia Iguape entre fevereiro de 2009 e janeiro de 2010.

Figura 4.8. Frequência de classes de comprimento padrão para Mugil curema amostrados na zona de surfe de praias arenosas da barra sul do sistema costeiro Cananéia Iguape entre fevereiro de 2009 e janeiro de 2010.

Figura 4.9. Frequência de classes de comprimento padrão para Mugil hospes amostrados na zona de surfe de praias arenosas da barra sul do sistema costeiro Cananéia Iguape entre fevereiro de 2009 e janeiro de 2010.

Figura 4.10. Frequência de classes de comprimento padrão para Mugil liza amostrados na zona de surfe de praias arenosas da barra sul do sistema costeiro Cananéia Iguape entre fevereiro de 2009 e janeiro de 2010.

Figura 4.11. Frequência de classes de comprimento padrão para Menticirrhus littoralis amostrados na zona de surfe de praias arenosas da barra sul do sistema costeiro Cananéia Iguape entre fevereiro de 2009 e janeiro de 2010 
Figura 4.12. Frequência de classes de comprimento padrão para Harengula clupeola amostrados na zona de surfe de praias arenosas da barra sul do sistema costeiro Cananéia Iguape entre fevereiro de 2009 e janeiro de 2010.

Figura 4.13. Frequência de classes de comprimento padrão para Anchoa tricolor amostrados na zona de surfe de praias arenosas da barra sul do sistema costeiro Cananéia Iguape entre fevereiro de 2009 e janeiro de 2010

Figura 4.14. Frequência de classes de comprimento padrão para Choloroscombrus chrysurus amostrados na zona de surfe de praias arenosas da barra sul do sistema costeiro Cananéia Iguape em dezembro de 2009.

Figura 4.15. Frequência de comprimento padrão para Atherinella brasiliensis amostrados na zona de surfe de praias arenosas da barra sul do sistema costeiro Cananéia Iguape entre fevereiro de 2009 e janeiro de 2010

Figura 4.16. Frequência mensal de ocorrência dos estádios de maturação gonadal de Atherinella brasiliensis coletados na zona de surfe de praias arenosas da barra sul do Sistema Costeiro Cananéia Iguape entre fevereiro de 2009 e janeiro de 2010. 


\section{Capítulo 1. INTRODUÇÃO GERAL}

\section{INTRODUÇÃO}

As condições ambientais têm um efeito direto sobre o recrutamento e, consequentemente, sobre o tamanho das populações. Habitats com condições ambientais físicas, químicas e biológicas inadequadas para os peixes têm como prováveis respostas a redução da fecundidade e da taxa de crescimento individual, além de um aumento da taxa de mortalidade (WENER, 2002). É clara a importância no reconhecimento e preservação dos habitats que favoreçam a sobrevivência dos peixes para a manutenção de seus estoques. Todavia, os peixes podem experimentar habitats diferentes, desde a desova até a maturidade (Hipótese do Triângulo de Migração HARDEN JONES, 1968). Apesar disso, é na fase inicial do ciclo de vida que as condições ambientais podem exercer maior influência sobre a sobrevivência dos peixes, pois, entre diversos outros fatores, é nesta fase que os organismos são mais vulneráveis às variações ambientais e possuem limitada capacidade de locomoção para atingir, por si só, os habitats adequados (HJORT, 1914).

Entende-se por recrutamento o processo de se adicionar novos indivíduos a um estágio específico do ciclo de vida da espécie (JENNINGS, 2001). Deste modo, a sobrevivência das fases iniciais do ciclo de vida, quando a mortalidade é mais elevada, relaciona-se ao sucesso do recrutamento de indivíduos ao estoque adulto, que por sua vez está relacionado ao tamanho das populações. O conhecimento dos possíveis fatores ambientais e das ações antrópicas que afetam a sobrevivência dos peixes, principalmente nas fases iniciais do desenvolvimento, é importante para a administração pesqueira, gerenciamento costeiro e preservação da espécie. Ressalta-se assim a importância do conhecimento dos locais de crescimento e alimentação dos juvenis.

As praias arenosas constituem a maior parte das áreas costeiras do mundo, representando uma importante área de recreação e abrigando uma grande variedade de recursos naturais (BROWN e MCLACHLAN, 1990). É uma área que sofre fortes pressões tanto naturais, como as exercidas pelos processos hidrográficos, biológicos e eólicos, alterando drasticamente as feições em um curto período de tempo 
(MCLACHALAN, 1983), quanto antrópicas, devido ao crescente processo de urbanização e exploração.

A zona de surfe das praias arenosas caracteriza-se como a faixa litorânea que se estende desde a linha da costa até o limite externo das células de circulação das correntes geradas pela própria ação das ondas (MCLACHALAN, 1983). É um ambiente em que a energia das ondas controla a maioria dos processos físicos, químicos e biológicos (BENNETT, 1989). Por mais que seja uma área de aparente estresse ambiental e tenha uma pequena variedade de nichos ecológicos, suporta uma fauna variada, principalmente de organismos zooplanctônicos e peixes (SPRING e WOODBUM, 1960). Juvenis recrutam nestas áreas, onde encontram alimento e proteção contra predadores devido à elevada turbulência e baixa profundidade (LASIAK, 1981). Deste modo, a zona de surfe das praias arenosas pode ser considerada uma importante área de crescimento e alimentação para muitas espécies de peixes (MCLACHLAN et al., 1981).

A ictiofauna da zona de surfe de praias arenosas é dinâmica, com pequeno número de espécies dominantes e residentes, com variação sazonal e espacial na abundância, e com predomínio de jovens (GIANNINI e PAIVA FILHO, 1995; SANTOS e NASH, 1995; GODEFROID et al., 2003; GODEFROID et al., 2004; VASCONCELLOS et al., 2007). Tal comunidade pode variar de acordo com sua permanência nesses ambientes, sendo que parte permanece períodos supra-anuais (GIBSON et al., 1996) ou ao longo do ano (BROWN e MCLACHLAN, 1990).

Trabalhos brasileiros sobre a ictiofauna de praias descrevem: a estrutura e as variações espaço-temporais das comunidades (PAIVA FILHO et al., 1987; PEREIRA, 1994; GIANNINI e PAIVA FILHO, 1995; SAUL e CUNNINGHAM, 1995; GAELZER e ZALMON, 2003; GOMES et al., 2003; ARAÚJO et al., 2008; LIMA e VIEIRA, 2009); as variações da fauna entre dia e noite (PESSANHA e ARAÚJO, 2003; OLIVEIRA NETO et al., 2004; GAELZER e ZALMON, 2008a); a influência da dinâmica e da morfologia praiais (SANTOS, 1994; FÉLIX et al., 2007a; VASCONCELLOS et al., 2007); a influência das marés (GODEFROID et al., 1998; GAELZER e ZALMON, 2008b); e aspectos tróficos (STEFANONI, 2008). Apesar de diversos autores terem estudado comunidades de peixes em praias brasileiras, na área de estudo do presente trabalho somente GIANNINI e PAIVA FILHO (1995) registraram a 
ocorrência de famílias e espécies na praia de Fora de Ilha Comprida, não mencionando, porém, qualquer informação sobre tamanho dos espécimes ou fase de seu ciclo de vida (jovem ou adulto). Saul e Cunningham (1995) estudaram a comunidade de peixes da zona de surfe da Ilha do Bom Abrigo. Em sistema contíguo, o de Paranaguá, cabe destacar o trabalho de Félix et al., (2007a) sobre variação sazonal das comunidades de peixes de praias com diferente morfodinamismo, mas que não foca o recrutamento ou a permanência das diferentes fases do ciclo de vida nas praias com diferentes graus de exposição.

As praias alvo deste estudo localizam-se na desembocadura de uma região estuarina. Pritchard (1967) define estuários como corpos d'água semiconfinados, que apresentam livre conexão com o mar e nos quais ocorre mistura de água salgada e água doce de origem fluvial. Por serem ecossistemas de transição entre o continente e o oceano, estão sujeitos à intensa ação de forças físicas, principalmente a entrada de água doce e a oscilação da maré (MIRANDA et al., 2002). Tais ações resultam em variações periódicas de fatores ambientais, como salinidade, temperatura, nutrientes e concentração de oxigênio (PERKINS, 1974; DAY et al., 1989). Apesar das rápidas e intensas variações ambientais, uma grande quantidade de peixes, incluindo parte dos recursos pesqueiros, é atraída para os estuários devido à alta produtividade e a abundância de áreas para serem usadas como refúgio (MCHUGH, 1985; YÁÑEZARANCIBIA, 1985). As larvas e juvenis encontram proteção contra predadores e alimento, o que resulta em uma diminuição na mortalidade e taxas de crescimento mais elevadas (MORAIS e MORAIS, 1994; BARLETTA-BERGAN et al., 2002). Além disso, as praias adjacentes a estuários constituem rotas de migração de diversos peixes em fase larval e juvenil, que passam uma ou mais fase de vida dentro dos estuários (COWLEY et al., 2001; WATT- PRINGLE e STRYDOM, 2003)

Uma compilação recente de dados sobre a ictiofauna do sistema costeiro Cananéia-Iguape apontou que tal região abriga pelo menos 169 espécies de peixes, sendo 163 Actinopterygii e seis Chondrichthyes, pertencentes a 58 e quatro diferentes famílias respectivamente. Sciaenidae é a família com o maior número de espécies (19), seguida por Carangidae (14) e Engraulidae (10). Dentre as espécies, 94\% são tipicamente marinhas e/ou estuarinas e se distribuem ao longo de todo o estuário (CONTENTE et al., 2010). Tal área é relevante para inúmeras espécies de peixes. Para 
Cathorops spixii, Stellifer rastrifer, Atherinella brasiliensis, Anchoviella lepidentostole e Achirus lineatus, é um ambiente em que todas as etapas de seu ciclo de vida são cumpridas; para Chloroscombrus chrysurus, Harengula clupeola e Oligoplites saliens é uma área de abrigo para juvenis, consequentemente de entrada de jovens, crescimento e recrutamento; e para outras espécies um local de desova (PERES-RIOS, 2001). Além disso, estudos anteriores registram a importância ecológica de diversas espécies da ictiofauna para a região (ZANI TEIXEIRA, 1983; MACIEL, 2001).

No Brasil, desde a colonização, as regiões costeiras têm sido amplamente utilizadas pelo homem de diferentes maneiras, causando diversos impactos ambientais para estas regiões. Segundo Mendonça (1998), na região de Cananéia a principal atividade econômica é a pesca praticada tanto dentro do estuário como na região costeira.

Quaisquer estudos que elucidam a biologia das espécies nas fases iniciais do seu ciclo de vida constituirão importantes informações para o manejo de áreas costeiras e para a administração pesqueira, principalmente de áreas estuarinas que abrigam expressões de processos biológicos fundamentais à reprodução, como áreas de desova e de abrigo para os juvenis da ictiofauna. Além disso, a região sul do sistema CananéiaIguape, que contém o Parque Estadual da Ilha do Cardoso, é também uma área de preservação ambiental do estado de São Paulo (APA). Assim sendo, informações sobre as fases iniciais do ciclo de vida dos peixes contribuirão para um melhor manejo e preservação da área.

\section{OBJETIVO GERAL E HIPÓTESES DE TRABALHO}

O objetivo geral deste trabalho é analisar a influência das variáveis ambientais na composição e estruturação da ictiofauna de ambientes praiais da barra sul do sistema costeiro Cananéia- Iguape.

As hipóteses a serem testadas são:

1) As variáveis abióticas influenciam a composição e a estruturação da comunidade ictíica da zona surfe de praias arenosas de maneiras distintas, quando analisadas em diferentes escalas temporais; 
2) As praias são utilizadas como área de crescimento ou como rota de migração para as espécies de actinopterígios encontradas em abundância nesse ambiente, que habitam o corpo principal do estuário ou mesmo a região costeira adjacente em tamanhos maiores.

\section{ÁREA DE ESTUDO}

Localizada ao sul da costa do estado de São Paulo, entre as latitudes de $24^{\circ} 40^{\prime} \mathrm{S}$ e $25^{\circ} 10^{\prime} \mathrm{S}$, o sistema Cananéia-Iguape é uma região lagunar separada do oceano pela ilha Comprida. Nos limites extremos da ilha Comprida estão as principais ligações dos canais com o oceano, sendo no norte a barra de Icapara e no sul a barra de Cananéia. Na região central e sul do sistema encontra-se a ilha de Cananéia, com aproximadamente $27 \mathrm{~km}$ de comprimento. A Ilha Comprida apresenta $70 \mathrm{~km}$ de comprimento, largura que varia de 3 a $5 \mathrm{~km}$ e altitudes quase sempre inferiores a $5 \mathrm{~m}$ (SUGUIO e MARTIN 1978). A Ilha é essencialmente arenosa, com exceção de uma intrusão alcalina, denominada Morrete, localizada na porção sul da Ilha (SPINELLI e GOMES, 2008). Os corpos de água que separam a ilha Comprida do Continente são denominados mar Pequeno ao sul e mar de Iguape ao Norte. O mar Pequeno se divide em dois corpos de água, o mar de Cubatão (separa a ilha de Cananéia do continente) e o mar de Cananéia (separa a ilha Comprida da de Cananéia), que se unem no extremo sul do sistema em um corpo de água denominado baía de Trapandé (Figura 1.1)

Os canais de circulação no sistema não são muito profundos, sendo $6 \mathrm{~m}$ a profundidade média do Mar Pequeno, $5 \mathrm{~m}$ a do Mar de Cubatão e do Mar de Cananéia. Os três mares podem atingir, em alguns pontos, um máximo de $12 \mathrm{~m}$ e de $10 \mathrm{~m}$ respectivamente (TESSLER e SOUZA, 1998), sendo que o maior registro está no canal de acesso ao mar na barra de Cananéia, cuja profundidade atinge $20 \mathrm{~m}$ (TESSLER et al., 1990).

Os principais mecanismos físicos que determinam os padrões de circulação geral e as propriedades das águas no sistema Cananéia-Iguape são: aportes fluviais, efeito dos campos de ventos e principalmente os movimentos de marés (TESSLER, 1982; MIYAO e NISHIRARA, 1989; MIRANDA et al., 1995; MIRANDA e CASTROFILHO, 1996; BRICHTA, 1999). 
Os canais de maré (gamboas) e os rios, principalmente os rios Taquari, Boacica, das Minas e Itapitangui são os principais responsáveis pela descarga fluvial na porção sul do sistema Cananéia-Iguape, influenciando fortemente a estrutura salina da baía de Trapandé e o canal do mar de Cubatão (BONETTI-FILHO e MIRANDA, 1997). Uma estimativa da contribuição do aporte fluvial no canal do mar de Cubatão e que também influi na baía de Trapandé e no canal do mar de Cananéia, apresenta valores médios de $43 \mathrm{~m}^{3} \cdot \mathrm{s}^{-1}$ (BONETTI-FILHO e MIRANDA, 1997). O canal do mar de Cananéia, que sofre uma menor influência destas gamboas e rios, possui uma coluna de água classificada como parcialmente misturada e fracamente estratificada (MIRANDA et al., 1995). Ao norte do sistema, o rio Ribeira de Iguape é o principal aporte fluvial através de um canal artificial denominado Valo Grande, sendo assim, são encontrados baixos valores de salinidade próximo a Pedra do Tombo, onde a influência deste canal é maior (MISHIMA et al, 1985).

Além do aporte fluvial, o aporte pluvial também influencia a salinidade do sistema Cananéia-Iguape. Tal região é caracterizada por altos índices de pluviosidade, geralmente havendo maiores valores na região sul do que no norte, atingindo até 2.300 mm de precipitação anual em Cananéia e 1700 mm em Iguape (RAMOS et al., 1980). Durante o ano os valores pluviométricos máximos na região são encontrados de dezembro a abril, com média mensal acima de $200 \mathrm{~mm}$, e mínimos entre maio e novembro, com média mensal no mínimo de 80 mm (SILVA, 1989).

Na barra de Cananéia o fluxo de maré enchente inicia-se 40 minutos antes do que na barra de Icapara. Logo após a entrada da maré na barra de Cananéia, este fluxo se divide em dois, um caminhando em sentido ao Mar de Cananéia e outro rumo ao Mar de Cubatão através da baía de Trapandé. Ao atingir o extremo norte da ilha de Cananéia, a onda de maré enchente que entrou no canal do mar de Cananéia se divide novamente em duas. Uma dirigindo-se ao canal do mar de Cubatão em sentido sul, a encontro de sua primeira ramificação que se desloca em sentido norte. A outra para o norte através do canal do mar Pequeno, encontrando-se com as ondas de marés fluidas em direção sul no canal do mar de Iguape, oriundas da barra de Icapara. Um fluxo inverso da maré enchente ocorre durante o processo da maré vazante, novamente na barra de Cananéia 40 minutos antes que na barra de Icapara (MINIUSSI, 1959).

Tanto no fundo quanto na superfície as correntes originárias dos fluxos de 
marés enchentes e vazantes apresentam-se semelhantes com velocidades entre 0,6 a 0,7 $\mathrm{m} . \mathrm{s}^{-1}$. Somente no sul do mar de Cananéia foram observadas medidas discrepantes entre a superfície e fundo durante o fluxo de maré vazante, com $1,2 \mathrm{~m} \cdot \mathrm{s}^{-1}$ e $0,7 \mathrm{~m} \cdot \mathrm{s}^{-1}$ respectivamente (MIYAO, 1976). A maré do litoral sul do estado de São Paulo é classificada como semi-diurna, com desigualdades diurnas, quase mistas. Na região sul do sistema estudado, as amplitudes de maré médias foram calculadas em 0,83 $\mathrm{m}$ na maré de sizígia e de 0,13 m na de quadratura (MIYAO e NISHIHARA, 1989). BarreraAlba (2004), analisando a evolução dos ciclos de marés na barra de Cananéia, observou que na coleta de inverno as oscilações foram superiores às registradas na coleta de verão, tanto na etapa de sizígia quanto na de quadratura. Provavelmente, tal fato está relacionado à maior incidência de frentes frias.

A desembocadura lagunar de Cananéia é caracterizada pela presença de grandes bancos arenosos em seu redor, os quais se modificam constantemente devido às complexas correntes existentes no local e pela predominância de uma corrente de deriva litorânea sentido SW-NE (TESSLER e SOUZA, 1998; NASCIMENTO Jr., 2006). Tais características físicas tornam a Ilha Comprida um setor extremamente sensível às variações antropogênicas e às oscilações relativas do nível do mar, previstas pelo Painel Intergovernamental sobre Mudanças Climáticas - IPCC (IPCC, 2010).

Dados coletados pela Estação Meteorológica do IOUSP em Cananéia entre os anos de 1956 e 2000 indicam uma temperatura média calculada para a região de 21,5 ${ }^{\circ} \mathrm{C}$, sendo que a maior temperatura média climatológica, $25,2{ }^{\circ} \mathrm{C}$ ocorre em fevereiro e a menor, $17,7^{\circ} \mathrm{C}$ ocorre no mês de julho. A máxima temperatura da superfície do mar nesses anos foi $27,9^{\circ} \mathrm{C}$ em fevereiro e a mínima $19,7^{\circ} \mathrm{C}$, em julho. A temperatura média da superfície do mar foi $23,9^{\circ} \mathrm{C}$, dois graus Celsius superior à temperatura do ar (BOMVENTI et al., 2006).

\section{MATERIAL E MÉTODOS}

$\underline{\text { Locais de amostragem e variáveis ambientais }}$

Foram amostradas seis praias com diferentes graus de exposição do sistema costeiro Cananéia-Iguape, totalizando três pontos de coleta na Ilha Comprida e três 
pontos na Ilha do Cardoso (Figura 1.2). Os graus de exposição foram classificados baseando-se, principalmente, na localização geográfica da praia. A praia da Ilha Comprida considerada como a mais exposta no presente estudo, apresenta sua porção submersa mais rasa marcada, em sua maioria, por dois tipos texturais mais evidentes, classificadas como areia fina a muito fina. Tal praia apresenta ondas de sentido sul e leste de aproximadamente 1 metro de altura (MARQUEZ e MAHIQUES, 2010). A mesma praia apresenta ainda uma ampla zona de espraiamento (média de $75 \mathrm{~m}$ ) e baixa declividade (média de $0,67^{\circ}$ ), sendo que os maiores valores de declividade concentramse próximos às extremidades da ilha (NASCIMENTO Jr., 2006). Apesar de não terem sido encontrados trabalhos que caracterizem a morfologia dos demais pontos amostrados no presente estudo, considerados para fins didáticos como praias intermediárias e praias abrigadas, pôde-se observar nas saídas de campo que, quanto mais para o interior do canal menor a altura das ondas e mais lodoso o sedimento. $\mathrm{O}$ mesmo padrão foi observado nas praias amostradas da Ilha do Cardoso.

A declividade das praias pode ser usada como índice do grau de exposição, e foi calculada a partir de um transecto perpendicular à costa até a isóbata de 5 metros, utilizando a carta náutica número 175, disponibilizada pela Diretoria de Hidrografia e Navegação (DHN-MM). As estimativas mostraram que a declividade das praias diminui quanto mais exposta a mesma, sendo os valores de 8,2\%, 5,4\% e 1,9\% obtidos, respectivamente, para a praia abrigada, intermediária e exposta da Ilha do Cardoso. Já para a praia abrigada da Ilha Comprida, a declividade foi $6,6 \%$, contrastando com 0,62 $\%$ obtida para a exposta da mesma ilha. A praia intermediária da Ilha Comprida apresenta uma alta declividade, calculada de $19 \%$. Na região, os resultados obtidos para a declividade relacionam-se com, além da força das ondas, a desembocadura do estuário e a existência dos bancos arenosos.

No começo do primeiro arrasto e no final do último em cada praia foram tomados os dados de temperatura, com termômetro de mercúrio, e de salinidade, com um refratômetro.

Os dados de altura de maré para o planejamento das coletas foi verificado na tábua de marés para o município de Cananéia disponível no sítio do IOUSP (www.mares.io.usp.br). Os dados de condições meteorológicas nos horários de coleta 
foram anotados, de acordo com a seguinte escala descritiva: ensolarado, sol entre nuvens, nublado, chuvisco/garoa e chuva.

\section{Coleta do material biológico}

Em cada praia foram realizados quatro arrastos consecutivos de aproximadamente $30 \mathrm{~m}$ cada, utilizando-se uma rede de "picaré" (arrasto de praia) de 9 $\mathrm{m}$ de comprimento e $1,5 \mathrm{~m}$ de altura, com panagem central e lateral de $3 \mathrm{~m}$ de comprimento cada e malha de $5 \mathrm{~mm}$ e $10 \mathrm{~mm}$ entre nós consecutivos, respectivamente. Os arrastos ocorreram tanto na maré baixa quanto na alta de sizígia. A maré baixa foi amostrada em seu pico do período matutino, enquanto a alta, em sua maioria, era amostrada durante o início da tarde, em horário próximo ao seu pico.

A periodicidade das coletas dependeu do objetivo a ser atingido: coletas mensais, ao longo de um ano, para se acompanhar as variações em uma maior escala de tempo e, coletas intensivas realizadas durante um mês do verão de 2009 , focando as variações que ocorreram em uma menor escala de tempo. As coletas mensais ocorreram tanto na Ilha Comprida quanto na Ilha do Cardoso, enquanto a intensiva do verão ocorreu apenas na Ilha Comprida.

Os arrastos da coleta intensiva ocorreram em dias alternados de 23 de janeiro a 18 de fevereiro de 2009. Escolheu-se concentrar as coletas no verão por ser o período de recrutamento em ambientes praiais de uma grande quantidade de espécies de peixes (e.g. LASIAK, 1984; BENNETT, 1989; GIANINNI e PAIVA FILHO, 1995; CLARK, 1996; GODEFROID et al., 2003; FÉLIX et al., 2006; ARAÚJO et al., 2008), sendo assim amostrada maiores diversidade e riqueza de espécies.

\section{$\underline{\text { Tomada de dados dos exemplares }}$}

Os exemplares foram identificados seguindo, principalmente, as seguintes literaturas: Figueiredo e Menezes (1978, 1980, 2000); Menezes e Figueiredo (1980, 1985); Richards (2006) e Santos-Ninin (2008). Devido à dificuldade de identificação dos juvenis de Mugilidae e falta de bibliografia adequada para a distinção específica dos representantes do sudeste brasileiro, a separação dos mugilídeos coletados foi baseada 
na chave apresentada por Vieira (1991). Esta chave de identificação foi concebida para os indivíduos habitantes do Rio Grande do Sul, que coincide com as três espécies mais abundantes no sudeste brasileiro. Foram adotadas as seguintes nomenclaturas: Mugil hospes (antes Mugil gaimardianus), Mugil liza (antes Mugil platanus) segundo Menezes et al. (2010), Mugil 1 para os juvenis que foram identificados por possuírem 13 elementos na nadadeira anal (dois espinhos e 11 raios) e Mugil 2 com dois espinhos e oito raios na nadadeira anal, que difere dos demais nas descrições.

Exemplares-testemunhos de todo o material coletado foram depositados no Laboratório de Peixes do Museu de Zoologia da Universidade de São Paulo, instituição credenciada para tal depósito e na "Coleção Biológica Marinha" do Instituto Oceanográfico/Universidade de São Paulo (Projeto AMBIO "Aprimoramento e Manutenção das Coleções Biológicas Marinhas”-IOUSP-PETROBRAS).

Os peixes obtidos foram medidos em ictiômetro com precisão de $1 \mathrm{~mm}$, tomando a medida do comprimento total (CT): distância da ponta do focinho até o término da nadadeira caudal; e do comprimento padrão (CP): distância da ponta do focinho até a base da nadadeira caudal. Obteve-se também o peso total (PT) em gramas (g) com precisão de 0,01 g. Os indivíduos foram dissecados para identificação macroscópica do sexo e do estádio de maturação gonadal segundo Vazzoler (1981, 1996) e Dias et al., (1998), separando deste modo os machos das fêmeas e os juvenis dos adultos, quando possível. Quando uma amostra por arrasto superava o máximo de 50 indivíduos de uma mesma espécie, a biometria era realizada em uma subamostra de 50 exemplares selecionados ao acaso e o excedente era apenas contabilizado e pesado.

O presente trabalho foi desenvolvido como parte do projeto "Avaliação dos padrões de dispersão das larvas de teleósteos e sua sobrevivência no sistema costeiro Cananéia-Iguape", financiado pelo CNPq - Edital Universal (486216/2007-1).

\section{$\underline{\text { Análise dos dados }}$}

As metodologias específicas para cada escala de tempo estudada, ou seja, coletas mensais ao longo de um ano ou coletas a cada dois dias para estudo com amostragem intensiva, serão descritas nos capítulos correspondentes. 


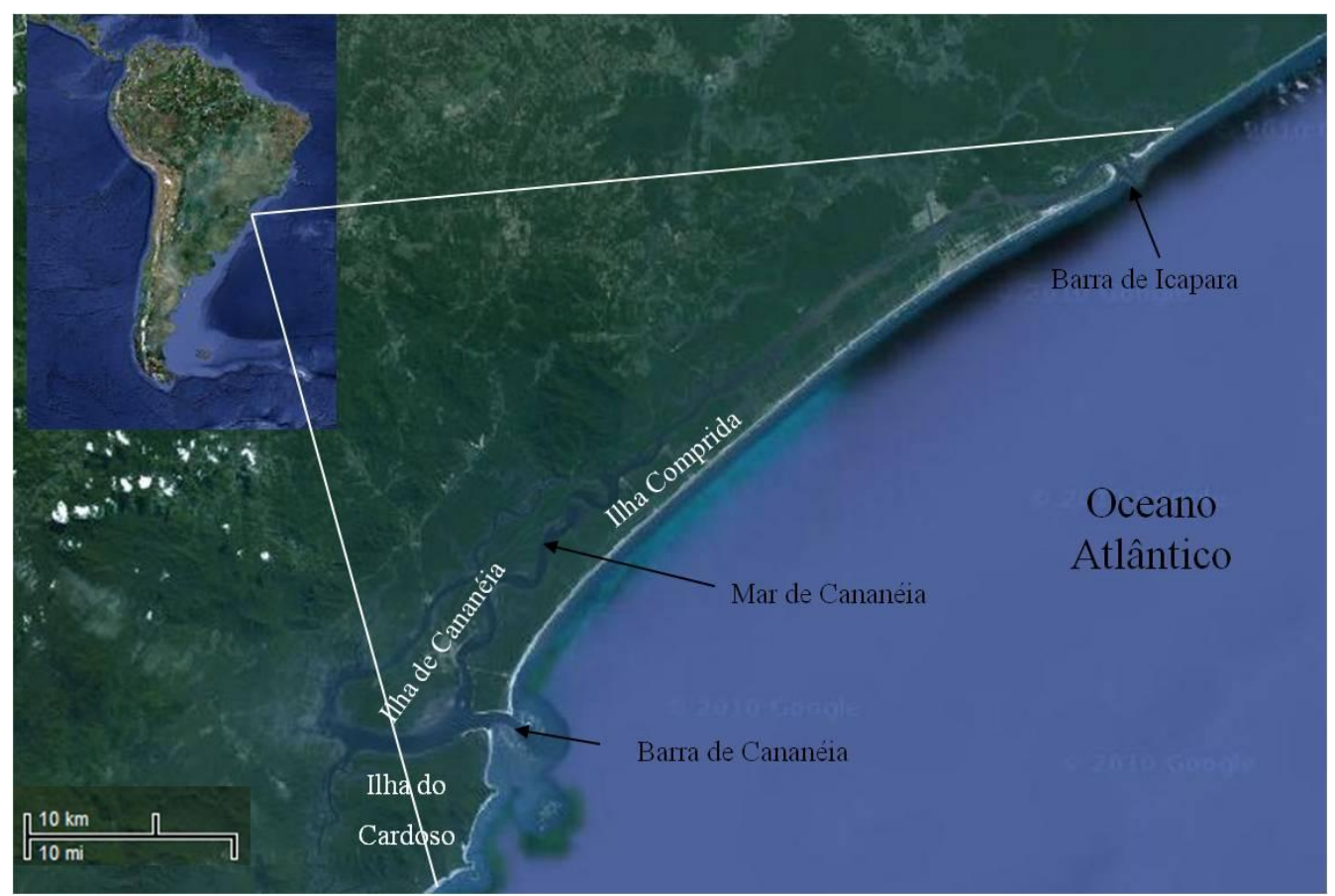

Figura 1.1. Imagem de satélite ilustrando a América do Sul e em destaque o Sistema Costeiro Cananéia- Iguape, localizado no litoral sul do estado de São Paulo, Brasil (Fonte: Google Earth). 


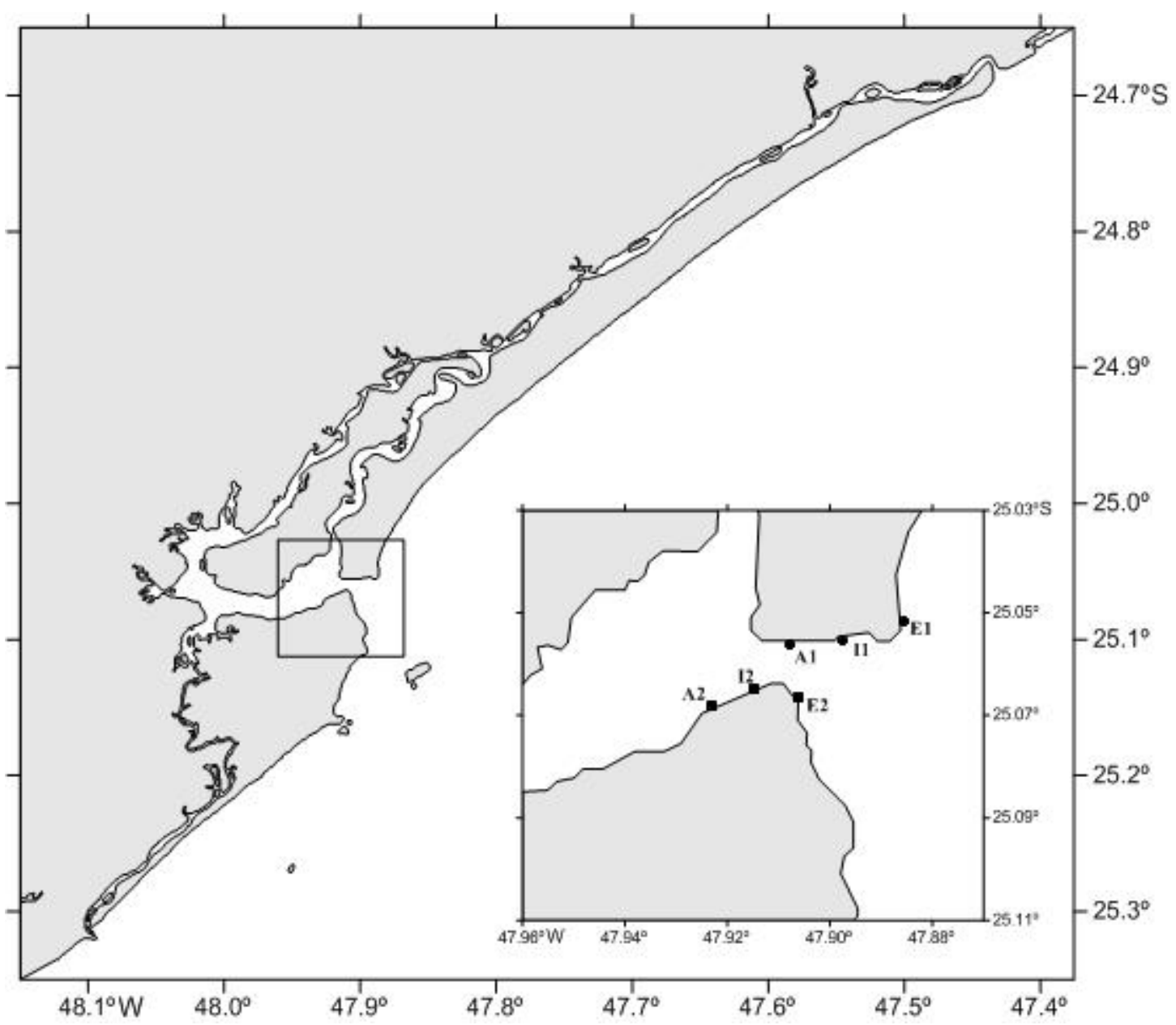

Figura 2.2 - Praias Abrigadas (A), Intermediárias (I) e Expostas (E) amostradas na Ilha Comprida (1) e na Ilha do Cardoso (2), localizadas na barra sul do sistema costeiro Cananéia-Iguape, São Paulo, Brasil. 
Capítulo 2. ASPECTOS ESTRUTURAIS DA ICTIOFAUNA DE AMBIENTES

PRAIAIS DA BARRA SUL DO SISTEMA COSTEIRO CANANÉIA-IGUAPE:

VARIAÇÕES DE LONGO PRAZO

\section{INTRODUÇÃO}

Os ambientes praiais representam o mais amplo dos ecossistemas sedimentares da costa do Brasil (ARAÚJO et al., 2008). São considerados áreas de alimentação e crescimento para uma grande quantidade de peixes juvenis e larvas, pois caracterizamse por alta turbidez, turbulência e pouca profundidade, dificultando seu uso por espécies de peixes de maior porte, oferecendo assim proteção contra a predação (LASIAK, 1981; MCLACHLAN et al., 1981; GAELZER e ZALMON, 2003). Apesar da produção primária "in situ" ser pouco significativa, o efeito das marés distribui os nutrientes e minerais através da comunidade da zona de surfe (CARTER, 1988), favorecendo abundância de recursos alimentares como, por exemplo, o fito- e o zooplâncton (SPRING e WOODBUM, 1960; AVILA, et al., 2009; SOUZA, et al., 2009; FERREIRA, et al., 2010). Praias adjacentes a estuários também servem como rotas de migração para diversos peixes em estágio larval ou juvenil que passaram uma ou mais fases de seu ciclo de vida dentro dos estuários (COWLEY et al., 2001; WATTPRINGLE e STRYDOM, 2003).

Diversos fatores influenciam a estruturação da comunidade ictíica da zona de surfe, sendo a relativa baixa diversidade e alta dominância de poucas espécies explicada principalmente pelo extremo hidrodinamismo das praias (CLARK et al., 1996; CLARK, 1997). A maioria das espécies presentes em tais ambientes é classificada como não residente, ocorrendo na zona de surfe em determinadas épocas do ano (BROWN e MACLACHLAN, 1990, FÉLIX et al., 2007a) ou fases do ciclo de vida (MODDE, 1980; LAYMAN, 2000). No oeste do oceano Atlântico, é possível notar a constância e abundância principalmente de indivíduos dos gêneros Trachinotus, Mugil, Menticirrhus, Harengula e Anchoa ou seus equivalentes ecológicos nas regiões costeiras (GIANNINI e PAIVA FILHO, 1995; LAYMAN, 2000; GODEFROID et al., 2003; FÉLIX et al., 2007a; LIMA e VIEIRA, 2009).

Quanto às variações ambientais, diversas comunidades foram descritas principalmente baseando-se nas variações sazonais e espaciais, apontando alguns padrões: um aumento na dominância e a diminuição na abundância e riqueza de 
espécies de peixes conforme aumenta o grau de exposição das praias (ROMER, 1990; TEIXEIRA e ALMEIDA, 1998; FÉLIX et al., 2007b; VASCONCELLOS et al., 2007); uma maior diversidade e riqueza nos meses mais quentes do ano (LASIAK, 1984; BENNETT, 1989; GIANINNI e PAIVA FILHO, 1995; CLARK, 1996; GODEFROID et al., 2003; ARAÚJO et al., 2008; LIMA E VIEIRA, 2009); maior diversidade em períodos secos ou chuvosos do ano (LIRA e TEIXEIRA, 2008; OLIVEIRA-SILVA et $a l .$, 2008; SANTANA e SEVERE, 2009).

No Brasil, trabalhos sobre a ictiofauna de praias descrevem, principalmente, a estrutura e as variações espaço-temporais das comunidades (PAIVA FILHO et al., 1987; PEREIRA, 1994; GIANNINI e PAIVA FILHO, 1995; SAUL e CUNNINGHAM, 1995; GAELZER e ZALMON, 2003; GOMES et al., 2003; ARAÚJO et al., 2008; OLIVEIRA-SILVA, 2008; LIMA e VIEIRA, 2009). Poucos trabalhos analisaram as variações na composição e estruturação entre dia e noite (PESSANHA e ARAÚJO, 2003; OLIVEIRA NETO et al., 2004; GAELZER e ZALMON, 2008a), a dinâmica e morfologia praiais (SANTOS, 1994; FÉLIX et al., 2007a; VASCONCELLOS et al., 2007), as marés (GODEFROID et al., 1998; GAELZER e ZALMON, 2008b) e os aspectos tróficos (STEFANONI, 2008).

No que se refere ao litoral paulista, a ictiofauna das praias ainda é pouco conhecida. Paiva Filho e Toscano (1987) analisaram a variação sazonal do Mar Casado - Guarujá e do Mar Pequeno- São Vicente; Giannini e Paiva Filho (1995) realizaram análise comparativa da ictiofauna em praias da Ilha Comprida, Santos, São Vicente e Ubatuba; e por fim, Saul e Cunningham (1995) estudaram a comunidade de peixes na Ilha do Bom Abrigo, localizada no litoral sul do Estado de São Paulo.

\section{OBJETIVOS ESPECÍFICOS}

- Descrever a composição e a estruturação da ictiofauna presente na zona de surfe de praias da Ilha Comprida e da Ilha do Cardoso;

- Verificar as variações dos fatores ambientais que influenciam, em longo prazo, a composição e estruturação da comunidade da ictiofauna do local. 


\section{MÉTOdo DE COLETA E TOMADA DOS DADOS}

Os arrastos para as coletas mensais foram realizados de dezembro de 2008 a janeiro de 2010, totalizando 14 meses nas praias da Ilha Comprida, e de fevereiro de 2009 a janeiro de 2010 nas praias da Ilha do Cardoso, totalizando 12 meses.

A metodologia da coleta dos espécimes e da tomada dos dados foi descrita no tópico "Material e Métodos" do Capítulo 1 desta dissertação.

\section{ANÁLISE DOS DADOS}

A Análise de Variância (One way ANOVA) foi usada para testar a significância das diferenças entre as médias mensais, por praia e por marés dos dados abióticos de temperatura e salinidade ao nível de confiança de $95 \%(\mathrm{p}<0,05)$.

Com a finalidade de identificar possíveis padrões entre os meses, as praias amostradas e as marés, em termos dos dados abióticos de temperatura e salinidade, foram utilizadas as análises de escalonamento não métrico $M D S$ e os grupos encontrados foram testados pela análise de similaridade (ANOSIM).

A partir dos dados biológicos, foram calculados os índices descritores da comunidade para o período como um todo, por praia e por diferentes marés, estimados das seguintes maneiras:

- Constância de ocorrência: $\mathrm{C}=$ pi $^{*} 100 * \mathrm{P}^{-1}$, em que $\mathrm{C}=$ constância de ocorrência, pi= número de coletas em que a espécie apareceu e $\mathrm{P}=$ número total de coletas. As espécies foram classificadas de acordo com os valores estimados: espécies constantes para $C \geq 50$, espécies acessórias para $50<C>25$ e espécies acidentais para C $\leq 25$ (DAJOZ, 1983).

- Dominância: $\mathrm{D}=\sum(\mathrm{ni} / \mathrm{n})^{2}$, em que ni é o número de indivíduos de determinada espécie i e n é o número total de indivíduos (BEGON et al., 2006).

- Diversidade de Shannon: $\mathrm{H}=-\sum \mathrm{ni} / \mathrm{n} \ln (\mathrm{ni} / \mathrm{n})(\mathrm{BEGON}$ et al., 2006).

- Índice de riqueza de Margalef: $M=(S-1) / \ln (n)$, em que $S$ é o número de espécies e n é o número de indivíduos (BEGON et al., 2006).

- Equitatividade: Diversidade de Shannon dividido pelo logaritmo do número de espécies (BEGON et al., 2006).

As diferenças entre os índices obtidos foram testadas através do método Bootstrap para testes de hipóteses, com 95\% de confiança. 
Com o objetivo de identificar as associações entre os meses, aplicou-se aos dados biológicos de abundância numérica por mês, transformados por raiz quadrada e com seleção das espécies mais abundantes, uma Análise de Agrupamento (“Cluster”). A similaridade entre os atributos foi calculada através do coeficiente de Bray-Curtis através do programa PAST.

Para avaliar a influência de cada variável abiótica na comunidade de peixes, foi feita uma Análise de Correspondência Canônica (CCA). Tal análise mostrou ser a mais apropriada para os dados em questão, pois após um estudo prévio utilizando a Análise de Correspondência Destendenciada (DCA) em uma matriz de fauna bruta (sem eliminar as raras e sem transformar os dados), obteve-se um valor de traço canônico alto (3,396) (LEGENDRE e LEGENDRE, 1998).

Espécies raras, aquelas com abundância relativa inferir a $0,2 \%$, foram eliminadas da matriz de dados bióticos, que continha a abundância numérica das espécies em cada amostra. Já os dados abióticos, depois de uma primeira análise utilizando-se uma única matriz, foram divididos em três matrizes: ambiental (salinidade e temperatura), temporal (maré alta, maré baixa e os meses do ano) e espacial (praias com diferentes graus de exposição). Em todas as análises os dados foram transformados por $\log (\mathrm{x}+1)$ e foi dado peso baixo às espécies raras.

A porcentagem de explicação das variáveis monitoradas, da interação das mesmas e do não explicável, foi calculada seguindo o proposto por Borcard et al. (1992).

\section{RESULTADOS}

$\underline{\text { Dados abióticos }}$

Os valores de temperatura obtidos tanto nas praias da Ilha Comprida quanto da Ilha do Cardoso variaram ao longo dos meses amostrados de forma semelhante e significativa ( $\mathrm{F}=227,2, \mathrm{p}<0,05$ e $\mathrm{F}=136,5, \mathrm{p}<0,05$, respectivamente), sendo as menores temperaturas correspondentes aos meses de maio a outubro (Figura 2.1 e 2.2), porém sem diferenças significativas nas diferentes praias de ambas as ilhas $(F=0,019, p>0,05$ e $\mathrm{F}=0,01421, \mathrm{p}>0,05$, respectivamente) (Figura 2.3 e 2.4). Nas praias da ilha Comprida não houve diferença significativa nos valores de temperatura medidos durante a maré alta e baixa $(\mathrm{F}=1,357, \mathrm{p}>0,05)$ (Figura 2.5). Já na ilha do Cardoso as temperaturas foram 
ligeiramente superiores na maré alta do que na baixa $(\mathrm{F}=6,02, \mathrm{p}<0,05)$ (Figura 2.6), provavelmente devido à diferença nos horários de coleta e ao fato de que a zona de espraiamento é formada por uma lâmina de água muito pequena. A temperatura máxima foi $30,5^{\circ} \mathrm{C}$ na ilha Comprida e $30^{\circ} \mathrm{C}$ na ilha do Cardoso, e a mínima $18^{\circ} \mathrm{C}$ em ambas as ilhas.

Mesmo sendo significativa a diferença entre os valores de salinidade ao longo dos meses amostrados em praias de ambas as ilhas $(\mathrm{F}=45,14, \mathrm{p}<0,05$ e $\mathrm{F}=11,31$, p $<0,05$ ), não se pôde observar um padrão nesta variação (Figura 2.7 e 2.8). A salinidade máxima obtida foi 36 nas praias expostas e a mínima foi, repectivamente, 10 e 21 na praia abrigada da Ilha do Cardoso (Figura 2.9) e da Ilha Comprida (Figura 2.10), ambas com diferenças significativas. Em relação às marés, observou-se que durante a maré alta foram medidos valores significativamente mais altos de salinidade tanto nas praias da ilha Comprida $(\mathrm{F}=13,96, \mathrm{p}<0,05)$ (Figura 2.11) quanto na ilha do Cardoso $(\mathrm{F}=9,402$, $\mathrm{p}<0,05$ ) (Figura 2.12), provavelmente devido ao fato de que, durante a maré baixa, as praias sofrem maior influência das águas interiores.

Tanto nas praias da ilha Comprida quanto nas do Cardoso, os resultados obtidos para as variáveis abióticas mensuradas indicam semelhança entre dois grupos de meses: maio, junho, julho, agosto, setembro e outubro; e entre novembro, dezembro, janeiro, fevereiro, março e abril. Estes grupos estão, provavelmente, correlacionados com os dados de temperatura. A análise de $n M D S$ possibilita a visualização de um agrupamento para a Ilha Comprida com os meses mais frios correlacionados negativamente com o eixo 1 e os mais quentes positivamente, enquanto as localidades de maior salinidade (praias expostas e algumas intermediárias) correlacionadas positivamente com o eixo 2 e as de menor salinidade (abrigadas e intermediárias) se correlacionam negativamente (Figura 2.13). Na Ilha do Cardoso os meses mais frios do ano se correlacionam positivamente ao segundo eixo, enquanto os de maior salinidade se correlacionam negativamente ao primeiro eixo (Figura 2.14). A rotina ANOSIM separou os dois agrupamentos tanto na Ilha Comprida $(R=0,80 ; p<0,0001)$ quanto na Ilha do Cardoso $(\mathrm{R}=0,63 ; \mathrm{p}<0,0001)$.

\section{Composição da ictiofauna}

\section{Ilha Comprida}

Um total de 8012 indivíduos, pertencentes a 23 famílias e 44 espécies foram 
capturados. Contribuindo com 98,2 \% do número de indivíduos coletados estão Mugilidae (46,0 \%), Carangidae (41,2 \%), Clupeidae (4,4 \%), Engraulidae (3,7\%) e Sciaenidae $(1,7 \%)$. As nove espécies mais abundantes foram representados por Trachinotus carolinus (30,6 \%), Mugil curema (27,6 \%), Mugil hospes (14,4\%), Trachinotus goodei (9,4\%), Harengula clupeola (4,4 \%), Mugil liza (3,3\%), as larvas não identificadas de Engraulidae e Gerreidae (2,7 e 1,3\% respectivamente) e Menticirrhus littoralis (1,2 \%), os quais contribuíram com 94,7 \% do número total amostrado. Através do índice de constância, T. carolinus e T. goodei foram consideradas como constantes, M. curema, M. hospes, M. liza e M. littoralis foram espécies acessórias e todas as demais acidentais (Tabela 2.1).

Além da alta contribuição numérica, as mesmas espécies foram também responsáveis pela grande representatividade em termos de biomassa. O peso total da captura foi 8.431,64 gramas, com Carangidae (66,5\%), Mugilidae (14,1\%) e Clupeidae $(12,6 \%)$ contribuindo com $94 \%$ da biomassa. Apenas oito espécies somaram $96 \%$ da biomassa. T. carolinus (31,7 \%), T. goodei (31,4 \%), H. clupeola (12,7 \%), M. curema $(9,1 \%)$, M. hospes $(4,9 \%)$ e M. littoralis (2,0 \%). Já Oligoplites saliens e Odonthestes argentinensis, apesar da baixa contribuição em freqüência relativa, 0,7 e $0,1 \%$ respectivamente, foram representativos em termos de biomassa, 2,8 e 1,6\% cada um (Tabela 2.2).

As espécies que apresentam exemplares de maior porte foram $O$. argentinensis, M. littoralis, T. goodei, Hyporhamphus unifasciatus e O. saliens. Os menores exemplares foram de T. carolinus, Sphoeroides sp., Menticirrhus americanus, $M$. littoralis, Oligoplites sp., Trachinotus falcatus e as larvas de gerreídeos (Tabela 2.3). Algumas destas espécies (M. littoralis, T. goodei, O. argentinensis e O. saliens) foram as que apresentaram as maiores variações de tamanho, com amplitude de mais de 100 mm entre o maior e o menor exemplar coletado. $99 \%$ dos indivíduos apresentaram comprimento padrão variando entre 1 e $80 \mathrm{~mm}$, com a maior abundância de exemplares ocorrendo entre a classe de tamanho de 21 a $40 \mathrm{~mm}$, reunindo $58 \%$ dos indivíduos medidos (Figura 2.15)

A média de peso dos indivíduos coletados foi $1,35( \pm 3,46)$ gramas. Os menores pesos foram de exemplares de Elops saurus, Sphoeroides sp., T. carolinus, Hemiramphus sp., Mugil 2 e as larvas de gerreídeos. Já os maiores pesos foram representados pelas espécies $T$. goodei, $M$. littoralis, $O$. argentinensis, $O$. saliens, as quais também possuem as maiores amplitude de peso e os maiores tamanhos (Tabela 
2.3).

Para quase a totalidade dos indivíduos coletados não foi possível identificar o sexo e o estádio de maturação das gônadas, como consequência da elevada abundância de exemplares cujas gônadas não foram localizadas devido a seu pequeno tamanho. Apenas duas fêmeas de $M$. littoralis foram classificadas como imaturas pela visualização das gônadas e duas fêmeas de $O$. argentinensis foram classificadas como em maturação, sendo o restante dos indivíduos amostrados considerados imaturos. Atherinella sp., Elops saurus, Micropogonias furnieri, alguns engraulídeos e todos os gerreídeos foram representados por exemplares em sua fase larval .

\section{Ilha do Cardoso}

Foram amostradas 20 famílias e 47 espécies, totalizando 7286 indivíduos. As famílias Mugilidae (37,0 \%), Carangidae (23,0 \%), Gerreidae (15,1\%), Atherinopsidae (9,3\%), Engraulidae (8,3\%), Sciaenidae $(3,6 \%)$ e Clupeidae $(2,3 \%)$ contribuíram com 98,6 \% do número de indivíduos coletados. Somando $79,4 \%$ do total amostrado, $M$. curema $(17,6 \%)$, larvas de Gerreidae (16,7 \%), M. hospes $(15,7 \%)$, T. carolinus $(15,5$ $\%)$, Atherinella brasiliensis $(9,2 \%)$ e Anchoa tricolor (4,6\%), foram as seis espécies mais representativas. Para os locais amostrados, notou-se a predominância de espécies de ocorrência acidental, sendo apenas T. carolinus e T. goodei consideradas constantes e A. brasiliensis, O. saliens, M.hospes, Mugil liza, M. curema, M. littoralis e as larvas de Engraulidae e Gerreidae consideradas acessórias (Tabela 2.4).

O peso total de captura foi 14.727,11 gramas, sendo que Atherinopsidae (35,5 $\%$ ) e Carangidae (32,2 \%) somaram 67,6 \% da biomassa. A. brasilensis (35,3\%), T. goodei $(11,6 \%)$, O. saliens $(9,5 \%)$ e $T$. carolinus $(9,1 \%)$ foram as espécies com maior representatividade em termos de biomassa, apesar de $T$. goodei e $O$. saliens terem baixa representatividade, 2,4 e 2,5\% respectivamente (Tabela 2.5).

Strongylura timucu, Paralichthys orbignyanus e Sphoeroides testudineus representam as espécies com maior comprimento padrão. Os indivíduos com menor porte pertencem às espécies T. carolinus, Oligoplites sp., M. littoralis e as larvas de Gerreidae. Já entre os exemplares com maior amplitude de comprimento padrão, mais de 100 mm, estão S. timucu, T. goodei, M. littoralis, O. saliens e A. brasiliensis (Tabela 2.6). $78 \%$ dos exemplares mediam entre 4 e $60 \mathrm{~mm}$, sendo a classe modal de comprimento padrão de 21 a $40 \mathrm{~mm}$ a mais abundante, somando $34 \%$ dos indivíduos coletados (Figura 2.16). 
O peso médio capturado foi $3,77( \pm 11,02)$ gramas. $S$. testudineus, $P$. orbignyanus e $S$. tiтиси foram as espécies com representantes mais pesados e com maiores comprimento padrão. Além das larvas de Gerreidae, Engraulidae, Micropogonias furnieri e Menticirrhus americanus, os juvenis de Hemiramphus sp., Oligoplites sp., M. littoralis e S. timиси representam as espécies com exemplares de menor peso. As maiores amplitude de peso foram encontradas para as espécies $S$. timucu, T. goodei, S. testudineus, O. saliens e A. brasiliensis (Tabela 2.6).

Não foi possível identificar o sexo da maioria dos exemplares amostrados devido ao pequeno porte dos mesmos, sendo as gônadas não localizadas ou eram muito diminutas, dificultando a classificação macroscópica. Estes indivíduos totalizaram 88,21 $\%$ do total amostrado, restando apenas 7,8 e 4,0 \% de fêmeas e machos respectivamente.

Entre as fêmeas, cuja gônada foi possível classificar macroscopicamente, observamos uma pequena representatividade de ovários maduros e esgotados, com apenas 5,54 e 1,30 \% do total amostrado respectivamente. Não foi observada nenhuma gônada hidratada. Os estádios imaturos $(39,74 \%)$ e em maturação $(53,42 \%)$ foram os mais abundantes. Os demais indivíduos cujo porte não permitiu a classificação nos diferentes estados de maturação foram considerados como imaturos e/ou juvenis.

Atherinella brasiliensis foi a única espécie representada por indivíduos adultos $(\mathrm{N}=176)$, juvenis $(\mathrm{N}=497)$, e em fase larval $(\mathrm{N}=1)$. S. testudineus e $S$. timucu foram representados por indivíduos adultos $(\mathrm{N}=2$ e $\mathrm{N}=9$ respectivamente) e juvenis. $P$. orbignyanus foi representada por um único indivíduo adulto. $M$. littoralis, $M$. americanus e os engraulídeos foram amostrados em sua fase juvenil e larval, já Porichthys porosissimus, Elops saurus, M. furnieri e todos os gerreídeos foram coletados apenas em sua fase larval.

Comparando-se a ictiofauna das praias da Ilha Comprida com a da Ilha do Cardoso, constata-se que as doze espécies seguintes ocorreram somente na Ilha Comprida: Tysolurus acus, Hyporhamphus unifasciatus, Atherinella sp., Mycteroperca sp., Mycteroperca tigris, Polydactylus virginicus, Abudefduf saxatilis, Parablennius pilicornis, Citharichthys arenaceus, Stephanolepis hispidus, Sphoeroides sp. e Chilomycterus spinosus. Por outro lado, a ictiofauna que ocorreu exclusivamente nas praias da Ilha do Cardoso foi composta por quinze espécies: Lycengraulis grossidens, Opisthonema oglinum, Platanichthys platana, Strongylura marina, Porichthys porosissimus, Atherinella brasiliensis, Chloroscombrus chrysurus, Lobotes surinamensis, Polydactilus oligodon, Umbrina coroides, Paralichthys orbignyanus, 
Etropus crossotus, Sphoeroides greeleyi, Sphoeroides testudineus, Chilomycterus sp. Cabe ressaltar que as diferenças encontradas podem estar relacionadas com a presença de fundos duros próximos ao local de coleta na Ilha Comprida, bem como as menores valores de salinidade encontrados na Ilha do Cardoso.

\section{Variações na composição e estruturação da ictiofauna}

\section{Ilha Comprida}

Analisando a variação espacial da ictiofauna observou-se um maior número de indivíduos coletados na praia intermediária, seguida pela abrigada e então a exposta. Não houve diferença significativa nos valores de riqueza entre as praias, entretanto a praia abrigada, ao contrário da intermediária é a mais diversa e uniforme entre elas (Tabela 2.7). A menor dominância foi apresentada pela praia abrigada, não havendo diferença significativa nos maiores valores apresentados pela fauna da exposta e intermediária, ambas dominadas por T. carolinus, T. goodei, M. curema e M. hospes. Além das quatro espécies dominantes nas praias expostas e intermediárias, na praia abrigada houve também maior abundância relativa de Mugil liza e Harengula clupeola (Tabela 2.7).

A distribuição de frequência das classes de comprimento padrão para todas as espécies indicou um predomínio de peixes variando de 5 a $55 \mathrm{~mm}$ nos três pontos de coleta, destacando-se a classe modal de 16 a $25 \mathrm{~mm}$ que representou aproximadamente $42 \%$ dos indivíduos amostrados na praia abrigada e intermediária, e 37,6 \% na exposta (Figura 2.17).

Durante a maré baixa foi coletado um maior número de indivíduos e de espécies, assim como foram encontrados os maiores valores de diversidade e riqueza (Tabela 2.8). Não houve diferença significativa entre os valores de equitatividade. A maré alta apresenta apenas os valores de dominância maiores que a baixa, sendo dominada principalmente por T. carolinus, T. goodei e M. curema (Tabela 2.8). Em ambas as marés, a classe modal predominante foi a de 11 a $30 \mathrm{~mm}$, somando aproximadamente $63 \%$ dos indivíduos amostrados (Figura 2.18).

Com relação à variação temporal, o maior número de peixes coletados ocorreu em dezembro de 2009 nas três praias (Figura 2.19). Na praia abrigada o segundo mês com maior abundância foi julho, devido à alta captura de H. clupeola. Já as praias intermediária e exposta mantiveram suas maiores representatividades em meses com 
temperaturas mais elevadas, principalmente de novembro a janeiro. (Figura 2.19).

A variação mensal do peso total assemelha-se à variação do número de indivíduos coletados, com um pico de peso total em julho na praia abrigada e um em dezembro de 2009 na intermediária e na exposta (Figura 2.20)

T. carolinus ocorreu em todos os meses de amostragem, enquanto T. goodei não ocorreu apenas em agosto. $M$. curema e $M$. littoralis ocorreram em onze dos quatorze meses de coleta. Mais da metade do número de espécies amostradas ocorreu esporadicamente em apenas um ou dois meses (Tabela 2.1). Nas três praias, novembro foi o mês com maior número de espécies amostradas, seguido por janeiro de 2010 na abrigada, fevereiro de 2009 na intermediária e dezembro de 2008 na exposta. O menor valor foi em agosto na abrigada e exposta, e em março na intermediária (Figura 2.21).

Os resultados obtidos para riqueza de Margalef mostram que os meses mais quentes são mais ricos que os meses mais frios, com picos em novembro e fevereiro de 2009. Apesar da grande quantidade de peixes coletados em dezembro de 2009, sua riqueza foi relativamente baixa, sugerindo a entrada de um número maior de indivíduos de poucas espécies na área. Janeiro e março de 2009, mesmo sendo meses de temperaturas elevadas, apresentaram baixos valores de riqueza. O mês com maior diversidade foi novembro de 2009, correspondendo ao mês com maior número de espécies obtidas. Já os menos diversos corresponderam aos meses de temperaturas mais frias, com uma queda acentuada em agosto. Dezembro de 2008 e 2009, apesar da elevada temperatura e grande quantidade de peixes amostrados, apresentaram valores baixos de diversidade, provavelmente devido à alta abundância de $M$. curema e $T$. carolinus. Com exceção novamente de dezembro, os meses com temperaturas mais baixas foram os que apresentaram maior dominância, principalmente pela abundância de H. clupeola e M. liza. O maior valor de dominância ocorreu em agosto, diminuindo até os menores valores correspondentes aos três meses seguintes. Contrastando com a dominância, agosto foi o mês com o menor valor de equitatividade, sendo setembro e outubro os com maiores (Figura 2.22).

O dendograma resultando da análise de agrupamento, considerando a abundância das espécies, ilustra as associações entre os meses mais frios (junho a outubro) e os mais quentes (novembro a abril). A única exceção foi o mês de maio que, apesar de já apresentar baixas temperaturas, esteve associado aos meses de temperatura mais elevadas. Dezembro e agosto de 2009 não se associaram a nenhum grupo, provavelmente devido a alta abundância de C. latus no primeiro e de $M$. liza no segundo 
(Figura 2.23). Agrupando os meses mais frios e os mais quentes observou-se que a maioria dos índices calculados variou significamente, com exceção da diversidade de Shannon (Tabela 2.9).

As variáveis abióticas avaliadas explicaram aproximadamente $38 \%$ da variabilidade dos dados biológicos, sendo apenas salinidade não significativa $(P \geq 0,05)$ pelo teste de permutação de Monte Carlo. O primeiro e o segundo eixo explicaram juntos 58,2 \% da relação espécies-ambiente, estando o primeiro correlacionado positivamente com o mês de agost e julho o e negativamente com temperatura, enquanto o segundo é correlacionado positivamente com a maré baixa. As correlações espécieambiente apresentaram altos valores tanto com o primeiro $(0,84)$, quanto com o segundo $(0,73)$ eixo (Tabela 2.10). Após análise do teste de permutação de Monte Carlo, verificou-se que os eixos canônicos foram significamente diferentes entre si (Traço= $0,825 ; \mathrm{F}=2,895 ; \mathrm{P}=0,0001)$.

A distribuição das espécies em relação às variáveis abióticas avaliada pela Análise de Correspondência Canônica está representada na figura 2.24. Dentre os dados ambientais, observamos que a temperatura explicou mais a variação na abundância da ictiofauna do que a salinidade, com 15,46\% da variabilidade (soma de todos os autovalores canônicos $=0,286$ ). Porém, ao se retirar a interação dos dados ambientais com os de tempo e espaço, a porcentagem de explicação diminui para apenas 2,48 \%. Foram mais abundantes em águas mais quentes as larvas de E. saurus e todas as espécies do gênero Mugil, com exceção de $M$. liza que juntamente com $O$. saliens e $H$. clupeola foram abundantes em águas mais frias (Figura 2.24).

A variação espacial explicou sozinha apenas $2,27 \%$ da variação na abundância da ictiofauna (soma de todos os autovalores canônicos $=0,042$ ), sendo apenas a praia abrigada significativa pelo teste de permutação de Monte Carlo. Retirando-se a interação com as variáveis relacionadas ao tempo, a porcentagem de explicação diminui pouco, para $2,1 \%$. T. goodei esteve negativamente correlacionado a praia abrigada, preferindo assim praias mais expostas (Figura 2.24).

A maior variação foi explicada pelas variáveis temporais, que totalizaram $35,17 \%$ de explicação (soma de todos os autovalores canônicos $=0,652$ ). Nesta variável, foi possível notar duas influências, uma nictemeral, relacionada com as diferentes amplitudes de marés, e outra sazonal, ao longo dos meses amostrados. Somente a variação nictemeral, excluindo o efeito sazonal, explicou 3,72 \%, enquanto a sazonalidade, sem o efeito das marés, explicou 31,23\%. As espécies T. goodei e $M$. 
littoralis foram mais abundantes nas amostragens realizadas durante a maré alta. Diferentemente, $T$. falcatus e as larvas de Gerreidae e Engraulidae foram abundantes na maré baixa.

Mesmo sendo a espécie mais abundante, T. carolinus, não mostrou tendência de explicação clara por nenhuma das variáveis abióticas analisadas, estando localizado próximo do centro do diagrama de ordenação (Figura 2.24).

\section{Ilha do Cardoso}

Para a ilha do Cardoso, apesar da maior quantidade de exemplares ter sido coletada na praia exposta, a mesma foi a que apresentou a menor riqueza entre as praias (Tabela 2.11). Não houve diferença significativa nos valores de riqueza entre as praias abrigada e intermediária, entretanto essa última apresentou o menor número de indivíduos obtidos. A praia intermediária foi mais diversa que a abrigada e então que a exposta. As duas últimas são igualmente equitativas, sendo que ambas apresentam menores valores que a intermediária. A praia com maiores valores de dominância foi a exposta, seguida pela abrigada e intermediária. As espécies dominantes na praia exposta foram M. hospes e T. carolinus. As larvas de Gerreidae e A. brasiliensis foram abundantes na praia abrigada, já na intermediária M. curema e T. carolinus foram as espécies mais representativas (Tabela 2.11).

Entre as três praias amostradas, não foi observado um padrão de distribuição para a frequência nas classes de comprimento padrão. Na praia abrigada e intermediária, aproximadamente $96 \%$ dos indivíduos amostrados mediam entre cinco e 105 mm, já na exposta essa mesma proporção corresponde às classes de cinco a $65 \mathrm{~mm}$. A classe modal de comprimento padrão mais abundante foi a de cinco a $15 \mathrm{~mm}$ na praia abrigada, e 16 a $25 \mathrm{~mm}$ na intermediária e exposta (Figura 2.25).

Ao comparar as amostragens realizadas durante a maré baixa e alta, observouse que durante a maré baixa foram obtidos os maiores valores de diversidade e riqueza, além da maior quantidade de indivíduos. Não houve diferença significativa no valor de equitatividade, sendo que na maré alta a dominância é maior que na baixa (Tabela 2.12). As larvas de Gerreidae e T. carolinus dominaram as amostragens realizadas durante a maré alta. $78 \%$ dos indivíduos amostrados durante a maré baixa mediam entre cinco e $65 \mathrm{~mm}$, já esta mesma proporção na alta correspondeu a espécimes de até $55 \mathrm{~mm}$. A classe modal de comprimento padrão predominante na maré baixa foi a de 16 a $25 \mathrm{~mm}$, enquanto na alta foi a de 26 a $35 \mathrm{~mm}$ (Figura 2.26). 
Com relação à variação temporal, a maior quantidade de indivíduos amostrados foi coletada em meses de temperatura mais quentes. Na praia intermediária e exposta, dezembro foi o mês com a maior quantidade de espécimes obtidos, sendo que nesta última $71 \%$ do total amostrado correspondem a tal mês. Já na abrigada, dezembro é o sexto mês com a maior quantidade de espécimes coletados, ficando novembro, janeiro e março com as primeiras colocações (Figura 2.27).

No geral, a variação mensal do peso total coletado aponta maio, junho e novembro como meses nos quais se obteve pouca biomassa, sendo os de maior dezembro, outubro, março e janeiro. A praia exposta apresentou os menores valores de peso total na maioria dos meses, com exceção de abril e dezembro, cujo valor superou a praia intermediária e abrigada respectivamente. Em março e outubro foram obtidos os maiores valores de biomassa na praia abrigada, sendo os menores obtidos em novembro e junho. Enquanto na praia intermediária os meses de dezembro, janeiro, julho e outubro foram os meses de maior captura em peso, o mês de maio foi aquele com a menor captura (Figura 2.28).

Observou-se que T. carolinus, T. goodei e A. brasiliensis ocorreram em todos os meses de coleta. O. saliens apenas não ocorreu em agosto, e M. littoralis em fevereiro. As larvas de Gerreidae e M. hospes não ocorreram nos meses de temperaturas mais baixas. Dezenove e nove espécies ocorreram, respectivamente, em um ou dois meses ao longo do ano (Tabela 2.4). No geral, nas três praias amostradas a menor quantidade de espécies coletadas corresponde aos meses mais frios do ano, principalmente entre junho e outubro. Já os maiores valores correspondem a meses de temperatura elevadas, havendo um pico em janeiro na praia abrigada, em fevereiro na intermediaria e em fevereiro e abril na exposta (Figura 2.29).

Ao longo do ano de coleta, os valores de riqueza de Margalef, diversidade de Shannon e equitatividade de Pielou variaram de forma semelhante, sendo outubro o mês com os maiores valores nos três índices, apesar da baixa quantidade de espécimes coletados. Após outubro, março e janeiro apresentaram altos valores de diversidade e riqueza, enquanto a equitatividade foi seguida por maio e março. Já os meses menos ricos e diversos foram agosto, setembro e novembro, sendo este último ainda o menos equitativo. Na maioria dos meses os dados de dominância contrastaram com os de equitatividade, sendo novembro e setembro os mais dominantes devido à grande captura de larvas de gerreídeos e A. brasiliensis respectivamente, e outubro e março os menos (Figura 2.30). 
O dendograma resultante da análise de grupamento mostra que dezembro não se agrupou com nenhum outro mês, fato provavelmente explicado por ter sido o único mês em que se coletou em abundância $C$. chrysurus. Os meses mais frios do ano em questão, julho, agosto setembro formaram um único grupo, contrastando com os demais meses (Figura 2.31).

Não houve diferença significativa nos valores de diversidade, riqueza e equitatividade para a ictiofauna ao se agrupar os meses mais quentes e os mais frios. Apenas na dominância a diferença foi significativa, sendo os meses de temperaturas baixas com maior dominância que os com temperatura mais elevadas (Tabela 2.13).

As variáveis abióticas avaliadas explicaram 41,32 \% da variabilidade dos dados biológicos, sendo apenas a salinidade não significativa $(\mathrm{P} \leq 0,05)$ pelo teste de permutação de Monte Carlo. Os dois primeiros eixos explicaram juntos 54,5\% da relação espécies-ambiente, sendo o primeiro correlacionado positivamente com a praia exposta e a maré alta, e negativamente com a praia abrigada; enquanto o segundo é correlacionado negativamente com a temperatura. As correlações espécie-ambiente apresentaram altos valores tanto com o primeiro $(0,84)$, quanto com o segundo $(0,82)$ eixo (Tabela 2.14). Os eixos canônicos foram significamente diferentes entre si pelo teste de permutação de Monte Carlo (Traço=1,114; $\mathrm{F}=3,16 ; \mathrm{P}=0,0001)$. A figura 2.32 ilustra a distribuição das espécies em relação às variáveis abióticas avaliadas pela Análise de Correspondência Canônica.

Analisando somente os dados ambientais de temperatura e salinidade, temos que a primeira explicou mais que a segunda a abundância da ictiofauna, com 13,93\% da variabilidade (soma de todos os autovalores canônicos $=0,321$ ). Ao se excluir a interação dos dados ambientais com os de tempo e espaço, a porcentagem de explicação diminui para apenas $2,70 \%$. Apresentaram preferências por águas mais quentes as larvas de Gerreidae, T. carolinus e M. hospes enquanto M. liza e A. brasiliensis por águas mais frias. (Figura 2.32).

Os diferentes tipos de praia explicaram $11,41 \%$ da variação na abundância da ictiofauna (soma de todos os autovalores canônicos = 0, 263). Retirando-se a interação com as variáveis relacionadas ao tempo, a porcentagem de explicação diminui aproximadamente $1 \%$. Foram mais abundantes na praia mais abrigada as espécies: $A$. brasiliensis, A. tricolor, S. timucu, A. lepidentostole e os engraulídeos em fase larval. Já M. hospes, T. carolinus, T. goodei e M. littoralis foram mais abundantes na mais exposta. 
As variáveis temporais explicaram 31,86 \% da variação na abundância da ictiofauna (soma de todos os autovalores canônicos $=0,734$ ). Nesta variável, também foi possível notar duas influências, uma relacionada com as diferentes amplitudes de marés e outra com o passar dos meses amostrados. Somente a variação nictemeral, excluindo o efeito sazonal, explicou 6,12 \%, enquanto a sazonalidade, sem o efeito das marés, explicou 26,26\%. Durante a maré alta foram amostrados $T$. carolinus e $M$. littoralis em abundância, enquanto na baixa A. tricolor, A. brasiliensis e S. timucu.

\section{DISCUSSÃO}

A ictiofauna encontrada no presente estudo foi composta por 44 espécies na Ilha Comprida e 47 na Ilha do Cardoso, ambas com dominância de poucas espécies, padrão este descrito em diversos estudos sobre comunidades de ambientes praiais (BROWN e MCLACHLAN, 1990; GODEFROID et al., 2003a; PESSANHA e ARAÚJO, 2003; FÉLIX et al., 2007b; STEFANONI, 2008). Espécies dos gêneros Trachinotus e Mugil foram abundantes nas praias das duas ilhas, entretanto na primeira houve também uma alta representatividade do gênero Harengula, enquanto na segunda de Atherinella e Anchoa.

Diversos estudos realizados no complexo estuarino e baía de Paranaguá, litoral paranaense, e ecossistema contíguo ao do presente estudo, apontam a importância dos gêneros citados acima na estruturação da ictiofauna do sistema, mesmo quando amostrados em diferentes praias e em anos distintos (GODEFROID et al., 1998; GODEFROID et al., 2003a; SPACH et al., 2004; FÉLIX et al., 2006; FÉLIX et al., 2007b, STEFANONI, 2008). Com exceção de Anchoa, tais gêneros são também representativos em praias do sul do Brasil (LIMA e VIEIRA, 2009). No litoral do Estado do Rio de Janeiro, os mesmo gêneros continuam a compor as ocorrências nas listagens, com certa abundância, porém, nota-se que a quantidade relativa de mugilídeos diminui (GAELZER e ZALMON, 2003; GOMES, et al.,2003; PESSANHA e ARAÚJO, 2003; VASCONCELLOS, 2007; GAELZER e ZALMON, 2008a; GAELZER e ZALMON, 2008b). Já em uma praia do Espírito Santo, não foi observada a ocorrência de mugilídeos e, apesar dos outros gêneros ocorreram, as espécies mais abundantes foram: Lutjanus synagris, Achosargus romboidalis, Eucinostomus lefroyi, Paralonchurus brasiliensis (ARAÚJO et al., 2008). Em praias da baía de Todos os Santos, Bahia, foram dominantes L. synaris, Larimus breviceps, Chaetodipterus faber, 
Polydactylus virginicus, Ophioscion punctatissimus e Conodon nobilis (OLIVEIRASILVA, 2008). Já em Pernambuco, aproximadamente $40 \%$ do total de espécies foi representado por $O$. punctatissimus (LIRA e TEIXEIRA, 2008). Notando-se uma grande diferença nas espécies que compõem a ictiofauna da zona de surfe de praias do Espírito Santo em direção ao Nordeste brasileiro.

As espécies dos gêneros mais abundantes do presente trabalho representam principalmente demersais e pelágicas de passagem, semelhantes ao padrão encontrado por Monteiro Neto et al. (2008) para o mesmo aparelho de pesca em praias do Rio de Janeiro.

O número de espécies deve ser entendido no contexto de que os trabalhos foram desenvolvidos somente no período de luz. Oliveira Neto et al. (2004) encontraram praticamente o dobro do número de espécies em arrastos de praia realizados durante a noite em relação aos diurnos.

Ao se comparar a ictiofauna da zona de surfe da barra de Cananéia com as espécies coletadas em trabalhos com rede de arrasto de fundo na região, em maiores profundidades (ZANI-TEIXEIRA, 1983; SAUL e CUNNINGHAM, 1995; e MACIEL, 2001), nota-se baixo número de espécies exclusivas da zona de surfe, indicando conectividade desta comunidade de peixes com outros habitats, tanto dentro quanto fora do sistema costeiro em questão.

A alta abundância de indivíduos em estádio juvenil e larval amostrada no presente estudo, totalizando $100 \%$ na Ilha Comprida e $99 \%$ na Ilha do Cardoso, corrobora a relevância da área de estudo para os estágios ontogênicos iniciais. Godefroid et al. (2003), Félix et al. (2007a), Inoue et al. (2008) e Stefanoni (2008) também encontraram altas proporções de indivíduos juvenis e/ou larvas. É importante ressaltar que, conforme já apontado por Suda et al. (2002), Godefroid et al. (2003) e Stefanoni (2008), o aparelho de pesca utilizado na maioria dos estudos realizados em zonas de surfe de praias arenosas são seletivos, principalmente devido ao pequeno tamanho da malha das redes. A tabela 2.15 mostra que o comprimento entre nós das redes utilizadas em diversos estudos variou entre 1 e $40 \mathrm{~mm}$, sendo a maioria delas de 5 mm. Além disso, a baixa velocidade na qual os arrastos de praias são realizados, juntamente com a dificuldade de se operar a rede com turbulência, resulta em uma menor captura de peixes de maior porte (SUDA et al., 2002). Os formatos corporais das espécies que apresentam os maiores comprimentos padrão obtidos nas praias da Ilha do Cardoso, ou seja, o corpo cilíndrico de $S$. timucu, achatado de $P$. orbignyanus e oval de 
S. testudineus são típicos de organismos nectônicos que não possuem natação sustentada (NYBAKKEN e BERTNESS, 2004). Tal coincidência provavelmente justifique o predomínio de espécimes de pequeno porte, uma vez que indivíduos tamanhos maiores e de natação mais rápida, podem vir a fugir da rede arrastada em baixa velocidade.

O grau de exposição de ondas dos ambientes praiais é considerado um dos principais fatores estruturadores das comunidades de peixes da zona de surfe (ROMER, 1990; CLARK, 1996a; GAELZER e ZALMON, 2003; VASCONCELLOS et al., 2007). No entanto, a influência da exposição da praia sobre a composição e estrutura da comunidade ictiofaunística pode ser pouco compreendida, principalmente na interconexão entre esta variável e outras, como a abundância de macroalgas e/ou matéria orgânica em decomposição, salinidade, e transparência da água, conforme apontado por Clark (1997). No presente trabalho, o grau de exposição explicou apenas $2,27 \%$ e 11,41 \% da variação da ictiofauna na Ilha Comprida e na Ilha do Cardoso, respectivamente. A diferença da porcentagem de explicação dos padrões encontrados entre as ilhas provavelmente está relacionada à maior amplitude de energia das ondas nas praias da Ilha do Cardoso.

Em diversos estudos ocorreu um aumento da riqueza de espécies e diversidade quanto maior a proteção da praia, enquanto as mais expostas foram dominadas por poucas espécies (ROMER, 1990; GAELZER e ZALMON, 2003; VASCONCELLOS et al., 2007). Este padrão foi observado também no presente trabalho, porém, assim como em Stefanoni (2008), talvez a área de estudo não seja apropriada para testar tal hipótese, pois há interações com outras variáveis, principalmente relacionadas com a presença do estuário. As aqui consideradas praias abrigadas e intermediárias estão sob forte influência de águas estuarinas, enquanto as expostas sob maior influência marinha. Clark et al. (1996b) demonstram que não se deve atribuir as variações na diversidade, abundância e dominância unicamente ao grau de exposição, mas sim considerar o conjunto de fatores que se interrelacionam dentro de cada ambiente.

Stefanoni (2008) aponta que a maior riqueza de espécies e diversidade de peixes observados nas praias mais protegidas pode estar relacionada a uma maior disponibilidade e acessibilidade do alimento em tais praias, quando comparadas com as mais expostas, pois a turbulência gerada pelas ondas pode ser um fator redutor da taxa de ingestão de alimento pelos peixes, devido à continua necessidade de ajuste da posição corpórea do indivíduo na coluna d'água e decréscimo do campo visual (CLARK, 1997). 
Nas praias de ambas as ilhas, $T$. goodei e M. littoralis estiveram associadas aos ambientes de alta energia, onde foram registradas as maiores salinidades, como reflexo da maior exposição, o que foi observado também por Félix et al. (2007a), Vasconcellos et al. (2007) e Stefanoni (2008). Diferentemente de estuários, em que a salinidade pode ser o fator estruturador (BARLETTA et al., 2005), nas praias mais expostas este fator isoladamente não é bom explicador da ictiofauna. Já nas praias da Ilha do Cardoso, as espécies que se correlacionaram com as praias mais protegidas são associadas também com regiões estuarinas (ZANI-TEIXEIRA, 1983; MACIEL, 2001; PERES-RIOS, 2001; RAMOS e VIEIRA, 2001).

Dentro das variações temporais observadas, que influenciaram em $30 \%$ da estruturação e composição da ictiofauna, foi observada uma pequena relevância da variação nictemeral, sendo a sazonal a mais representativa, tanto na Ilha Comprida quanto na Ilha do Cardoso. Apesar de as principais alterações sazonais mensuráveis estarem relacionadas com a temperatura, tendo sido observados dois agrupamentos claros de meses, um com temperaturas mais frias e outro com temperaturas mais quentes, a temperatura sozinha, apesar de significativa, mostrou baixa porcentagem de explicação na variação da ictiofauna. Deste modo, ressalta-se o já apontado por Ross et al. (1987) e Félix et al. (2007a), que as mudanças sazonais na comunidade de peixes da zona de surfe são reflexos principalmente de padrões de recrutamento determinados pela atividade reprodutiva e pela circulação costeira.

No geral, os meses mais quentes foram os mais ricos, diversos e abundantes em ictiofauna, enquanto os mais frios apresentaram maior dominância. Assim como no presente estudo, diversos trabalhos, como Lasiak (1984), Bennett (1989), Giannini e Paiva Filho (1995), Clark (1996a), Godefroid et al. (2003); Félix et al. (2006) e Araújo et al. (2008), encontraram as maiores diversidades e abundâncias nos meses mais quentes, coincidindo com a época reprodutiva de um grande número de espécies de peixes. As altas temperaturas favorecem a multiplicação do fitoplâncton, e por sua vez do zooplâncton, aumentando a quantidade de alimento disponível para as larvas e juvenis, e consequentemente, as suas chances de sobrevivência (NYBAKKEN e BERTNESS, 2004).

Porém, o grande problema em estudos sobre dinâmica populacional ou aspectos reprodutivos da ictiofauna é a freqüência de amostragem. Desta forma, relacionar os meses mais quentes (final de primavera ou verão) e a captura de exemplares juvenis na mesma época carece de acuidade, uma vez que o tamanho dos 
indivíduos capturados e sua taxa de crescimento devem ser investigados e relacionados com a época de desova, e não com a época reprodutiva. Estudos sobre taxas de crescimento das espécies mais abundantes das praias não estão disponíveis para estas espécies, o que pode se restringir as interpretações dos resultados.

A relativa baixa porcentagem de explicação dos parâmetros abióticos sobre a ictiofauna é devido à dificuldade de se mensurar todas as variáveis ambientais, temporais e espaciais que influenciam a comunidade de peixes da zona de surfe. Outras variáveis abióticas, além das avaliadas no presente estudo, são apontadas como responsáveis pela variação dos dados biológicos, por exemplo: transparência da água (PESSANHA e ARAÚJO, 2003), velocidade do vento (LIMA e VIEIRA, 2009), abundância de macrófitas (GOMES et al., 2003) e de macroalgas (TEIXEIRA e ALMEIDA, 1998; GAELZER e ZALMON, 2003). Além do mais, dentro dos fatores biológicos há uma série de relações inter- e intra-específicas que são difíceis de serem isoladas e avaliadas, prejudicando a distinção de padrões da variação da ictiofauna. 
Tabela 2.1. Frequencia relativa (\%) dos indivíduos da ictiofauna ao longo dos meses amostrados nas praias da Ilha Comprida, contribuição total e constância de ocorrência (C). *=espécies com representantes em fase larval.

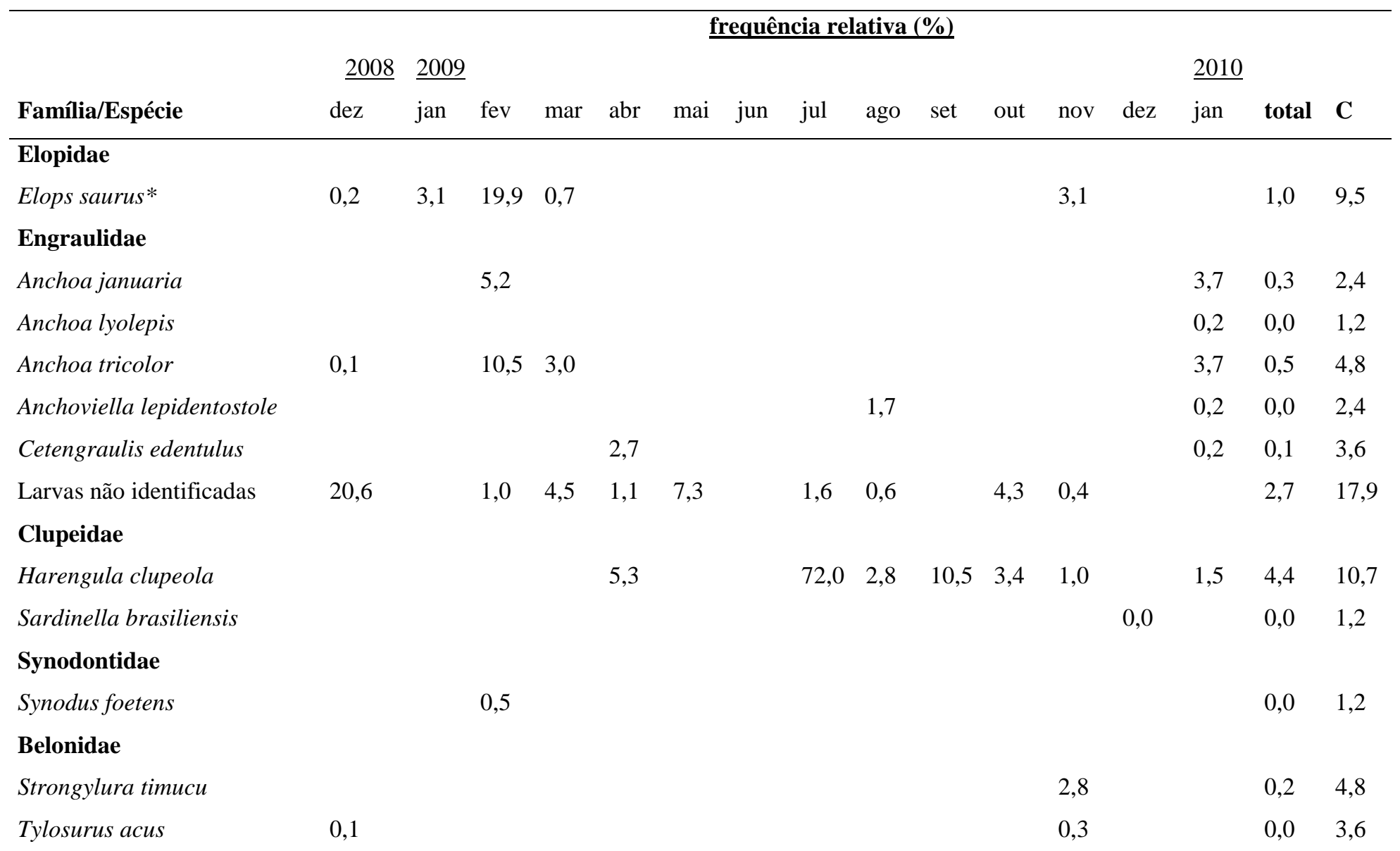


Tabela 2.1. continuação

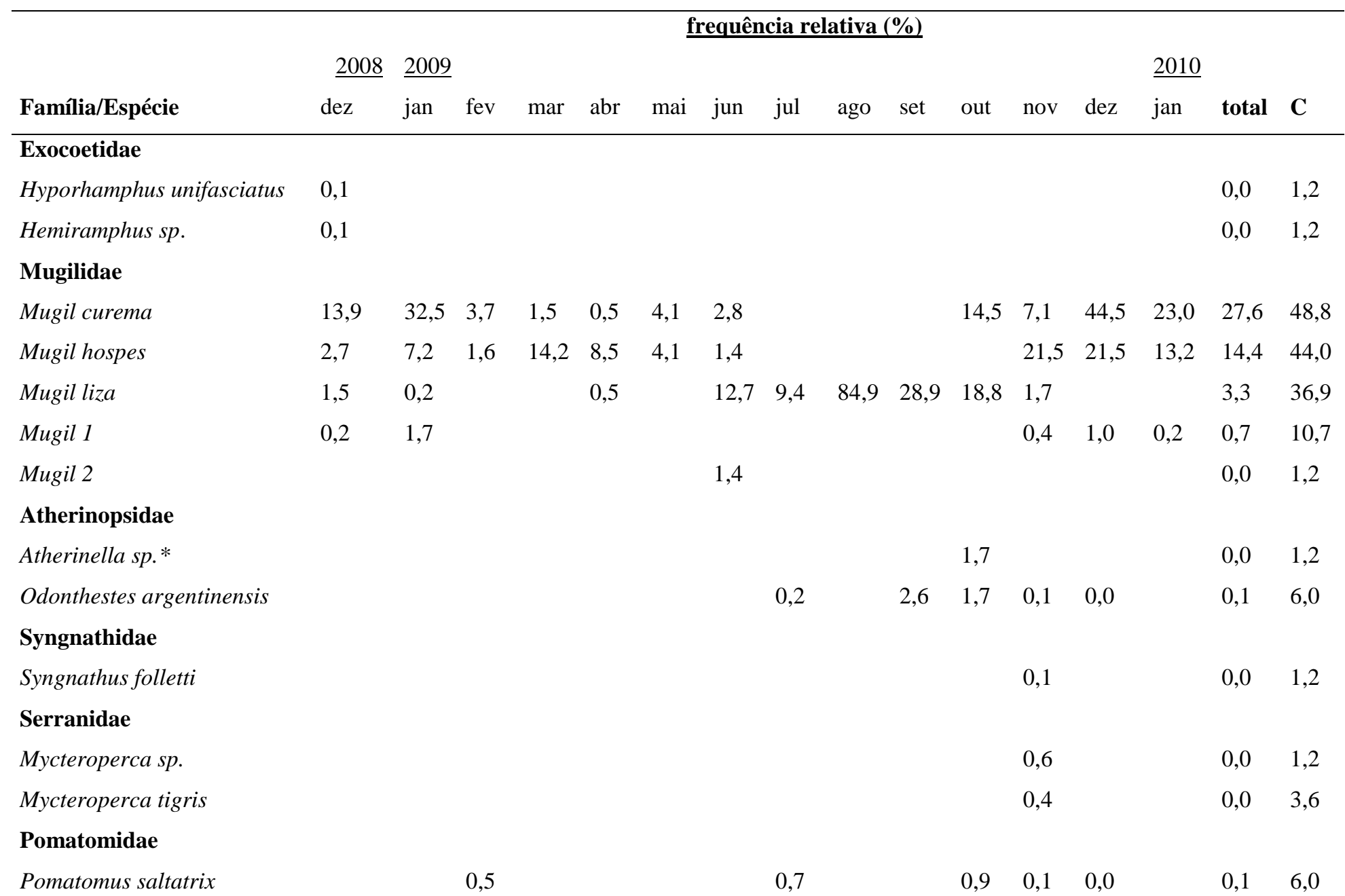


Tabela 2.1. continuação

frequência relativa (\%)

\begin{tabular}{|c|c|c|c|c|c|c|c|c|c|c|c|c|c|c|c|c|}
\hline \multirow[b]{3}{*}{ Família/Espécie } & \multicolumn{16}{|c|}{ frequência relativa $(\%)$} \\
\hline & $\underline{2008}$ & $\underline{2009}$ & & & & & & & & & & & & $\underline{2010}$ & & \\
\hline & dez & jan & fev & mar & abr & mai & jun & jul & ago & set & out & nov & dez & jan & total & $\mathbf{C}$ \\
\hline \multicolumn{17}{|l|}{ Carangidae } \\
\hline Caranx latus & & & & & & & & & & & & & 0,5 & & 0,2 & 1,2 \\
\hline Oligoplites saliens & & & 1,0 & & 4,8 & & & 3,7 & 8,4 & & 0,9 & 0,6 & 0,1 & 1,0 & 0,7 & 19,0 \\
\hline Oligoplites sp. & 0,1 & & & & & & & & & & & & & 0,2 & 0,0 & 2,4 \\
\hline Selene vômer & 0,1 & & & & & & & & & & & & & & 0,0 & 1,2 \\
\hline Trachinotus carolinus & 54,8 & 25,5 & 35,1 & 38,1 & 38,8 & 37,9 & 47,9 & 3,7 & 1,7 & 21,1 & 33,3 & 25,0 & 29,5 & 33,3 & 30,6 & 86,9 \\
\hline Trachinotus falcatus & 0,4 & 0,9 & 0,5 & & 0,5 & & & & & & & 2,4 & 0,1 & 0,2 & 0,4 & 16,7 \\
\hline Trachinotus goodei & 3,5 & 28,4 & 15,2 & 35,8 & 15,4 & 40,2 & 31,0 & 8,0 & & 15,8 & 14,5 & 15,0 & 2,5 & 16,7 & 9,3 & 82,1 \\
\hline \multicolumn{17}{|l|}{ Gerreidae } \\
\hline Larvas não identificadas & 0,9 & & 2,6 & 2,2 & 18,6 & & & & & & & 5,4 & 0,3 & 1,0 & 1,3 & 17,9 \\
\hline \multicolumn{17}{|l|}{ Haemulidae } \\
\hline Pomadasys corvinaeformis & & & & & 1,1 & & & & & & & & & & 0,0 & 1,2 \\
\hline \multicolumn{17}{|l|}{ Polynemidae } \\
\hline Polydactylus virginicus & & & & & & & & & & & & 0,1 & & & 0,0 & 1,2 \\
\hline \multicolumn{17}{|l|}{ Sciaenidae } \\
\hline Menticirrhus americanus & & & & & & & & & & 5,3 & & 3,6 & & & 0,3 & 4,8 \\
\hline Menticirrhus littoralis & & 0,5 & 1,0 & & 2,1 & 6,4 & 2,8 & 0,7 & & 15,8 & 4,3 & 7,1 & 0,1 & 1,5 & 1,2 & 28,6 \\
\hline Micropogonias furnieri* & & & & & & & & & & & & 0,6 & & & 0,0 & 1,2 \\
\hline
\end{tabular}


Tabela 2.1. continuação

\begin{tabular}{|c|c|c|c|c|c|c|c|c|c|c|c|c|c|c|c|c|}
\hline \multirow[b]{3}{*}{ Família/Espécie } & \multicolumn{16}{|c|}{ frequência relativa (\%) } \\
\hline & $\underline{2008}$ & $\underline{2009}$ & & & & & & & & & & & & $\underline{2010}$ & & \\
\hline & $\operatorname{dez}$ & jan & fev & mar & $\mathrm{abr}$ & mai & jun & jul & ago & set & out & nov & $\mathrm{dez}$ & jan & total & C \\
\hline \multicolumn{17}{|l|}{ Pomacentridae } \\
\hline Abudefduf saxatilis & & & 0,5 & & & & & & & & & 0,3 & & & 0,0 & 2,4 \\
\hline \multicolumn{17}{|l|}{ Blenniidae } \\
\hline Parablennius pilicornis & & & 0,5 & & & & & & & & & & & & 0,0 & 1,2 \\
\hline \multicolumn{17}{|l|}{ Paralichthyidae } \\
\hline Citharichthys arenaceus & 0,1 & & & & & & & & & & 1,7 & & & & 0,0 & 2,4 \\
\hline \multicolumn{17}{|l|}{ Monacanthidae } \\
\hline Stephanolepis hispidus & & & 0,5 & & & & & & & & & & & & 0,0 & 1,2 \\
\hline \multicolumn{17}{|l|}{ Tetraodontidae } \\
\hline Sphoeroides sp. & 0,2 & & & & & & & & & & & 0,6 & & & 0,1 & 3,6 \\
\hline \multicolumn{17}{|l|}{ Diodontidae } \\
\hline Chilomycterus spinosus & 0,1 & & & & & & & & & & & & & & 0,0 & 1,2 \\
\hline Total de indivíduos & 854 & 584 & 191 & 134 & 188 & 219 & 71 & 435 & 179 & 38 & 117 & 721 & 3873 & 408 & 8012 & \\
\hline Total de espécies & 19 & 9 & 17 & 8 & 13 & 6 & 7 & 9 & 6 & 7 & 12 & 25 & 13 & 16 & 44 & \\
\hline Total de famílias & 10 & 4 & 11 & 5 & 7 & 4 & 3 & 7 & 4 & 5 & 8 & 15 & 7 & 6 & 23 & \\
\hline
\end{tabular}


Tabela 2.2. Peso total (g) das oito espécies da ictiofauna com maiores contribuições relativas (\%) da amostragem realizada nas praias da Ilha Comprida.

\begin{tabular}{llccc}
\hline \multicolumn{1}{c}{ Família } & \multicolumn{1}{c}{ Espécie } & $\begin{array}{c}\text { Peso Total } \\
(\mathbf{g})\end{array}$ & N & $\begin{array}{c}\text { Contribuição } \\
\text { relativa (\%) }\end{array}$ \\
\hline Carangidae & Trachinotus carolinus & 2670,67 & 2451 & 31,67 \\
Carangidae & Trachinotus goodei & 2647,85 & 743 & 31,40 \\
Clupeidae & Harengula clupeola & 1061,38 & 349 & 12,59 \\
Mugilidae & Mugil curema & 766,96 & 2214 & 9,10 \\
Mugilidae & Mugil hospes & 414,05 & 1153 & 4,91 \\
Carangidae & Oligoplites saliens & 234,86 & 53 & 2,79 \\
Sciaenidae & Menticirrhus littoralis & 166,94 & 99 & 1,98 \\
Atherinopsidae & Odonthestes argentinensis & 135,04 & 6 & 1,60 \\
\hline
\end{tabular}

Tabela 2.3. Médias de comprimento padrão $(\mathrm{mm})$ e do peso (g) das espécies da ictiofauna, em ordem alfabética, amostrados nas praias da Ilha Comprida, com seus valores mínimo, máximo e desvio padrão.

\begin{tabular}{lcccccccc}
\hline \multirow{2}{*}{ Espécie } & \multicolumn{3}{c}{ Comprimento padrão $(\mathrm{mm})$} & \multicolumn{5}{c}{ Peso (g) } \\
\cline { 2 - 9 } & Média & DP & Min & Max & Média & DP & Min & Max \\
\hline Abudefduf saxatilis & 19,00 & 2,00 & 17 & 21 & 0,37 & 0,09 & 0,29 & 0,47 \\
Anchoa januaria & 39,76 & 4,56 & 34 & 55 & 0,92 & 0,38 & 0,48 & 2,34 \\
Anchoa lyolepis & & & 36 & 36 & & & 0,58 & 0,58 \\
Anchoa tricolor & 42,63 & 6,66 & 27 & 55 & 1,13 & 0,49 & 0,23 & 2,29 \\
Anchoviella lepidentostole & 42,13 & 8,02 & 31 & 48 & 0,92 & 0,45 & 0,34 & 1,28 \\
Atherinella sp. & 17,50 & 0,71 & 17 & 18 & 0,05 & 0,01 & 0,04 & 0,05 \\
Caranx latus & 38,74 & 1,41 & 37 & 42 & 1,79 & 0,14 & 1,54 & 2,01 \\
Cetengraulis edentulus & 54,83 & 3,13 & 50 & 58 & 2,22 & 0,34 & 1,66 & 2,54 \\
Chilomycterus spinosus & & & 23 & 23 & & & 1,83 & 1,83 \\
Citharichthys arenaceus & 75,00 & 4,36 & 70 & 78 & 6,82 & 1,25 & 5,39 & 7,71 \\
Elops saurus & 30,35 & 3,13 & 16 & 38 & 0,11 & 0,11 & 0,02 & 1 \\
Harengula clupeola & 52,79 & 6,00 & 26 & 80 & 3,08 & 1,07 & 0,33 & 8,46 \\
Hemiramphus sp. & 32,00 & & 32 & 32 & & & 0,02 & 0,02 \\
Hyporhamphus unifasciatus & & & 125 & 125 & & & 4,01 & 4,01 \\
Larva de Engraulidae & 21,45 & 3,14 & 16 & 32 & 0,09 & 0,06 & 0,03 & 0,4 \\
Larva de Gerreidae & 10,20 & 1,51 & 6 & 15 & 0,03 & 0,01 & 0,02 & 0,06 \\
Menticirrhus americanus & 13,20 & 5,34 & 6 & 27 & 0,10 & 0,13 & 0,03 & 0,54 \\
Menticirrhus littoralis & 31,92 & 22,46 & 7 & 156 & 1,81 & 6,92 & 0,03 & 48,87 \\
Micropogonias furnieri & 33,50 & 9,29 & 22 & 42 & 0,83 & 0,52 & 0,24 & 1,36
\end{tabular}


Tabela 2.3. continuação

\begin{tabular}{lcccccccc}
\hline \multirow{2}{*}{\multicolumn{1}{c}{ Espécie }} & \multicolumn{3}{c}{ Comprimento padrão $(\mathrm{mm})$} & \multicolumn{5}{c}{ Peso $(\mathrm{g})$} \\
\cline { 2 - 9 } & Média & DP & Min & Max & Média & DP & Min & Max \\
\hline Mugil curema & 22,86 & 3,20 & 14 & 37 & 0,27 & 0,13 & 0,05 & 1,42 \\
Mugil hospes & 22,97 & 6,33 & 16 & 66 & 0,33 & 0,56 & 0,06 & 5,57 \\
Mugil liza & 20,84 & 2,01 & 12 & 35 & 0,21 & 0,08 & 0,05 & 1,13 \\
Mugil 1 & 23,53 & 3,02 & 16 & 28 & 0,29 & 0,12 & 0,06 & 0,64 \\
Mugil 2 & & & 21,5 & 21,5 & & & 0,02 & 0,02 \\
Mycteroperca sp. & 20,00 & 1,15 & 19 & 21 & 0,23 & 0,06 & 0,18 & 0,29 \\
Mycteroperca tigris & 18,33 & 0,29 & 18 & 18,5 & 0,21 & 0,01 & 0,20 & 0,22 \\
Odonthestes argentinensis & 109,33 & 56,96 & 52 & 171 & 22,51 & 22,48 & 1,77 & 45,27 \\
Oligoplites saliens & 59,43 & 26,62 & 14 & 118 & 4,43 & 5,23 & 0,08 & 22,83 \\
Oligoplites sp. & 12,00 & 5,66 & 8 & 16 & & & 0,10 & 0,10 \\
Parablennius pilicornis & & & 17 & 17 & & & 0,13 & 0,13 \\
Polydactylus virginicus & & & 36 & 36 & & & 0,81 & 0,81 \\
Pomadasys corvinaeformis & 49,00 & 2,83 & 47 & 51 & 2,82 & 0,68 & 2,34 & 3,30 \\
Pomatomus saltatrix & 64,64 & 17,95 & 32 & 89 & 5,22 & 3,26 & 0,54 & 10,58 \\
Sardinella brasiliensis & & & 40 & 40 & & & 1,60 & 1,60 \\
Selene vomer & & & 24 & 24 & & & 0,90 & 0,90 \\
Sphoeroides sp. & 6,50 & 1,38 & 4 & 8 & 0,03 & 0,01 & 0,02 & 0,04 \\
Stephanolepis hispidus & & & 23 & 23 & & & 0,62 & 0,62 \\
Strongylura timucu & 40,75 & 13,09 & 13 & 66 & 0,72 & 2,47 & 0,04 & 10 \\
Syngnathus folletti & & & 58 & 58 & & & 0,08 & 0,08 \\
Synodus foetens & & & 41 & 41 & & & 0,38 & 0,38 \\
Trachinotus carolinus & 25,97 & 11,82 & 1,5 & 71 & 1,04 & 1,47 & 0,02 & 15,13 \\
Trachinotus falcatus & 19,53 & 6,58 & 9 & 38 & 0,57 & 0,51 & 0,06 & 2,67 \\
Trachinotus goodei & 40,66 & 18,94 & 11,5 & 152 & 3,56 & 6,73 & 0,06 & 83,79 \\
Tylosurus acus & 37,33 & 13,05 & 25 & 51 & 0,11 & 0,10 & 0,03 & 0,23 \\
\hline
\end{tabular}


Tabela 2.4. Frequência relativa (\%) dos indivíduos da ictiofauna ao longo dos meses amostrados nas praias Ilha do Cardoso, contribuição total, e constância de ocorrência (C). *=espécies com representantes em fase larval; **=espécies com indivíduos em fase larval e adulta.

\begin{tabular}{|c|c|c|c|c|c|c|c|c|c|c|c|c|c|c|}
\hline \multirow{3}{*}{ Família/espécie } & \multicolumn{13}{|c|}{ frequencia relativa $(\%)$} & \multirow[b]{3}{*}{ C } \\
\hline & \multicolumn{4}{|l|}{$\underline{2009}$} & \multirow[b]{2}{*}{ jun } & \multirow[b]{2}{*}{ jul } & \multirow[b]{2}{*}{ ago } & \multirow[b]{2}{*}{ set } & \multirow[b]{2}{*}{ out } & \multirow[b]{2}{*}{ nov } & \multicolumn{3}{|c|}{$\underline{2010}$} & \\
\hline & fev & mar & $\mathrm{abr}$ & mai & & & & & & & dez & jan & Total & \\
\hline Elopidae & & & & & & & & & & & & & & \\
\hline Elops saurus* & 4,1 & 0,8 & & & & & & & 3,3 & 0,3 & & 0,1 & 0,5 & 19,7 \\
\hline Engraulidae & & & & & & & & & & & & & & \\
\hline Anchoa januaria & & & & & & & & & & & 0,2 & 5,3 & 0,6 & 4,2 \\
\hline Anchoa lyolepis & & 1,1 & & 0,7 & & & & & & & & & 0,1 & 2,8 \\
\hline Anchoa tricolor & 9,3 & 11,1 & 0,4 & & 1,4 & & & & & & 0,2 & 31,6 & 4,6 & 14,1 \\
\hline Anchoviella lepidentostole & 0,2 & 1,1 & & & & & 0,7 & & & & & 2,5 & 0,3 & 9,9 \\
\hline Cetengraulis edentulus & & & 7,7 & & & & & & & & & 0,7 & 0,5 & 4,2 \\
\hline Larvas não identificadas & 3,7 & 2,5 & 4,6 & 4,8 & 23,4 & 1,8 & 1,4 & & 6,6 & 3,9 & & 1,0 & 2,2 & 36,6 \\
\hline Lycengraulis grossidens & 0,2 & 0,3 & & & & & & & & & & & 0,0 & 2,8 \\
\hline Clupeidae & & & & & & & & & & & & & & \\
\hline Harengula clupeola & 2,4 & 9,5 & 2,6 & 4,1 & & 2,9 & 24,3 & 26,5 & 1,2 & & & 1,4 & 2,2 & 23,9 \\
\hline Opisthonema oglinum & & & 0,4 & & & & & & & & & 0,1 & 0,0 & 2,8 \\
\hline Platanichthys platana & & & & & & & & & & & 0,0 & & 0,0 & 1,4 \\
\hline Sardinella brasiliensis & & & & & & & & & & & 0,2 & & 0,1 & 1,4 \\
\hline Synodontidae & & & & & & & & & & & & & & \\
\hline Synodus foetens & & & & & & & 0,7 & & & & & & 0,0 & 1,4 \\
\hline Belonidae & & & & & & & & & & & & & & \\
\hline Strongylura marina & & & & & & & & & & & 0,0 & & 0,0 & 1,4 \\
\hline Strongylura tiтиси & & 1,1 & 1,1 & 0,7 & & & & & & 0,4 & & 0,5 & 0,2 & 12,7 \\
\hline
\end{tabular}


Tabela 2.4. continuação

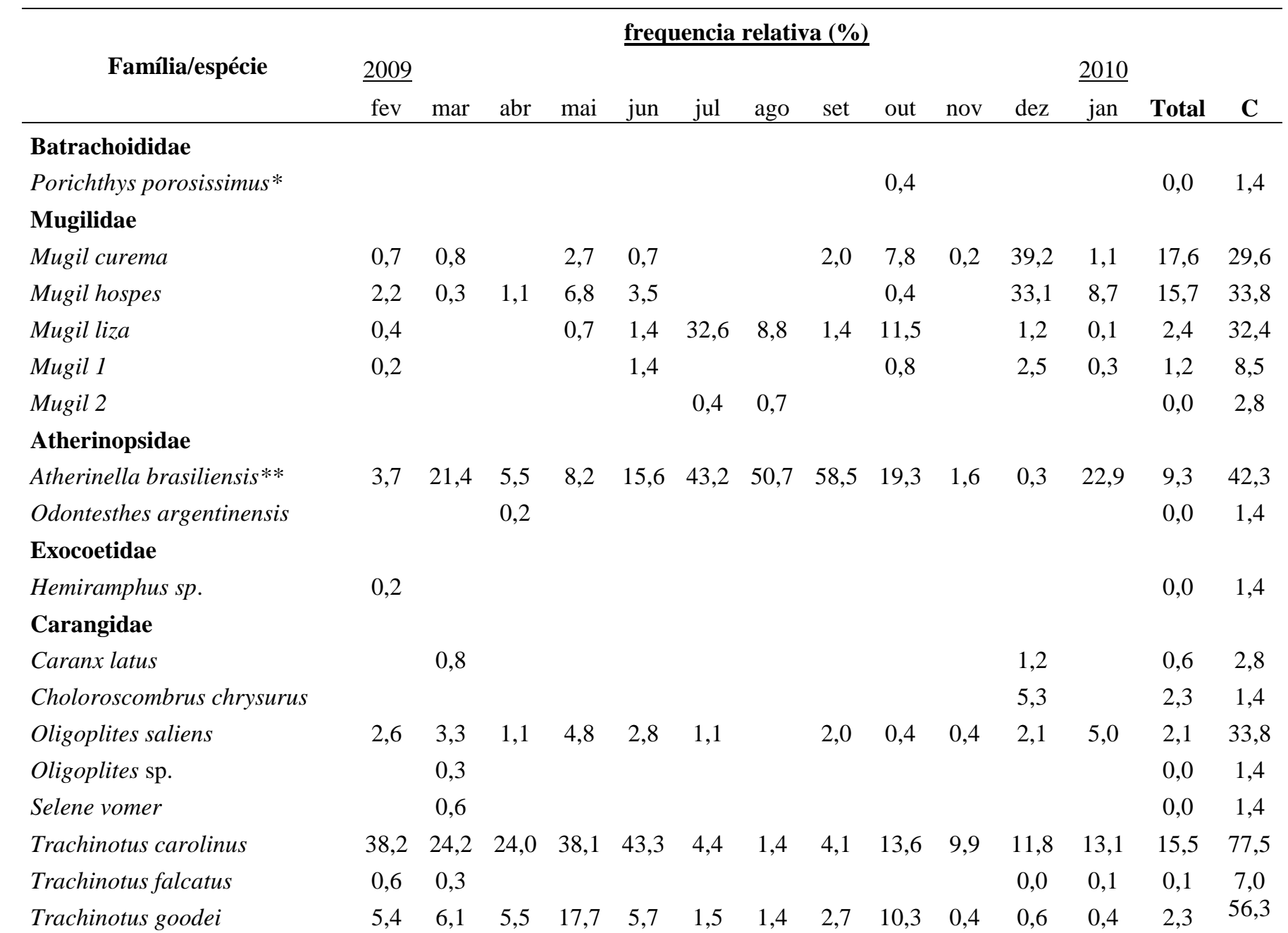


Tabela 2.4. continuação

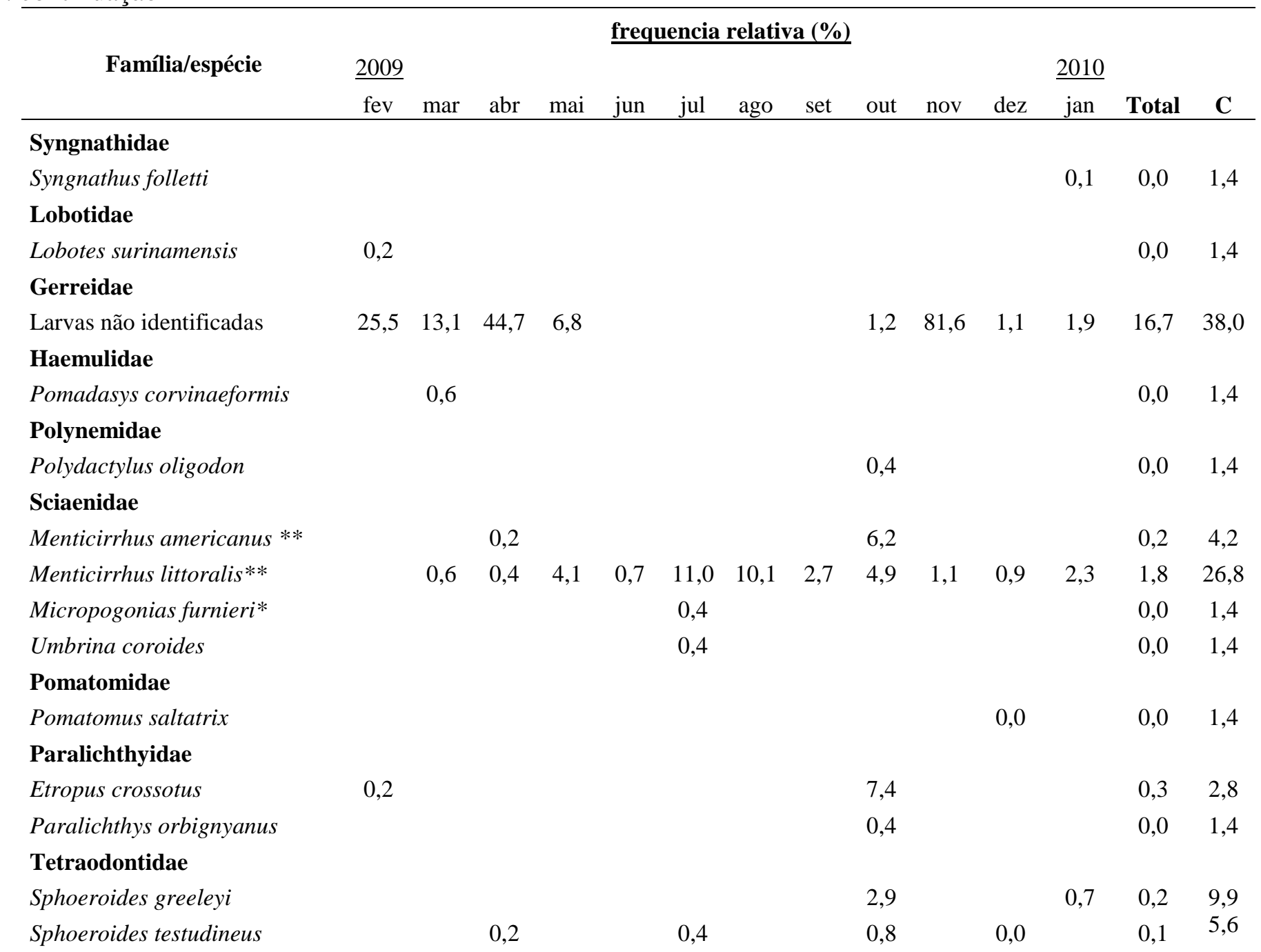


Tabela 2.4. continuação

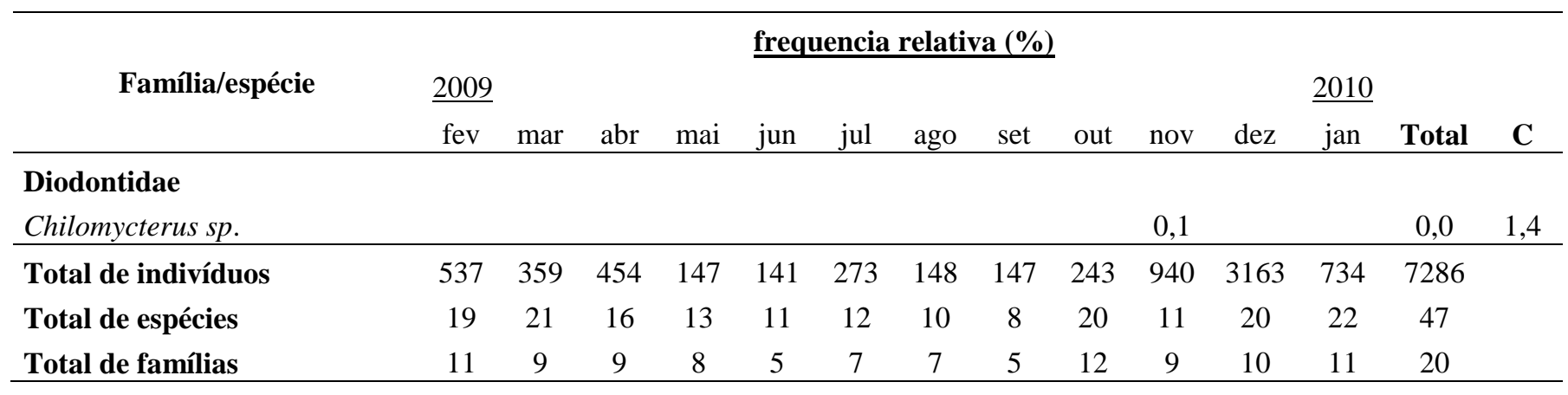


Tabela 2.5. Peso total (g) das quatro espécies da ictiofauna com maiores contribuições relativas (\%) da amostragem realizada nas praias da Ilha do Cardoso.

\begin{tabular}{lllll}
\hline Família & Espécie & Peso Total $(\mathbf{g})$ & N & $\begin{array}{l}\text { Contribuição } \\
\text { relativa (\%) }\end{array}$ \\
\hline Carangidae & Trachinotus carolinus & 1346,35 & 1132 & 9,14 \\
Carangidae & Oligoplites saliens & 1395,58 & 156 & 9,48 \\
Carangidae & Trachinotus goodei & 1703,48 & 171 & 11,57 \\
Atherinopsidae & Atherinella brasiliensis & 5204,38 & 674 & 35,34 \\
\hline
\end{tabular}

Tabela 2.6. Médias de comprimento padrão $(\mathrm{mm})$ e do peso $(\mathrm{g})$ das espécies da ictiofauna, em ordem alfabética, amostrados nas praias da Ilha do Cardoso, com seus valores mínimo, máximo e desvio padrão. * = fase larval

\begin{tabular}{lcccccccc}
\hline \multirow{1}{*}{\multicolumn{1}{c}{ Espécie }} & \multicolumn{3}{c}{ Comprimento padrão } & \multicolumn{5}{c}{ Peso (g) } \\
& \multicolumn{3}{c}{ (mm) } & & & \\
\cline { 2 - 9 } & Média & DP & Mín & Máx & Média & DP & Mín & Máx \\
\hline Anchoa januaria & 39,92 & 13,71 & 25 & 85 & 1,31 & 1,62 & 0,22 & 7,52 \\
Anchoa lyolepis & 41,40 & 5,41 & 33 & 46 & 1,03 & 0,48 & 0,49 & 1,57 \\
Anchoa tricolor & 44,94 & 8,49 & 26 & 73 & 1,34 & 0,85 & 0,22 & 6,62 \\
Anchoviella lepidentostole & 38,67 & 9,13 & 23 & 53 & 0,83 & 0,50 & 0,16 & 1,98 \\
Atherinella brasiliensis & 80,45 & 19,80 & 25 & 125 & 7,80 & 5,14 & 0,3 & 27,75 \\
Atherinella brasiliensis* & & & 19 & 19 & & & 0,08 & 0,08 \\
Caranx latus & 40,26 & 13,74 & 33 & 86 & 3,03 & 4,24 & 1,41 & 18,65 \\
Cetengraulis edentulus & 53,97 & 6,22 & 33 & 73 & 2,57 & 0,88 & 0,48 & 6,4 \\
Chilomycterus sp. & & & 25 & 25 & & & 1,54 & 1,54 \\
Choloroscombrus chrysurus & 32,13 & 5,08 & 22 & 40 & 0,85 & 0,30 & 0,35 & 1,46 \\
Etropus crossotus & 37,56 & 5,89 & 31 & 59 & 0,45 & 0,77 & 0,13 & 3,18 \\
Elops saurus* & 30,95 & 4,62 & 20 & 39 & 0,10 & 0,04 & 0,05 & 0,18 \\
Harengula clupeola & 57,65 & 8,80 & 25 & 80 & 4,25 & 1,69 & 0,23 & 10,55 \\
Hemiramphus sp. & & & 22 & 22 & & & 0 & 0 \\
Larva de Engraulidae & 25,87 & 6,99 & 15 & 53 & 0,23 & 0,35 & 0,03 & 1,96 \\
Larva de Gerreidae & 10,88 & 1,75 & 8 & 15 & 0,04 & 0,02 & 0,02 & 0,2
\end{tabular}


Tabela 2.6. continuação

\begin{tabular}{|c|c|c|c|c|c|c|c|c|}
\hline \multirow[t]{2}{*}{ Espécie } & \multicolumn{4}{|c|}{$\begin{array}{c}\text { Comprimento padrão } \\
(\mathbf{m m})\end{array}$} & \multicolumn{4}{|c|}{ Peso (g) } \\
\hline & Média & DP $\mathrm{N}$ & Mín 1 & Máx & Média & DP & Mín & Máx \\
\hline Lobotes surinamensis & & & 14 & 14 & & & 0,2 & 0,2 \\
\hline Lycengraulis grossidens & 63,50 & 14,85 & 53 & 74 & 4,02 & 2,09 & 2,54 & 5,5 \\
\hline Menticirrhus americanus & 28,50 & 4,39 & 19 & 34 & 0,54 & 0,20 & 0,14 & 0,81 \\
\hline Menticirrhus americanus* & 13,20 & 2,28 & 10 & 16 & 0,07 & 0,03 & 0,03 & 0,11 \\
\hline Menticirrhus littoralis & 31,47 & 13,44 & 9 & 126 & 1,03 & 2,98 & 0,03 & 32,66 \\
\hline Menticirrhus littoralis* & 11,67 & 1,53 & 10 & 13 & & & 0,04 & 0,04 \\
\hline Micropogonias furnieri* ${ }^{*}$ & & & 11 & 11 & & & 0,03 & 0,03 \\
\hline Mugil curema & 24,57 & 6,44 & 14 & 76 & 0,42 & 1,11 & 0,038 & 10,1 \\
\hline Mugil hospes & 35,35 & 17,62 & 17 & 69 & 1,65 & 1,95 & 0,08 & 6,5 \\
\hline Mugil liza & 21,09 & 1,21 & 18 & 26 & 0,21 & 0,04 & 0,06 & 0,42 \\
\hline Mugil 1 & 26,87 & 10,80 & 17 & 54 & 0,70 & 1,14 & 0,09 & 3,65 \\
\hline Mugil 2 & 21,50 & 0,71 & 21 & 22 & 0,20 & 0,01 & 0,19 & 0,2 \\
\hline Odontesthes argentinensis & & & 122 & 2122 & & & 17,64 & 17,64 \\
\hline Oligoplites saliens & 81,36 & 21,91 & 11 & 127 & 8,03 & 5,37 & 0,05 & 27,96 \\
\hline Oligoplites sp. & & & 8 & 8 & & & 0 & 0 \\
\hline Opisthonema oglinum & 53,00 & 1,00 & 52 & 54 & 2,78 & 0,14 & 2,65 & 2,93 \\
\hline Paralichthys orbignyanus & & & 242 & 242 & & & 240,84 & 240,84 \\
\hline Platanichthys platana & & & 26 & 26 & & & 0,31 & 0,31 \\
\hline Polydactylus oligodon & & & 32 & 32 & & & 0,57 & 0,57 \\
\hline Pomadasys corvinaeformis & 45,50 & 0,71 & 45 & 46 & 2,47 & 0,25 & 2,29 & 2,64 \\
\hline Pomatomus saltatrix & & & 72 & 72 & & & 4,98 & 4,98 \\
\hline Porichthys porosissimus* & & & 16 & 16 & & & 0,08 & 0,08 \\
\hline Sardinella brasiliensis & 46,00 & 3,94 & 40 & 50 & 1,37 & 0,38 & 0,89 & 1,86 \\
\hline Selene vômer & 82,50 & 13,44 & 73 & 92 & 19,84 & 8,35 & 13,93 & 25,74 \\
\hline Sphoeroides greeleyi & 48,38 & 15,95 & 29 & 71 & 7,75 & 6,75 & 1,09 & 20,98 \\
\hline Sphoeroides testudineus & 185,00 & 12,44 & 171 & 199 & 218,56 & 27,67 & 203,16 & 260,03 \\
\hline Strongylura marina & & & 119 & 119 & & & 2,21 & 2,21 \\
\hline Strongylura timucu & 253,97 & 152,25 & 518,5 & 5460 & 53,67 & 58,26 & 0,03 & 184,47 \\
\hline Syngnathus folletti & & & 70 & 70 & & & 0,14 & 0,14 \\
\hline Synodus foetens & & & 83 & 83 & & & 4,72 & 4,72 \\
\hline
\end{tabular}


Tabela 2.6. continuação

\begin{tabular}{lccccccccc}
\hline \multirow{1}{*}{\multicolumn{1}{c}{ Espécie }} & \multicolumn{3}{c}{ Comprimento padrão } & \multicolumn{5}{c}{ Peso (g) } \\
& \multicolumn{3}{c}{$(\mathbf{m m})$} & & & & \\
\cline { 2 - 10 } & Média & DP & Mín & Máx & Média & DP & Mín & Máx \\
\hline \multirow{2}{*}{$\begin{array}{l}\text { Trachinotus carolinus } \\
\text { Trachinotus falcatus }\end{array}$} & 28,42 & 11,80 & 4 & 64 & 1,21 & 1,33 & 0,04 & 11,09 \\
Trachinotus goodei & 26,67 & 17,17 & 11 & 56 & 1,64 & 2,12 & 0,08 & 5,55 \\
Umbrina coroides & 61,28 & 25,16 & 16 & 134 & 9,96 & 11,44 & 0,17 & 68,68 \\
& & & 32 & 32 & & & 73 & 73 \\
\hline
\end{tabular}

Tabela 2.7. Frequência relativa (\%) das espécies da ictiofauna amostrados nas diferentes praias da Ilha Comprida. *=espécies com indivíduos em fase larval. Valores em negrito representam diferenças significativas.

\begin{tabular}{|c|c|c|c|}
\hline \multirow[t]{2}{*}{ Família / espécies } & \multicolumn{3}{|c|}{ frequência relativa $(\%)$} \\
\hline & Abrigada & Intermediária & Exposta \\
\hline \multicolumn{4}{|l|}{ Elopidae } \\
\hline Elops saurus* & 1,16 & 0,77 & 0,99 \\
\hline \multicolumn{4}{|l|}{ Engraulidae } \\
\hline Anchoa januaria & 0,66 & & \\
\hline Anchoa lyolepis & 0,03 & & \\
\hline Anchoa tricolor & 1,02 & & 0,05 \\
\hline Anchoviella lepidentostole & 0,11 & & \\
\hline Cetengraulis edentulus & 0,13 & 0,05 & \\
\hline Larvas de Engraulidae & 0,76 & 4,12 & 4,86 \\
\hline \multicolumn{4}{|l|}{ Clupeidae } \\
\hline Harengula clupeola & 8,85 & 0,57 & \\
\hline Sardinella brasiliensis & 0,03 & & \\
\hline \multicolumn{4}{|l|}{ Synodontidae } \\
\hline Synodus foetens & & 0,05 & \\
\hline \multicolumn{4}{|l|}{ Belonidae } \\
\hline Strongylura timucu & 0,08 & 0,72 & 0,09 \\
\hline Tylosurus acus & 0,05 & 0,05 & \\
\hline \multicolumn{4}{|l|}{ Exocoetidae } \\
\hline Hyporhamphus unifasciatus & & & 0,05 \\
\hline Hemiramphus sp. & & 0,05 & \\
\hline
\end{tabular}


Tabela 2.7. continuação

\begin{tabular}{ccc}
\hline Família /espécie & \multicolumn{3}{c}{ frequência relativa (\%) } \\
Abrigada Intermediária Exposta
\end{tabular}

Mugilidae

Mugil curema

$\begin{array}{lll}47,37 & 11,78 & 7,79\end{array}$

Mugil liza

$5,47 \quad 1,20$

1,37

Mugil hospes

$3,10 \quad 39,85$

9,58

Mugil 1

0,13

2,11

0,28

Mugil 2

0,05

Atherinopsidae

Atherinella sp.*

0,05

Odonthestes argentinensis

0,10

0,19

Syngnathidae

Syngnathus folletti

0,05

\section{Serranidae}

Mycteroperca sp.

0,19

Mycteroperca tigris

0,10

0,05

Pomatomidae

Pomatomus saltatrix

$0,16 \quad 0,05$

Carangidae

Caranx latus

0,50

Oligoplites saliens

$0,71 \quad 0,81$

0,42

Oligoplites sp.

$0,03 \quad 0,05$

Selene vômer

0,05

Trachinotus carolinus

$23,59 \quad 20,79$

52,83

Trachinotus falcatus

$0,45 \quad 0,43$

0,24

Trachinotus goodei

4,49

12,93

14,26

\section{Gerreidae}

Larvas não identificadas

$0,63 \quad 2,25$

1,56

\section{Haemulidae}

Pomadasys corvinaeformis $\quad 0,05$

\section{Polynemidae}

Polydactylus virginicus 
Tabela 2.7. continuação

\begin{tabular}{|c|c|c|c|}
\hline \multirow[t]{2}{*}{ Família /espécie } & \multicolumn{3}{|c|}{ frequência relativa (\%) } \\
\hline & Abrigada & Intermediária & Exposta \\
\hline \multicolumn{4}{|l|}{ Sciaenidae } \\
\hline Menticirrhus americanus & 0,11 & & 1,13 \\
\hline Menticirrhus littoralis & 0,26 & 0,77 & 3,45 \\
\hline Micropogonias furnieri* & & & 0,19 \\
\hline \multicolumn{4}{|l|}{ Pomacentridae } \\
\hline Abudefduf saxatilis & & 0,14 & \\
\hline \multicolumn{4}{|l|}{ Blenniidae } \\
\hline Parablennius pilicornis & & 0,05 & \\
\hline \multicolumn{4}{|l|}{ Paralichthyidae } \\
\hline Citharichthys arenaceus & 0,03 & 0,10 & \\
\hline \multicolumn{4}{|l|}{ Monacanthidae } \\
\hline Stephanolepis hispidus & & 0,05 & \\
\hline \multicolumn{4}{|l|}{ Tetraodontidae } \\
\hline Sphoeroides sp. & & & 0,28 \\
\hline \multicolumn{4}{|l|}{ Diodontidae } \\
\hline Chilomycterus spinosus & & & 0,05 \\
\hline Total de indivíduos & 2285 & 3609 & 2118 \\
\hline Total de espécies & 28 & 28 & 24 \\
\hline Total de famílias & 12 & 19 & 14 \\
\hline Riqueza de Margalef & 3,49 & 3,3 & 3 \\
\hline Diversidade de Shannon & 2,03 & 1,54 & 1,66 \\
\hline Equitatividade de Pielou & 0,61 & $\mathbf{0 , 4 6}$ & $\mathbf{0 , 5 2}$ \\
\hline Dominância_D & 0,21 & 0,31 & 0,32 \\
\hline
\end{tabular}


Tabela 2.8. Índices ecológicos calculados para a ictiofauna capturada durante a maré alta e baixa das diferentes praias da Ilha Comprida. $*=$ diferenças significativas.

\begin{tabular}{llll}
\hline & \multicolumn{3}{c}{ Maré } \\
Índice & Alta & Baixa & Boot $\mathrm{p}$ \\
\hline $\mathrm{N}^{\circ}$ espécies & 26 & 39 & $0,024^{*}$ \\
$\mathrm{~N}^{\circ}$ indivíduos & 2262 & 5750 & $0^{*}$ \\
Dominancia_D & 0,27 & 0,21 & $0^{*}$ \\
Diversidade de Shannon & 1,77 & 1,93 & $0^{*}$ \\
Riqueza de Margalef & 3,24 & 4,39 & $0,017^{*}$ \\
Equitatividade de Pielou & 0,54 & 0,53 & 0,859 \\
\hline
\end{tabular}

Tabela 2.9. Índices ecológicos calculados para a ictiofauna capturada durante os meses frios e quentes das praias da Ilha Comprida. * =diferenças significativas.

\begin{tabular}{llll}
\hline & \multicolumn{2}{c}{ Meses } & \\
Índice & Frios & Quentes & Boot $\mathrm{p}$ \\
\hline $\mathrm{N}^{\circ}$ espécies & 16 & 42 & $0^{*}$ \\
$\mathrm{~N}^{\circ}$ indivíduos & 1059 & 6953 & $0^{*}$ \\
Dominancia_D & 0,20 & 0,24 & $0^{*}$ \\
Diversidade de Shannon & 1,84 & 1,77 & 0,13 \\
Riqueza de Margalef & 2,15 & 4,63 & $0^{*}$ \\
Equitatividade de Pielou & 0,66 & 0,47 & $0^{*}$ \\
\hline
\end{tabular}


Tabela 2.10. Correlação das variáveis significativas para a explicação da estrutura da ictiofauna das praias Ilha Comprida com os quatro primeiros eixos e resumo estatístico dos dados.

\begin{tabular}{lllll}
\hline \multirow{2}{*}{\begin{tabular}{c} 
Correlação das variáveis significativas \\
\multicolumn{1}{c}{ com os eixos }
\end{tabular}} & \multicolumn{4}{c}{ Eixos } \\
\cline { 2 - 5 } Praia Abrigada & 0,191 & 0,3302 & 0,0172 & 0,0984 \\
Maré alta & $-0,2252$ & $-0,6367$ & 0,0908 & $-0,1832$ \\
Maré baixa & 0,2252 & 0,6367 & $-0,0908$ & 0,1832 \\
dez/08 & 0,0037 & 0,4529 & 0,6332 & $-0,2828$ \\
fev/09 & $-0,127$ & 0,0141 & $-0,1975$ & $-0,0958$ \\
abr/09 & 0,0552 & 0,1022 & $-0,3676$ & 0,3678 \\
mai/09 & $-0,1399$ & $-0,2372$ & 0,172 & 0,1327 \\
jul/09 & 0,4753 & $-0,1803$ & $-0,105$ & 0,4039 \\
ago/09 & 0,6796 & $-0,0153$ & 0,0114 & 0,0004 \\
Nov09 & $-0,0544$ & 0,14 & $-0,6534$ & $-0,609$ \\
Temperatura & $-0,6081$ & 0,3144 & $-0,5412$ & 0,1809 \\
\hline Resumo estatístico & & & & \\
Autovalores & 0,289 & 0,122 & 0,09 & 0,064 \\
Correlação espécie-ambiente & 0,842 & 0,727 & 0,713 & 0,619 \\
Porcentagem de variância acumulada: & & & & \\
nos dados de espécies & 15,6 & 22,2 & 27 & 30,5 \\
na relação espécie ambiente & 40,9 & 58,2 & 70,9 & 79,9 \\
Soma de todos autovalores naturais & & & & 1,854 \\
Soma de todos autovalores canônicos & & & & 0,707 \\
\hline
\end{tabular}


Tabela 2.11. Freqüência relativa (\%) das espécies da ictiofauna amostrados na diferentes praias da Ilha do Cardoso. *= espécies com indivíduos em fase larval; **= espécies com indivíduos em fase larval e adulta; ***=espécies com indivíduos em fase juvenil e adulta. Valores em negrito representam diferenças significativas.

\begin{tabular}{lccc}
\hline Família/ espécies & \multicolumn{3}{c}{ frequência relativa (\%) } \\
& Abrigada & Intermediária & Exposta \\
\hline Atherinopsidae & \multirow{2}{*}{7,3} & 7,8 & 0,3 \\
Atherinella brasiliensis ${ }^{* *}$ & 21,3 & 0,0
\end{tabular}

\section{Batrachoididae}

Porichthys porosissimus*

0,0

\section{Belonidae}

Strongylura marina

0,0

Strongylura timuсu

0,6

0,1

0,0

\section{Carangidae}

Caranx latus

Choloroscombrus chrysurus 4,9

Oligoplites saliens

4,5

Oligoplites $s p$. 0,0

Selene vômer

0,1

Trachinotus carolinus

Trachinotus falcatus

0,1

0,1

Trachinotus goodei

\section{Clupeidae}

Harengula clupeola

Opisthonema oglinum

Platanichthys platana

6,3

0,7

0,5

0,1

0,0

Sardinella brasiliensis

0,0

0,2

Diodontidae

Chilomycterus sp.

0,0

\section{Elopidae}

Elops saurus* 
Tabela 2.11. continuação

\begin{tabular}{lccc}
\hline Família/ espécies & \multicolumn{3}{c}{ frequência relativa (\%) } \\
& Abrigada & Intermediária & Exposta \\
\hline Engraulidae & 0,4 & 1,2 & \\
Anchoa januaria & 0,2 & & \\
Anchoa lyolepis & 4,1 & 8,3 & 0,0 \\
Anchoa tricolor & 0,6 & 0,4 & \\
Anchoviella lepidentostole & 1,7 & 0,2 & \\
Cetengraulis edentulus & 3,9 & 1,5 & 1,4 \\
Larvas não identificadas & & 0,1 & \\
Lycengraulis grossidens & & & \\
Exocoetidae & & 0,0 & \\
Hemiramphus sp. & & & 12,1 \\
Gerreidae & 40,6 & 3,8 & \\
Larvas não identificadas & &
\end{tabular}

Haemulidae

Pomadasys corvinaeformis $\quad 0,1$

Lobotidae

Lobotes surinamensis

0,0

Mugilidae

Mugil curema

$\begin{array}{lll}0,8 & 39,7 & 3,6\end{array}$

Mugil liza

3,6

1,5

Mugil hospes

2,6

44,5

Mugil 1

0,1

Mugil 2

0,1

Paralichthyidae

Etropus crossotus

0,8

0,1

Paralichthys orbignyanus

0,0

\section{Polynemidae}

Polydactylus oligodon

0,0

Pomatomidae

Pomatomus saltatrix

\section{Sciaenidae}

Menticirrhus americanus**

$0,3 \quad 0,4$

Menticirrhus littoralis**

0,0

0,3

Micropogonias furnieri*

0,0

Umbrina coróides 
Tabela 2.11. continuação

\begin{tabular}{lccc}
\hline Família/ espécies & \multicolumn{3}{c}{ frequência relativa (\%) } \\
& Abrigada & Intermediária & Exposta \\
\hline Syngnathidae & & & \\
Syngnathus folletti & 0,0 & & \\
Synodontidae & & & \\
Synodus foetens & 0,0 & & \\
Tetraodontidae & & & 0,0 \\
Sphoeroides greeleyi & 0,4 & 0,1 & \\
Sphoeroides testudineus & & 0,1 & 3265 \\
\hline Total de indivíduos & 2036 & 1985 & 21 \\
Total de espécies & 33 & 34 & 11 \\
Total de famílias & 15 & 15 & $\mathbf{2 , 4 7 2}$ \\
Riqueza de Margalef & 4,200 & 4,346 & $\mathbf{1 , 6 9 0}$ \\
Diversidade de Shannon & $\mathbf{2 , 0 8 4}$ & $\mathbf{2 , 4 8 0}$ & 0,550 \\
Equitatividade de Pielou & 0,596 & $\mathbf{0 , 7 0 0}$ & $\mathbf{0 , 2 4 0}$ \\
Dominância_D & $\mathbf{0 , 2 2 3}$ & $\mathbf{0 , 1 2 0}$ & \\
\hline
\end{tabular}

Tabela 2.12. Índices ecológicos calculados para a ictiofauna capturada durante maré alta e baixa das diferentes praias da Ilha do Cardoso. ${ }^{*}=$ diferenças significativas.

\begin{tabular}{llll}
\hline & \multicolumn{3}{c}{ Maré } \\
Índice & Alta & Baixa & Boot $\mathrm{p}$ \\
\hline $\mathrm{N}^{\circ}$ espécies & 26 & 43 & $0,02^{*}$ \\
$\mathrm{~N}^{\circ}$ indivíduos & 1245 & 6041 & $0^{*}$ \\
Dominancia_D & 0,20 & 0,14 & $0^{*}$ \\
Diversidade de Shannon & 2,12 & 2,32 & $0^{*}$ \\
Riqueza de Margalef & 3,51 & 4,82 & $0,01^{*}$ \\
Equitatividade de Pielou & 0,65 & 0,62 & 0,93 \\
\hline
\end{tabular}


Tabela 2.13. Índices ecológicos calculados para a ictiofauna capturada durante os meses frios e quentes agrupados na Ilha do Cardoso. $*$ =diferenças significativas.

\begin{tabular}{llll}
\hline & \multicolumn{2}{c}{ Meses } & \\
Índice & Frios & Quentes & Boot $\mathrm{p}$ \\
\hline $\mathrm{N}^{\circ}$ espécies & 28 & 40 & 0,48 \\
$\mathrm{~N}^{\circ}$ indivíduos & 1099 & 6187 & $0^{*}$ \\
Dominancia_D & 0,17 & 0,14 & $0^{*}$ \\
Diversidade de Shannon & 2,21 & 2,27 & 0,17 \\
Riqueza de Margalef & 3,86 & 4,47 & 0,40 \\
Equitatividade de Pielou & 0,66 & 0,61 & 0,76 \\
\hline
\end{tabular}

Tabela 2.14. Correlação das variáveis significativas para a explicação da estrutura da ictiofauna da Ilha do Cardoso com os quatro primeiros eixos e resumo estatístico dos dados.

\begin{tabular}{lcccc}
\hline \multirow{2}{*}{\begin{tabular}{lcccc} 
Correlação das variáveis significativas \\
\cline { 2 - 5 }
\end{tabular}} & \multicolumn{5}{c}{ Eixos os eixos } & 2 & 3 & 4 \\
\cline { 2 - 5 } Dezembro & 0,3179 & 0,203 & 0,6998 & 0,3057 \\
Janeiro & $-0,1815$ & 0,0492 & 0,4429 & $-0,3217$ \\
Junho & $-0,0015$ & 0,0042 & $-0,0526$ & $-0,0537$ \\
Novembro & 0,0109 & $-0,4957$ & $-0,2619$ & 0,3959 \\
Outubro & 0,0971 & 0,2236 & $-0,254$ & 0,3282 \\
Praia Abrigada & $-0,6748$ & $-0,0323$ & $-0,1926$ & 0,0562 \\
Praia Intermediária & 0,0129 & 0,0598 & 0,236 & $-0,3381$ \\
Praia Exposta & 0,6995 & $-0,0305$ & $-0,0512$ & 0,3058 \\
Maré Alta & 0,5054 & 0,0211 & $-0,3216$ & $-0,4958$ \\
Maré Baixa & $-0,5054$ & $-0,0211$ & 0,3216 & 0,4958 \\
Temperatura & 0,0583 & $-0,7298$ & 0,5439 & $-0,1321$ \\
\hline Resumo estatístico & & & & \\
Autovalores & 0,31 & 0,208 & 0,15 & 0,113 \\
Correlação espécie-ambiente & 0,839 & 0,822 & 0,861 & 0,79 \\
Porcentagem de variância acumulada: & & & & \\
nos dados de espécies & 13,5 & 22,5 & 29 & 33,9 \\
na relação espécie ambiente & 32,6 & 54,5 & 70,2 & 82,1 \\
Soma de todos autovalores naturais & & & & \\
Soma de todos autovalores canônicos & & & & 2,304 \\
\hline
\end{tabular}


Tabela 2.15. Tamanho de rede e de malha utilizadas em diferentes estudos relativos à ictiofauna de zona de surfe em praias.

\begin{tabular}{|c|c|c|c|}
\hline \multirow{2}{*}{ Localização } & \multicolumn{2}{|c|}{$\underline{\text { Rede }}$} & \multirow[t]{2}{*}{ Fonte } \\
\hline & Tamanho (m) & Malha ( entre nós) & \\
\hline África do Sul & $25 \times 2$ & $10 \mathrm{~mm}$ & Bennett, 1989 \\
\hline Costa do Cabo & $30 \times 2$, saco de 2 & $12 \mathrm{~mm}$ & Clark et al., 1994 \\
\hline Eerste Estuary & $30 \times 2$, saco de 2 & $12 \mathrm{~mm}$ & Clark et al., 1994 \\
\hline Zandlev Estuary & $30 \times 2$, saco de 2 & $12 \mathrm{~mm}$ & Clark et al., 1996a \\
\hline False Bay & $31 \times 2$, saco de 2 & $12 \mathrm{~mm}$ & Clark et al., 1996b \\
\hline Saldanha Bay & Rede de plâncton & & Harris e Curris, 1996 \\
\hline St Lucia Estuary Month & $60 \times 2$, saco de 2 & $40 \mathrm{~mm} \mathrm{e} 17 \mathrm{~mm}$ & Lasiak, 1984a \\
\hline King's Beach & $60 \times 2$, saco de 2 & $40 \mathrm{~mm} \mathrm{e} 17 \mathrm{~mm}$ & Lasiak, 1984a \\
\hline King's Beach & $60 \times 2$, saco de 2 & $40 \mathrm{~mm} \mathrm{e} 17 \mathrm{~mm}$ & Lasiak, 1984b \\
\hline 2 Estuários & $1,5 \times 4,5$ & $0,5 \mathrm{~mm}$ & Strydom, 2003 \\
\hline \multicolumn{4}{|l|}{ Brasil } \\
\hline Ilha do Frade, ES & $6 \times 2$ & $10 \mathrm{~mm}$ & Araujo et al., 2008 \\
\hline Paranaguá, PR & $15 \times 2,6$ & $5 \mathrm{~mm}$ & Félix et al., 2007a \\
\hline Paranaguá (Praias estuarinas), PR & $15 \times 2,6$ & $5 \mathrm{~mm}$ & Félix et al., 2007b \\
\hline Arraial do Cabo, RJ & $30 \times 2$ & $5 \mathrm{~mm}$ & Félix et al.,2006 \\
\hline Arraial do Cabo, RJ & $25 \times 2$ & $10 \mathrm{~mm}$ & Gaelzer e Zalmon, 2003 \\
\hline Arraial do Cabo, RJ & $25 \times 2$ & $10 \mathrm{~mm}$ & Gaelzer e Zalmon, 2008a \\
\hline São Paulo - várias praias & $25 \times 2$ & $10 \mathrm{~mm}$ & Gaelzer e Zalmon, 2008b \\
\hline Sistema costeiro Cananéia-Iguape & $15 \times 1,5$ & 5 e $10 \mathrm{~mm}$ & Presente trabalho, 2011 \\
\hline São Paulo -várias praias & $15 \times 1,5$ & $5 \mathrm{~mm}$ & Giannini e Paiva Filho, 1995 \\
\hline Paranaguá, PR & $18 \times 2$ & $1 \mathrm{~mm}$ & Godefroid et al. 1998 \\
\hline Rio de Janeiro, RJ & $25 \times 3$, saco de 2,5 & $12 \mathrm{~mm}$ & Gomes et al.,2003 \\
\hline Praia do Cassino, RS & $30 \times 1,8$ & $12 \mathrm{~mm}$ & Lima e Vieira, 2009 \\
\hline Itamaracá, PE & $5 \times 1,5$ & $8 \mathrm{~mm}$ & Lira e Teixeira, 2008 \\
\hline Guarujá e São Vicente, SP & $15 \times 1,5$ & $10 \mathrm{~mm}$ & Paiva Filho e Toscano,1987 \\
\hline Baia de Sepetiba, RJ & $10 \times 2,5$ & $7 \mathrm{~mm}$ & Pessanha e Araújo,2003 \\
\hline Ilha do Bom Abrigo, SP & $42 \times 4$ & $25 \mathrm{~mm}$ & Saul e Cunningram, 1995 \\
\hline Rio de Janeiro, RJ & $10 \times 2$ & $7 \mathrm{~mm}$ & Vasconcellos et al., 2007 \\
\hline \multicolumn{4}{|l|}{ EUA } \\
\hline Virginia Island & $8 \times 1,5$, saco de 1 & $5 \mathrm{~mm}$ & Layman, 2000 \\
\hline New Jersey & $15,2 \times 1,8$, saco de 1,8 & $6 \mathrm{~mm}$ & Wilber et al.,2003 \\
\hline
\end{tabular}


Tabela 2. 15. Continuação

\begin{tabular}{|c|c|c|c|}
\hline \multirow[t]{2}{*}{ Localização } & \multicolumn{2}{|c|}{$\underline{\text { Rede }}$} & \multirow[t]{2}{*}{ Fonte } \\
\hline & Tamanho (m) & Malha ( entre nós) & \\
\hline \multicolumn{4}{|l|}{ Japão } \\
\hline Sanrimatsubara & $26 \times 2$, saco de 2 & $4 \mathrm{~mm}$ e $1 \mathrm{~mm}$ & Inoue et al., 2008 \\
\hline Doigahama & $26 \times 2$, saco de 2 & $4 \mathrm{~mm}$ e $1 \mathrm{~mm}$ & Suda et al.,2002 \\
\hline \multicolumn{4}{|l|}{ México } \\
\hline Golfo do México & $9 \mathrm{~m}$ & $3 \mathrm{~mm}$ & Modde, 1980 \\
\hline \multicolumn{4}{|l|}{ Portugal } \\
\hline Açores & $20 \mathrm{~m}$ & $\begin{array}{l}32 \mathrm{~mm} \text { nas asas, e } \\
8 \mathrm{~mm} \text { no centro }\end{array}$ & Santos e Nash, 1995 \\
\hline
\end{tabular}




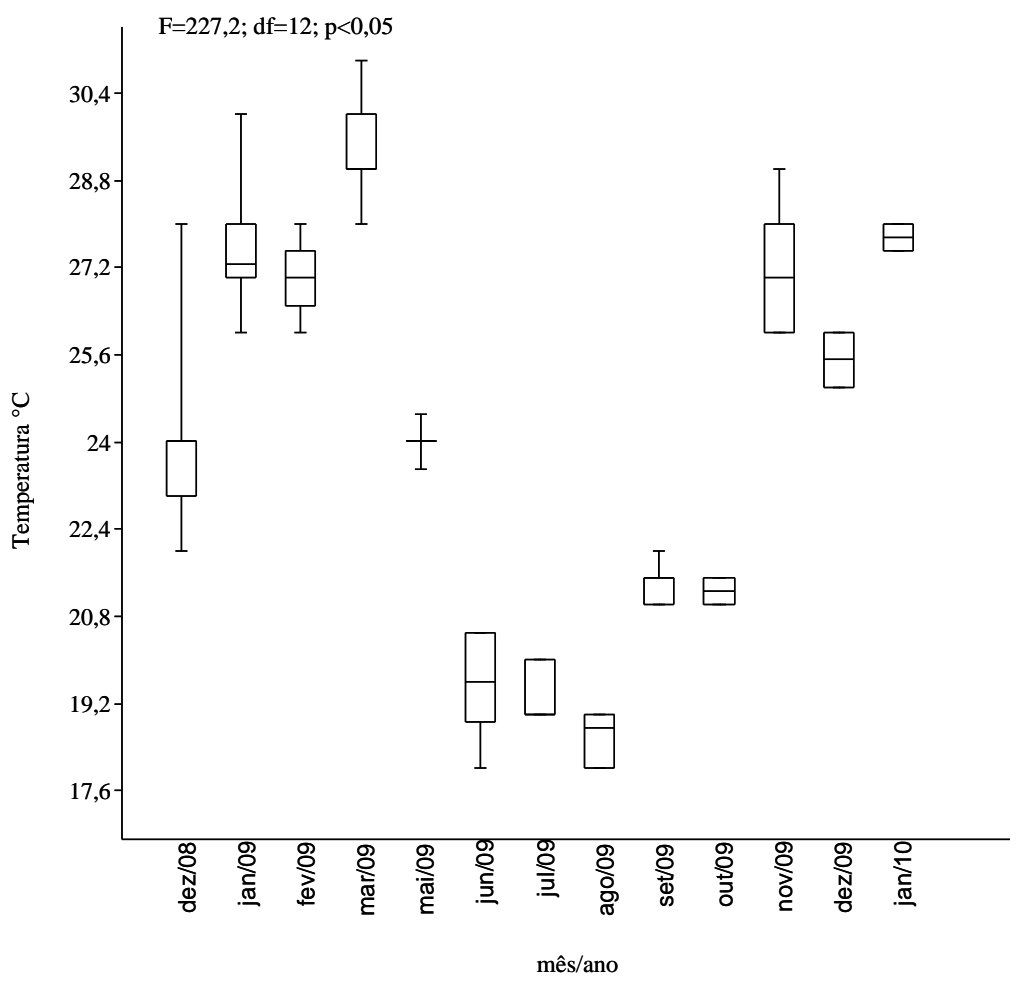

Figura 2.1. Variações de temperatura média medida na zona de surfe de praias arenosas da Ilha Comprida entre dezembro de 2008 e janeiro de 2010 (linhas horizontais representam as médias, os retângulos o desvio padrão e I o erro padrão).

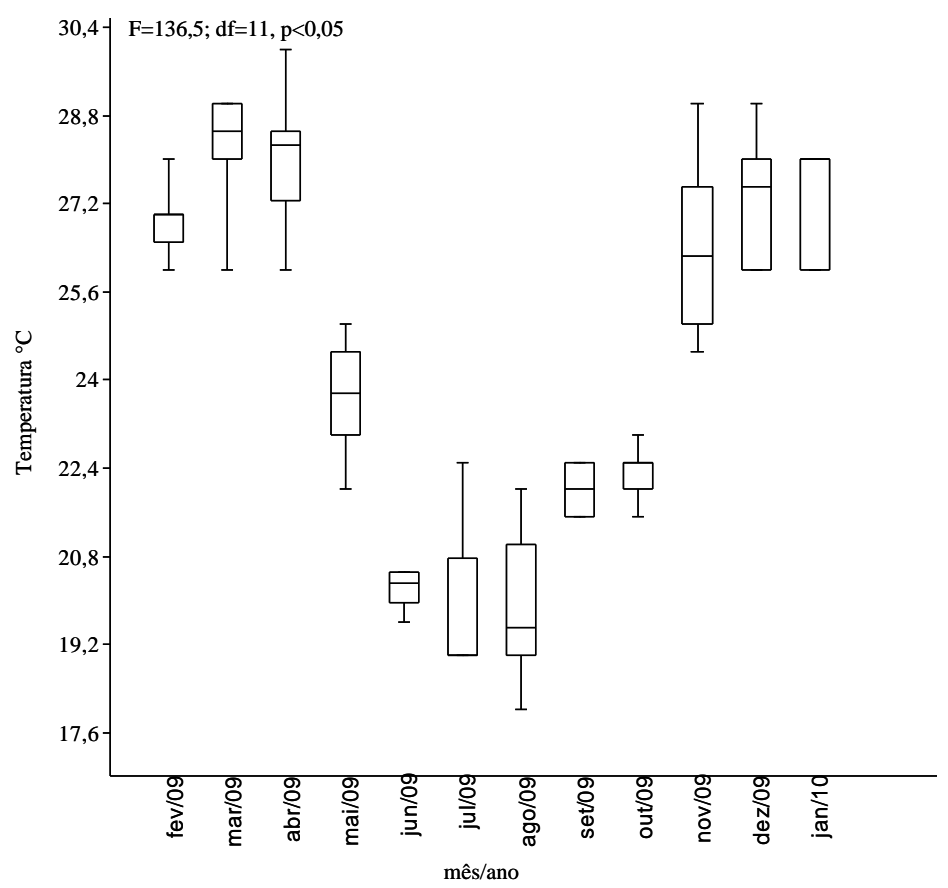

Figura 2.2. Variações de temperatura média medida na zona de surfe de praias arenosas da Ilha do Cardoso entre fevereiro de 2009 e janeiro de 2010 (linhas horizontais representam as médias, os retângulos o desvio padrão e I o erro padrão). 


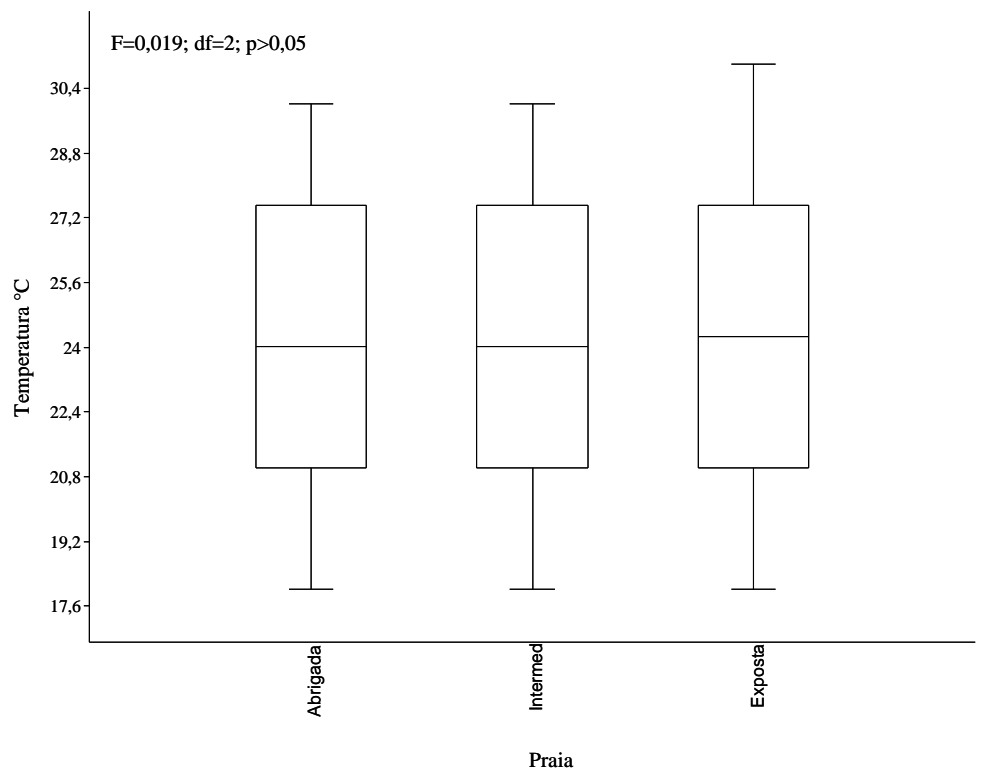

Figura 2.3. Variações de temperatura média medida na zona de surfe de diferentes praias arenosas da Ilha Comprida entre dezembro de 2008 e janeiro de 2010 (linhas horizontais representam as médias, os retângulos o desvio padrão e I o erro padrão) (Intermed=Intermediária).

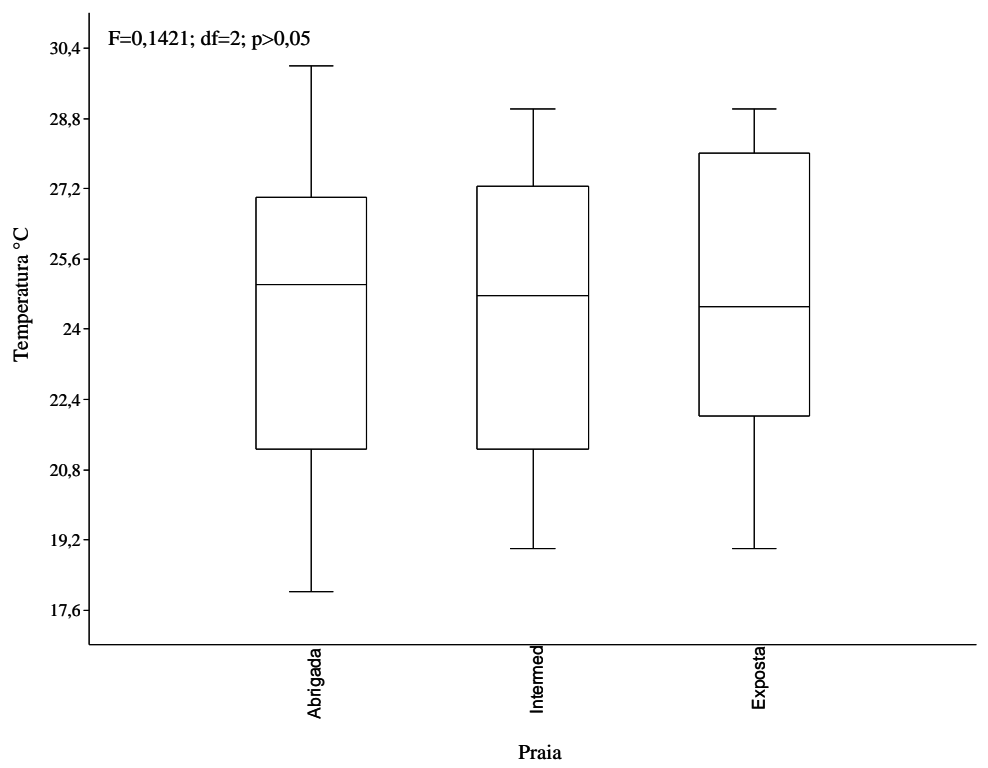

Figura 2.4. Variações de temperatura média medida na zona de surfe de diferentes praias arenosas da Ilha do Cardoso entre fevereiro de 2009 e janeiro de 2010 (linhas horizontais representam as médias, os retângulos o desvio padrão e I o erro padrão) (Intermed=Intermediária). 


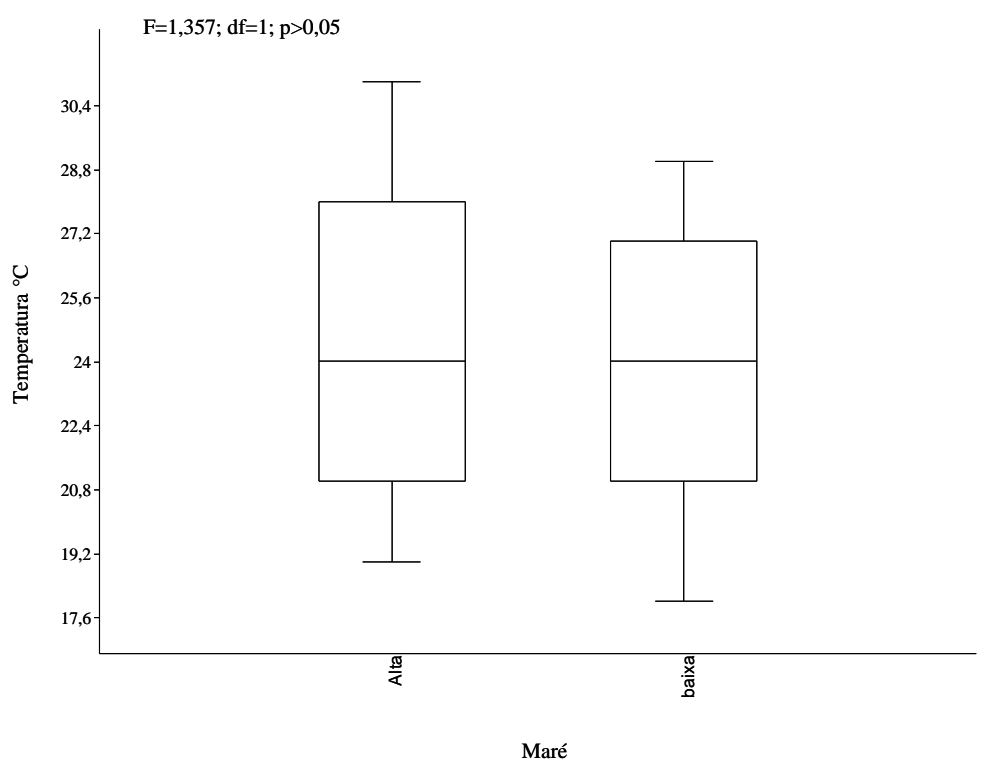

Figura 2.5. Variações de temperatura média medida durante a maré alta e baixa na zona de surfe de praias arenosas da Ilha Comprida de dezembro de 2008 a janeiro de 2010 (linhas horizontais representam as médias, os retângulos o desvio padrão e I o erro padrão).

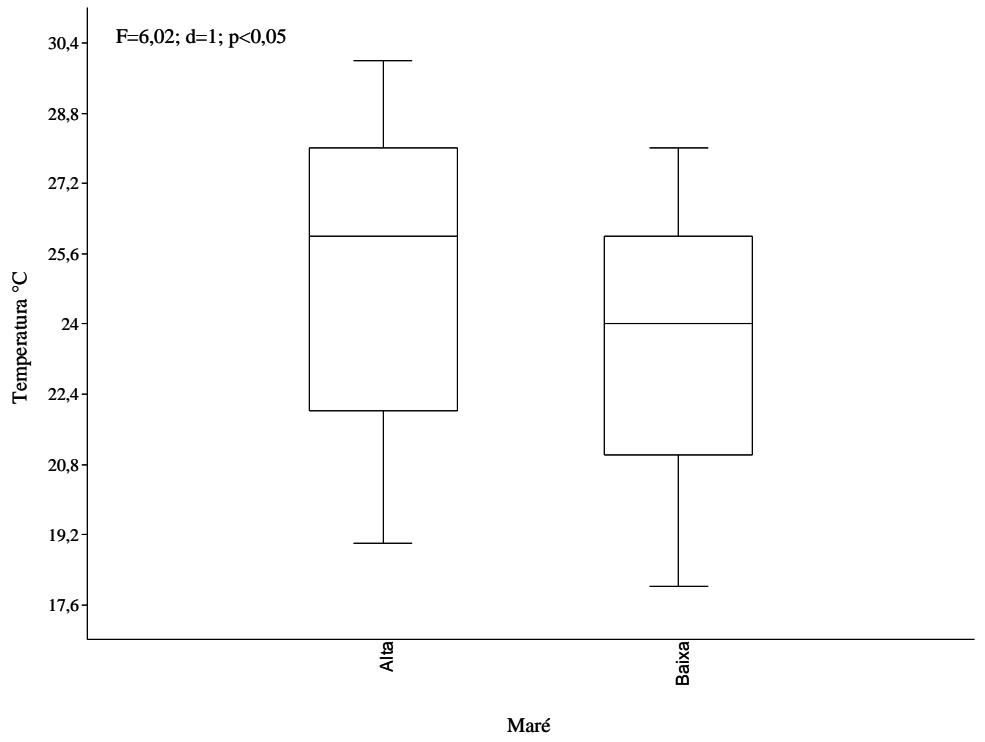

Figura 2.6. Variações de temperatura média medida durante a maré alta e baixa na zona de surfe de praias arenosas da Ilha do Cardoso de fevereiro de 2008 a janeiro de 2010 (linhas horizontais representam as médias, os retângulos o desvio padrão e I o erro padrão). 


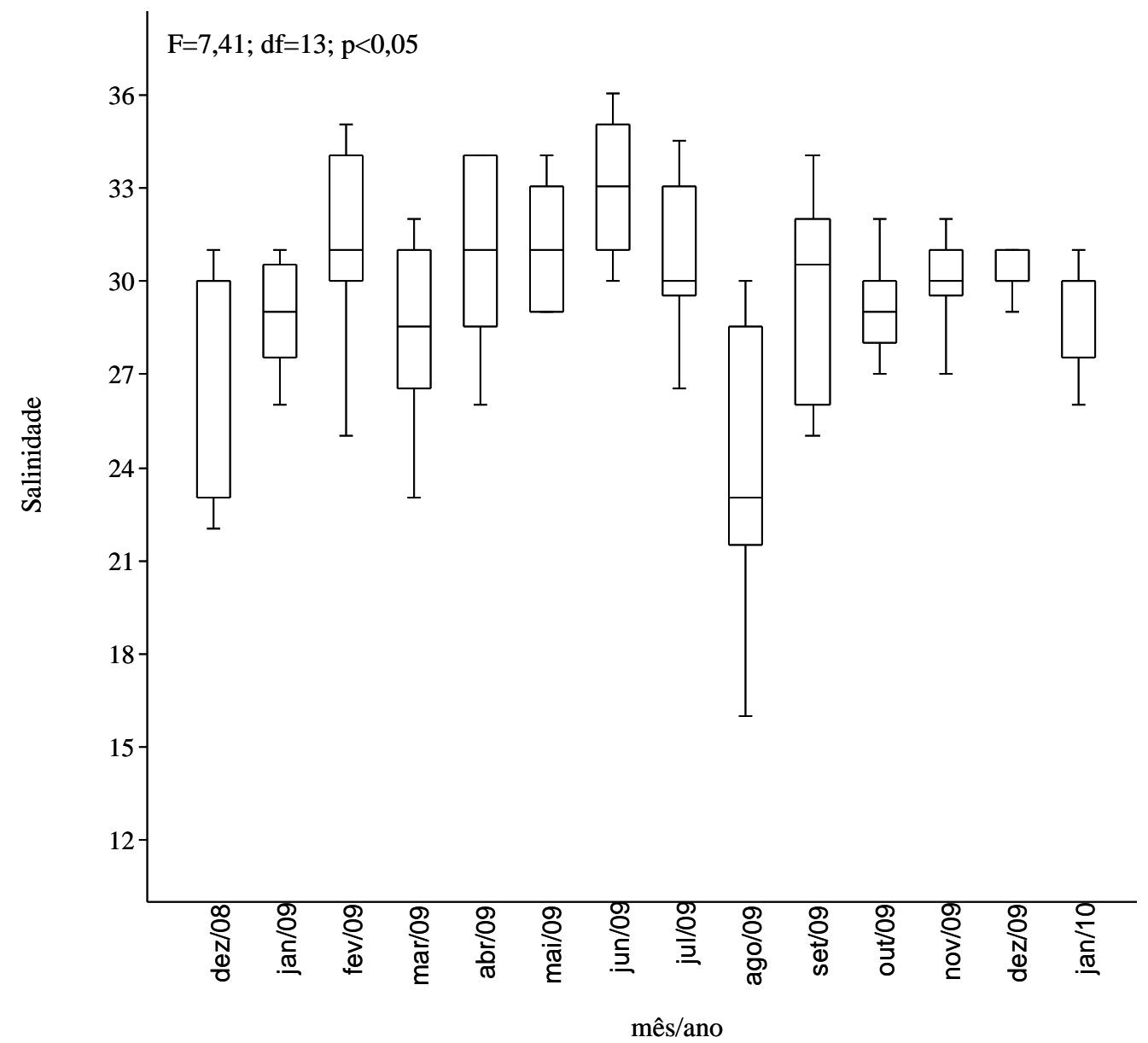

Figura 2.7. Variações de salinidade média medida na zona de surfe de praias arenosas da Ilha Comprida entre dezembro de 2008 e janeiro de 2010 (linhas horizontais representam as médias, os retângulos o desvio padrão e I o erro padrão). 


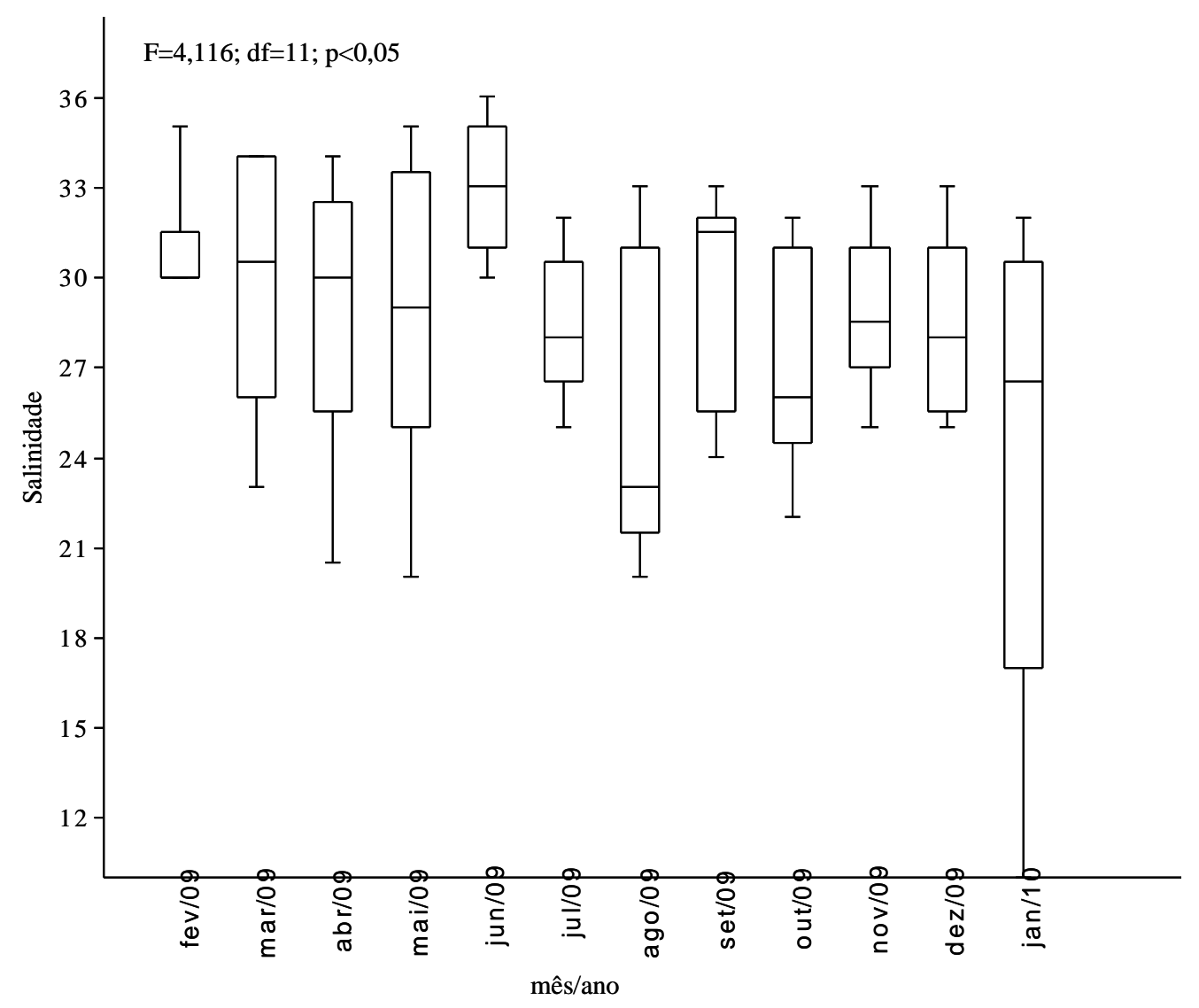

Figura 2.8. Variações de salinidade média medida na zona de surfe de praias arenosas da Ilha do Cardoso entre fevereiro de 2010 e janeiro de 2010 (linhas horizontais representam as médias, os retângulos o desvio padrão e I o erro padrão). 


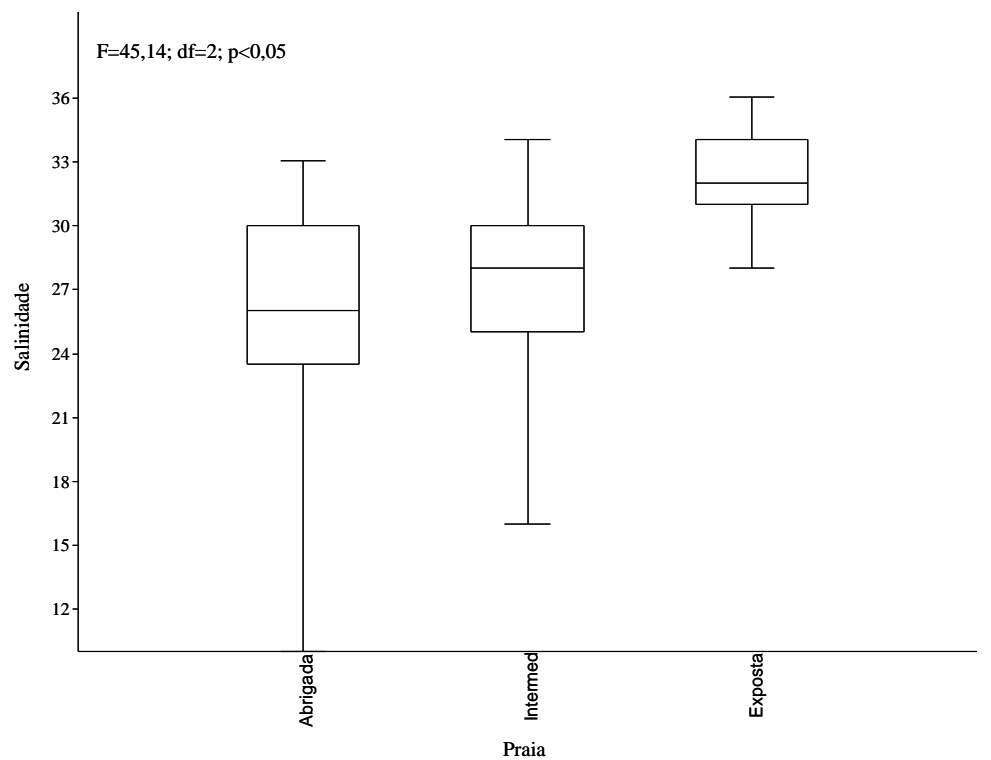

Figura 2.9. Variações de salinidade média medida na zona de surfe de diferentes praias arenosas da Ilha do Cardoso entre fevereiro de 2009 e janeiro de 2010 (linhas horizontais representam as médias, os retângulos o desvio padrão e I o erro padrão) (Intermed=Intermediária).

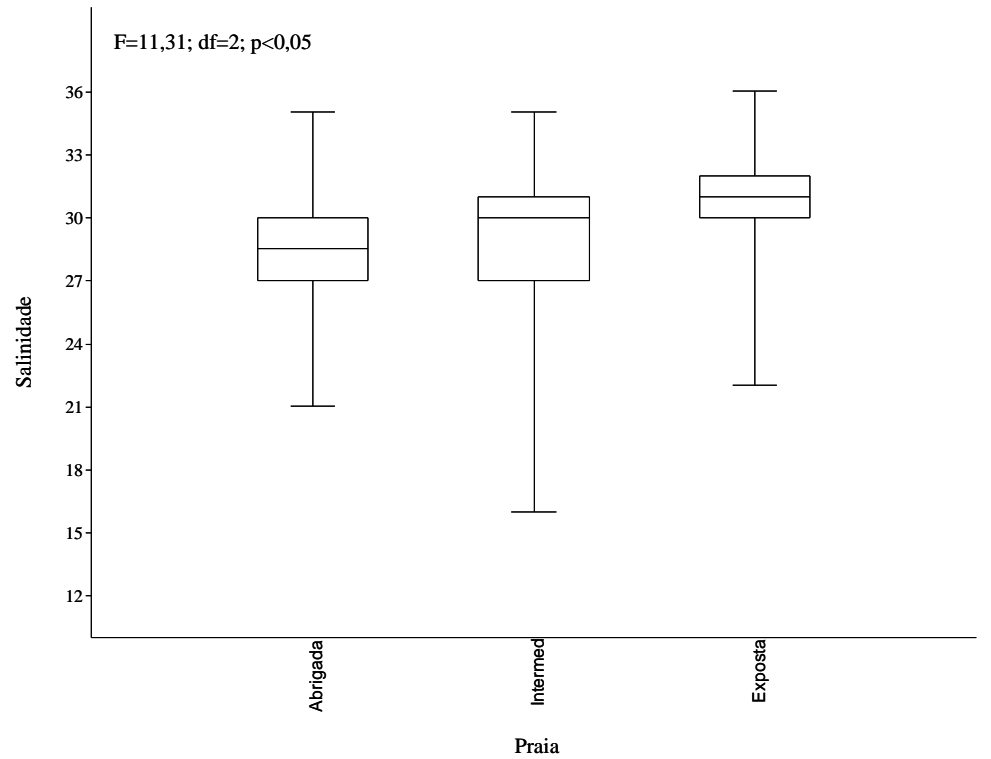

Figura 2.10. Variações de salinidade média medida na zona de surfe de diferentes praias arenosas da Ilha Comprida entre dezembro de 2008 e janeiro de 2010 (linhas horizontais representam as médias, os retângulos o desvio padrão e I o erro padrão) (Intermed=Intermediária). 


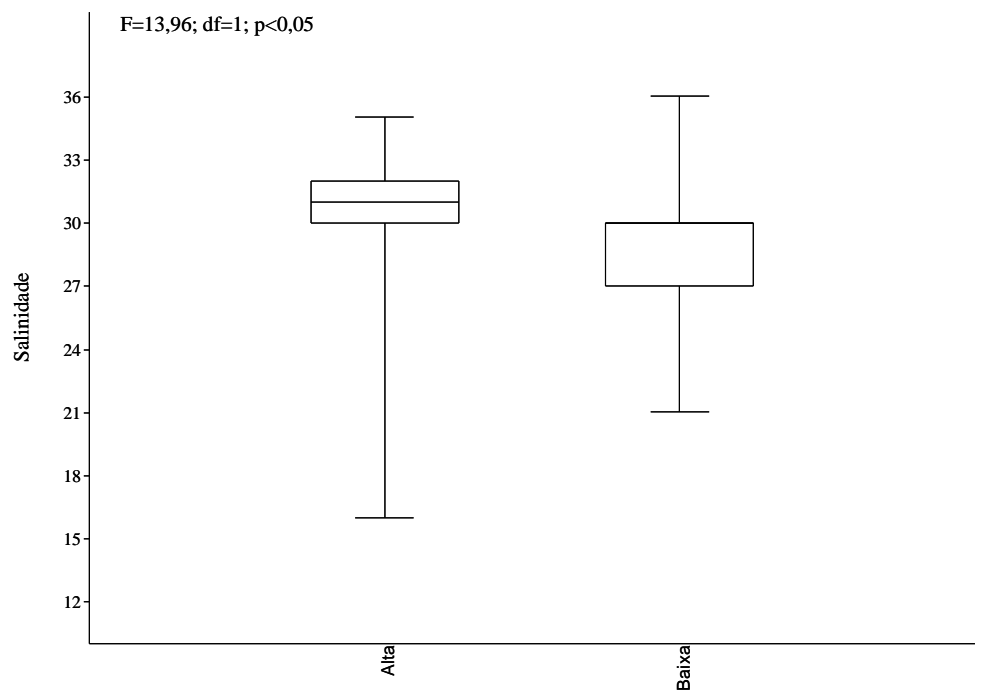

Maré

Figura 2.11. Variações de salinidade média medida durante a maré alta e baixa na zona de surfe de praias arenosas da Ilha Comprida de dezembro de 2008 a janeiro de 2010 (linhas horizontais representam as médias, os retângulos o desvio padrão e I o erro padrão).

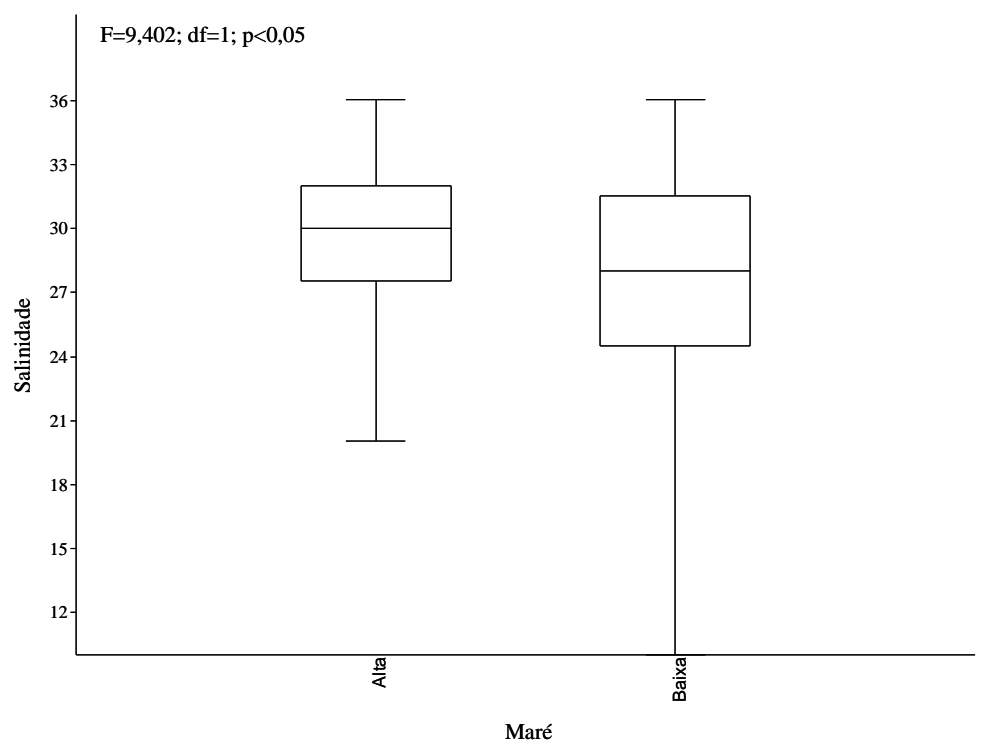

Figura 2.12. Variações de salinidade média medida durante a maré alta e baixa na zona de surfe de praias arenosas da Ilha do Cardoso de fevereiro de 2009 a janeiro de 2010 (linhas horizontais representam as médias, os retângulos o desvio padrão e I o erro padrão). 


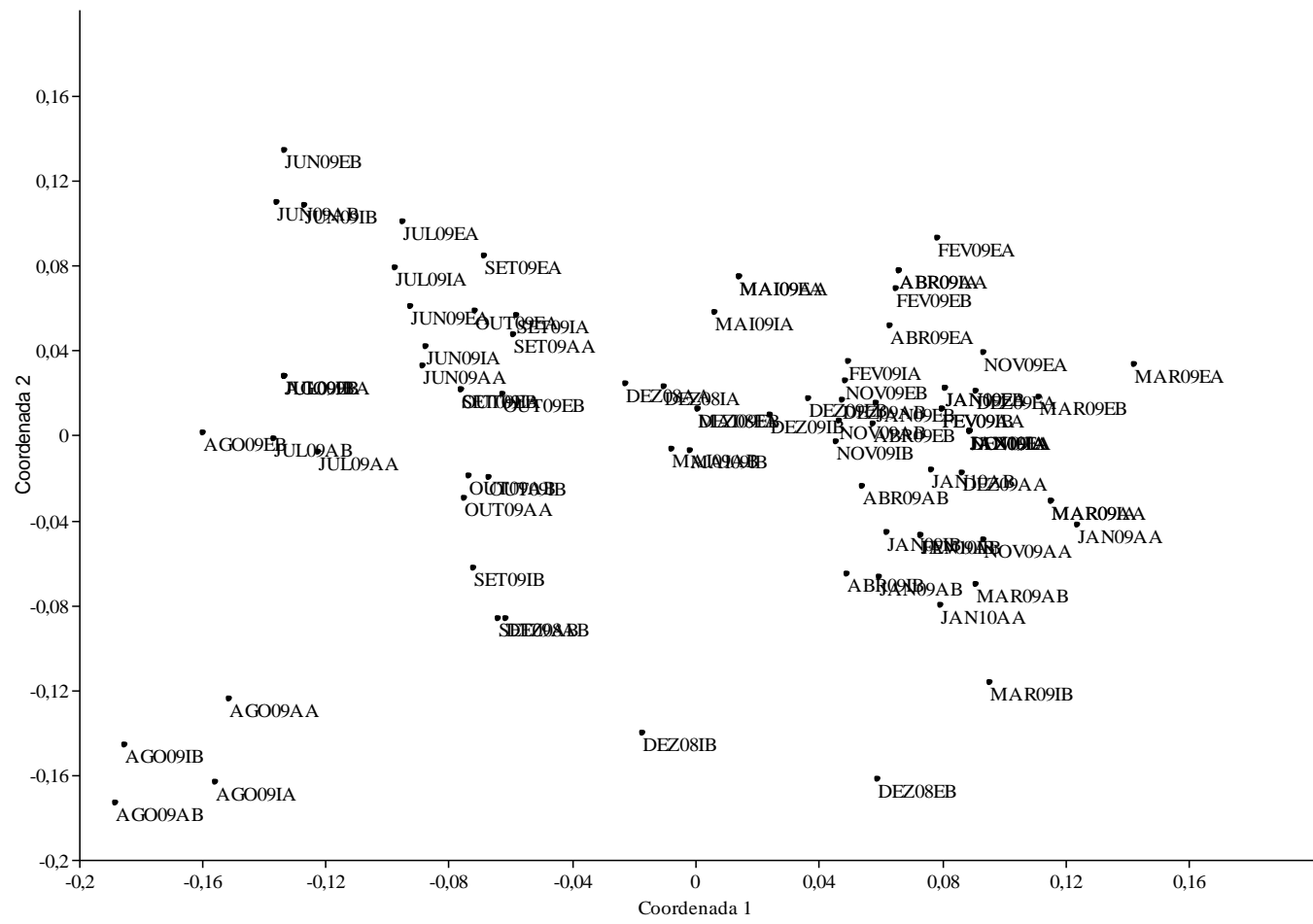

Figura 2.13. Distribuição dos dados mensais dos fatores abióticos mensurados nas três praias e nas diferentes marés amostradas entre dezembro de 2008 e janeiro de 2010 na Ilha Comprida obtida pela análise de escalonamento multidimensional não métrico $M D S$. Códigos $=$ meses + ano + tipo de praia $(\mathrm{A}=$ abrigada, $\mathrm{I}=$ Intermediária e $\mathrm{E}=$ exposta $)+$ maré $(\mathrm{A}=$ alta e $\mathrm{B}=$ Baixa $)$. 


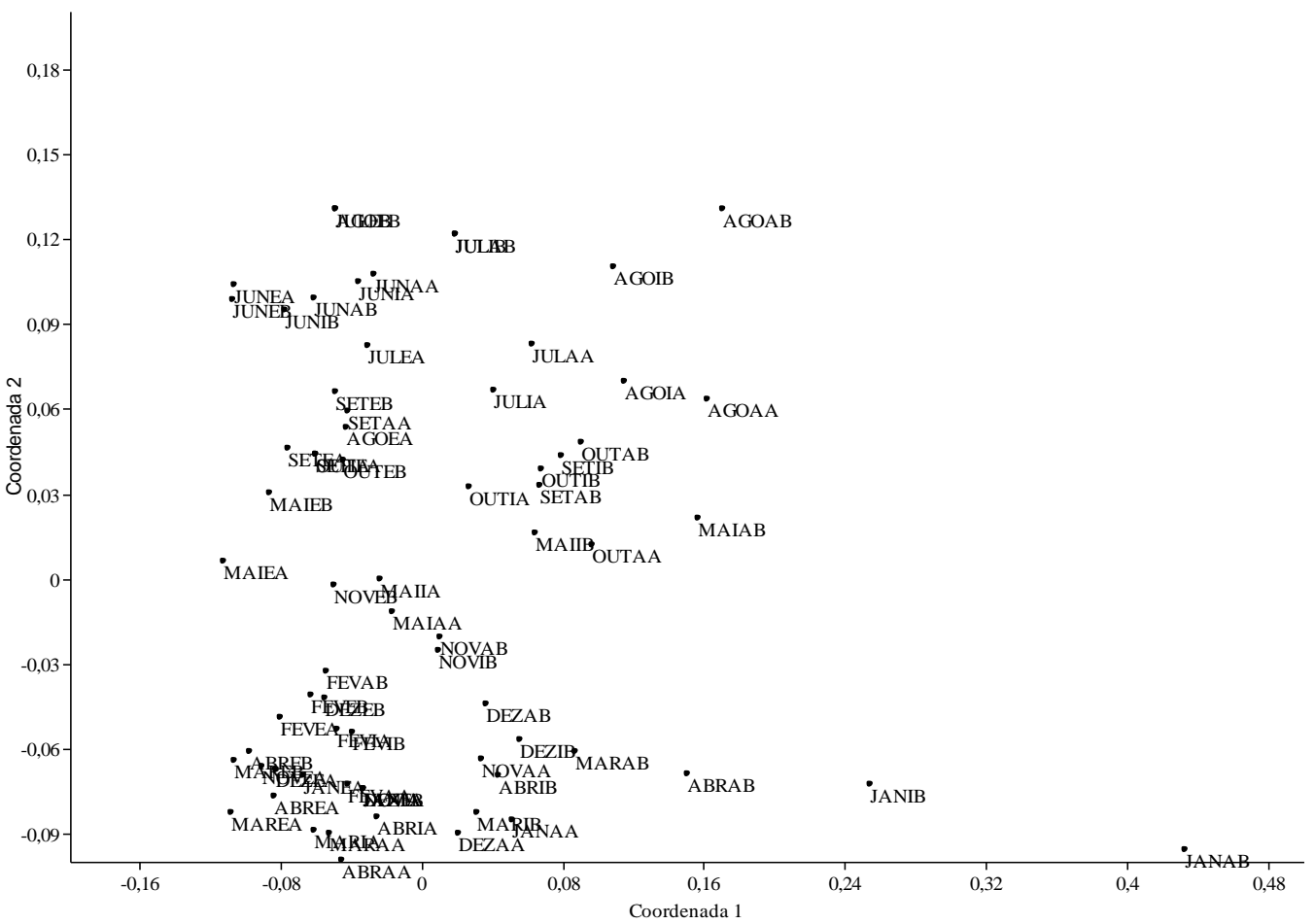

Figura 2.14. Distribuição dos dados mensais dos fatores abióticos mensurados nas três praias e nas diferentes marés amostradas entre fevereiro de 2009 e janeiro de 2010 na Ilha do Cardoso obtida pela análise de escalonamento multidimensional não métrico $M D S$. Códigos $=$ meses + ano + tipo de praia $(\mathrm{A}=$ abrigada, $\mathrm{I}=$ Intermediária e $\mathrm{E}=$ exposta $)+$ maré $(\mathrm{A}=$ alta e $\mathrm{B}=$ Baixa $)$. 


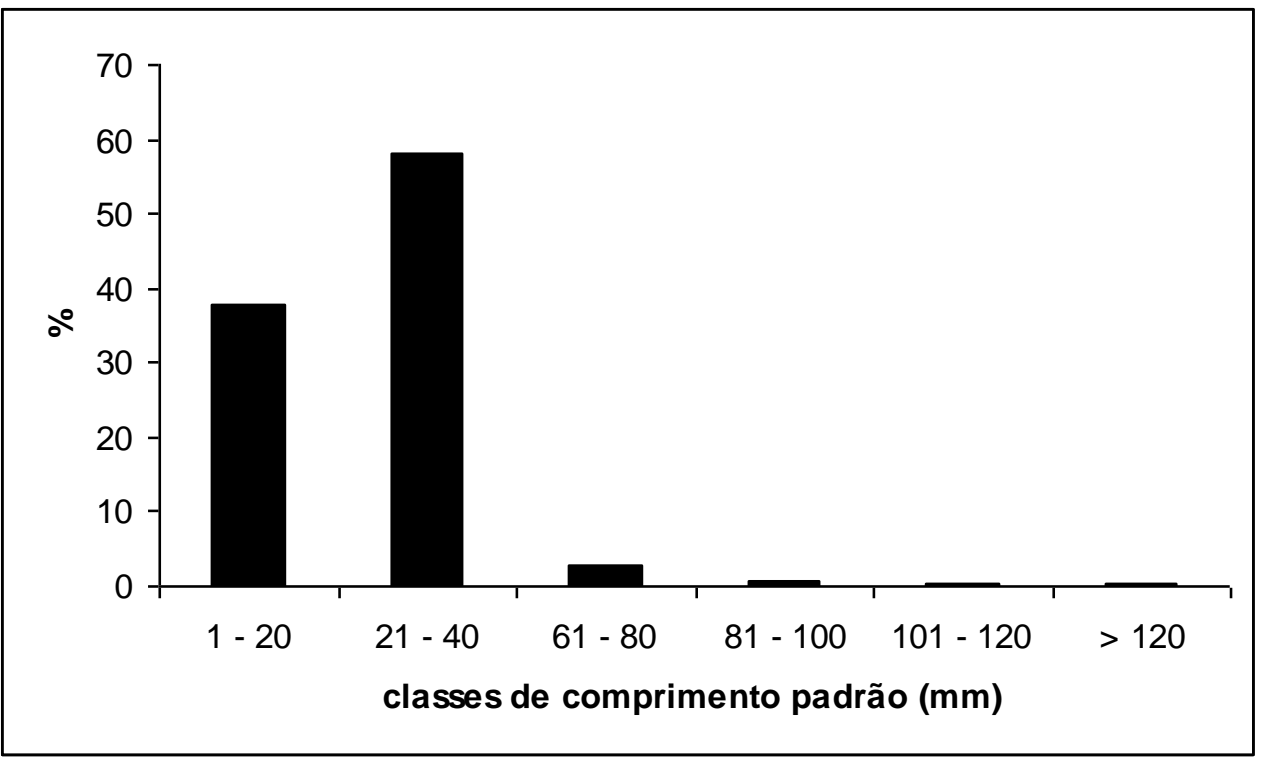

Figura 2.15. Distribuição de frequência das classes de comprimento padrão dos exemplares da ictiofauna obtidos nas praias da Ilha Comprida $(\mathrm{N}=4051)$.

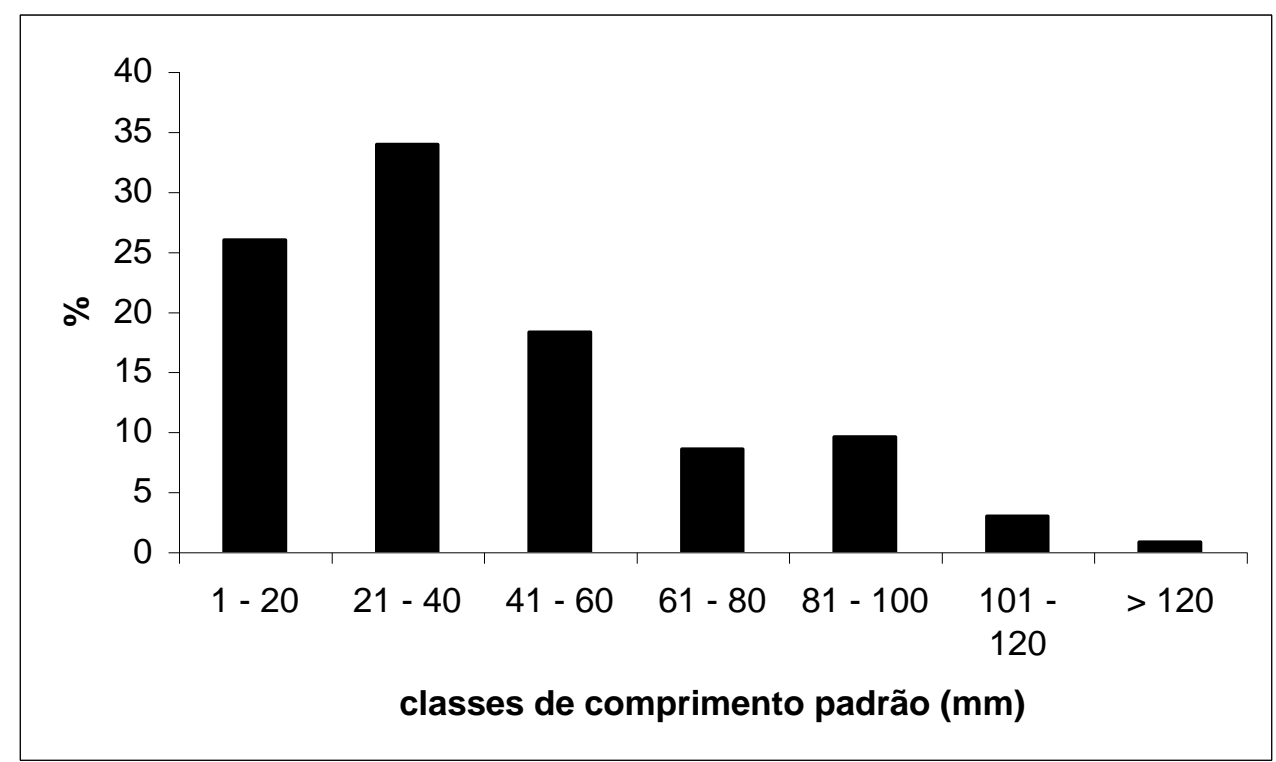

Figura 2.16. Distribuição de frequência das classes de comprimento padrão dos exemplares da ictiofauna capturados nas praias da Ilha do Cardoso $(\mathrm{N}=3968)$. 


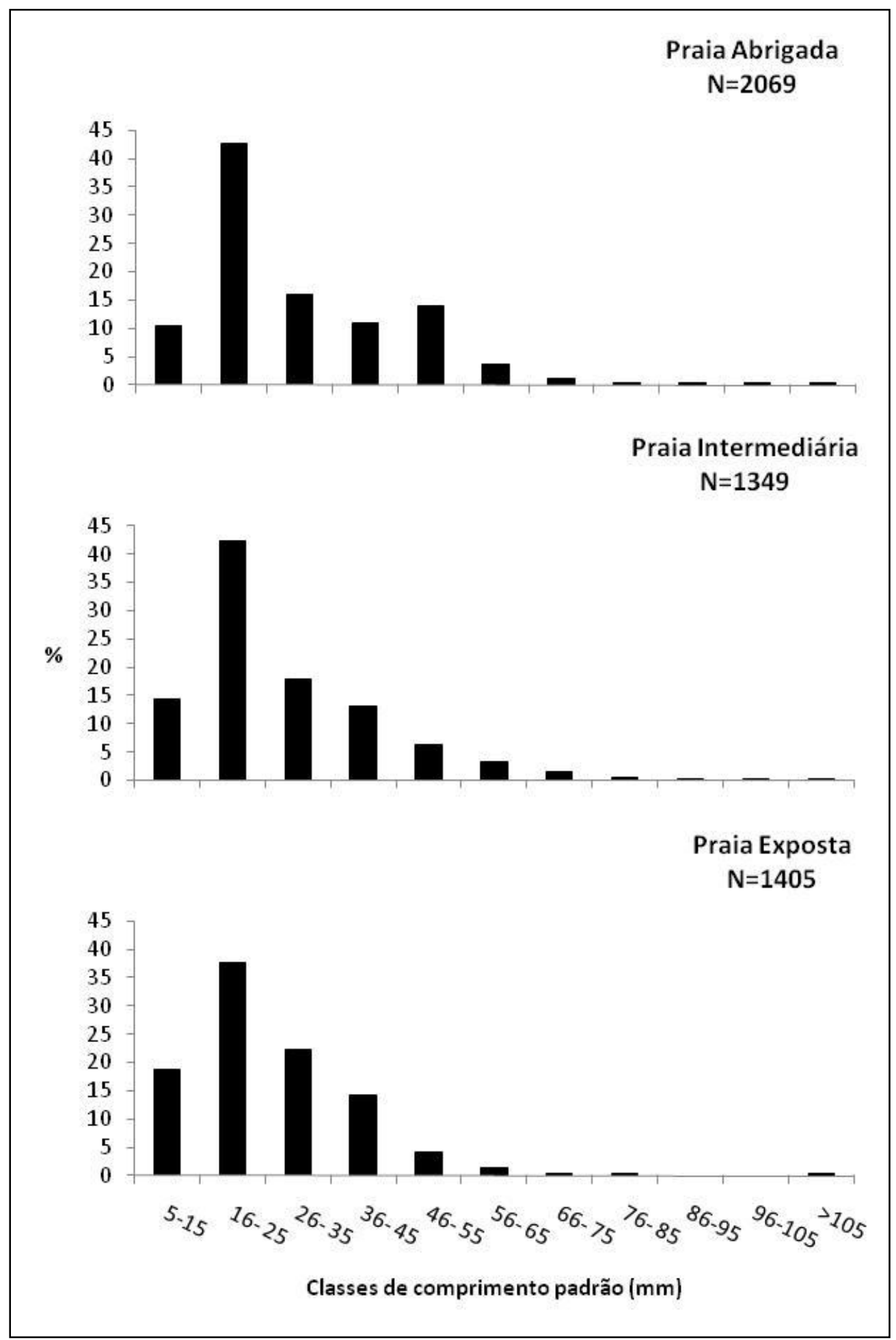

Figura 2.17. Distribuição de frequência das classes de comprimento padrão, em milímetros, dos exemplares de peixes obtidos nas diferentes praias da Ilha Comprida. 


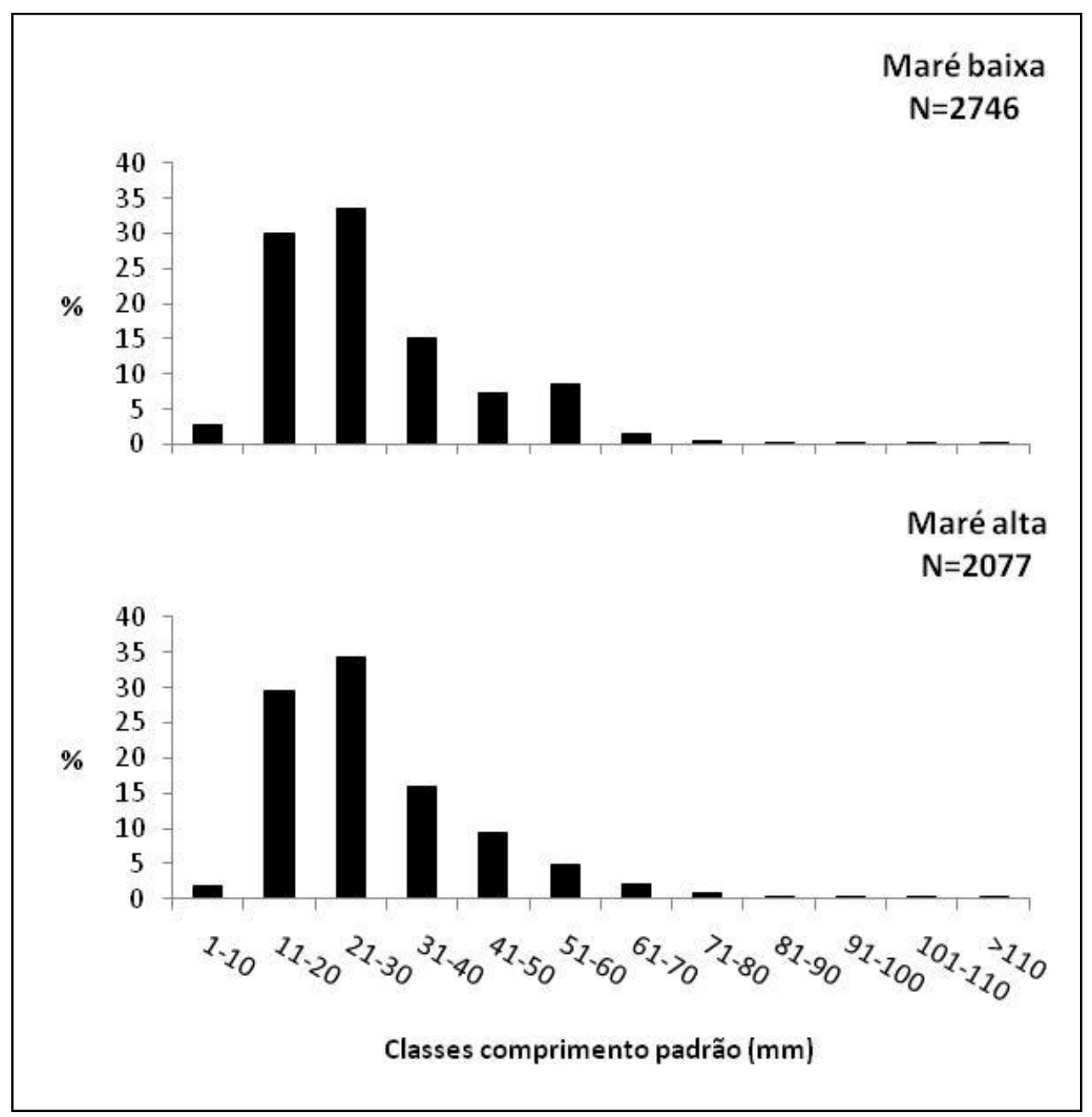

Figura 2.18. Distribuição de frequência das classes de comprimento padrão, em milímetros, dos exemplares de peixes obtidos nas praias da Ilha Comprida durante diferentes marés. 


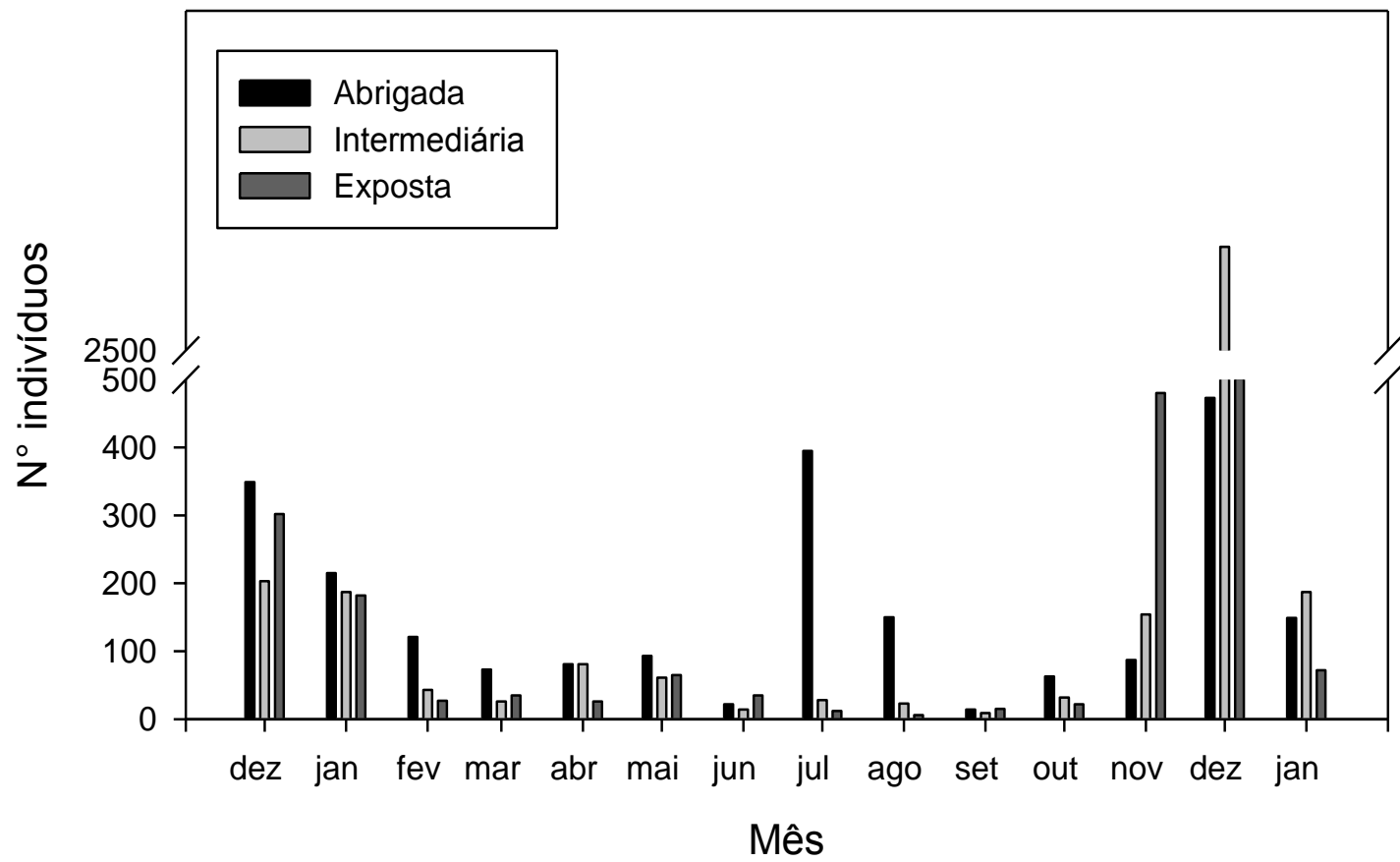

Figura 2.19. Número de indivíduos da ictiofauna capturados por praia ao longo dos meses amostrados na Ilha Comprida dezembro de 2008 a janeiro de 2010.

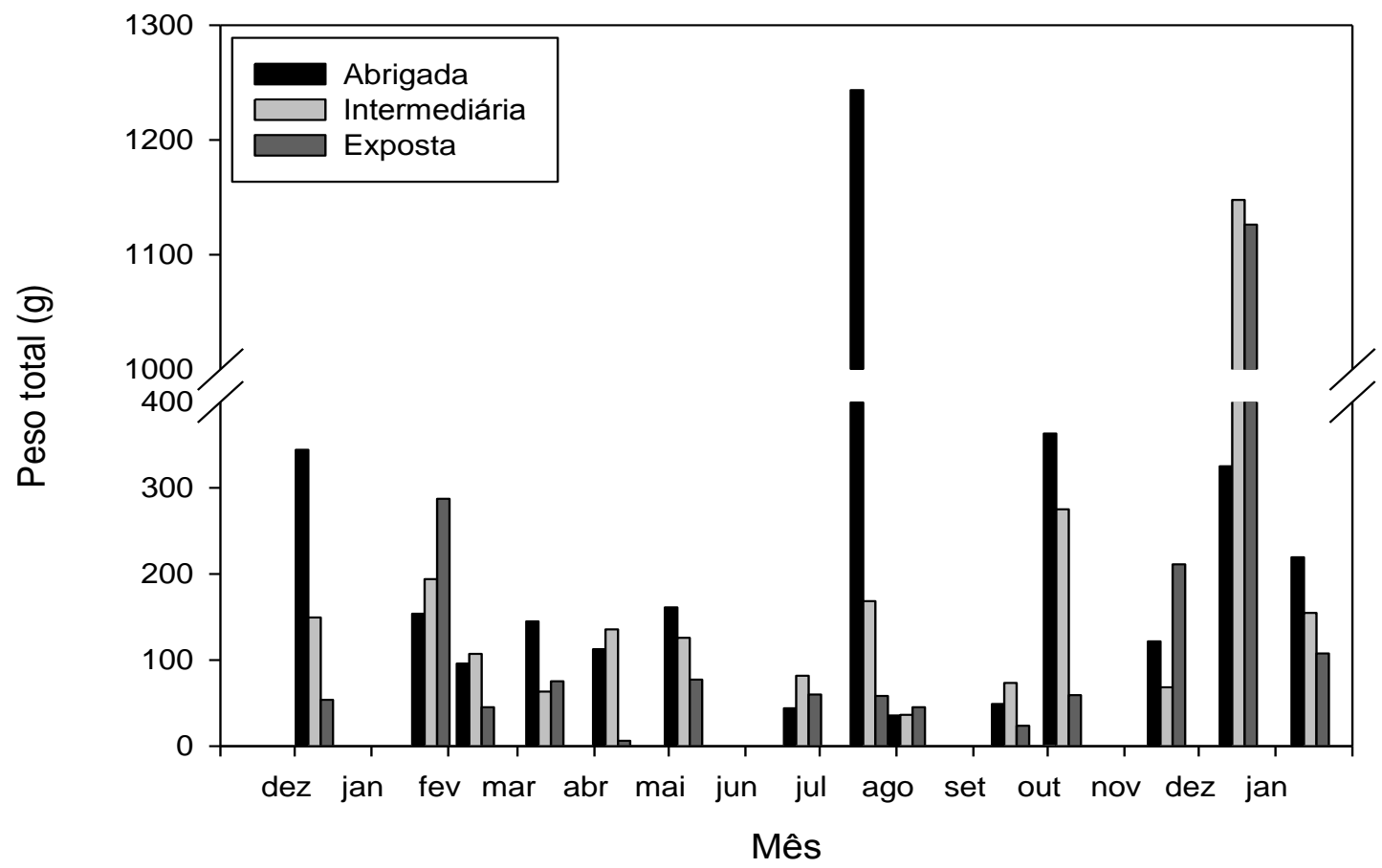

Figura 2.20. Peso total da ictiofauna obtido por praia ao longo dos meses amostrados na Ilha Comprida de dezembro de 2008 a janeiro de 2010. 


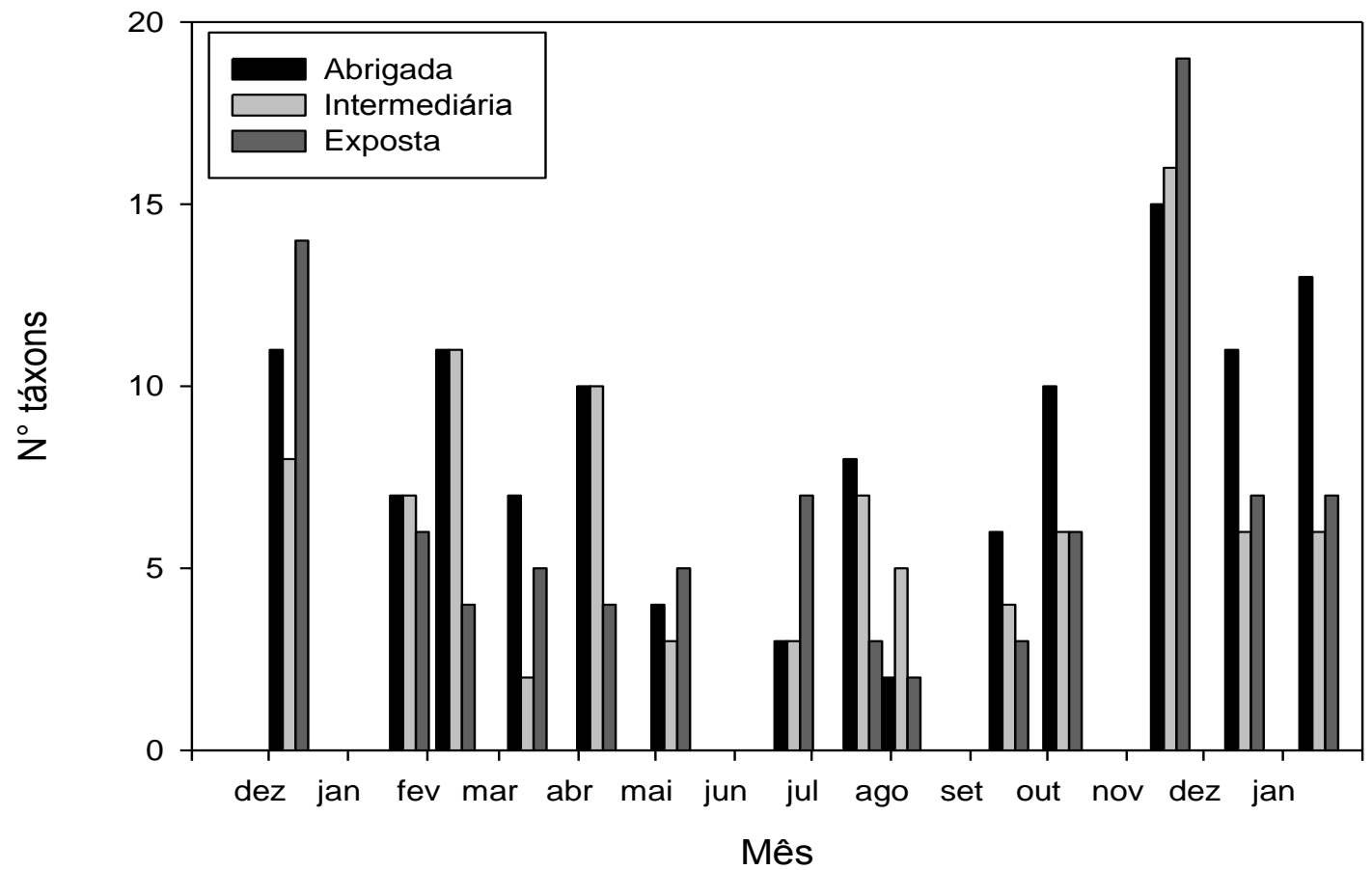

Figura 2.21. Número de espécies da ictiofauna identificados por praia ao longo dos meses amostrados na Ilha Comprida de dezembro de 2008 a janeiro de 2010.

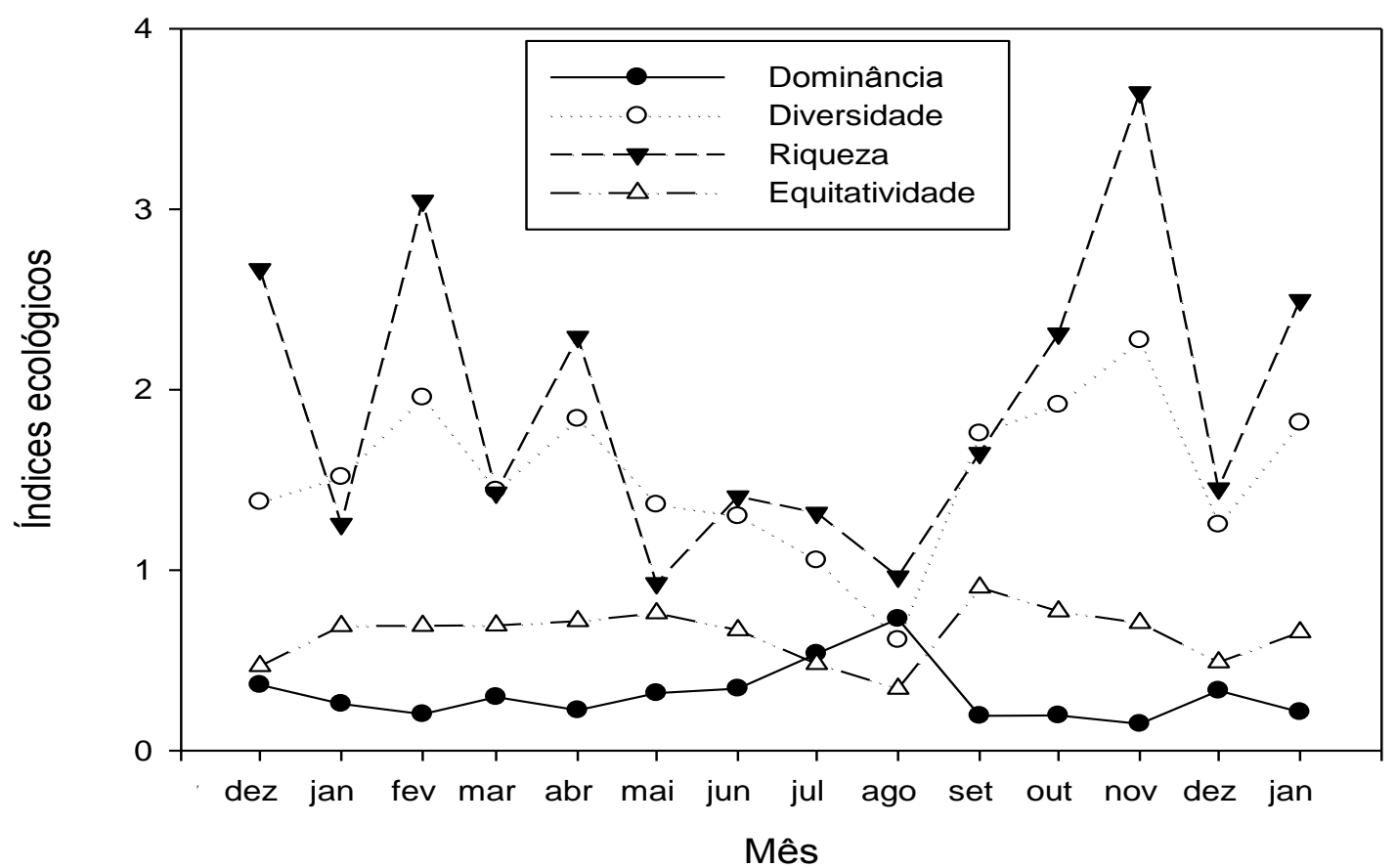

Figura 2.22. Variação mensal dos índices ecológicos calculados com dados de ictiofauna obtidos nas praias da Ilha Comprida de dezembro de 2008 a janeiro de 2010. 


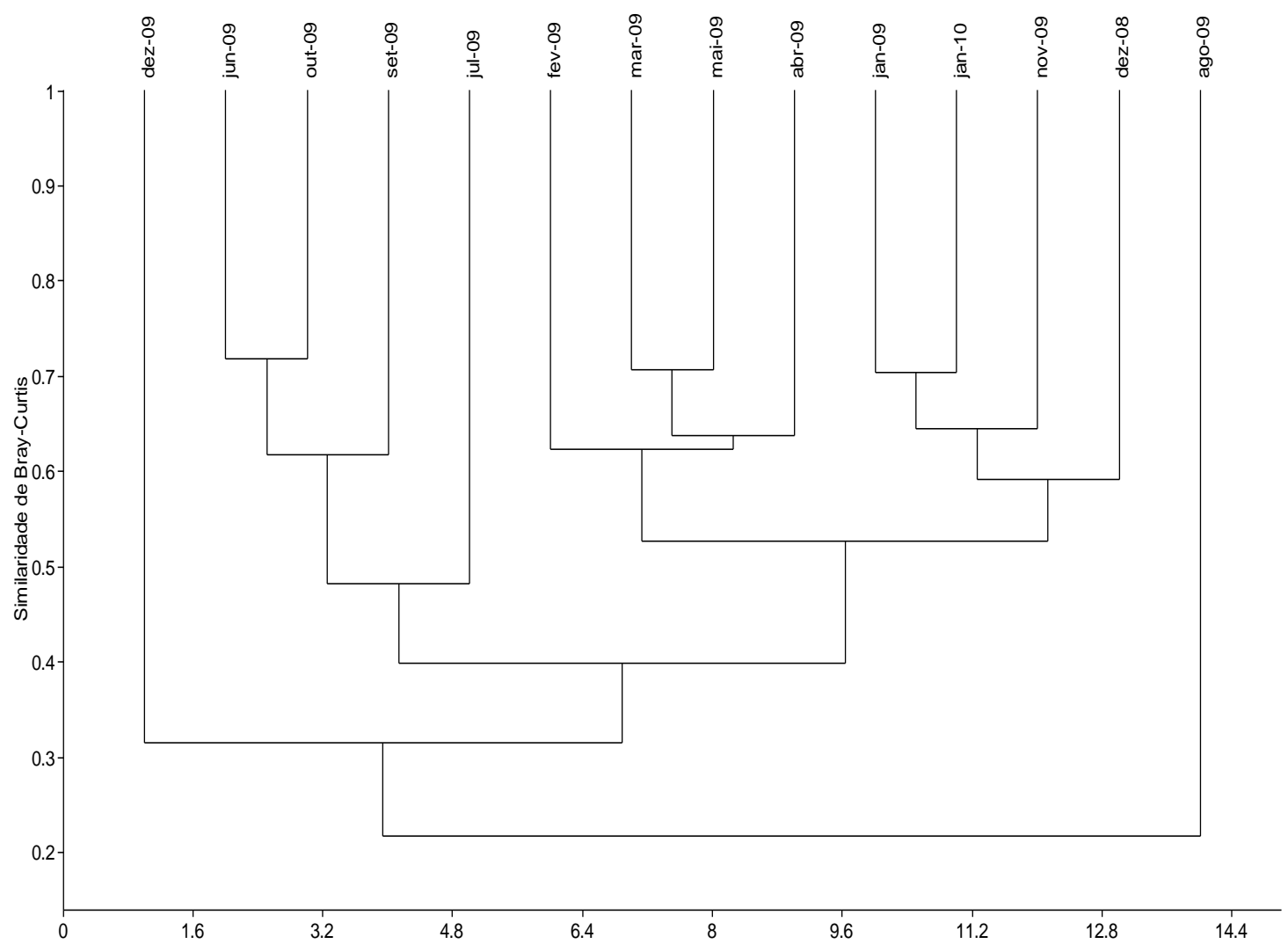

Figura 2.23. Dendograma resultante da análise de agrupamento realizada com dados de ocorrência numérica mensal da ictiofauna obtidos em praias da Ilha Comprida de dezembro de 2008 a janeiro de 2010. 


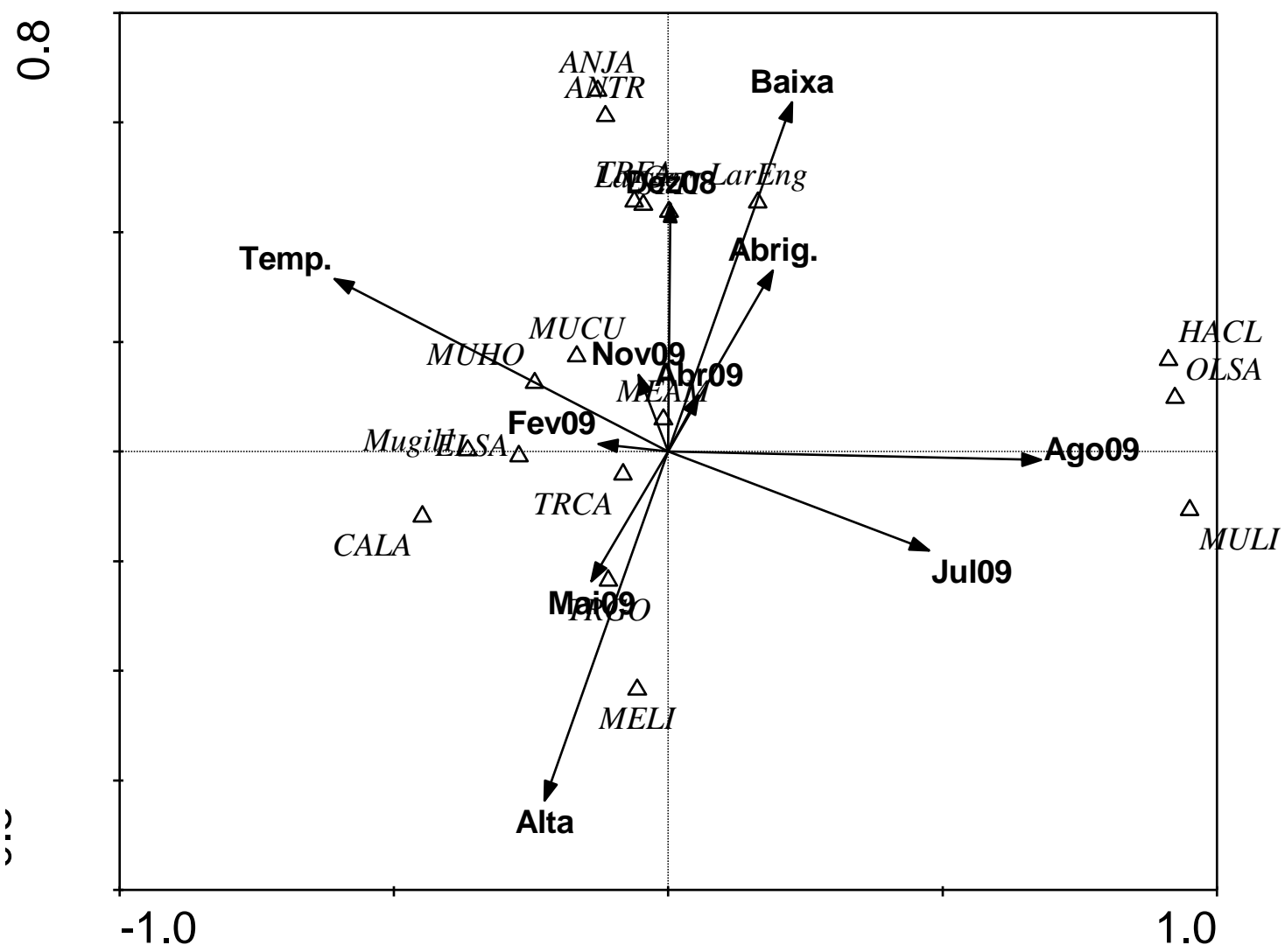

Figura 2.24. Diagrama de ordenação (biplot) da Análise de Correspondência Canônica incluindo as espécies da ictiofauna amostradas mensalmente entre dezembro de 2008 e janeiro de 2010 nas diferentes praias da Ilha Comprida e as variáveis abióticas significativas (representadas por vetores). As espécies foram codificadas pelas duas primeiras letras do nome do gênero e do epíteto específico; exemplo: TRCA= Trachinotus carolinus. 


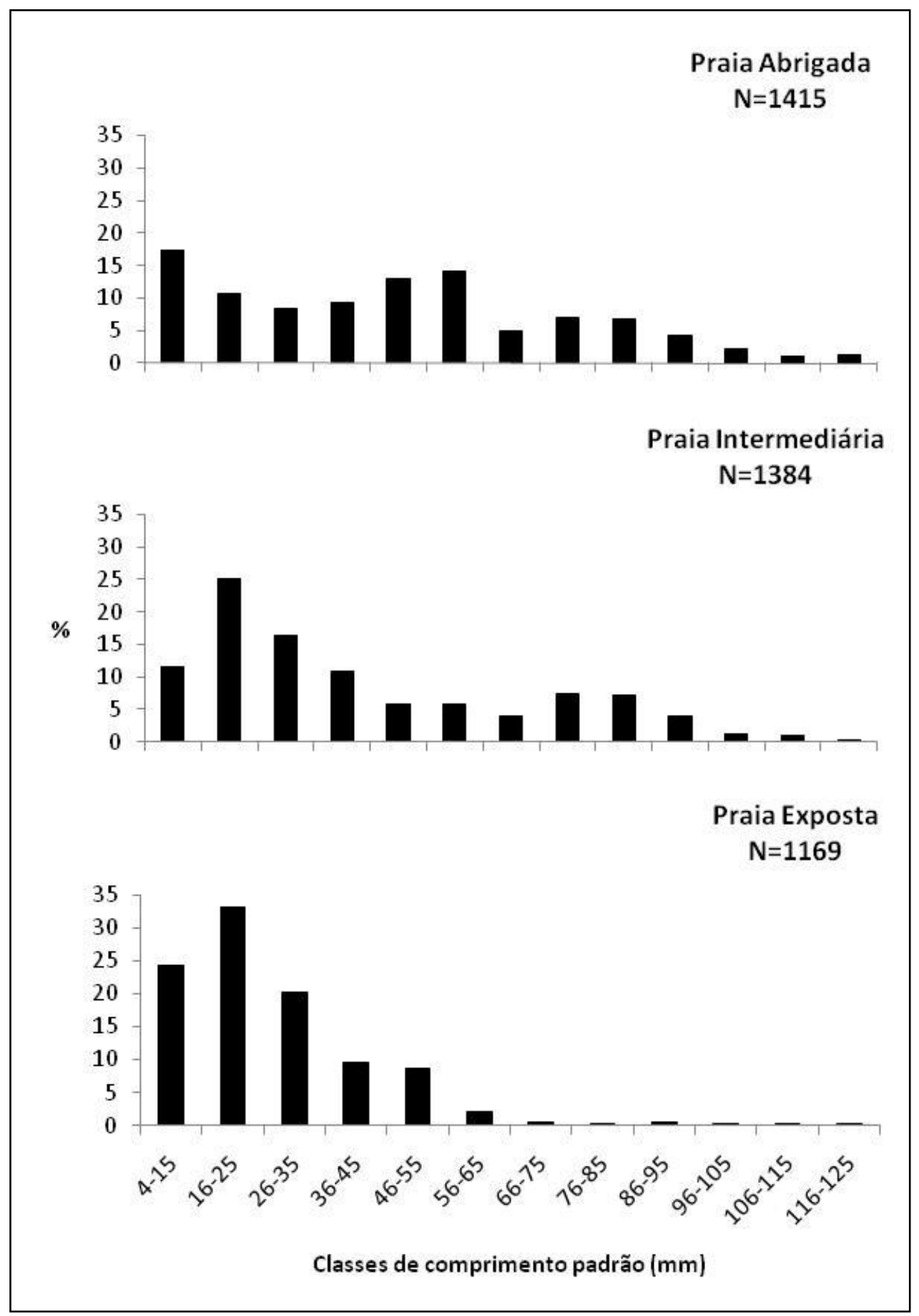

Figura 2.25. Distribuição de frequência das classes de comprimento padrão, em milímetros, dos exemplares de peixes obtidos nas diferentes praias da Ilha do Cardoso. 


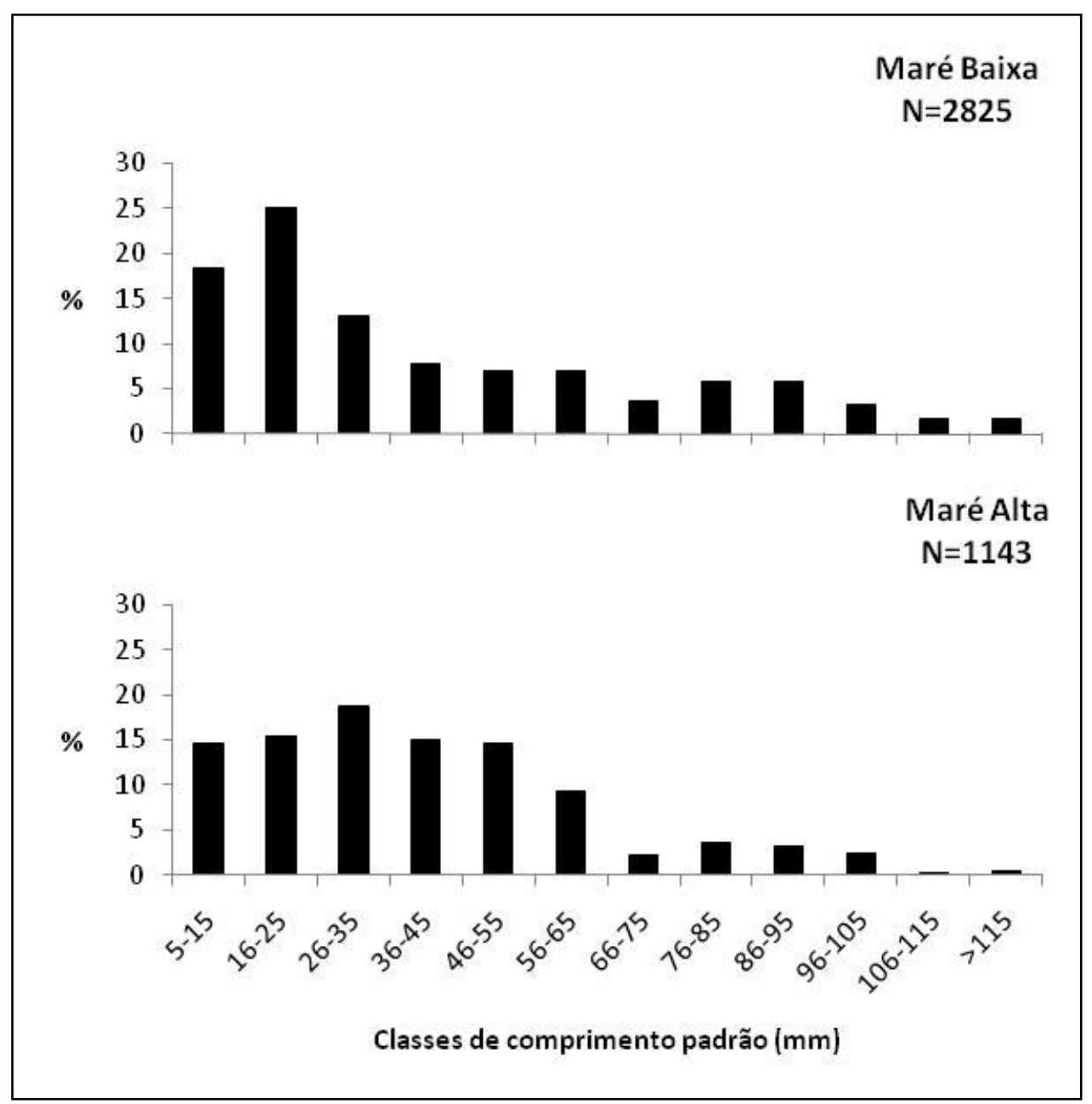

Figura 2.26. Distribuição de frequência das classes de comprimento padrão, em milímetros, dos exemplares de peixes obtidos nas praias da Ilha do Cardoso durante as diferentes marés. 


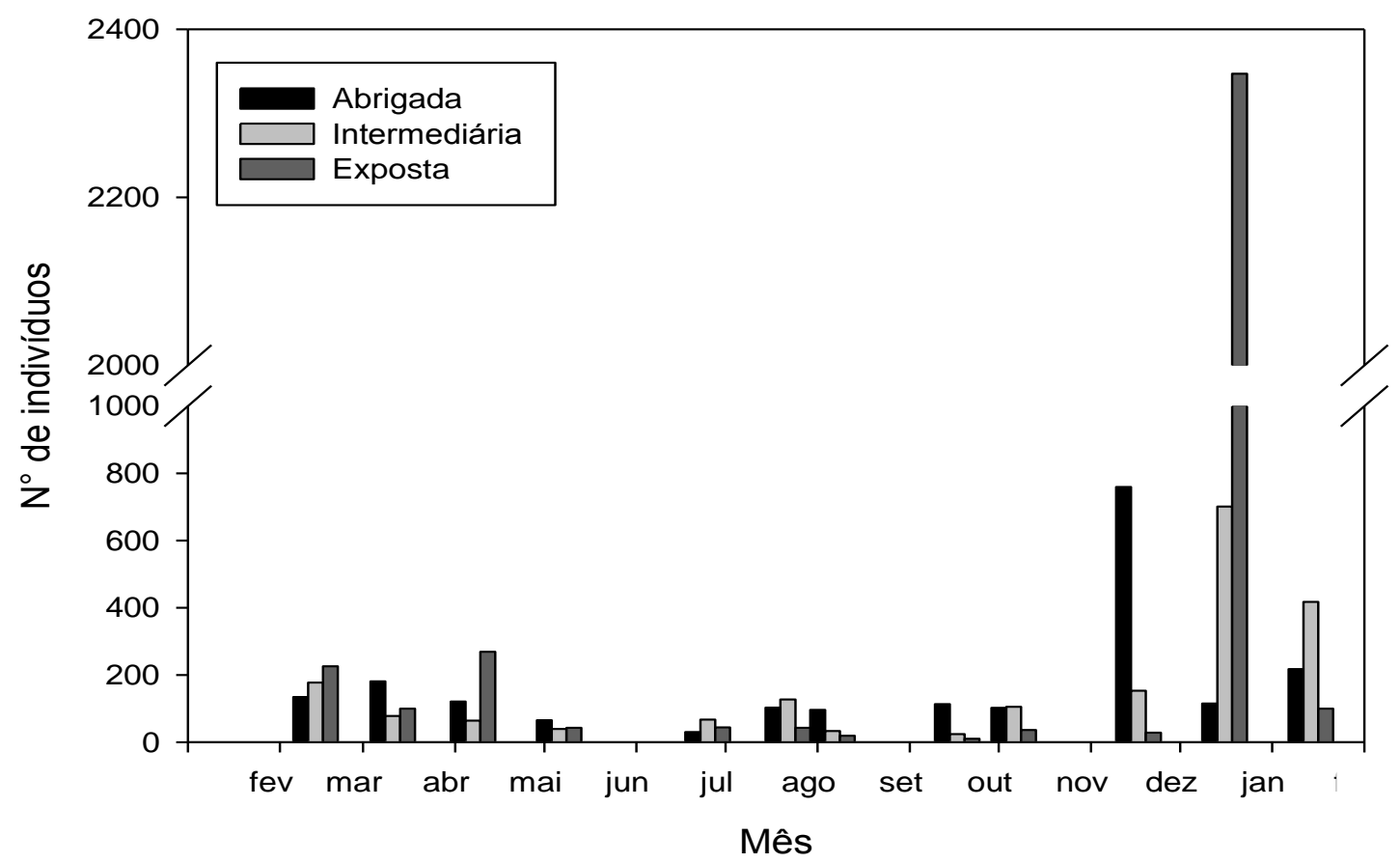

Figura 2.27. Número de indivíduos da ictiofauna capturados por praia ao longo do ano de coleta nas praias da Ilha do Cardoso de fevereiro de 2009 a janeiro de 2010.

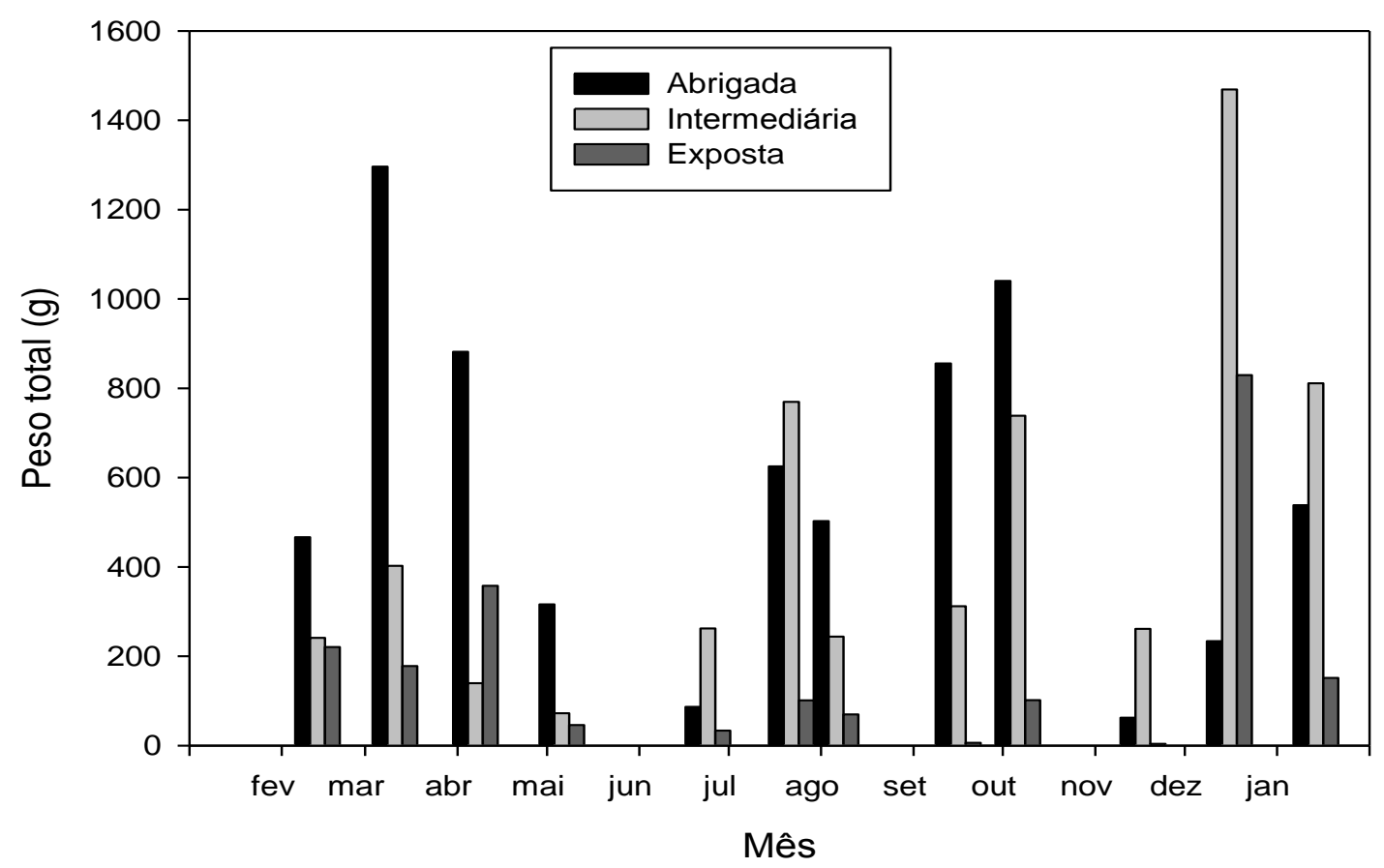

Figura 2.28. Peso total da ictiofauna obtido por praia ao longo do ano de coleta nas praias da Ilha do Cardoso de fevereiro de 2009 a janeiro de 2010. 


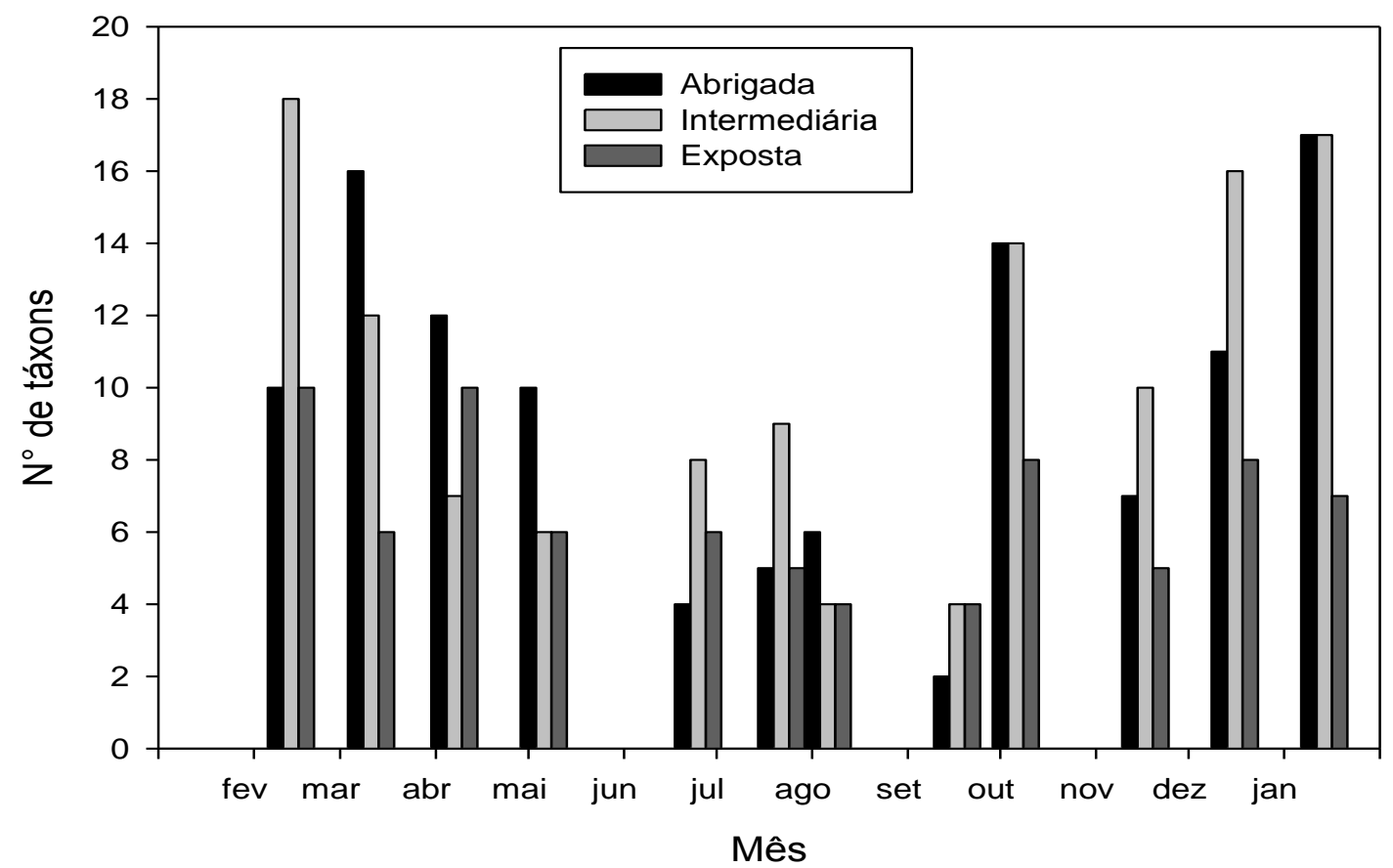

Figura 2.29. Número de espécies da ictiofauna identificadas em nível específico ou de gênero por praia ao longo do ano de coleta nas praias da Ilha do Cardoso de fevereiro de 2009 a janeiro de 2010.

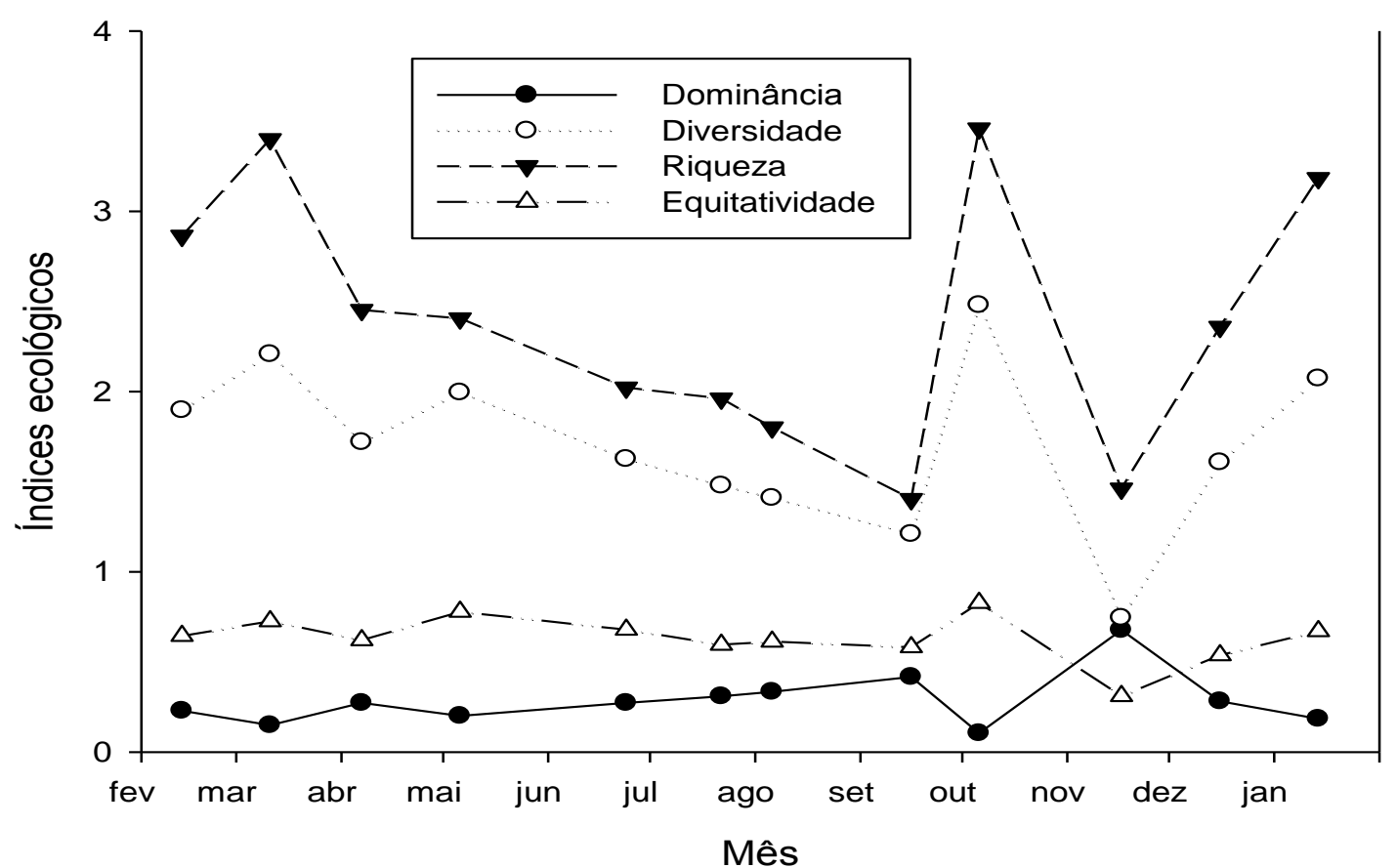

Figura 2.30. Variação mensal dos índices ecológicos calculados com dados obtidos nas praias da Ilha do Cardoso de fevereiro de 2009 a janeiro de 2010. 


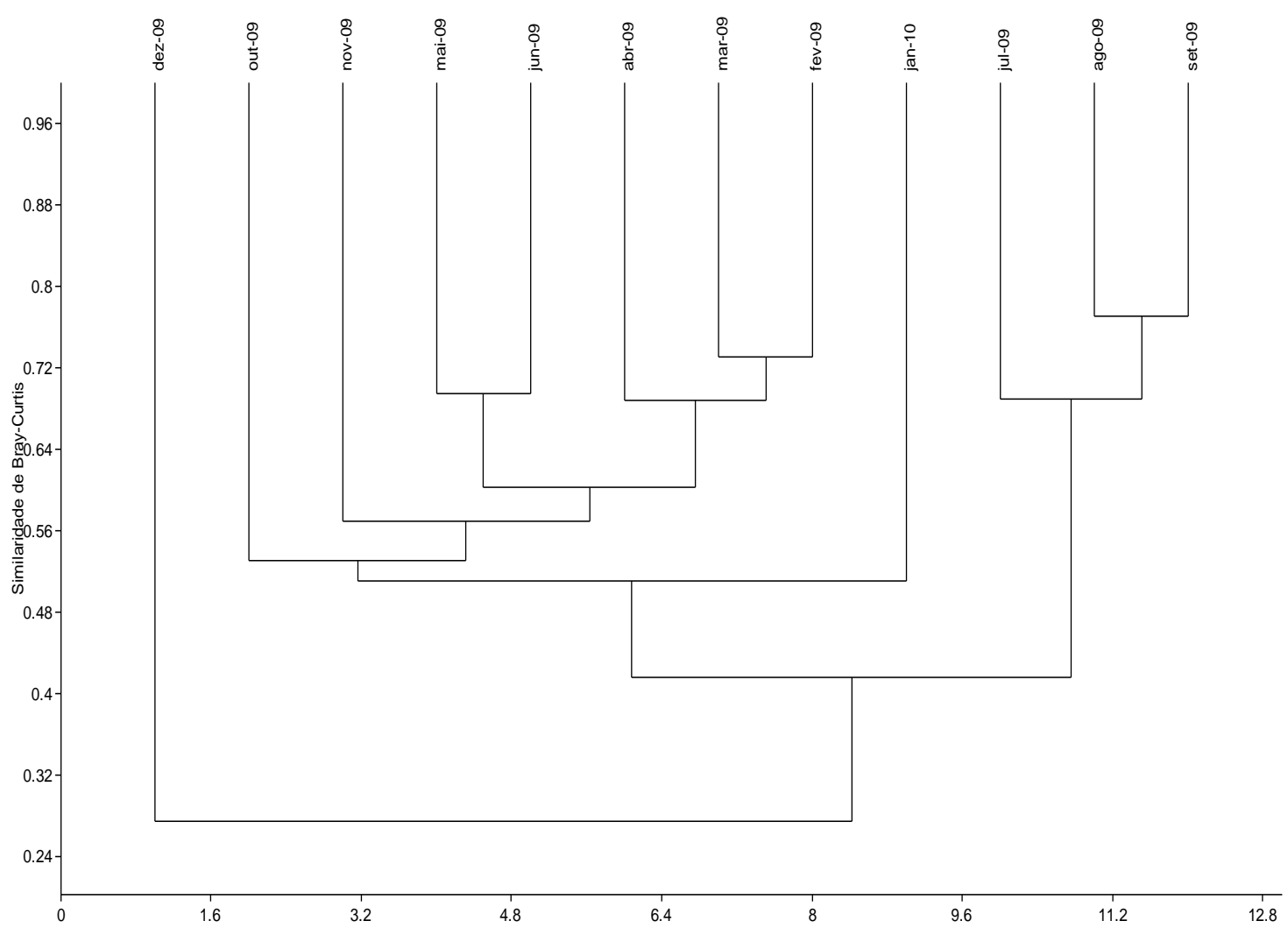

Figura 2.31. Dendograma resultante da análise de agrupamento realizada com dados de ocorrência numérica mensal da ictiofauna obtidos em praias da Ilha do Cardoso de fevereiro de 2009 a janeiro de 2010. 


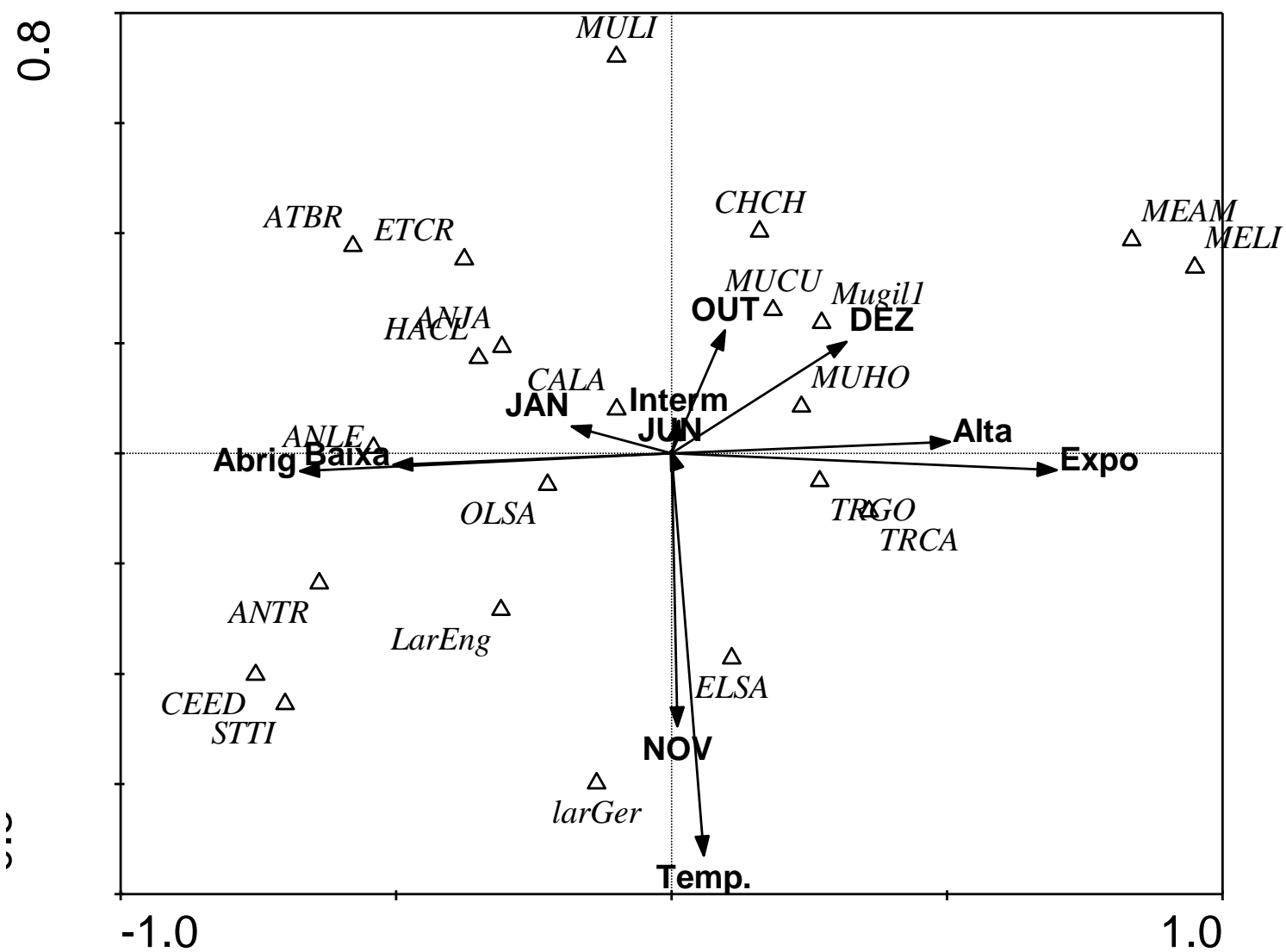

Figura 2.32. Diagrama de ordenação (biplot) da Análise de Correspondência Canônica incluindo as espécies da ictiofauna amostradas mensalmente entre fevereiro de 2009 a janeiro de 2010 nas diferentes praias da Ilha do Cardoso e as variáveis abióticas significativas (representadas por vetores). As espécies foram codificadas pelas duas primeiras letras do nome do gênero e do epíteto específico; exemplo: TRCA= Trachinotus carolinus. 
Capítulo 3. ASPECTOS ESTRUTURAIS DA ICTIOFAUNA DE AMBIENTES

PRAIAIS DA BARRA SUL DO SISTEMA COSTEIRO CANANÉIA-IGUAPE:

VARIAÇÕES DE CURTO PRAZO

INTRODUÇÃO

Praias arenosas representam a maior parte das áreas costeiras do mundo e provêem inúmeros bens e serviços ao homem, sobretudo por abrigarem grande variedade de recursos naturais e por constituírem extensas áreas de recreação (BROWN e MCLACHLAN, 1990). É um ecossistema dinâmico fortemente estruturado por processos hidrodinâmicos, biológicos e eólicos, que alteram drasticamente feições praiais em curta escala temporal. Além disso, pressões antrópicas, sobretudo as associadas à urbanização têm significativo impacto em tais sistemas costeiros (MCLACHALAN, 1983).

A zona de surfe de praias arenosas representa a faixa litorânea que se estende da linha da costa até o limite externo das células de circulação das correntes geradas pela ação das ondas (MCLACHALAN, 1983). Apesar de se caracterizar por alto hidrodinamismo, tal componente do ambiente praial constitui uma área de alimentação e crescimento à fase larval e juvenil de inúmeras espécies de peixes, o que é atribuído à elevada disponibilidade de alimento e à proteção contra predadores (LASIAK, 1981; MCLACHLAN et al., 1981).

Vários trabalhos revelam que a composição e abundância da fauna ictíica diferem consistentemente entre praias expostas e abrigadas, o que é atribuído ao grau de exposição e o hidrodinamismo. De acordo com Romer (1990), Félix et al. (2007) e Vasconcellos et al. (2007), o grau de exposição é, geralmente, positivamente associado ao aumento na dominância e à diminuição na abundância e riqueza de actinopterígios. Além disso, tem-se registrado maior abundância em marés baixas do que marés altas (LASIAK, 1984a; GIBSON et al., 1996).

O ambiente da zona de surfe sofre oscilações em diferentes escalas temporais. Além de eventos biológicos como recrutamento e migrações, tais oscilações têm forte papel estruturador da ictiofauna. Variações ambientais pontuais em curta e média escalas (i.e. diárias e mensais) são grandemente influenciadas pelos ciclos diários e 
mensais de marés, enquanto mudanças sazonais, em longa escala, são caracterizadas por oscilações de temperatura, salinidade e meteorológicas, como as entradas de frentes frias (LASIAK, 1984a; LASIAK, 1984b; ). Diversos estudos descrevem associações de variações sazonais de vetores abióticos na zona de surfe às modificações da abundância e diversidade na ictiofauna (PAIVA FILHO et al., 1987; PEREIRA, 1994; GIANNINI e PAIVA FILHO, 1995; SAUL e CUNNINGHAM, 1995; GAELZER e ZALMON, 2003; GOMES et al., 2003; ARAÚJO et al., 2008; LIMA e VIEIRA, 2009). No entanto os meios pelos quais as oscilações temporais de curta e média escalas atuam na estruturação da ictiofauna permanecem pouco estudados. Rodrigues et al. (2010) estudaram variações circadianas da ictiofauna, sem verificar a existência de ciclo nictemeral, sendo os resultados atribuídos ao alto dinamismo da zona de arrebentação.

A falta de estudos sobre as variações da ictiofauna de praias em curta escala de tempo e a existência de grande diversidade em ambientes costeiros e estuarinos justifica a necessidade de estudos nesse ambiente, cujo dinamismo é elevado.

\section{OBJETIVOS ESPECÍFICOS}

- Descrever a composição e estruturação da ictiofauna presente na zona de surfe da Ilha Comprida;

- Verificar as variações de curto prazo que influenciam a composição e a estrutura da comunidade de actinopterígios do local.

\section{MÉTODO DE COLETA E TOMADA DOS DADOS}

Os arrastos da coleta intensiva ocorreram em dias alternados de 23 de janeiro a 18 de fevereiro de 2009, totalizando quatorze dias.

A metodologia de coleta dos espécimes e da tomada dos dados foi descrita no item "Material e Métodos" do Capítulo 1 desta dissertação. 
ANÁLISE DOS DADOS

A Análise de Variância (One way ANOVA) foi usada para testar a significância das diferenças entre as médias dos dados abióticos de temperatura e salinidade ao nível de confiança de $95 \%$ ( $\mathrm{p}<0,05)$, quando analisados os diferentes dias de coleta, praias e marés.

A partir dos dados biológicos, foram calculados os índices descritores da comunidade para o período como um todo, por praia e marés, estimados das seguintes maneiras:

- Constância de ocorrência: $\mathrm{C}=$ pi*100*P-1, em que $\mathrm{C}=$ constância de ocorrência, pi= número de coletas em que a espécie apareceu e $\mathrm{P}=$ número total de coletas. As espécies foram classificadas de acordo com os valores estimados: espécies constantes para $\mathrm{C} \geq 50$, espécies acessórias para $50<\mathrm{C}>25$ e espécies acidentais para $\mathrm{C} \leq 25$ (Dajoz, 1983).

- Dominância: $\mathrm{D}=\sum(\mathrm{ni} / \mathrm{n}) 2$, em que ni é o número de indivíduos de determinada espécie i e n é o número total de indivíduos (BEGON et al., 2006).

- Diversidade de Shannon: $\mathrm{H}=-\sum \mathrm{ni} / \mathrm{n} \ln (\mathrm{ni} / \mathrm{n})(\mathrm{BEGON}$ et al., 2006).

- Índice de riqueza de Margalef: $M=(S-1) / \ln (n)$, em que $S$ é o número de espécies e n é o número de indivíduos (BEGON et al., 2006).

- Equitatividade: Diversidade de Shannon dividido pelo logaritmo do número de espécies (BEGON et al., 2006).

As diferenças entre os índices obtidos foram testadas através do método Bootstrap para testes de hipóteses, com 95\% de confiança.

Para avaliar a influência de cada variável na comunidade de peixes, foi feita uma Análise de Correspondência Canônica (CCA). Tal análise mostrou ser a mais apropriada para os dados em questão, pois após um estudo prévio utilizando a Análise de Correspondências Destendenciada (DCA) em uma matriz de fauna bruta, ou seja, sem eliminar as raras e sem transformar os dados, obteve-se um valor de traço canônico alto (3,396) (LEGENDRE e LEGENDRE, 1998).

Espécies raras, aquelas em que ocorreram menos de 10 indivíduos ao longo dos dias de amostragem, foram eliminadas da matriz de dados bióticos, que continha a abundância numérica das espécies em cada amostra. Já os dados abióticos monitorados, 
depois de uma primeira análise utilizando-se uma única matriz, foram divididos em três matrizes: ambientais (salinidade e temperatura), temporais (maré alta e baixa, maré de sizígia e de quadratura, e dias) e espaciais (praias com diferentes graus de exposição). Os dias foram numerados conforme as coletas foram realizadas, sendo o dia 1 correspondente a data de 23 de janeiro, o dia 2 a 25 de janeiro, e assim sucessivamente até o dia 14, correspondente a data de 18 de fevereiro de 2009. Em todas as análises os dados foram transformados por $\log (\mathrm{x}+1)$ e foi atribuído peso baixo às espécies raras.

A porcentagem de explicação das variáveis monitoradas, da interação das mesmas e do que não pode ser explicado pelas análises, foi calculada seguindo o proposto por Borcard et al. (1992).

\section{RESULTADOS}

\section{$\underline{\text { Dados abióticos }}$}

A análise dos dados ambientais mostrou que houve uma variação significativa dos valores de temperatura ao longo dos dias amostrados $(\mathrm{F}=10,71, \mathrm{p}<0,05)$ (Figura 3.1). As coletas em que se observaram as menores temperaturas médias foram aquelas em que ocorreram entradas de frentes frias na região. Deste modo, apesar de ensolarado, o dia 23 de janeiro apresentou ventos fortes e foi seguido, nos dois próximos dias de coleta, por tempo nublado e com chuvisco. Do mesmo modo, os dias 12, 14 e 16 de fevereiro foram dias chuvosos.

A variação de temperatura foi também significativa ao se analisar, isoladamente, os valores obtidos na maré alta e baixa $(\mathrm{F}=15,42, \mathrm{p}<0,05)$ (Figura 3.2). Acredita-se que a temperatura média ligeiramente maior na maré alta esteja relacionada com o horário da coleta, uma vez que as coletas na maré baixa foram realizadas no início da manhã, enquanto na maré alta durante a tarde. Em relação às praias, não houve diferença significativa nos valores de temperatura $(\mathrm{F}=0,2754, \mathrm{p}>0,05)$ (Figura 3.3). A temperatura máxima obtida foi $30^{\circ} \mathrm{C}$ e a mínima $26^{\circ} \mathrm{C}$.

Igualmente à temperatura, a salinidade variou significamente nos diferentes dias amostrados $(\mathrm{F}=10,15, \mathrm{p}<0,05)$ (Figura 3.4) e nas diferentes marés $(\mathrm{F}=19,56$, $\mathrm{p}<0,05$ ) (Figura 3.5). A queda de salinidade observada no dia 4 de fevereiro relaciona- 
se às fortes pancadas de chuva que ocorreram no dia anterior, sendo até mesmo observado, nas praias abrigada e intermediária, o intemperismo causado pelas chuvas, bem como o transporte do sedimento para o mar. Já o baixo valor de salinidade ocorrido a partir do dia 14 de fevereiro relaciona-se à entrada de frente fria que ocorreu no dia 12 e ocasionou chuvas nos próximos cinco dias. Já variação observada nas diferentes marés é resultado da intrusão de água salgada no canal durante a maré alta.

Entretanto, diferentemente da temperatura, os valores de salinidade variaram significamente nas diferentes praias amostradas $(\mathrm{F}=16,12, \mathrm{p}<0,05)$ (Figura 3.6), sendo os maiores valores observados na exposta (máximo 35; mínimo 25) e os menores na abrigada (máximo 32; mínimo 20) e na intermediária (máximo 31; mínimo 20). A mistura da água continental com a água salgada provavelmente ocasiona a diferença de salinidade observada conforme o ponto de coleta se afasta do interior do canal.

\section{Composição da ictiofauna}

Foram capturados 4709 exemplares pertencentes a 37 diferentes espécies dentro de 18 famílias, sendo que Carangidae e Mugilidae representaram 83\% dos indivíduos amostrados, com 31,6 \% e 51,5\% cada uma, respectivamente. As espécies mais a abundantes foram Trachinotus carolinus (27,6 \%), Trachinotus goodei (22,2\%), Mugil curema (17,1\%) e Mugil hospes (13,8\%) (Tabela 3.1). Os menores espécimes coletados foram identificados como Ophioscion punctatissimus e Menticirrhus americanus, com 8 e $9 \mathrm{~mm}$ de comprimento total, respectivamente. Já os maiores, com $112 \mathrm{~mm}$, foram Oligoplites saliens e T. goodei. Ambos representam também as maiores amplitudes de tamanho, sendo que para $T$ goodei a diferença entre o mínimo e o máximo de comprimento total foi $96 \mathrm{~mm}$ e em O. saliens $102 \mathrm{~mm}$ (Tabela 3.1). Dos indivíduos mensurados, $99 \%$ mediu entre 8 e $65 \mathrm{~mm}$, sendo a classe modal mais abundante a que variou entre 26 e $45 \mathrm{~mm}$, totalizando $51,5 \%$ de representatividade (Figura 3.7).

O peso total capturado foi 5.558,56 g., com Carangidae representando 83,1\% da biomassa amostrada. Consequentemente, as espécies com maiores valores de peso somados foram T. carolinus e $T$ goodei, totalizando, respectivamente, 32,50 \% e 49,30 $\%$ do total obtido. O peso individual médio foi $1,25( \pm 1,75)$ gramas. Os menores pesos 
individuais foram observados nas larvas e nos indivíduos de menor comprimento, enquanto os maiores em $M$. curema e em $M$. hospes, sendo que ambos também tiveram a maior variação entre o mínimo e máximo pesado.

A maioria das espécies amostradas foi representada por indivíduos em sua fase juvenil. Tal fato foi comprovado quando, na dissecção dos exemplares para a identificação do sexo e classificação macroscópica do estádio de maturação, não foi possível localizar as gônadas, devido ao pequeno porte dos indivíduos. Além disso, conforme mostrado na tabela 3.1, o comprimento total máximo amostrado de cada espécie é bastante inferior ao relatado na literatura para as espécies. Apenas para Elops saurus, Menticirrhus americanus, Micropogonias furnieri, todos os gerreídeos e alguns engraulídeos foram coletados exemplares em sua fase larval, identificados pela falta de escamas. Não foi amostrado nenhum espécime adulto.

A comunidade amostrada apresentou-se formada por três espécies constantes (Trachinotus goodei, Trachinotus carolinus e Mugil curema), uma única espécie acessória (Mugil hospes) e diversas espécies acidentais (Tabela 3.1). Este padrão de constância de ocorrência das espécies manteve-se semelhante quando se analisa separadamente o tipo de praia e as marés. As únicas mudanças foram a maior constância de Mugil hospes na praia abrigada na maré alta, e que Trachinotus falcatus passa a ser espécie acessória na praia abrigada e na maré baixa.

\section{Variações na composição e estruturação da ictiofauna}

Os maiores valores de número de indivíduos, quantidade de espécies e diversidade foram calculados para a praia abrigada, seguidos pelos da intermediária e então pela exposta. Não houve diferenças significativas entre a praia abrigada e intermediária nos valores de riqueza e equitatividade, sendo ambas mais ricas e uniformes que a exposta. A praia exposta foi a que apresentou maior valor de dominância, sendo representada com $88 \%$ de abundância pelas espécies T.goodei, $T$. carolinus e M. hospes (Tabela 3.2).

Em relação às marés, observou-se que a maré baixa apresentou maior riqueza, diversidade, uniformidade e menor dominância do que a maré alta (Tabela 3.3). Na situação de maré alta houve a dominância principalmente por T. carolinus e T. goodei. 
Uma porcentagem de 36,36 \% da variabilidade dos dados biológicos foi explicada pelas variáveis abióticas monitoradas, sendo apenas os dados ambientais de temperatura e salinidade não significativos $(\mathrm{P} \leq 0,05)$ pelo teste de permutação de Monte Carlo. Os dois primeiros eixos explicaram 53,2 \% na relação espécies-ambiente, sendo o primeiro eixo correlacionado positivamente com maré baixa, praia abrigada, maré de sizígia e dias 4, 5, 7 e 11; enquanto o segundo é correlacionado positivamente com praia exposta, dias 1, 11 e 12, e maré de quadratura. Os dados biológicos foram correlacionados principalmente com o primeiro eixo $(0,765)$ (Tabela 3.4). Os eixos canônicos foram significativamente diferentes entre si após análise do teste de permutação de Monte Carlo (Traço=0,454; $\mathrm{F}=2,879 ; \mathrm{P}=0,0001$ ). A figura 3.8 representa a distribuição das espécies em relação às variáveis abióticas significativas, conforme a Análise de Correlação Canônica.

Numa análise descritiva das variáveis ambientais, mas estatisticamente não significativa, observa-se que a salinidade explicou sozinha 3,91\%, explicando mais a abundância da ictiofauna do que a temperatura. Entretanto, ao se retirar a influência do tempo e espaço, a porcentagem de explicação da salinidade diminui para $0,78 \%$.

Analisando-se somente a variação espacial, ou seja, as diferentes praias, obtêm-se uma porcentagem de explicação de 5,08 \% (soma de todos os autovalores canônicos $=0,052$ ). Retirando-se a influência das variáveis relacionadas ao tempo, a porcentagem de explicação aumenta para $6,75 \%$. Interpretando-se o gráfico de $T$ value, no qual são criados os círculos de Van Dobben, observa-se que T. goodei e Menticirrhus littoralis estão correlacionados à praia exposta, enquanto Mugil liza, Mugil 1, M. curema, Trachinotus falcatus, Oligoplites saliens, Anchoa tricolor, Harengula clupeola, Pomatomus saltatrix e as larvas de Engraulidae à praia abrigada (Figura 3.9).

A variação temporal explicou 29,52 \% (soma de todos os autovalores canônicos $=0,302$ ) da estruturação da comunidade estudada. Retirando-se a influência espacial em tal variação, a porcentagem de explicação cai ligeiramente para 29,23\%. Os dias em que os valores obtidos foram significativos correspondem aos dias em que ocorreram mudanças meteorológicas: no dia 23 de janeiro ocorreu a entrada de uma frente fria na região, e ventava muito; seguido pelo dia 25 , que estava chuvoso. Os dias 29 e 31 do mesmo mês estavam ensolarados depois de uma seqüência de dias chuvosos. Já no dia 4 de fevereiro, apesar de ensolarado, foi verificada uma queda brusca nos 
valores de salinidade devido às intensas chuvas no dia anterior. E para finalizar nos dias 12 e 14 de fevereiro entrou novamente uma frente fria, ocasionando a mudança de dias ensolarados para chuvosos.

Nas variações temporais monitoradas é possível notar duas influências, uma diária relacionada com as diferentes amplitudes de marés, e outra ao longo do mês amostrado, relacionada aos diferentes dias amostrados e seus descritores ambientais e meteorológicos. A variação nictemeral explicou sozinha apenas 2,64 \% da estruturação da comunidade ictíica, sendo que o efeito da variação ao longo dos dias de coleta explicou 27,66 \%. Correlacionada com as amostragens realizadas durante a maré alta está a espécie T. goodei, enquanto que com a baixa $H$. clupeola, A. tricolor e as larvas de Engraulidae, conforme ilustrado pela figura 3.10. Já analisando a influência das fases de sizígia e de quadratura na comunidade estudada, verificou que a mesma não se relaciona com nenhuma das espécies analisadas (Figura 3.11).

T. carolinus, mesmo sendo a espécie mais abundante, não apresentou relação clara com nenhuma das variáveis abióticas estudadas, posicionando-se próxima do centro do diagrama de ordenação (Figura 3.8)

Dos 63,73 \% não explicados pelas variáveis ambientais monitoradas, 30,26 \% é resíduo, ou seja, variação ao acaso, e 33,47 \% é padrão, o que significa que uma variação nos dados está relacionada com variáveis não monitoradas e/ou com variáveis não medidas completamente.

\section{DISCUSSÃO}

A tabela 3.5 apresenta uma compilação de resultados de trabalhos existentes na literatura, ilustrando que o planejamento da periodicidade de coleta de ictiofauna apresenta, em sua maioria, frequência mensal, ao longo de um ou mais anos. Poucos tiveram coletas sazonais ou sem padrão temporal distinto. Não foi encontrado nenhum trabalho que utilizasse um esforço amostral semelhante ao efetuado para o presente estudo, concentrando as coletas em um único mês do verão e com alta frequência. A exceção é o trabalho de Rodrigues et al. (2010), com coletas a cada quatro horas num período total de três dias. 
Ao se optar por este planejamento de coleta, acreditou-se que as variações de uma curta escala de tempo na fauna ictíica seriam melhor representadas, uma vez que os efeitos das variações sazonais seriam minimizados.

Por maior que tenha sido o aumento da frequência ou o esforço amostral, as principais características da estrutura e composição da comunidade da zona de surfe se mantiveram, como o predomínio de exemplares de pequeno porte, sem expressão macroscópica dos sexos, e um pequeno número de espécies dominantes e constantes (GIANNINI e PAIVA FILHO, 1995; SANTOS e NASH, 1995; GODEFROID et al., 2003; GODEFROID et al., 2004; VASCONCELLOS et al., 2007).

A exposição das praias influenciou a estrutura da comunidade estudada, de modo a que valores crescentes de riqueza, diversidade e abundância, e decrescentes de dominância, foram maiores em praias mais protegidas, de forma similar aos resultados observados por Paiva Filho e Toscano (1987), Romer (1990), Clark (1997), Gaelzer e Zalmon (2003), Godefroid (2003), Félix et al. (2007), e Vasconcellos et al. (2007).

A maior abundância e riqueza em praias mais protegidas podem estar relacionadas com uma maior disponibilidade de alimento (MCFARLAND, 1963; CLARK, 1990), ou com uma menor turbulência, permitindo que mais espécies ocupem a área onde ocorrem distúrbios físicos de menor intensidade (BEGON et al., 2006). Outro fator a ser considerado seria a própria efetividade da amostragem, pois a força das ondas na praia mais exposta dificultou os arrastos em muitas coletas.

O grau de exposição dos ambientes praiais é considerado um dos principais fatores estruturadores das comunidades de peixes da zona de surfe (ROMER, 1990; CLARK, 1996; GAELZER e ZALMON, 2003; VASCONCELLOS et al., 2007). No entanto, a influência da exposição da praia sobre a composição e estrutura da comunidade ictíica pode ser pouco compreendida, principalmente na sobreposição de efeitos nesta variável, como a abundância de macroalgas e/ou matéria orgânica em decomposição e transparência da água (CLARK, 1997; TEIXEIRA e ALMEIDA, 1998). No presente trabalho, o grau de exposição explicou apenas $5,08 \%$ da variação da ictiofauna na Ilha Comprida.

Assim como apontado por Stefanoni (2008), talvez a área de estudo não seja apropriada para testar a hipótese do grau de exposição sobre a comunidade de peixes, pois há interações com outras variáveis, principalmente relacionadas com a presença do 
estuário. As aqui consideradas praias abrigadas e intermediárias estão sob forte influência de águas estuarinas, enquanto as expostas sob maior influência marinha. $T$ goodei e $M$. littoralis se correlacionaram, no presente trabalho, com a praia exposta, sendo que a primeira espécie foi capturada em abundância na Ilha do Bom Abrigo, localizada externamente ao sistema costeiro Cananéia- Iguape (SAUL e CUNNINGHAM, 1995), enquanto a segunda é relatada em dados de desembarques pesqueiros realizados fora do estuário (MENDONÇA e KATSURAGAWA, 1997). As espécies que se correlacionaram com as praias mais abrigadas ocorrem em diversos pontos no interior do sistema estudado (ZANI-TEIXEIRA, 1983; MACIEL, 2001). Clark et al. (1996) demonstram que não se deve atribuir as variações na diversidade, abundância e dominância unicamente ao grau de exposição, mas sim considerar o conjunto de fatores que se interrelaciona em cada ambiente.

Um maior número de indivíduos e de espécies capturados durante a maré baixa foi também registrado em praias arenosas por Gibson et al. (1996), Godefroid et al. (1998), Suda et al. (2002), e Gaelzer e Zalmon (2008a), e em uma planície de maré por Godefroid et al. (2003). Tal fato provavelmente ocorra porque nos arrastos realizados durante a maré alta são amostradas aquelas espécies capazes de acompanhar o espraiamento em locais mais rasos ou que migraram para áreas mais rasas conforme a maré enche, como as espécies do gênero Trachinotus, que foram abundantemente capturadas tanto na maré baixa quanto na alta. Além disso, na maré baixa se concentram exemplares das espécies que usam a zona de espraiamento e também aquelas da região sempre submersa. Resultado diferente, de maior riqueza durante a maré alta, foi observado por Layman (2000) devido à presença de uma grande quantidade de espécimes classificados como adultos transitórios em busca de alimento. Segundo Brown e McLachlan (1990), a maré alta permite que peixes de maiores tamanhos ou adultos alcancem áreas mais rasas em busca de invertebrados da zona entre-marés. A maior abundância do gênero Trachinotus durante a maré alta foi anteriormente registrada por Layman (2000) e Godefroid et al. (2003). Os autores acreditam que indivíduos de tal gênero realizam a migração para a zona de espraiamento relacionada às marés, tanto para a busca de alimento, quanto para proteção. A variação nictemeral ao longo dos dias amostrados explicou sozinha apenas $1,86 \%$ da variação na ictiofauna. 
Comparando os resultados obtidos no presente capítulo (variações de curto prazo) com o capítulo 2 (variações de longo prazo), é possível notar uma semelhança no número de espécies obtidas, nas espécies que predominaram na comunidade e, principalmente, na estruturação da ictiofauna quando se analisam os resultados dos diferentes índices ecológicos nas diferentes praias e marés. Entretanto, ao se comparar a explicação das variáveis abióticas na estruturação da comunidade ictíica, notou-se que a temperatura é significativa apenas quando analisada em longo prazo, ressaltando a importância da sazonalidade, ou até mesmo do recrutamento, na estruturação da comunidade.

A porcentagem de explicação entre as diferentes praias foi maior quando analisados os dados obtidos das amostragens intensivas, realizadas com maior frequência em um curto período de tempo. Já as diferenças na porcentagem de explicação da maré baixa/alta na ictiofauna foram de menos de $1 \%$ ao analisar as diferentes escalas temporais, podendo-se inferir que para tal variável, a frequência amostral não alterará o resultado. Wilson e Sheaves (2001) observaram que a variação mensal e da maré de sizígia e quadratura (variações de longo prazo) tiveram maior influência na composição da ictiofauna do que as marés enchente e vazante (variação de curto prazo). Lasiak (1984a) observou um número estável de espécies tanto no período de curto quanto de longo prazo, sendo que o número de indivíduos foi maior nas amostragens de curto prazo e, a diversidade variou mais nas de longo prazo. Poucos trabalhos comparam a estruturação da ictiofauna em diferentes escalas temporais, evidenciando que é preciso dar mais atenção para as variações de curto prazo, negligenciadas na maioria dos trabalhos.

Além das variáveis abióticas avaliadas no presente estudo, alguns autores apontam outras variáveis como as responsáveis pela variação dos dados biológicos, por exemplo: transparência da água (PESSANHA e ARAÚJO, 2003), velocidade do vento (LIMA e VIEIRA, 2009), abundância de macrófitas (GOMES et al., 2003) e de macroalgas (TEIXEIRA e ALMEIDA, 1998; GAELZER e ZALMON, 2003).

A alta porcentagem do valor não explicado pelas variáveis ambientais monitoradas no presente estudo indica a necessidade de se efetuar estudos mensurando e avaliando um maior número de variáveis abióticas, em diferentes escalas temporais, 
para que se possam fornecer mais subsídios ao entendimento da comunidade ictíica em ambientes dinâmicos como zona rasa de ambientes praiais. 
Tabela 3.1. Abundância (\%), constância de ocorrência (C), comprimento total máximo (Max CT) e mínimo (min CT) medido e o máximo obtido na literatura, em milímetros, de cada espécie amostrada na Ilha Comprida entre 23 de janeiro de 2009 e 18 de fevereiro de 2009.*fase larval; ** Froese, R.; Pauly, D. Ed. 2010. Fish Base. World Wide Web electronic publication. www.fishbase.org, versão (09/2010).

\begin{tabular}{|c|c|c|c|c|c|}
\hline Família/ espécie & $\%$ & $\mathbf{C}$ & $\begin{array}{c}\text { Mín CT } \\
\text { (mm) }\end{array}$ & $\begin{array}{c}\text { Máx CT } \\
\text { (mm) }\end{array}$ & $\begin{array}{c}\text { Máx CT } \\
\text { Bibliografia*** }\end{array}$ \\
\hline \multicolumn{6}{|l|}{ Elopidae } \\
\hline Elops saurus* & 3,61 & 19,05 & 19 & 42 & 900 \\
\hline \multicolumn{6}{|l|}{ Engraulidae } \\
\hline Anchoa lyolepis & 0,04 & 1,19 & 36 & 47 & 83 \\
\hline Anchoa tricolor & 1,70 & 5,95 & 33 & 71 & 100 \\
\hline Anchoviella lepidentostole & 0,40 & 2,38 & 40 & 67 & 130 \\
\hline Larva de Engraulidae* & 3,84 & 9,52 & 19 & 34 & - \\
\hline Lycengraulis grossidens & 0,04 & 1,19 & 42 & 53 & 270 \\
\hline \multicolumn{6}{|l|}{ Clupeidae } \\
\hline Opisthonema oglinum & 0,15 & 1,19 & 72 & 95 & 300 \\
\hline Harengula clupeola & 0,23 & 2,38 & 72 & 95 & 170 \\
\hline \multicolumn{6}{|l|}{ Atherinopsidae } \\
\hline Atherinella brasiliensis & 0,13 & 3,57 & 32 & 59 & 150 \\
\hline \multicolumn{6}{|l|}{ Belonidae } \\
\hline Strongylura timиси & 0,15 & 3,57 & 26 & 86 & 610 \\
\hline \multicolumn{6}{|l|}{ Blenniidae } \\
\hline Parablennius pilicornis & 0,02 & 1,19 & 19 & 19 & 150 \\
\hline \multicolumn{6}{|l|}{ Synodontidae } \\
\hline Synodus foetens & 0,02 & 1,19 & 47 & 47 & 365 \\
\hline \multicolumn{6}{|l|}{ Mugilidae } \\
\hline Mugil curema & 17,05 & 66,67 & 17 & 60 & 450 \\
\hline Mugil hospes & 13,76 & 46,43 & 19 & 45 & 200 \\
\hline Mugil liza & 0,32 & 4,76 & 22 & 75 & 1000 \\
\hline Mugil 1 & 0,49 & 11,90 & 22 & 42 & - \\
\hline \multicolumn{6}{|l|}{ Syngnathidae } \\
\hline Syngnathus folletti & 0,02 & 1,19 & 93 & 93 & 200 \\
\hline Syngnathus sp. & 0,02 & 1,19 & 92 & 92 & - \\
\hline \multicolumn{6}{|l|}{ Serranidae } \\
\hline Mycteroperca sp. & 0,02 & 1,19 & 22 & 22 & - \\
\hline \multicolumn{6}{|l|}{ Pomatomidae } \\
\hline Pomatomus saltatrix & 0,45 & 4,76 & 75 & 106 & 1000 \\
\hline
\end{tabular}


Tabela 3.1. continuação

\begin{tabular}{|c|c|c|c|c|c|}
\hline Família/ espécie & $\%$ & $\mathbf{C}$ & $\begin{array}{c}\text { Mín CT } \\
\text { (mm) }\end{array}$ & $\begin{array}{c}\text { Máx CT } \\
(\mathbf{m m})\end{array}$ & $\begin{array}{c}\text { Máx CT } \\
\text { Bibliografia }^{* * *}\end{array}$ \\
\hline \multicolumn{6}{|l|}{ Carangidae } \\
\hline Caranx latus & 0,15 & 2,38 & 44 & 59 & 800 \\
\hline Chloroscombrus chrysurus & 0,30 & 3,57 & 10 & 39 & 300 \\
\hline Oligoplites saliens & 0,79 & 14,29 & 10 & 112 & 500 \\
\hline Oligoplites sp. & 0,04 & 2,38 & 14 & 15 & - \\
\hline Trachinotus carolinus & 27,59 & 96,43 & 12 & 101 & 460 \\
\hline Trachinotus falcatus & 0,45 & 19,05 & 13 & 61 & 1200 \\
\hline Trachinotus goodie & 22,17 & 96,43 & 16 & 112 & 500 \\
\hline \multicolumn{6}{|l|}{ Lobotidae } \\
\hline Lobotes surinamensis & 0,02 & 1,19 & 38 & 38 & 730 \\
\hline \multicolumn{6}{|l|}{ Gerreidae } \\
\hline Larva de Gerreidae* & 5,03 & 11,90 & 10 & 20 & - \\
\hline \multicolumn{6}{|l|}{ Sciaenidae } \\
\hline Menticirrhus americanus* & 0,15 & 2,38 & 9 & 13 & 465 \\
\hline Menticirrhus littoralis & 0,45 & 13,10 & 19 & 60 & 450 \\
\hline Micropogonias furnieri* & 0,11 & 1,19 & 13 & 20 & 515 \\
\hline Ophioscion punctatissimus & 0,11 & 2,38 & 8 & 52 & 225 \\
\hline Umbrina coroides & 0,13 & 1,19 & 40 & 52 & 210 \\
\hline \multicolumn{6}{|l|}{ Pomacentridae } \\
\hline Abudefduf saxatilis & 0,02 & 1,19 & 27 & 27 & 200 \\
\hline \multicolumn{6}{|l|}{ Monacanthidae } \\
\hline Stephanolepis hispidus & 0,02 & 1,19 & 28 & 28 & 275 \\
\hline \multicolumn{6}{|l|}{ Diodontidae } \\
\hline Chilomycterus spinosus & 0,02 & 1,19 & 19 & 19 & 250 \\
\hline
\end{tabular}

Tabela 3.2. Índices descritores de comunidade durante o verão de 2009 nas diferentes praias amostradas da Ilha Comprida, e valor do teste de BOOTSTRAP (Boot P) com 95 $\%$ de confiança. Abr.=praia abrigada; Exp.= praia exposta; Interm.= praia intermediária. $*=$ diferenças significativas.

\begin{tabular}{|c|c|c|c|c|c|c|}
\hline \multirow[b]{2}{*}{ Índice } & \multicolumn{3}{|c|}{ Praia } & \multicolumn{3}{|c|}{$\underline{\text { Boot } \mathbf{P}}$} \\
\hline & Abrigada & Intermediária & Exposta & Abr. x Interm. & Abr. x Exp. & Interm. x Exp. \\
\hline N॰ de espécies & 31 & 26 & 13 & 0,26 & $0 *$ & $0 *$ \\
\hline No de indivíduos & 2451 & 1446 & 812 & $0^{*}$ & $0^{*}$ & $0^{*}$ \\
\hline Dominância_D & 0,17 & 0,20 & 0,34 & $0^{*}$ & $0^{*}$ & $0^{*}$ \\
\hline Diversidade de Shannon & 2,06 & 1,92 & 1,35 & $0^{*}$ & $0^{*}$ & $0^{*}$ \\
\hline Riqueza de Margalef & 3,84 & 3,44 & 1,79 & 0,25 & $0^{*}$ & $0^{*}$ \\
\hline Equitatividade de Pielou & 0,60 & 0,59 & 0,53 & 0,68 & $0,01^{*}$ & $0,03^{*}$ \\
\hline
\end{tabular}


Tabela 3.3. Índices descritores de comunidade durante o verão de 2009 na maré baixa e alta da Ilha Comprida, e valor do teste de BOOTSTRAP (Boot P) com 95\% de confiança. $*$ = diferenças significativas.

\begin{tabular}{lccc}
\hline \multicolumn{1}{c}{ Índice } & \multicolumn{2}{c}{ Maré } \\
\cline { 3 - 4 } & Alta & Baixa & Boot. P \\
\hline No de espécies & 18 & 35 & $0^{*}$ \\
No de indivíduos & 1752 & 2957 & $0 *$ \\
Dominância_D & 0,25 & 0,16 & $0 *$ \\
Diversidade de Shannon & 1,61 & 2,16 & $0 *$ \\
Riqueza de Margalef & 2,28 & 4,25 & $0 *$ \\
Equitatividade de Pielou & 0,56 & 0,61 & $0,02^{*}$ \\
\hline
\end{tabular}

Tabela 3.4. Sumário da Análise de Correspondência Canônica (CCA) sobre a abundância de espécies de peixes amostrados na Ilha Comprida durante o verão de 2009.

\begin{tabular}{lcccc}
\hline \multirow{2}{*}{\multicolumn{1}{c}{ Correlação das variáveis }} & \multicolumn{4}{c}{ Eixos } \\
\cline { 2 - 5 } significativas com os eixos & 1 & 2 & 3 & 4 \\
\hline Maré alta & $-0,3186$ & 0,0002 & $-0,1589$ & $-0,0992$ \\
Maré baixa & 0,3186 & $-0,0002$ & 0,1589 & 0,0992 \\
Praia Abrigada & 0,3687 & $-0,1917$ & 0,0702 & $-0,2355$ \\
Praia Intermediária & $-0,0195$ & 0,0668 & 0,0052 & $-0,0388$ \\
Praia Exposta & $-0,3909$ & 0,1423 & $-0,084$ & 0,3047 \\
Dia 1 & $-0,2039$ & 0,1409 & $-0,0899$ & 0,12 \\
Dia 2 & $-0,0035$ & $-0,1636$ & $-0,1571$ & $-0,0288$ \\
Dia 4 & 0,1281 & 0,099 & $-0,4262$ & $-0,0222$ \\
Dia 5 & 0,4743 & 0,1527 & 0,036 & 0,3613 \\
Dia 7 & 0,0409 & $-0,3753$ & 0,0864 & 0,1316 \\
Dia 11 & 0,1258 & 0,2497 & $-0,1312$ & $-0,2816$ \\
Dia 12 & $-0,0159$ & 0,3336 & 0,4511 & $-0,0795$ \\
Quadratura & $-0,3487$ & $-0,4539$ & 0,1155 & 0,0719 \\
Sizígia & 0,3487 & 0,4539 & $-0,1155$ & $-0,0719$ \\
\hline Resumo estatístico & & & & \\
Autovalores & 0,124 & 0,074 & 0,058 & 0,038 \\
Correlação espécie-ambiente & 0,765 & 0,664 & 0,687 & 0,602 \\
Porcentagem de variância acumulada: & & & & \\
nos dados de espécies & 12,1 & 19,3 & 25 & 28,7 \\
na relação espécie ambiente & 33,4 & 53,2 & 68,7 & 79 \\
Soma de todos autovalores naturais & & & & \\
Soma de todos autovalores canônicos & & & & 1,023 \\
\hline
\end{tabular}


Tabela 3.5. Estudos selecionados sobre a ictiofauna da zona de surfe de praias arenosas amostrados com diferentes esforços em diversos locais e por diferentes tipos de arrasto de praia.

\begin{tabular}{|c|c|c|c|c|}
\hline Localidade/local & $\begin{array}{c}\mathbf{N}^{\circ} \text { de } \\
\text { espécies }\end{array}$ & $\begin{array}{c}\text { Total } \\
\text { amostrado }\end{array}$ & Esforço amostral & Fonte \\
\hline \multicolumn{5}{|l|}{ África do Sul } \\
\hline Costa do Cabo & 20 & 40306 & Mensal - 13 meses & Bennett, 1989 \\
\hline Eerste Estuary & 13 & 30335 & Ago, Nov 1991; Jan, Mai,1992 & Clark et al., 1994 \\
\hline Zandlev Estuary & 15 & 41402 & Ago, Nov 1991; Jan, Mai,1992 & Clark et al., 1994 \\
\hline False Bay & 45 & 68610 & Mensal - 2 anos & Clark et al., 1996a \\
\hline False Bay & 45 & 68610 & Mensal - 2 anos & Clark et al., 1996b \\
\hline Saldanha Bay & 24 & 25676 & 4 dias em Abril, 1994 & Clark,1997 \\
\hline St Lucia Estuary Month & 47 & 2931 & Mensal - 1 ano & Harris e Cyrus, 1996 \\
\hline King's Beach & 50 & 3970 & Mensal - 2 anos & Lasiak, 1984a \\
\hline King's Beach & 36 & 4071 & Jan e Ago 1979 & Lasiak, 1984b \\
\hline Algoa Bay & 59 & & Compilação de dados & Romer, 1990 \\
\hline 2 Estuários & 28 & 2739 & Verão - 2 dias em cada mês & Strydom,2003 \\
\hline \multicolumn{5}{|l|}{ Brasil } \\
\hline Maceió, AL & 63 & 4449 & $\begin{array}{c}\text { Mensal - } 1 \text { ano } \\
\text { Abr, Nov 2003; Mar, Ago }\end{array}$ & Teixeira e Almeida, 1998 \\
\hline Itamaracá, PE & 25 & 417 & 2004 & Lira e Teixeira, 2008 \\
\hline Baía de todos os Santos,BA & 75 & 1100 & Mensal - 1 ano & Oliveira-Silva, et al., 2008 \\
\hline Ilha do Frade, ES & 45 & 2689 & Mensal - 1 ano & Araújo et al., 2008 \\
\hline Arraial do Cabo, RJ & 41 & 12636 & Mensal- 1 ano & Gaelzer e Zalmon, 2003 \\
\hline Arraial do Cabo, RJ & 60 & 26357 & Mensal - 1 ano & Gaelzer e Zalmon, 2008a \\
\hline Arraial do Cabo, RJ & 52 & 8751 & $\begin{array}{c}\text { Mensal - } 1 \text { ano } \\
\text { Ago,Nov, } 1998 \text { e Fev, Jun, }\end{array}$ & Gaelzer e Zalmon, 2008b \\
\hline Baia de Sepetiba, RJ & 55 & 48768 & 1999 & Pessanha e Araújo,2003 \\
\hline Rio de Janeiro, RJ & 68 & 4562 & Mensal - 1 ano & Gomes et al.,2003 \\
\hline Rio de Janeiro, RJ & 38 & 6464 & Trimestral - 1 ano & Vasconcellos et al., 2007 \\
\hline Guarujá e São Vicente, SP & 42 & 5723 & Mensal - 1 ano & $\begin{array}{c}\text { Paiva Filho e Toscano,1987 } \\
\text { Giannini e Paiva Filho, }\end{array}$ \\
\hline São Paulo - várias praias & 99 & 54384 & Compilação de dados & 1995 \\
\hline Ilha do Bom Abrigo, SP & 53 & 1035 & Sazonal - 1 ano & Saul e Cunningham, 1995 \\
\hline Paranaguá, PR & 70 & 14516 & Bimestral - 1 ano & Godefroid et al. 1998 \\
\hline Paranaguá, PR & 110 & 47012 & Mensal - 1 ano & Godefroid et al., 2003a \\
\hline Balneário de Atami,PR & 72 & 9446 & Mensal - 1 ano & Godefroid et al., 2003b \\
\hline Balneário de Atami, PR & 70 & 7553 & Mensal - 1 ano & Godefroid et al., 2004 \\
\hline Praias estuarinas, $\mathrm{PR}$ & 43 & 5740 & Mensal - 1 ano & Félix et al.,2006 \\
\hline Paranaguá, PR & 63 & 26866 & Mensal - 1 ano & Félix et al., 2007 \\
\hline Praia do Cassino, RS & 37 & 10066 & Mensal - 1 ano & Lima e Vieira, 2009 \\
\hline Praia do Cassino, RS & 28 & 26725 & Sazonal - 1 ano & Rodrigues et al., 2010 \\
\hline \multicolumn{5}{|l|}{ Colômbia } \\
\hline \multirow{2}{*}{\multicolumn{5}{|c|}{ Emirados Árabes }} \\
\hline & & & & \\
\hline Kuwait Bay & 37 & 6809 & Primavera-Verão, 1989 & Abou-Seedo et al.,1990 \\
\hline \multicolumn{5}{|l|}{ Escócia } \\
\hline \multicolumn{5}{|l|}{ EUA } \\
\hline Virginia Island & 12 & 4607 & Mensal - 1 ano & Layman, 2000 \\
\hline New Jersey & 57 & 292868 & 2 semanas Verão/Outono -anos & Wilber et al.,2003 \\
\hline
\end{tabular}


Tabela 3.5. continuação

\begin{tabular}{|c|c|c|c|c|}
\hline Localidade/local & $\begin{array}{c}\mathrm{N}^{\circ} \text { de } \\
\text { espécies }\end{array}$ & $\begin{array}{c}\text { Total } \\
\text { amostrado }\end{array}$ & Esforço amostral & Fonte \\
\hline Ilhas Maurício & 112 & 9429 & Ago 2001 a Mar 2003 & Sato et al., 2008 \\
\hline \multicolumn{5}{|l|}{ Japão } \\
\hline Sanrimatsubara & 32 & 734 & Mai, Ago e Nov - 2 anos & Inoue et al., 2008 \\
\hline Doigahama & 101 & 17608 & Mensal- 5 anos & Suda et al.,2002 \\
\hline \multicolumn{5}{|l|}{ México } \\
\hline Golfo do México & 76 & 154469 & entre 1975 e 1977 sem padrão & Modde, 1980 \\
\hline \multicolumn{5}{|l|}{ Portugal } \\
\hline Açores & 24 & 39350 & Mensal - 1 ano & Santos e Nash, 1995 \\
\hline
\end{tabular}




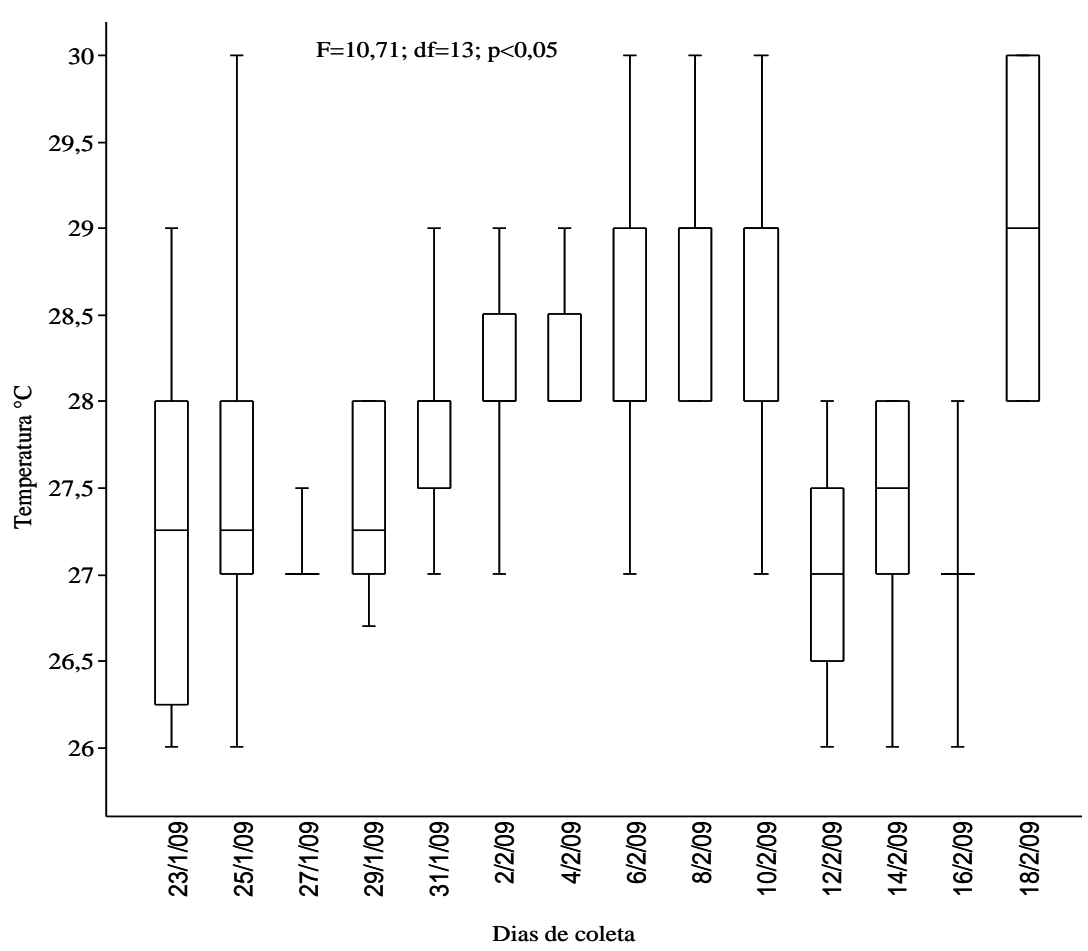

Figura 3.1. Variações de temperatura média medida na zona de surfe de praias arenosas da Ilha Comprida de 23 de janeiro de 2009 a 18 de fevereiro de 2009 (linhas horizontais representam as médias, os retângulos o desvio padrão e $I$ o erro padrão). df= graus de liberdade. 


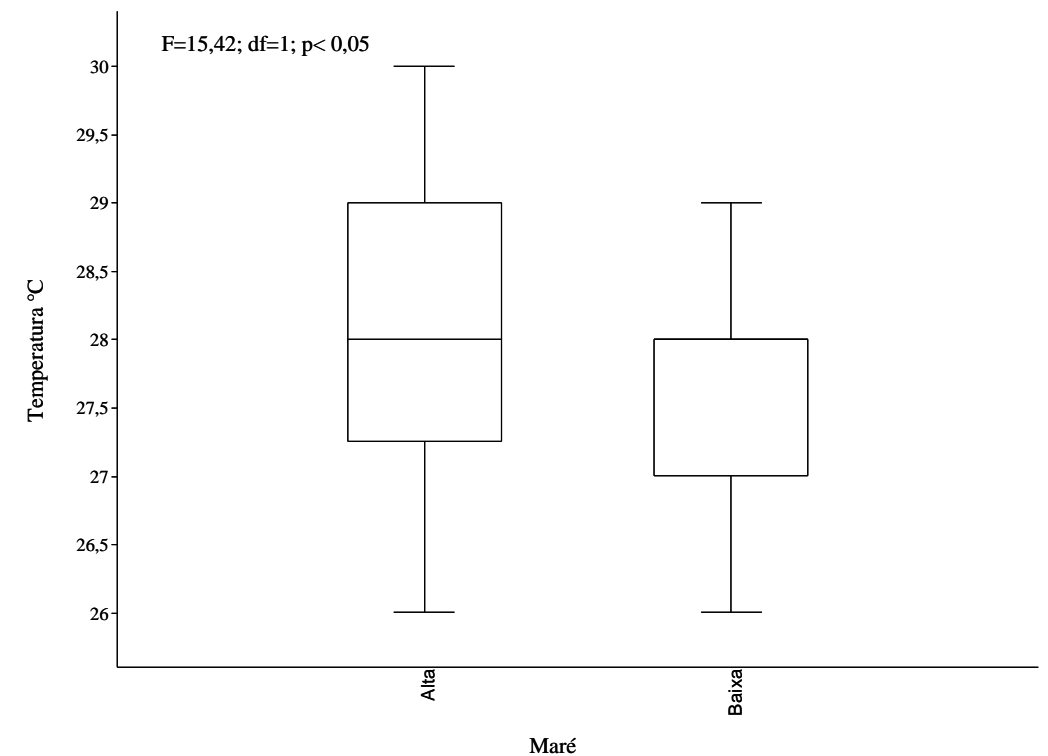

Figura 3.2. Variações de temperatura média medida durante a maré alta e baixa na zona de surfe de praias arenosas da Ilha Comprida de 23 de janeiro de 2009 a 18 de fevereiro de 2009 (linhas horizontais representam as médias, os retângulos o desvio padrão e I o erro padrão). $\mathrm{df}=$ graus de liberdade.

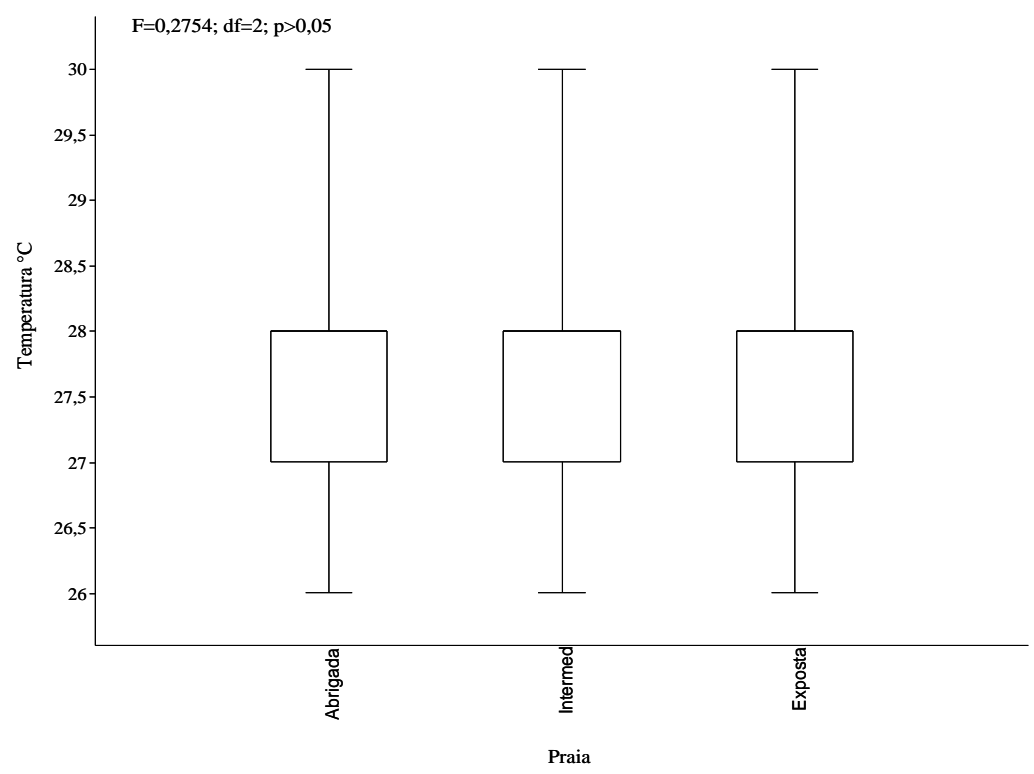

Figura 3.3. Variações de temperatura média medida na zona de surfe de diferentes praias da Ilha Comprida entre 23 de janeiro de 2009 e 18 de fevereiro de 2009 (linhas horizontais representam as médias, os retângulos o desvio padrão e I o erro padrão) (Intermed=Intermediária). df=graus de liberdade. 


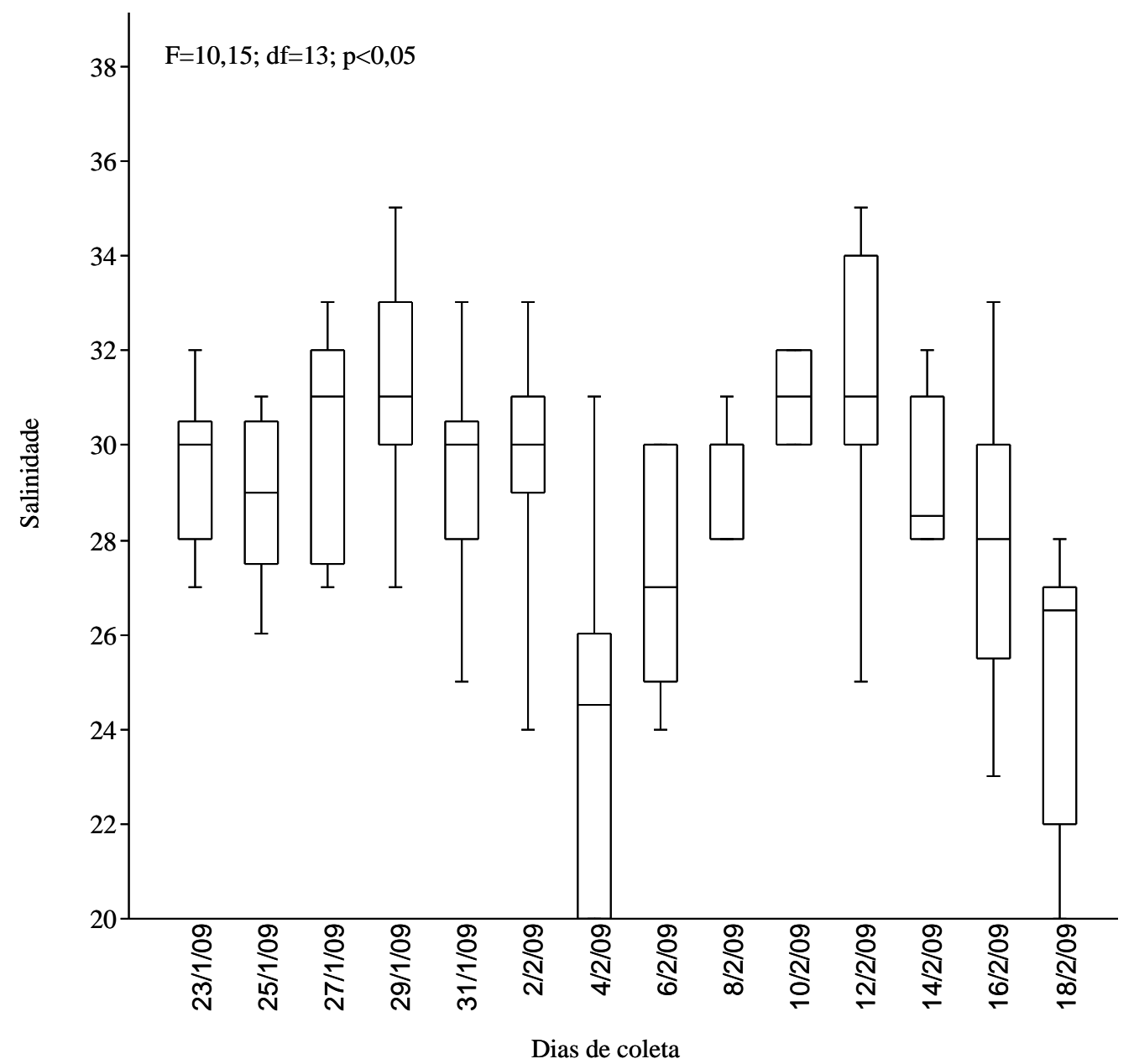

Figura 3.4. Variações de salinidade média medida na zona de surfe de praias arenosas da Ilha Comprida de 23 de janeiro de 2009 a 18 de fevereiro de 2009 (linhas horizontais representam as médias, os retângulos o desvio padrão e $I$ o erro padrão). df=graus de liberdade. 


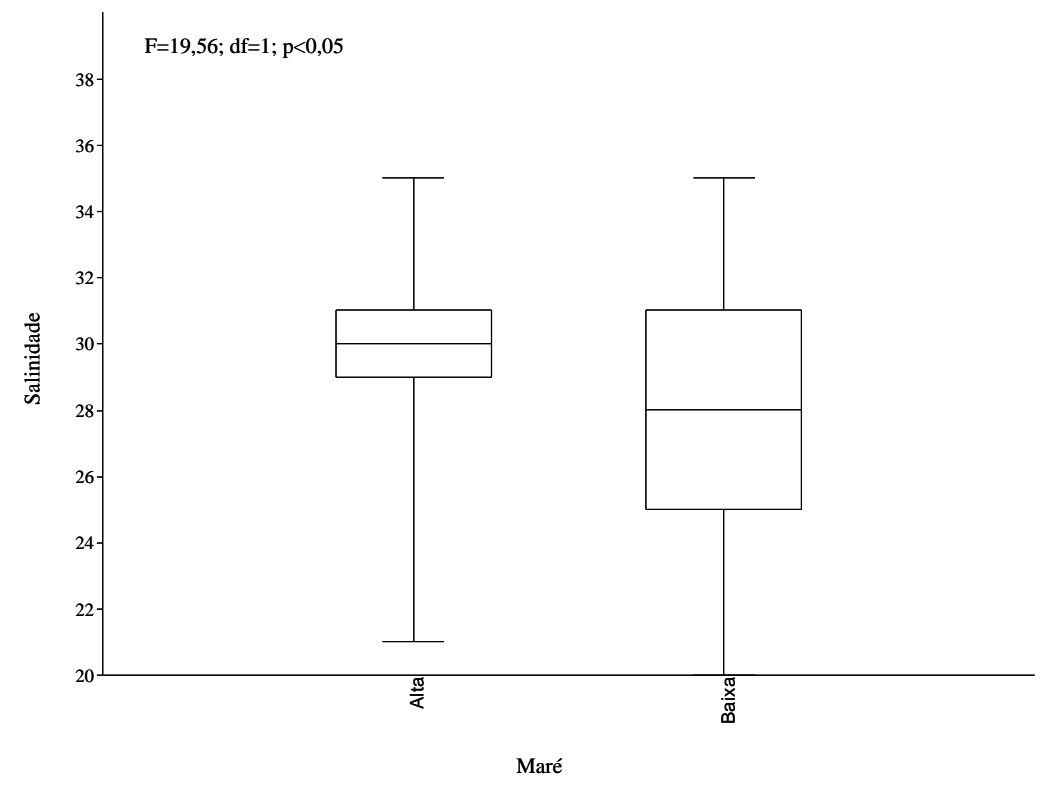

Figura 3.5. Variações de salinidade média medida durante a maré alta e baixa na zona de surfe de praias arenosas da Ilha Comprida de 23 de janeiro de 2009 a 18 de fevereiro de 2009 (linhas horizontais representam as médias, os retângulos o desvio padrão e I o erro padrão). $\mathrm{df}=$ graus de liberdade.

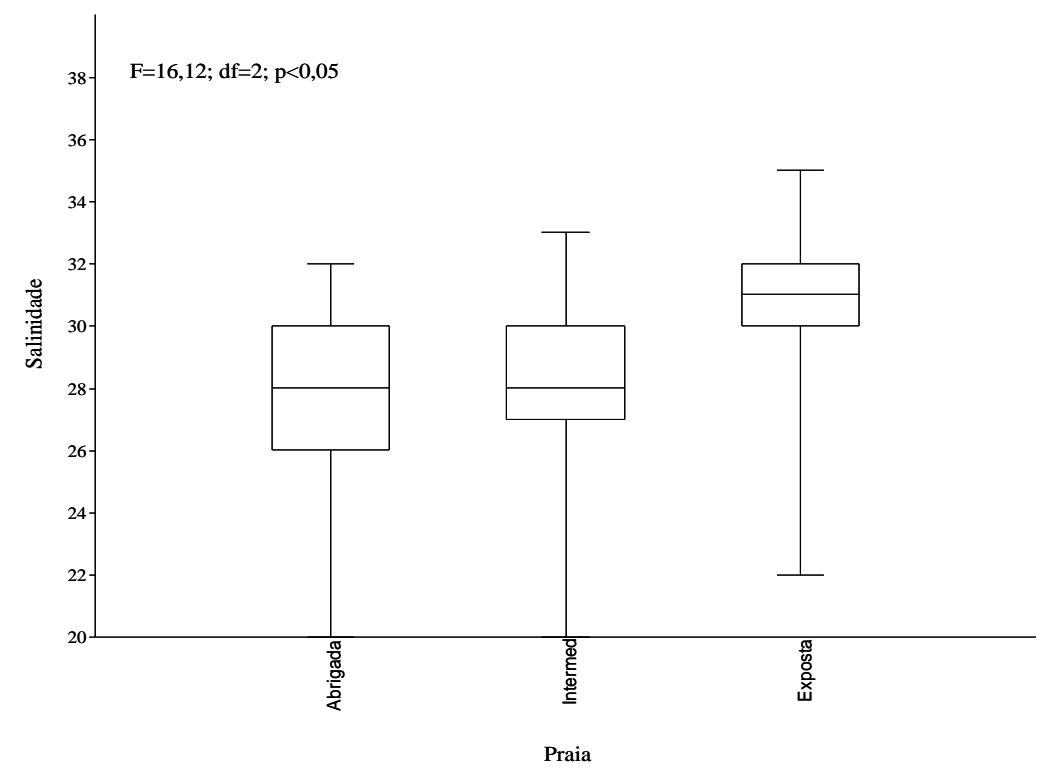

Figura 3.6. Variações de salinidade média medida na zona de surfe de diferentes praias da Ilha Comprida entre 23 de janeiro de 2009 e 18 de fevereiro de 2009 (linhas horizontais representam as médias, os retângulos o desvio padrão e I o erro padrão) (Intermed= Intermediária). $\mathrm{df}=$ graus de liberdade. 


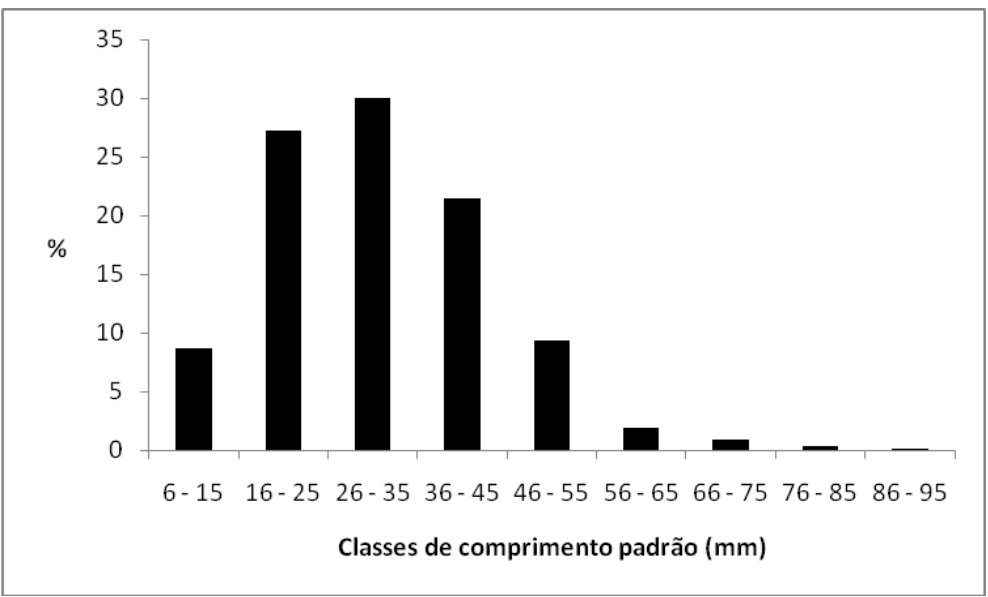

Figura 3.7. Classes de comprimento padrão, em milímetros, de todos os exemplares amostrados na zona de surfe de praias da Ilha Comprida entre 23 de janeiro de 2009 e 18 de fevereiro de $2009(\mathrm{~N}=4571)$.

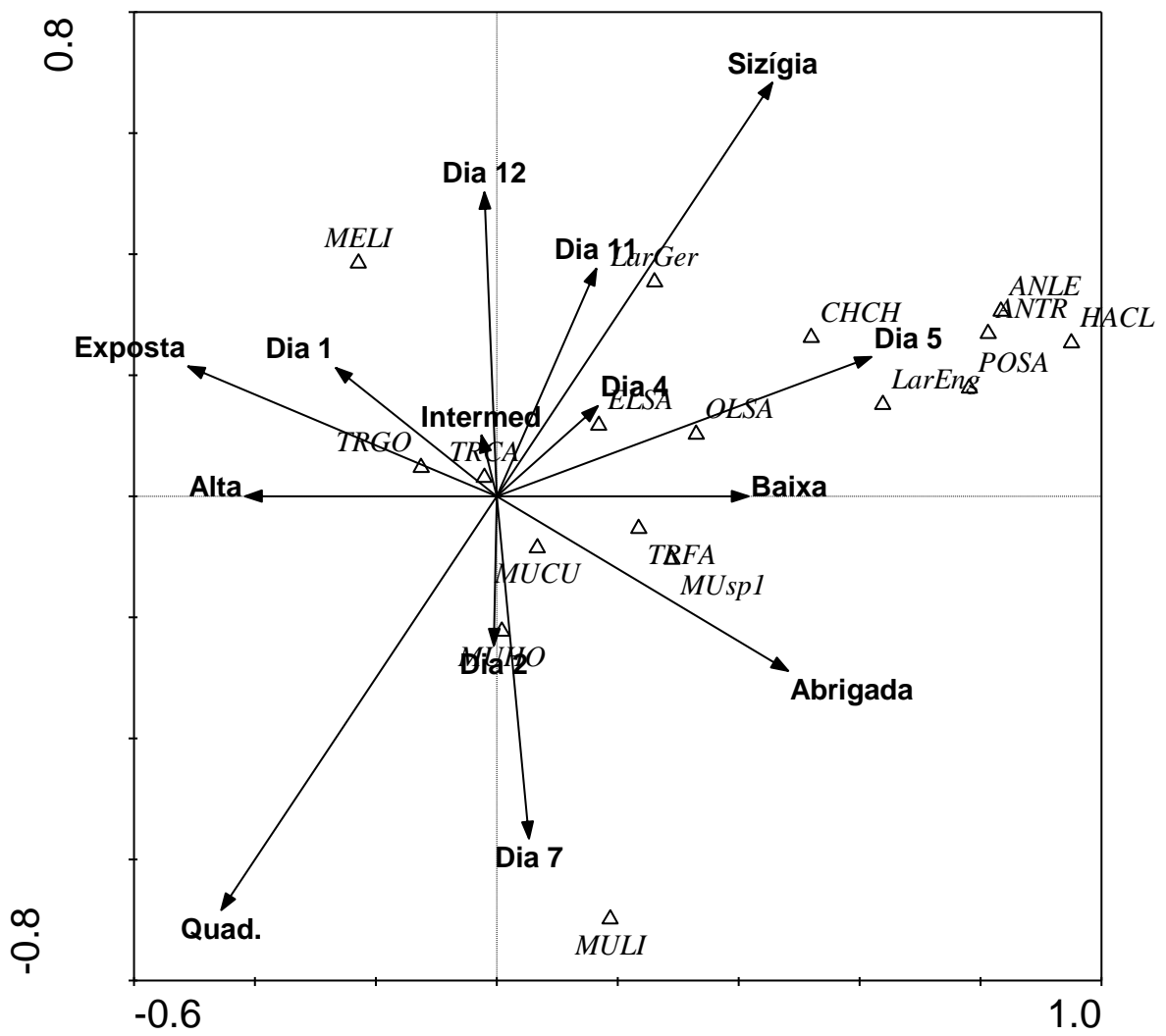

Figura 3.8. Diagrama de ordenação da Análise de Correspondência Canônica incluindo as espécies amostradas durante o verão de 2009 na Ilha Comprida e as variáveis abióticas significativas, representadas por vetores. $\mathrm{O}$ nome das espécies está codificado pelas duas primeiras letras do gênero e do epíteto específico (exemplo: TRCA= Trachinotus carolinus). 


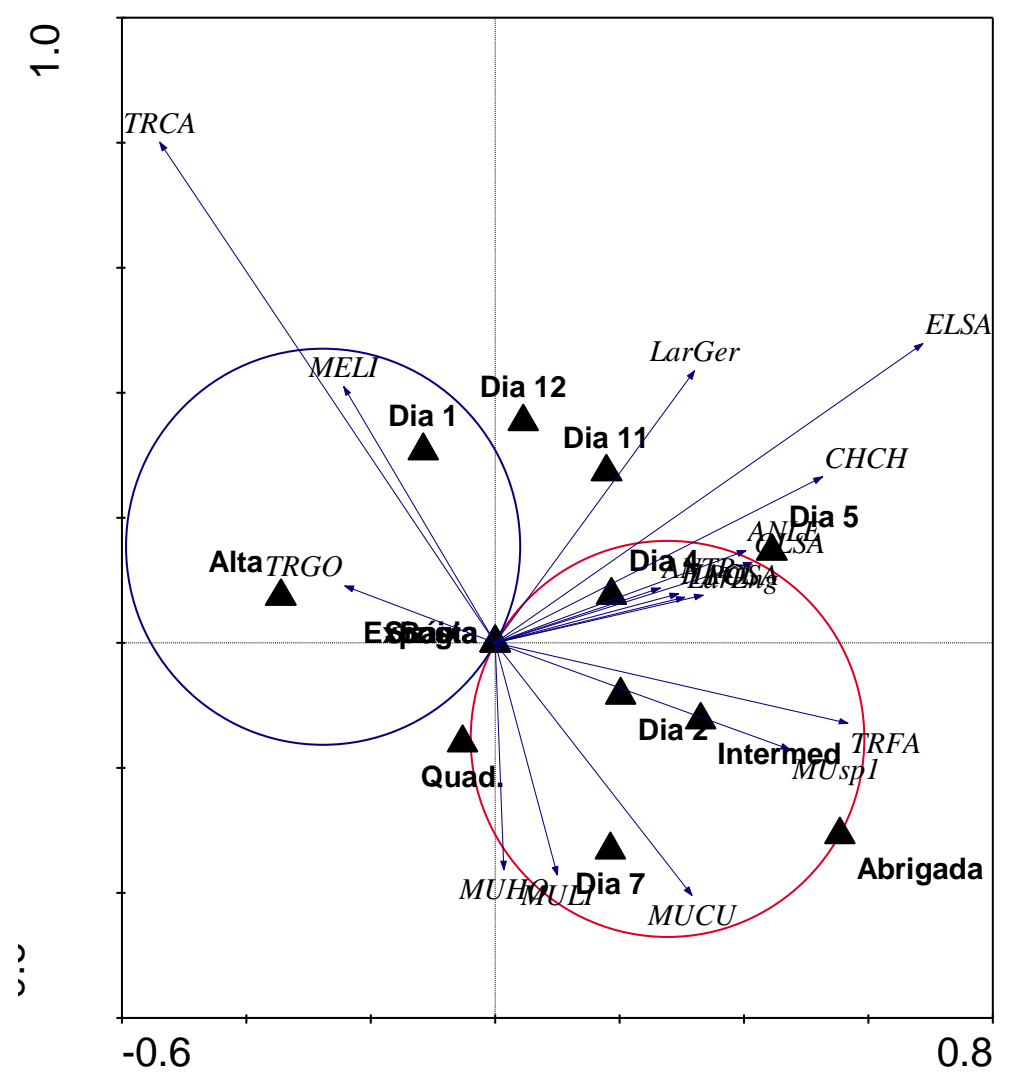

Figura 3.9. Valores de $T$ value com o círculo de Van Dobben em vermelho representando a praia abrigada e o em azul a praia exposta. As espécies que estão com seus vetores representados dentro do círculo correlacionam-se com o mesmo. O nome das espécies está codificado pelas duas primeiras letras do gênero e do epíteto específico (exemplo: TRCA= Trachinotus carolinus). 


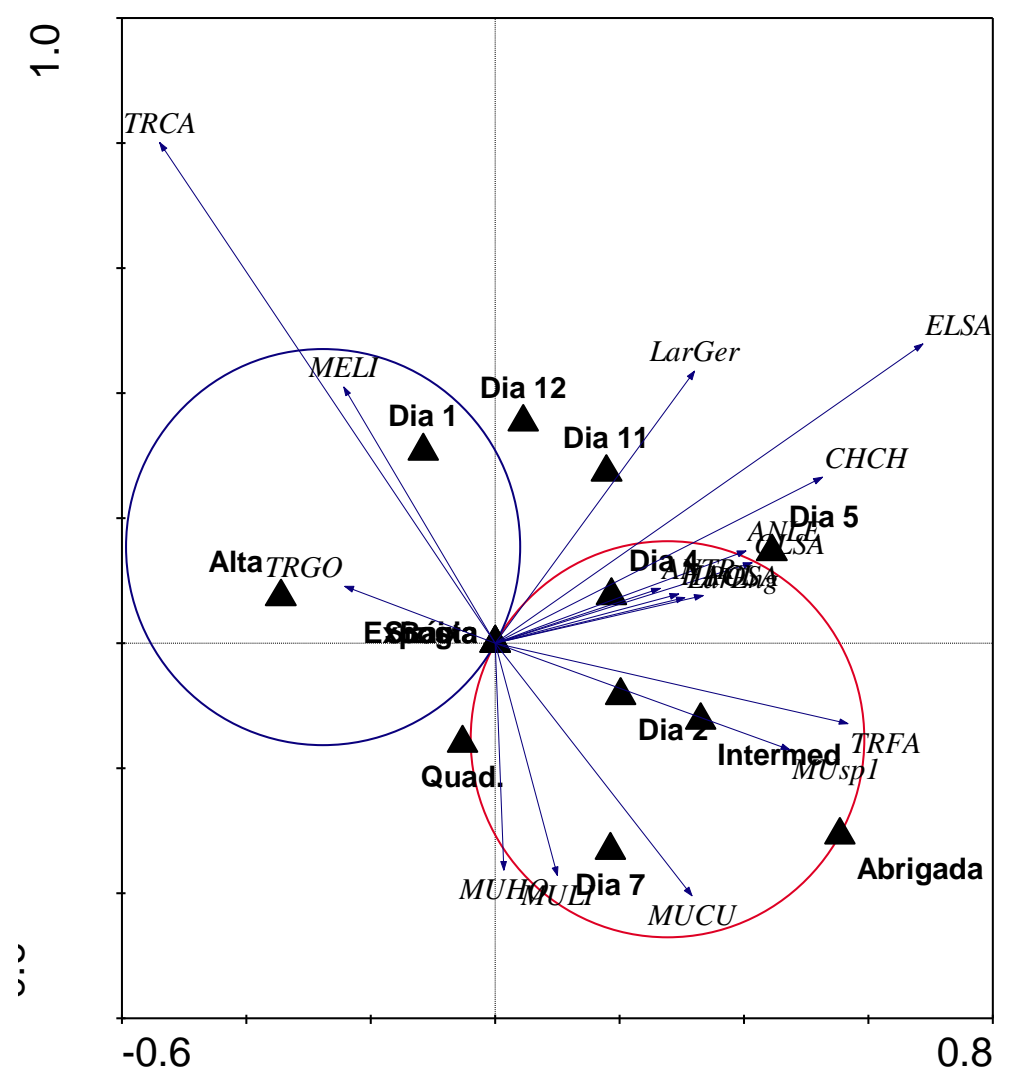

Figura 3.10. Valores de $T$ value com o círculo de Van Dobben em vermelho representando a maré alta e o em azul a maré baixa. As espécies que estão com seus vetores representados dentro do círculo correlacionam-se com o mesmo. $\mathrm{O}$ nome das espécies está codificado pelas duas primeiras letras do gênero e da espíteto específico (exemplo: TRCA= Trachinotus carolinus). 


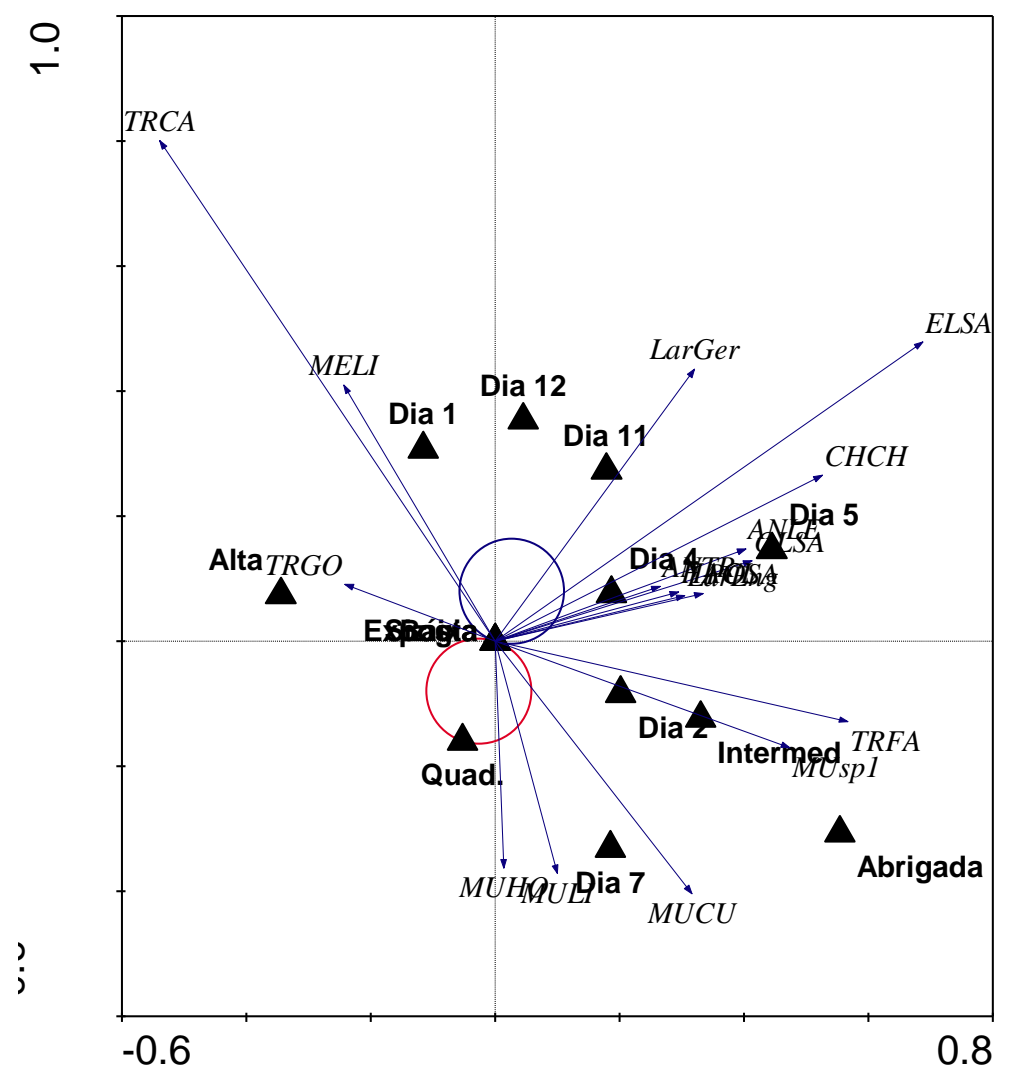

Figura 3.11. Valores de $T$ value com o círculo de Van Dobben em vermelho representando as fases de quadratura e o em azul a de sizígia. As espécies que estão com seus vetores representados dentro do círculo correlacionam-se com o mesmo. $\mathrm{O}$ nome das espécies está codificado pelas duas primeiras letras do gênero e do epíteto específico (exemplo: TRCA= Trachinotus carolinus). 


\title{
Capítulo 4. RECRUTAMENTO DA ICTIOFAUNA EM ÁREAS RASAS DE PRAIAS
} ARENOSAS DA BARRA SUL DO SISTEMA COSTEIRO CANANÉIA-IGUAPE

\author{
INTRODUÇÃO
}

A sobrevivência das fases iniciais do ciclo de vida está relacionada ao sucesso do recrutamento de indivíduos ao estoque adulto, que por sua vez está relacionado ao tamanho das populações. O conhecimento dos possíveis fatores ambientais e das ações antrópicas que afetam a sobrevivência dos peixes, principalmente nas fases iniciais do desenvolvimento, é importante para a administração pesqueira, gerenciamento costeiro e preservação da espécie.

Incluindo os peixes, os organismos que vivem na zona entre-marés estão sujeitos a flutuações que incluem as de temperatura, turbulência e propriedades químicas, entre outras, em diferentes escalas temporais (SELLESLAGH e AMARA, 2008).

A zona de surfe das praias arenosas pode ser considerada uma importante área de crescimento e alimentação para muitas espécies de peixes (MCLACHLAN et al., 1981). Os juvenis são recrutados, porque tais áreas proporcionam disponibilidade de alimento e proteção contra predadores (LASIAK, 1981). Apesar da produção primária "in situ" ser pouco significativa nas praias arenosas, o efeito das marés distribui os nutrientes e minerais através da comunidade (CARTER, 1988). Além disso, as praias adjacentes a estuários constituem rotas de migração de diversos peixes em fase larval e juvenil, que passam uma ou mais fases de seu ciclo de vida dentro dos estuários (COWLEY et al., 2001; WATT- PRINGLE e STRYDOM, 2003).

Uma compilação recente de dados sobre a ictiofauna do sistema costeiro Cananéia-Iguape apontou que tal região abriga pelo menos 169 espécies de peixes, sendo 163 Actinopterygii e seis Chondrichthyes inseridos em 58 e quatro diferentes famílias, respectivamente (CONTENTE et al., 2010a). Dentre estas, $94 \%$ são tipicamente marinhas e/ou estuarinas e se distribuem ao longo de todo o sistema (CONTENTE et al., 2010a). Este sistema estuarino, por suas características hidrográficas, foi classificado por Bérgamo (2000) e Bernardes e Miranda (2001), segundo classificação de Hansen e Rattray, como parcialmente misturado (Tipo 2). Bérgamo (2000) também sugere que as trocas entre a drenagem continental e as águas 
da região costeira adjacente são mais efetivas pelo canal do Mar de Cananéia. Tal fato não contribui para a ocorrência de espécies de águas interiores.

A área possui uma relevante importância para inúmeras espécies de peixes. Para Cathorops spixii, Stellifer rastrifer, Antherinella brasiliensis, Anchoviella lepidentostole e Achirus lineatus, é um ambiente em que todas as etapas de seu ciclo de vida são cumpridas; para Chloroscombrus chrysurus, Harengula clupeola e Oligoplites saliens é uma área de abrigo para juvenis, consequentemente de entrada de jovens, crescimento e recrutamento; e para outras espécies como um local de desova (PERESRIOS, 2001). Estudos anteriores registram ainda a importância de diversas espécies da ictiofauna para a região (ZANI TEIXEIRA, 1983, CUNNINGHAM e SAUL, 1995; MACIEL, 2001).

Os principais produtos pesqueiros do litoral sul do Estado de São Paulo são: a manjuba (Achoviella lepidentostole), o camarão sete-barbas (Xiphopenaeus kroyeri), a pescada-foguete (Macrodon ancylodon), a tainha (Mugil platanus), o parati (Mugil curema), a corvina (Micropogonias furnieri), o bagre-branco (Genidens barbus) e a ostra (Crassostrea brasiliana) (MENDONÇA e MIRANDA, 2008), sendo a pesca costeira e estuarina uma atividade socioeconômica de relevante importância para os moradores das cidades que margeiam o sistema costeiro Cananéia-Iguape (MENDONÇA e KATSURAGAWA, 1997; MENDONÇA e KATSURAGAWA, 2001).

\section{OBJETIVO ESPECÍFICO}

- Descrever a presença de recrutas das espécies de peixes mais abundantes em praias arenosas da barra sul do sistema costeiro Cananéia-Iguape, analisando a época de sua ocorrência e como as principais espécies utilizam a região estudada.

\section{Método DE COLETA E TOMADA DOS DADOS}

A metodologia da coleta dos espécimes e da tomada dos dados foi descrita no capítulo 1 deste trabalho. 
Para o presente estudo, trabalhou-se com as onze espécies mais abundantes (ocorrência maior que $1 \%$ nas coletas) das praias amostradas, excluindo as espécies representadas exclusivamente por indivíduos em fase larval.

A partir das medidas, foi estimada a equação da relação comprimento padrãocomprimento total descrita pelo modelo linear. A Análise de Variância (One way ANOVA) foi usada para testar a significância das diferenças entre as médias mensais dos dados abióticos de temperatura e salinidade ao nível de confiança de 95\% ( $\mathrm{p}<0,05)$.

Com o intuito de verificar as associações entre as espécies ao longo do ano de coleta empregou-se a análise de agrupamento com coeficiente de similaridade de BrayCurtis aos dados de abundância transformados por Hellinger (ocorrência numérica de cada espécie por mês dividido pelo total de indivíduos obtidos da espécie, seguido pela raiz quadrada desta proporção). A diferença entre os grupos formados foi testada utilizando-se o teste não paramétrico One way ANOSIM, do programa PAST.

Com relação à ictiofauna, as estações do ano foram agrupadas neste estudo, da seguinte forma: primavera $=$ setembro, outubro e novembro; verão $=$ dezembro, janeiro e fevereiro; outono = março, abril e maio; inverno $=$ junho, julho e agosto. Optou-se por agrupar os meses em estações do ano, pois não havia número suficiente de indivíduos por espécie para a realização de uma análise mensal. Para avaliar se os espécimes estão utilizando as praias como áreas para o crescimento, foram analisados os histogramas de classes de comprimento padrão de cada espécie por estação do ano. As diferenças na variação da proporção do número de exemplares de cada classe de tamanho por estação foi testada pelo teste não paramétrico de Friedman, com nível de confiabilidade de $99 \%$ $(\mathrm{p}<0,01)$ (SOKAL e ROHLF, 1995).

A classificação do estádio de maturação gonadal foi realizada seguindo o proposto por Dias et al. (1998). Sempre que as gônadas não eram visualizadas a olho desarmado após a dissecção dos exemplares, os mesmos eram considerados imaturos e sem expressão macroscópica do sexo.

\section{RESULTADOS}

A temperatura variou significativamente ao longo do ano amostrado, principalmente entre os meses mais quentes (novembro a abril) e os mais frios (maio a 
outubro) (Figura 4.1). A temperatura máxima medida foi $31^{\circ} \mathrm{C}$ em março e a mínima 18 ${ }^{\circ} \mathrm{C}$ em junho e agosto. Apesar de as diferenças de salinidade terem sido significativas entre os meses, não foi observado padrão ao longo do ano nessas diferenças, sendo tal variação provavelmente causada por outros fatores como a localização da praia amostrada e/ou pluviosidade (Figura 4.2). A salinidade mínima foi 10 em janeiro e 36 em junho. Quando se considera o agrupamento em estações do ano, aqui proposto, notase que as estações com menor variação são o inverno (junho, julho e agosto) e o verão (dezembro, janeiro e fevereiro), enquanto a primavera e o outono revelam as diferenças mais acentuadas.

Foram amostrados 13.861 espécimes pertencentes a 24 famílias e 57 espécies. Destes, 34 ocorreram em ambas às ilhas, 10 ocorreram somente na Ilha Comprida e 13 na Ilha do Cardoso. As espécies que foram amostradas exclusivamente em uma das ilhas foram raras, não ultrapassando 20 exemplares coletados. A única exceção foi Choloroscombrus chrysurus que ocorreu em abundância $(\mathrm{N}=145)$ somente na Ilha do Cardoso. Numericamente, Mugil curema (23,01 \%), Trachinotus carolinus (21,40 \%), Mugil hospes (16,12\%), larvas de Gerreidae (9,46 \%), Trachinotus goodei $(5,18 \%)$, Atherinella brasiliensis (4,88 \%), Harengula clupeola (3,68\%), Mugil liza (3,05\%), Anchoa tricolor (2,68 \%), Oligoplites saliens (1,67\%), Menticirrhus littoralis (1,62\%), larvas de Engraulidae (1,44 \%) e C. chrysurus (1,05\%) foram as espécies mais abundantes e, excluindo-se as larvas, foram utilizados na descrição do padrão de recrutamento (Tabela 4.1). Tais espécies foram amostradas no estágio juvenil, excetuando-se A. brasiliensis, em cuja amostra observaram-se indivíduos adultos $(\mathrm{N}=170)$ e uma única larva.

A análise de agrupamento da abundância total nos meses de coleta, destacamse dois grupos consistentes, um com os meses de temperaturas mais altas (janeiro a abril) e outro com os meses mais frios (julho a outubro), sendo que dezembro fica destacado dos demais pela alta abundância de C. chrysurus (Figura 4.3).

Através do dendograma resultante da análise de agrupamento das espécies, com $65 \%$ de similaridade, as espécies foram associadas a cinco grupos $(R=0,7692 ; p=$ 0,0092) (Figura 4.4). Aparentemente, os grupos formados pelas espécies refletem a relação entre abundância e temperatura ou estações do ano. O primeiro grupo foi formado por $M$. curema, M. hospes e C. chrysurus, espécies cuja maior ocorrência associa-se aos meses mais quentes do ano, não sendo obtidas em meses de temperaturas mais baixas. H. clupeola e A. brasiliensis formaram o segundo grupo, tendo sua maior 
ocorrência associada aos meses de julho a setembro. O maior de todos os grupos foi composto por O. saliens, T. carolinus, T. goodei e M. littoralis, espécies que foram abundantes ao longo de todo o ano de coleta, com maiores representações em meses de temperaturas elevadas. M. liza e A. tricolor representam sozinhas seus grupos, sendo a primeira espécie de ocorrência o ano todo, principalmente em julho e agosto, e a segunda coletada abundantemente de dezembro a março, esporadicamente em abril e junho, e sem registro de ocorrência nos demais meses (Tab. 4.1).

Os carangídeos foram abundantes em todas as estações do ano, principalmente no verão. Eles foram amostrados em uma grande amplitude de comprimento (Mínimo: 1,5 mm; Máximo: $152 \mathrm{~mm}$ ). A distribuição das classes de tamanho dos peixes variou significamente entre as estações para T. carolinus e T. goodei (Teste de Friedaman, $\mathrm{p}<0,01)$. As equações lineares obtidas da relação do comprimento total com o comprimento padrão para as espécies foram: $\mathrm{y}=0,7402 \mathrm{x}+1,2211, \mathrm{R}^{2}=0,9756$ para $T$. carolinus; e $\mathrm{y}=0,7283 \mathrm{x}+2.2831, \mathrm{R}^{2}=0,9858$.

Aparentemente juvenis de $T$. goodei começam a recrutar na região na primavera, pois aproximadamente $55 \%$ dos indivíduos amostrados em tal estação é de pequeno porte $(0$ a $20 \mathrm{~mm}$ ), apresentando ligeiro crescimento de tamanho individual ao longo das estações seguintes. No inverno não foram amostrados indivíduos menores que $30 \mathrm{~mm}$, sendo também a estação com maiores porcentagens de espécimes maiores que $50 \mathrm{~mm}$ (Figura 4.5). Em T. carolinus não foi observado um padrão claro de crescimento individual ao longo das estações, uma vez que indivíduos das menores classes de tamanho foram abundantes em todas as épocas de coleta (Figura 4.6).

Em $O$. saliens não foi observada uma variação da distribuição das classes de tamanho entre as estações (Teste de Friedman, p=0,0145) (Figura 4.7). Tal espécie apresentou duas modas sequenciais entre o verão e o outono, mas no inverno as duas modas se encontram, sendo que na primavera os maiores indivíduos não permanecem na área. $\mathrm{O}$ comprimento total e padrão variaram linearmente conforme a seguinte equação: $y=0,7969 x+2,7849, R^{2}=0,9077$.

Os mugilídeos apresentaram uma pequena amplitude de comprimento padrão, sendo a maioria dos indivíduos amostrados entre 20 e $30 \mathrm{~mm}$. Para $M$. curema nota-se um aumento progressivo de tamanho dos indivíduos entre a primavera e o inverno, nas classes entre 5 e 25-30 mm, com abundância máxima no verão (Figura 4.8). Somente em $M$. hospes a variação da distribuição das classes de tamanho entre as estações foi conspícua e significativa (Teste de Friedman, $\mathrm{p}=0,003$ ) (Figura 4.9). Sendo que, no 
inverno, os poucos indivíduos na área são os de maior comprimento. Para M. liza, o padrão se repete em relação à pequena faixa de tamanho, porém a espécie apresentou maior abundância no inverno e ocorrência dos maiores indivíduos, em pequenas proporções, também no inverno (Figura 4.10). Para nenhuma das três espécies foi observado um padrão de crescimento individual ao longo das estações na área amostrada, o que, aliado à estreita faixa de tamanho dos indivíduos, sugere uma entrada constante de indivíduos ao longo do ano, porém com maior abundância em épocas diferentes: $M$. curema e $M$. hospes foram mais abundantes no verão, enquanto $M$. liza no inverno (Figura 4.8, Figura 4.9 e Figura 4.10). Para M. curema, M. hospes e M. liza, os comprimentos total e padrão variaram conforme as seguintes equações, respectivamente: $y=0,7527 x+2,1708, R^{2}=0,9683 ; y=0,7684 x+1,494, R^{2}=0,9921 ; y=$ $0,7779 x+1,0625, R^{2}=0,8639$.

O único representante abundante da família Sciaenidae na área, M. littoralis, recruta na zona de surfe das praias amostradas durante a primavera, época em que aproximadamente $36 \%$ dos indivíduos obtidos mediam entre 5 e $20 \mathrm{~mm}$. No verão e no outono a classe modal mais abundante foi de 25 a $30 \mathrm{~mm}$, seguido por 30 a $35 \mathrm{~mm}$ no inverno, mostrando um ligeiro crescimento no tamanho individual ao longo do ano (Figura 4.11). A distribuição das classes de tamanho dos peixes para tal espécie variou significamente entre as estações (Teste de Friedman, $\mathrm{p}=0,000$ ). A equação $\mathrm{y}=0,8138 \mathrm{x}+0,3931, \mathrm{R}^{2}=0,9897$ relaciona a variação entre os valores de comprimento total e padrão.

Indivíduos de pequeno porte de $H$. clupeola foram coletados unicamente no verão, sendo significativa a distribuição das classes de comprimento padrão entre as estações (Teste de Friedman, p=0,000). No inverno, estação na qual tal espécie foi mais abundante, $54 \%$ dos indivíduos mediam de 50 a $55 \mathrm{~mm}$ (Figura 4.12). O comprimento total e padrão variaram linearmente conforme a seguinte equação: $y=0,7366 x+3,6557$, $\mathrm{R}^{2}=0,8872$.

Como A. tricolor e C. chrysurus não ocorreram em todas as estações do ano, não foi possível realizar uma análise do crescimento populacional destas espécies (Figura 4.13 e Figura 4.14). O comprimento total e padrão variaram linearmente conforme as seguintes equações: $\mathrm{y}=0,7909 \mathrm{x}+1,8029, \mathrm{R}^{2}=0,9755$; e $\mathrm{y}=0,7756 \mathrm{x}+0,5684$, $\mathrm{R}^{2}=0,9755$, para A. tricolor e $C$. chrysurus, respectivamente.

A. brasiliensis foi a única espécie com representantes de todas as fases do desenvolvimento gonadal na área de estudo. Indivíduos das menores classes de 
comprimento padrão ocorreram no verão, cuja classe modal dominante foi a de 50 a 60 mm. Nas estações seguintes é possível observar um crescimento do tamanho populacional, pois no outono $22 \%$ dos indivíduos mediam entre 70 a $80 \mathrm{~mm}$, no inverno $35 \%$ entre 80 e $90 \mathrm{~mm}$ e na primavera $34 \%$ entre 90 e $100 \mathrm{~mm}$ (Figura 4.15), sendo significativas as diferenças na proporção do número de indivíduos das diferentes classes de comprimento padrão entre as estações (Teste de Friedman, p=0,000). A distribuição mensal dos estádios de maturação de A. brasiliensis, aponta a dominância de indivíduos com gônadas imaturas $(65,61 \%)$ e em maturação $(30 \%)$ em todos os meses amostrados, com raras ocorrências de maduras $(3,16 \%)$ e desovadas $(0,79 \%)$. A alta porcentagem dos indivíduos em maturação dos meses de setembro a novembro relaciona-se com a alta classe modal de comprimento padrão observada na primavera, contrastando com o mês de janeiro, que por apresentar aproximadamente $97 \%$ dos indivíduos imaturos relaciona com as pequenas classes modais observada no verão (Figura 4.16). Para A. brasiliensis, o comprimento total e padrão variaram linearmente conforme a seguinte equação: $y=0,8257 x+0,1676, R^{2}=0,9793$.

\section{DISCUSSÃO}

Áreas protegidas em que ocorre agregação de juvenis são benéficas ao recrutamento, pois reduzem a mortalidade de indivíduos de pequeno tamanho (WRIGHT et al., 2010). As zonas de surfe de praias arenosas apresentam esta função, pois as espécies de peixes ali presentes são, em sua maioria, juvenis migrantes sazonais ou esporádicos, sendo uma minoria residente (MCLACHLAN, 1983). Considerando como espécies residentes de uma localidade aquelas que passam o ciclo de vida inteiro sem migrar, ou seja, são amostradas com gônadas em todos os estádios de maturação e seu número de ocorrência é constante ao longo do ano, somente A. brasiliensis poderia ser classificada como tal na área estudada, muito embora Fernandez (2007) mostrou que há deslocamentos entre praia e rio para esta espécie no litoral norte do estado de São Paulo. Félix et al. (2007b) estudando praias do Pontal do Sul, no Paraná, também não classificaram nenhuma espécie como residente. Apesar de Modde (1980) considerar seis espécies de peixes residentes na zona de surfe de praias do Golfo do México, entre elas T. carolinus e M. littoralis, não foi analisado o estádio de maturação gonadal ou a fase do ciclo de vida em que os peixes foram amostrados, sendo sua classificação baseada unicamente nas classes de comprimento dos indivíduos e na frequência de ocorrência 
mensal durante os três anos de estudo. Mesmo assim, o autor aponta que mais da metade dos peixes coletados são migrantes juvenis, que podem estar utilizando a área como refúgio ou como rota de migração. Para Layman (2000) a maioria das espécies coletadas foi classificada como juvenis sazonais, que utilizam as águas rasas como berçários, ou adultos transitórios, que são mais abundantes em outros habitats marinhos.

De maneira geral, as principais mudanças temporais na abundância e na estrutura da comunidade devem-se às variações nas espécies-chave e reflete diferentes épocas de recrutamento (SELLESLAGH e AMARA, 2008).

Das onze espécies abundantes na barra de Cananéia e, portanto utilizadas na descrição do padrão de recrutamento, cinco são consideradas de hábito demersal, e seis pelágicas (MACIEL, 2001). A tabela 4.2, montada com base em dados de estudos que efetuaram coletas em pontos no interior do sistema costeiro Cananéia-Iguape (ZANITEIXEIRA, 1983; MACIEL, 2001) e em uma praia da Ilha do Bom Abrigo, ilha essa localizada exteriormente à desembocadura do sistema (SAUL e CUNNINGHAM, 1995), mostra que, independentemente do artefato de pesca utilizado, todas as espécies analisadas no presente estudo foram anteriormente amostradas no interior do sistema ou próximo à sua saída. Destas, apenas H. clupeola, A. tricolor, M. curema, T. carolinus e $T$ goodei foram também amostradas fora do sistema, na Ilha do Bom Abrigo. Além disso, dados de desembarque da pesca costeira e estuarina em Cananéia relatam a ocorrência de M. littoralis, T. carolinus e T. goodei fora do estuário (MENDONÇA e KATSURAGAWA, 1997), enquanto os mugilídeos são importantes recursos pesqueiros estuarinos (MENDONÇA e KATSURAGAWA, 2001). Tais fatos reforçam a idéia de que indivíduos destas onze espécies aqui estudadas, que são capturadas pela pesca artesanal e pelas prospecções de pesquisa voltadas à captura de adultos, são recrutados como jovens do ano nas praias do sul do sistema costeiro Cananéia-Iguape. As capturas das praias não apresentam espécies abundantes cujo ciclo de vida se completaria na plataforma continental média ou externa, onde seriam capturadas pela pesca e relatadas em dados estatísticos. A exceção é o relato da captura de pampo (T. carolinus) desembarcado por traineiras em Itajaí (SCHWINGEL e OCCHIALINI, 2007); porém, este trabalho não apresenta os locais de captura dos exemplares.

O gênero Trachinotus é representado por peixes de hábito costeiro, bastante comum em zona de surfe (MENEZES e FIGUEIREDO, 1980). Diversos trabalhos em praias brasileiras (GIANNINI e PAIVA FILHO, 1995; GODEFROID et al., 2003; FÉLIX et al., 2007b; VASCONCELLOS et al., 2007; GAELZER e ZALMON, 2008a) 
e estrangeiras (MODDE, 1980; SANTOS e NASH, 1995; LAYMAN, 2000) apontam a alta abundância de juvenis de Trachinotus na zona de surfe, porém pouco se sabe quanto ao local e o período de desova das espécies do gênero, impossibilitando a realização de uma análise concisa do padrão de recrutamento dos mesmos na área de estudo. T. goodei ocorre geralmente em grandes cardumes na zona de surfe de praias arenosas, usualmente associado a águas mais salinas, enquanto $T$. carolinus é encontrado em pequenos ou grandes cardumes ao longo de praias arenosas, enseadas, e baías com águas salobras (CARPENTER, 2002). Das quatro espécies que representam este gênero no sudeste brasileiro, apenas T. marginatus não foi amostrada na área de estudo.

Aparentemente, juvenis de T. goodei recrutam principalmente na primavera, apresentando um claro padrão de crescimento sazonal, enquanto T. carolinus, como previamente descrito por Félix et al. (2007), recruta o ano todo. Na Flórida, Estados Unidos, juvenis de T. carolinus formam imensos cardumes ao longo das praias de abril até julho (CARPENTER, 2002). Como em T. goodei foram amostradas classes de comprimento padrão maiores do que as obtidas para seu congênere acredita-se que a seletividade da rede não influenciou a captura de T. carolinus de comprimentos maiores, podendo ser inferido que, a partir dos 60-70 mm, indivíduos de tal espécie migram para águas mais profundas, conforme anteriormente apontado por Fields (1962), Modde (1980) e Félix et al. (2007b). Provavelmente a desova de T. carolinus ocorra em águas oceânicas (CARPENTER, 2002).

Lemos et al. (2010) estudando T. marginatus na Praia do Cassino, observou que o recrutamento ocorre nos meses de verão e outono e, utilizando dois tipos de amostradores, conseguiu visualizar um deslocamento modal das classes de comprimento total, sugerindo que por volta dos $190 \mathrm{~mm}$ a espécie se desloca para áreas mais profundas ou ainda para outras latitudes. Contrariamente, o método de pesca utilizado no presente trabalho pode não ter capturado indivíduos de $T$. goodei de maiores classes de comprimento, pois Godefroid et al., 2003 estudando a ictiofauna da Praia do Atami amostrou indivíduos adultos da espécie em questão e, durante os dias de amostragens na Ilha Comprida, observou-se diversas pessoas pescando com linha e anzol e obtendo espécimes de $T$. goodei de maiores classes de comprimento padrão do que as obtidas com a rede de arrasto de praia.

Pouco se pode inferir sobre os padrões de recrutamento ou ocupação da área por $C$. chrysurus e $O$. saliens, pois a primeira ocorreu em abundância um único mês e 
na segunda não foi observado um padrão deslocamento das modas de comprimento padrão durante as diferentes estações do ano. Peres-Rios (2001) relata que tais espécies passam a fase juvenil dentro do sistema costeiro Cananéia-Iguape, principalmente nas praias.

Os mugilídeos, representados pelas tainhas e paratis, são peixes costeiros, encontrados abundantemente em estuários. Na zona rasa de praias arenosas são comuns grupos numerosos de indivíduos de pequeno tamanho, principalmente perto da desembocadura dos rios (MENEZES e FIGUEIREDO, 1985). No geral, desovam em mar aberto e os juvenis deslocam-se para águas costeiras penetrando nos estuários ou até mesmo em rios, onde se estabelecem (MENEZES e FIGUEIREDO, 1985; VIEIRA e SCALABRIN, 1991; CHANG, 2000; MARIN et al., 2003; SILVA, 2007). O mesmo padrão é descrito para $M$. liza (na literatura antes referida como $M$. platanus), com desova em águas de plataforma continental, com deriva de ovos e larvas, assentamento de juvenis no fundo em zonas de surfe (VIEIRA, 1991). Para as três espécies obteve-se uma pequena variação de comprimento o ano todo, não sendo observado um padrão claro de crescimento sazonal dos mesmos na área.

Padrão semelhante ao aqui descrito sobre épocas de recrutamento dos indivíduos juvenis e sua maior abundância em zonas de surfe de praias foi apresentado por Vieira (1991) para as espécies de mugilídeos $M$. hospes (referida como $M$. gaimaridanus), M. curema e M. liza (referida como M. platanus) na Lagoa dos Patos. No caso particular de $M$. liza, as maiores abundâncias de juvenis em arrastos de praia foram encontradas entre julho e setembro (VIEIRA e SCALABRIN, 1991).

Como foram obtidos exemplares de outras espécies de mais de $100 \mathrm{~mm}$ comprimento padrão, acredita-se que a pequena amplitude de tamanho na qual a maioria dos mugilídeos foi coletada não seja causada exclusivamente pela seletividade da rede. Duas hipóteses são sugeridas para explicar tal amplitude de tamanho: 1) por serem peixes ágeis, de natação rápida (quase 13 comprimentos do corpo por segundo, segundo Rulifson, 1977), os mugilídeos de maior porte conseguem fugir da rede, que é arrastada manualmente, em baixa velocidade; 2) os mugilídeos de pequeno porte utilizam as praias amostradas como rota entre o mar e o estuário, permanecendo nas mesmas por um curto período de tempo.

De maneira geral, sabe-se que peixes têm a capacidade de evitar as redes por estímulo visual, influenciando o sucesso da captura (WARDLE, 1993). Diversos trabalhos analisaram diferenças na captura entre o período diurno e noturno, apontando 
principalmente as diferenças dos índices ecológicos, sem focar no tamanho individual (PESSANHA e ARAÚJO, 2003; OLIVEIRA NETO et al., 2004; GAELZER e ZALMON, 2008a). Apenas Ross et al. (1987) mostra que das oito espécies mais abundantes na zona de surfe do Golfo do México, apenas Anchoa hepsetus mostrou um aumento significativo em peso nas coletas noturnas comparadas com as diurnas. Assim sendo, a primeira hipótese poderia ter sido corroborada se tivéssemos realizado amostragens noturnas e nessas se coletassem mugilídeos de maior porte.

O período reprodutivo dos mugilídeos, no qual se insere o período de desova, varia conforme a espécie e o local estudado. Para Mugil platanus (atualmente chamado de $M$. liza) o período de desova vai de setembro a novembro, na Baía do Paranaguá (ESPER et al., 2001) e de junho a outubro em Cananéia (ANDRADE-TALMELLI et $a l .$, 1996). Vieira e Scalabrin (1991) relatam que a migração da tainha do estuário da Lagoa dos Patos para o mar (plataforma continental média) começa em abril e maio (outono), sendo o pico da desova da espécie em maio e junho. Os autores apontam ainda que o recrutamento ocorre o ano todo, principalmente durante o inverno e a primavera.

Já para $M$. curema o período de desova vai de fevereiro a maio no Golfo do México (AGUIRRE e GALLARDO-CABELLO, 2004). No litoral paulista, dependendo da região, o período desova é do final da primavera ao início do verão em Santos- São Vicente (SP) (CERGOLE, 1986; FERREIRA, 1989) e de outubro a novembro e em abril, em Cananéia (FERNADEZ, com. pess.). Marin et al. (2003) mostram que, de setembro a janeiro, adultos de $M$. curema migram de uma lagoa localizada na Ilha Margarita, Venezuela, para desovar em mar aberto, sendo que o recrutamento dos juvenis no interior da mesma lagoa ocorre principalmente entre março e junho. Em estuários da Carolina do Sul, Estados Unidos, a desova de Mugil cephalus vai de outubro a abril, enquanto o recrutamento dos juvenis ocorre de janeiro a maio. Assim como apresentado por Vieira (1991), os juvenis de M. curema e M. hospes foram mais abundantes no verão, sendo que nos meses mais frios do ano ambos são escassos e/ou ausentes, quando então ocorre um predomínio de $M$. liza. A defasagem entre o período de desova descrito na literatura para M. liza e M. curema e a época de seu recrutamento nas praias amostradas pode ser uma importante evidência de que a segunda hipótese apresentada anteriormente seja verdadeira.

Em diversas praias do litoral do Brasil, Sciaenidae apresenta a ocorrência de grande número de espécies e alta abundância (GIANNINI e PAIVA FILHO, 1995; SAUL e CUNNINGHAM, 1995; GODEFROID et al., 2003; ARAÚJO et al., 2008; 
GAELZER e ZALMON, 2008a; LIMA e VIEIRA, 2009). Entretanto, na área de estudo do presente trabalho, apenas uma espécie, Menticirrhus. littoralis, foi abundante. Tal espécie ocorre em fundos de areia e lama, principalmente em ambientes praiais, enquanto os juvenis são abundantes em águas rasas de praias arenosas, não sendo comuns em estuários (MENEZES e FIGUEIREDO, 1980). Tanto Modde (1980) e Félix et al. (2007b) consideraram que o recrutamento de M. littoralis acontece ao longo de todo o ano, não sendo observado um padrão de deslocamento das modas de comprimento dos indivíduos amostrados. Porém, no presente trabalho os juvenis parecem recrutar principalmente na primavera, quando se observa um aumento das modas de comprimento padrão, indicando um crescimento em tamanho dos indivíduos nas praias amostradas. O período reprodutivo desta espécie no sul do Brasil é de setembro a março, com pico no final da primavera (BRAUN e FONTOURA, 2004). A primavera foi também a estação na qual as larvas de M. littoralis são mais abundantes na costa do Paraná (GODEFROID et al., 2001), o que corroboraria o período de recrutamento observado no presente estudo. A falta de indivíduos adultos nas águas rasas das praias estudadas pode estar relacionada ao comportamento migratório, ou com a seletividade da rede. Segundo Braun e Fontoura (2004), exemplares adultos habitam águas mais profundas, retornando para a costa para desovar, sendo que a primeira maturação ocorre com aproximadamente $23 \mathrm{~cm}$. Godefroid et al. (2004) utilizando como artefato de pesca uma rede arrastada com a ajuda de uma canoa com motor de popa, amostrando em profundidades entre 8 e 12 metros, mostrou que M. littoralis utiliza o balneário de Atami tanto para desova quanto para recrutamento.

O peixe rei, A. brasiliensis, foi o único do presente estudo que apresentou, mesmo que em pequenas proporções, fêmeas desovadas e maduras. Entretanto, não foi observada nas amostragens nenhuma gônada com ovócitos hidratados. Sabendo-se que a hidratação dos ovócitos indica desova eminente (HUNTER e GOLDBERG, 1980; DIAS et al., 1998), pode-se concluir que o peixe-rei não utiliza as praias amostradas, durante o período diurno, para tal finalidade. Provavelmente A. brasiliensis sobe o estuário ou um pequeno riacho próximo à praia abrigada da Ilha do Cardoso para desova, pois, conforme mostrado por Fernandez (2007), a espécie apresenta migrações diárias, saindo da zona de surfe da praia de Itamambuca e subindo o rio de mesmo nome para desovar. Os ovos de Atherinopsidae possuem filamentos que são utilizados para a adesão na vegetação aquática (HUAQUÍN, 1980; MARÍN et al., 1995), fato este que provavelmente explique a preferência das fêmeas por sair das praias amostradas para 
desovarem, pois as mesmas não possuem vegetação para servir como substrato para os ovos.

Peres-Rios (2001) estudando A. brasiliensis no sistema costeiro CananéiaIguape mostra que a desova ocorre ao longo de todo o ano, com maior intensidade no inverno e na primavera. Tal intensidade de desova na primavera pode estar relacionada com o início do recrutamento dos juvenis nas praias amostradas durante o verão. Pessanha e Araújo (2001) e Fernandez (2007) também apontaram o verão como época de recrutamento de A. brasiliensis em zonas rasas de ambientes praiais. No sistema estuarino da baía de Paranaguá, a análise do deslocamento das modas das classes de comprimento indica a existência de um padrão de crescimento ao longo do ano, com os espécimes de maior tamanho mais abundantes na primavera, quando acontece o pico reprodutivo, resultando na alta abundância de recrutas do ano durante o verão (FÁVARO et al., 2003, 2007; CONTENTE et al., 2010b). O mesmo padrão de crescimento anual e recrutamento foram observados na área de estudo do presente trabalho.

Mesmo com a ocorrência de Sardinella brasiliensis e Opisthonema oglinum, $H$. clupeola, popularmente conhecida como sardinha-cascuda, foi a única espécie abundante de Clupeidae. Sua abundância na zona de surfe de praias arenosas brasileiras já foi anteriormente apontada por diversos autores (GIANNINI e PAIVA FILHO, 1995; PESSANHA e ARAÚJO, 2003; VASCONCELLOS et al., 2007; GAELZER e ZALMON, 2008a) principalmente durante o inverno (SAUL e CUNNINGHAM, 1995; FÉLIX et al., 2007b). Em Pontal do Sul, Paraná, a menor média de comprimento padrão dos indivíduos de $H$. clupeola foi observada em fevereiro, sendo que a partir desse mês essa média vai aumentando gradativamente atingindo o máximo de $80 \mathrm{~mm}$ em janeiro, mês em que foi amostrada uma alta porcentagem de indivíduos em maturação e maduros (FÉLIX et al., 2007b). A espécie em questão passa a fase juvenil no sistema costeiro Cananéia-Iguape, principalmente nas praias (PERES-RIOS, 2001).

A maioria dos trabalhos sobre a ictiofauna de zonas rasas de praias arenosas faz uma análise da comunidade como um todo, sem focar em cada população individualmente. Acredita-se que, deste modo, muitas informações sobre cada espécie sejam perdidas, o que dificulta o entendimento da relação entre desova e recrutamento para cada espécie. Da mesma forma, é difícil interpretar os padrões de recrutamento de cada uma das espécies com seus padrões reprodutivos, buscando uma explicação para a 
flutuação sazonal observada na comunidade, ou até mesmo para entender a importância do ambiente para a ictiofauna.

O presente estudo esclarece a importância das praias arenosas da barra sul do sistema costeiro Cananéia-Iguape para os juvenis da ictiofauna analisada, quer seja como rota de migração, ou como área de crescimento, principalmente na primavera e no verão, quando ocorre o recrutamento da maioria das espécies. Infelizmente esta é a época em que ocorre o maior impacto na área pelo turismo. É relevante lembrar que muitas dessas espécies são importantes comercialmente para a região, ressaltando ainda mais a necessidade de preservação desses habitats costeiros, principalmente adjacentes aos estuários, uma vez que o recrutamento bem sucedido terá grande chance de resultar em maiores populações adultas e, deste modo, contribuir para a sustentabilidade dos estoques e para o equilíbrio dos ecossistemas costeiros. 
Tabela 4.1. Frequência relativa mensal e total (\%) das espécies amostradas na barra sul do sistema costeiro Cananéia-Iguape de fevereiro de 2009 a janeiro de 2010, e o local em que elas foram obtidos. IM= Ilha Comprida e IR= Ilha do Cardoso.

\begin{tabular}{|c|c|c|c|c|c|c|c|c|c|c|c|c|c|c|}
\hline \multirow[t]{2}{*}{ Família/Espécie } & \multicolumn{12}{|c|}{ frequencia relativa mensal (\%) } & \multirow{2}{*}{$\begin{array}{c}\text { Total } \\
(\%)\end{array}$} & \multirow[t]{2}{*}{ Local } \\
\hline & fev & $\operatorname{mar}$ & $\mathrm{abr}$ & mai & jun & jul & ago & set & out & nov & dez & jan & & \\
\hline \multicolumn{15}{|l|}{ Elopidae } \\
\hline Elops saurus & 8,2 & 0,8 & & & & & & & 2,2 & 1,5 & & 0,1 & 0,7 & IC e IR \\
\hline \multicolumn{15}{|l|}{ Engraulidae } \\
\hline Anchoa janиаria & 1,4 & & & & & & & & & & 0,1 & 4,7 & 0,5 & IC e IR \\
\hline Anchoa lyolepis & & 0,8 & & 0,3 & & & & & & & & 0,1 & & IC e IR \\
\hline Anchoa tricolor & 9,6 & 8,9 & 0,3 & & 0,9 & & & & & & 0,1 & 21,6 & 2,7 & IC e IR \\
\hline Anchoviella lepidentostole & 0,1 & 0,8 & & & & & 1,2 & & & & & 1,7 & 0,2 & IC e IR \\
\hline Cetengraulis edentulus & & & 6,2 & & & & & & & & & 0,5 & 0,3 & IC e IR \\
\hline Larva de Engraulidae & 3,0 & 3,0 & 3,6 & 6,3 & 15,6 & 1,7 & 0,9 & & 5,8 & 2,4 & & 0,6 & 1,4 & IC e IR \\
\hline Lycengraulis grossidens & 0,1 & 0,2 & & & & & & & & & & & & IR \\
\hline \multicolumn{15}{|l|}{ Clupeidae } \\
\hline Harengula clupeola & 1,8 & 6,9 & 3,4 & 1,6 & & 45,3 & 12,5 & 23,2 & 1,9 & 0,4 & & 1,4 & 3,7 & IC e IR \\
\hline Opisthonema oglinum & & & 0,3 & & & & & & & & & 0,1 & & IR \\
\hline Platanichthys platana & & & & & & & & & & & & & & IR \\
\hline Sardinella brasiliensis & & & & & & & & & & & 0,1 & & & IC e IR \\
\hline \multicolumn{15}{|l|}{ Synodontidae } \\
\hline Synodus foetens & 0,1 & & & & & & 0,3 & & & & & & & IC e IR \\
\hline \multicolumn{15}{|l|}{ Batrachoididae } \\
\hline Porichthys porosissimus & & & & & & & & & 0,3 & & & & & IR \\
\hline
\end{tabular}


Tabela 4.1. continuação

\begin{tabular}{|c|c|c|c|c|c|c|c|c|c|c|c|c|c|c|}
\hline \multirow[t]{2}{*}{ Família/Espécie } & \multicolumn{12}{|c|}{ frequencia relativa mensal (\%) } & \multirow{2}{*}{$\begin{array}{c}\text { Total } \\
(\%)\end{array}$} & \multirow[t]{2}{*}{ Local } \\
\hline & fev & mar & $\mathrm{abr}$ & mai & jun & jul & ago & set & out & nov & $\mathrm{dez}$ & jan & & \\
\hline \multicolumn{15}{|l|}{ Mugilidae } \\
\hline Mugil curema & 1,5 & 1,0 & 0,2 & 3,6 & 1,4 & & & 1,6 & 10,0 & 3,2 & 42,1 & 8,9 & 23,0 & IC e IR \\
\hline Mugil hospes & 2,1 & 4,1 & 3,3 & 5,2 & 2,8 & & & & 0,3 & 9,3 & 26,7 & 10,3 & 16,1 & IC e IR \\
\hline Mugil liza & 0,3 & & 0,2 & 0,3 & 5,2 & 18,4 & 50,5 & 7,0 & 13,9 & 0,7 & 0,5 & 0,1 & 3,1 & IC e IR \\
\hline Mugil 1 & 0,1 & & & & 0,9 & & & & 0,6 & 0,2 & 1,7 & 0,3 & 0,9 & IC e IR \\
\hline Mugil 2 & & & & & 0,5 & 0,1 & 0,3 & & & & & & & IC e IR \\
\hline \multicolumn{15}{|l|}{ Atherinopsidae } \\
\hline Atherinella brasiliensis & 2,7 & 15,6 & 3,9 & 3,3 & 10,4 & 16,7 & 22,9 & 46,5 & 13,6 & 0,9 & 0,1 & 14,7 & 4,9 & IC e IR \\
\hline Odontesthes argentinensis & & & 0,2 & & & 0,1 & & 0,5 & 0,6 & 0,1 & & & 0,1 & IC e IR \\
\hline \multicolumn{15}{|l|}{ Belonidae } \\
\hline Strongylura marina & & & & & & & & & & & & & & IR \\
\hline Strongylura timиси & & 0,8 & 0,8 & 0,3 & & & & & & 1,4 & & 0,4 & 0,3 & IC e IR \\
\hline Tylosurus acus & & & & & & & & & & 0,1 & & & & IC \\
\hline \multicolumn{15}{|l|}{ Exocoetidae } \\
\hline Hemiramphus sp. & 0,1 & & & & & & & & & & & & & IC e IR \\
\hline Hyporhamphus unifasciatus & & & & & & & & & & & & & & IC \\
\hline \multicolumn{15}{|l|}{ Syngnathidae } \\
\hline Syngnathus folletti & & & & & & & & & & 0,1 & & 0,1 & & IC e IR \\
\hline
\end{tabular}


Tabela 4.1. continuação

\begin{tabular}{|c|c|c|c|c|c|c|c|c|c|c|c|c|c|c|}
\hline \multirow[t]{2}{*}{ Família/Espécie } & \multicolumn{12}{|c|}{ frequencia relativa mensal $(\%)$} & \multirow{2}{*}{$\begin{array}{c}\text { Total } \\
(\%)\end{array}$} & \multirow[t]{2}{*}{ Local } \\
\hline & fev & $\operatorname{mar}$ & $\mathrm{abr}$ & mai & jun & jul & ago & set & out & nov & $\operatorname{dez}$ & jan & & \\
\hline \multicolumn{15}{|l|}{ Carangidae } \\
\hline Caranx latus & & 0,6 & & & & & & & & & 0,8 & & 0,4 & IC e IR \\
\hline Choloroscombrus chrysurus & & & & & & & & & & & 2,1 & & 1,0 & IR \\
\hline Oligoplites saliens & 2,2 & 2,4 & 2,2 & 1,9 & 1,9 & 2,7 & 4,6 & 1,6 & 0,6 & 0,5 & 1,3 & 3,6 & 1,7 & IC e IR \\
\hline Oligoplites sp. & & 0,2 & & & & & & & & & & 0,1 & 0,0 & IC e IR \\
\hline Selene vomer & & 0,4 & & & & & & & & & & & 0,0 & IC e IR \\
\hline Trachinotus carolinus & 37,4 & 28,0 & 28,3 & 38,0 & 44,8 & 4,0 & 1,5 & 7,6 & 20,0 & 16,4 & 21,5 & 20,3 & 21,4 & IC e IR \\
\hline Trachinotus falcatus & 0,5 & 0,2 & 0,2 & & & & & & & 1,0 & 0,1 & 0,2 & 0,2 & IC e IR \\
\hline Trachinotus goodei & 8,0 & 14,2 & 8,4 & 31,1 & 14,2 & 5,5 & 0,6 & 5,4 & 11,7 & 6,7 & 1,6 & 6,2 & 5,2 & IC e IR \\
\hline \multicolumn{15}{|l|}{ Lobotidae } \\
\hline Lobotes surinamensis & 0,1 & & & & & & & & & & & & & IR \\
\hline \multicolumn{15}{|l|}{ Gerreidae } \\
\hline Larva de Gerreidae & 19,5 & 10,1 & 37,1 & 2,7 & & & & & 0,8 & 48,5 & 0,6 & 1,6 & 9,5 & IC e IR \\
\hline \multicolumn{15}{|l|}{ Haemulidae } \\
\hline Pomadasys corvinaeformis & & 0,4 & 0,3 & & & & & & & & & & & IC e IR \\
\hline \multicolumn{15}{|l|}{ Polynemidae } \\
\hline Polydactylus oligodon & & & & & & & & & 0,3 & & & & & IR \\
\hline Polydactylus virginicus & & & & & & & & & & 0,1 & & & & IC \\
\hline \multicolumn{15}{|l|}{ Sciaenidae } \\
\hline Menticirrhus americanus & & & 0,2 & & & & & 1,1 & 4,2 & 1,6 & & & 0,3 & IC e IR \\
\hline Menticirrhus littoralis & 0,3 & 0,4 & 0,9 & 5,5 & 1,4 & 4,7 & 4,6 & 5,4 & 4,7 & 3,7 & 0,5 & 2,0 & 1,6 & IC e IR \\
\hline Micropogonias furnieri & & & & & & 0,1 & & & & 0,2 & & & & IC e IR \\
\hline Umbrina coroides & & & & & & 0,1 & & & & & & & & IR \\
\hline
\end{tabular}


Tabela 4.1. continuação

\begin{tabular}{|c|c|c|c|c|c|c|c|c|c|c|c|c|c|c|}
\hline \multirow[t]{2}{*}{ Família/Espécie } & \multicolumn{12}{|c|}{ frequencia relativa mensal (\%) } & \multirow{2}{*}{$\begin{array}{c}\text { Total } \\
(\%)\end{array}$} & \multirow[t]{2}{*}{ Local } \\
\hline & fev & mar & $\mathrm{abr}$ & mai & jun & jul & ago & set & out & nov & dez & jan & & \\
\hline \multicolumn{15}{|l|}{ Serranidae } \\
\hline Abudefduf saxatilis & 0,1 & & & & & & & & & 0,1 & & & & IC \\
\hline Mycteroperca sp. & & & & & & & & & & 0,2 & & & & IC \\
\hline Mycteroperca tigris & & & & & & & & & & 0,2 & & & & IC \\
\hline \multicolumn{15}{|l|}{ Blenniidae } \\
\hline Parablennius pilicornis & 0,1 & & & & & & & & & & & & & IC \\
\hline \multicolumn{15}{|l|}{ Pomatomidae } \\
\hline Pomatomus saltatrix & 0,1 & & & & & 0,4 & & & 0,3 & 0,1 & & & 0,1 & IC e IR \\
\hline \multicolumn{15}{|l|}{ Paralichthyidae } \\
\hline Citharichthys arenaceus & & & & & & & & & 0,6 & & & & & IC \\
\hline Etropus crossotus & 0,1 & & & & & & & & 5,0 & & & & 0,1 & IR \\
\hline Paralichthys orbignyanus & & & & & & & & & 0,3 & & & & & IR \\
\hline \multicolumn{15}{|l|}{ Monacanthidae } \\
\hline Stephanolepis hispidus & 0,1 & & & & & & & & & & & & & IC \\
\hline \multicolumn{15}{|l|}{ Tetraodontidae } \\
\hline Sphoeroides greeleyi & & & 0,2 & & & & & & 1,9 & & & 0,4 & 0,1 & IR \\
\hline Sphoeroides sp. & & & & & & & & & & 0,2 & & & & IC \\
\hline Sphoeroides testudineus & & & & & & 0,1 & & & 0,6 & & & & & IR \\
\hline \multicolumn{15}{|l|}{ Diodontidae } \\
\hline Chilomycterus spinosus & & & & & & & & & & 0,1 & & & & IC e IR \\
\hline
\end{tabular}


Tabela 4.2. Ocorrência das espécies mais abundantes no presente estudo amostradas em outras regiões do sistema costeiro CananéiaIguape, e a arte de pesca utilizada na amostragem das mesmas. ${ }^{1}$ SAUL e CUNNINGHAM (1995); ${ }^{2}$ ZANI-TEIXEIRA; ${ }^{3}$ MACIEL (2001).

\begin{tabular}{|c|c|c|c|c|c|}
\hline \multirow[t]{3}{*}{ Família/ espécie } & \multicolumn{5}{|c|}{ Local amostrado/ arte de pesca } \\
\hline & \multirow{2}{*}{$\begin{array}{c}\text { Ilha do Bom } \\
\text { Abrigo }^{1}\end{array}$} & \multirow{2}{*}{$\begin{array}{c}\text { Baia de } \\
\text { Trapandé }^{2} \\
\begin{array}{c}\text { Arrasto de } \\
\text { fundo }\end{array}\end{array}$} & \multicolumn{3}{|c|}{ Sistema costeiro Cananéia Iguape ${ }^{3}$} \\
\hline & & & Arrasto de fundo & Arrasto de superficie & Lanço nas margens \\
\hline \multicolumn{6}{|l|}{ Clupeidae } \\
\hline Harengula clupeola & $\mathrm{X}$ & $\mathrm{X}$ & $\mathrm{X}$ & $\mathrm{X}$ & $\mathrm{X}$ \\
\hline \multicolumn{6}{|l|}{ Engraulidae } \\
\hline Anchoa tricolor & $\mathrm{X}$ & $\mathrm{x}$ & $\mathrm{x}$ & $\mathrm{x}$ & $\mathrm{x}$ \\
\hline \multicolumn{6}{|l|}{ Mugilidae } \\
\hline Mugil curema & $\mathrm{X}$ & & $\mathrm{X}$ & $\mathrm{X}$ & $\mathrm{X}$ \\
\hline \multicolumn{6}{|l|}{ Mugil hospes } \\
\hline Mugil Liza & & & $\mathrm{x}$ & & $\mathrm{x}$ \\
\hline \multicolumn{6}{|l|}{ Atherinopsidae } \\
\hline Atherinella brasiliensis & & & $\mathrm{X}$ & $\mathrm{X}$ & $\mathrm{X}$ \\
\hline \multicolumn{6}{|l|}{ Carangidae } \\
\hline Choloroscombrus chrysurus & & $\mathrm{x}$ & $\mathrm{x}$ & $\mathrm{x}$ & $\mathrm{x}$ \\
\hline Oligoplites saliens & & $\mathrm{x}$ & $\mathrm{x}$ & $\mathrm{x}$ & $\mathrm{x}$ \\
\hline Trachinotus carolinus & $\mathrm{X}$ & $\mathrm{X}$ & $\mathrm{X}$ & $\mathrm{X}$ & $\mathrm{X}$ \\
\hline Trachinotus goodei & $\mathrm{X}$ & & & & $\mathrm{X}$ \\
\hline Sciaenidae & & & & & \\
\hline Menticirrhus littoralis & & & $\mathrm{x}$ & & $\mathrm{x}$ \\
\hline
\end{tabular}




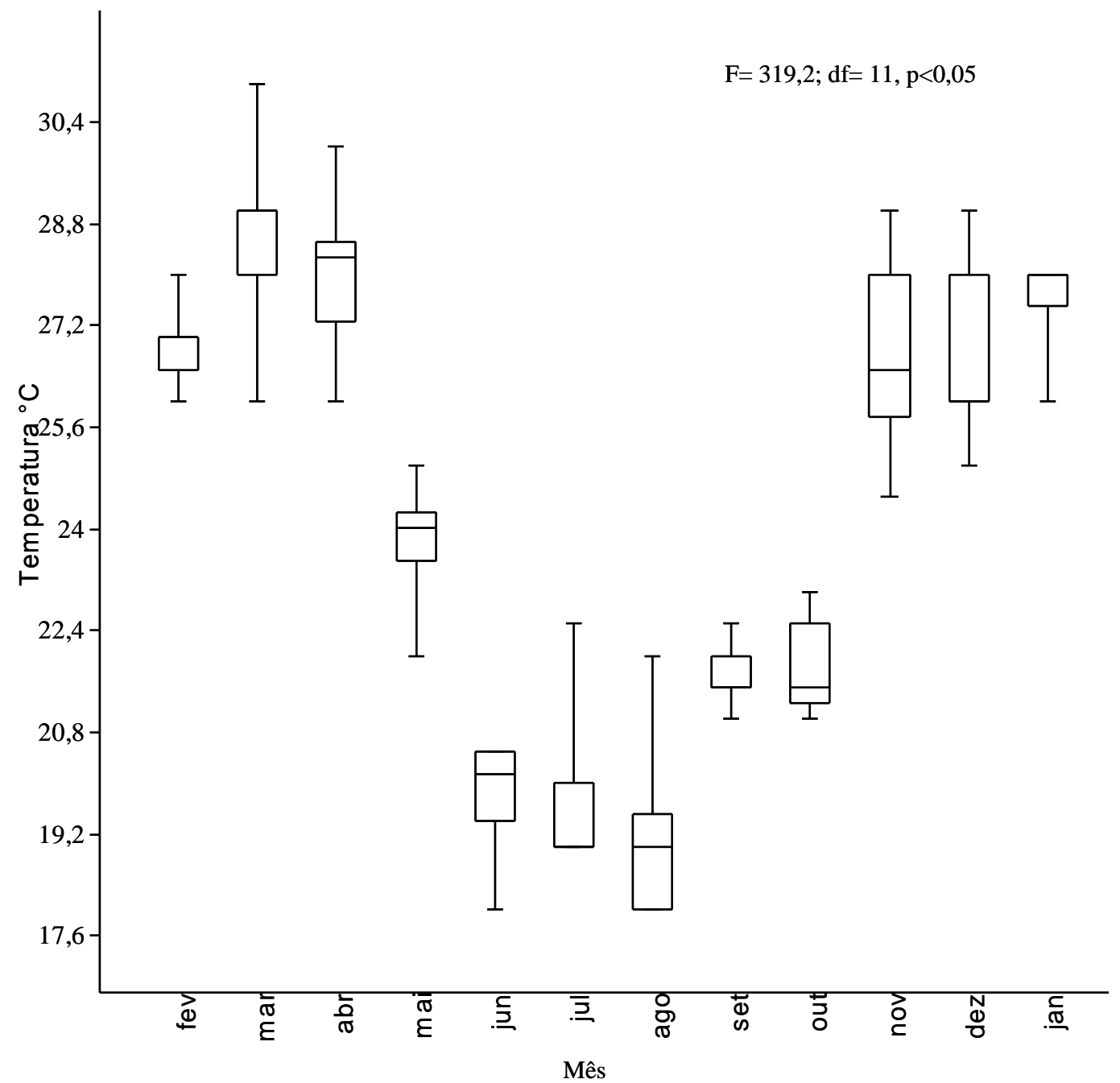

Figura 4.1. Variação de temperatura média mensal medida na zona de surfe de praias arenosas da barra sul do Sistema Costeiro Cananéia-Iguape de fevereiro de 2009 a janeiro de 2010 (linhas horizontais representam as médias, os retângulos o desvio padrão e I o erro padrão). 


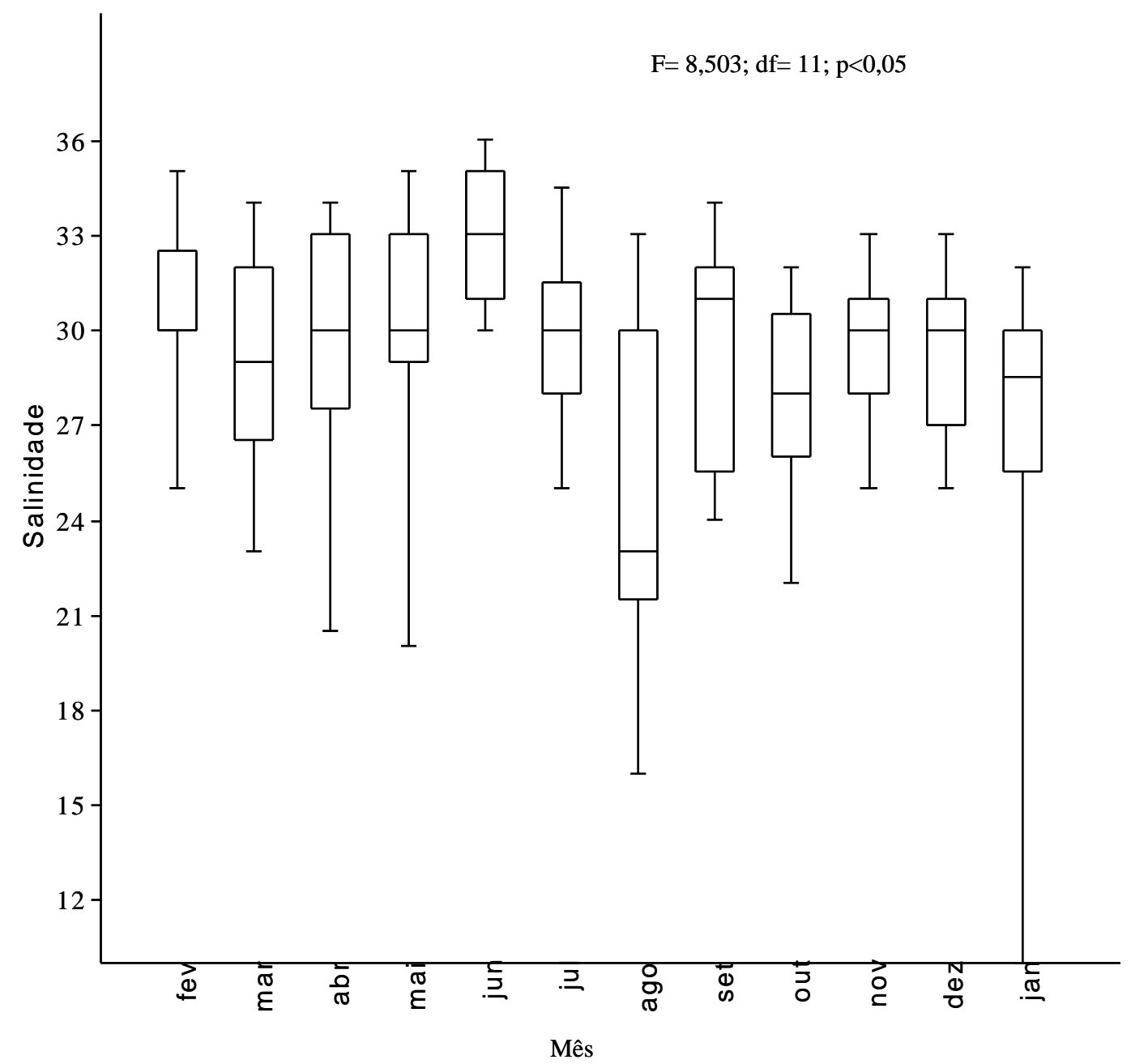

Figura 4.2. Variação de salinidade média mensal medida na zona de surfe de praias arenosas da barra sul do Sistema Costeiro Cananéia-Iguape de fevereiro de 2009 a janeiro de 2010 (linhas horizontais representam as médias, os retângulos o desvio padrão e I o erro padrão). 


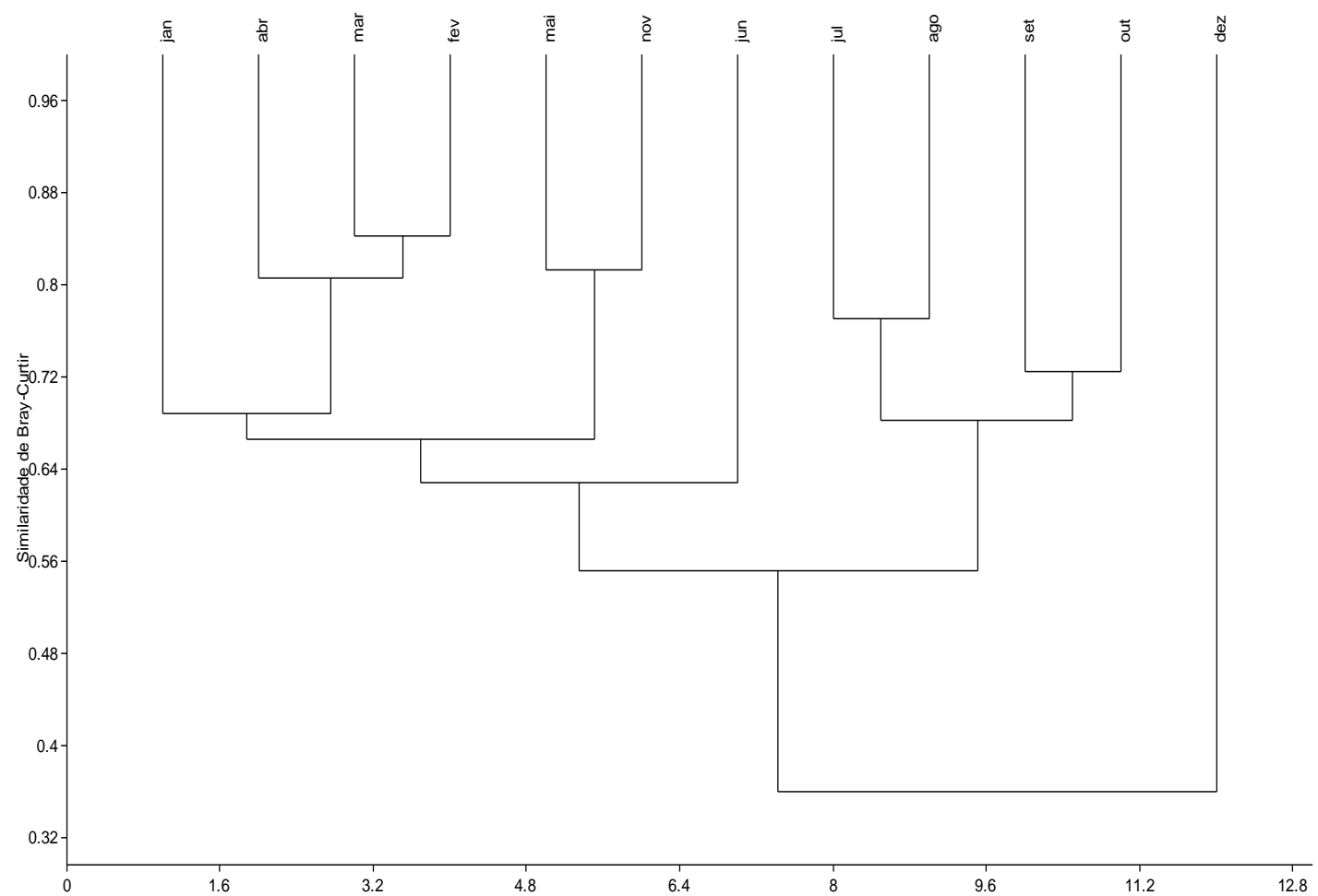

Figura 4.3. Dendograma resultante da análise de agrupamento da abundância total nos meses de coleta realizada com dados de ocorrência numérica mensal, transformados por Hellinger. 


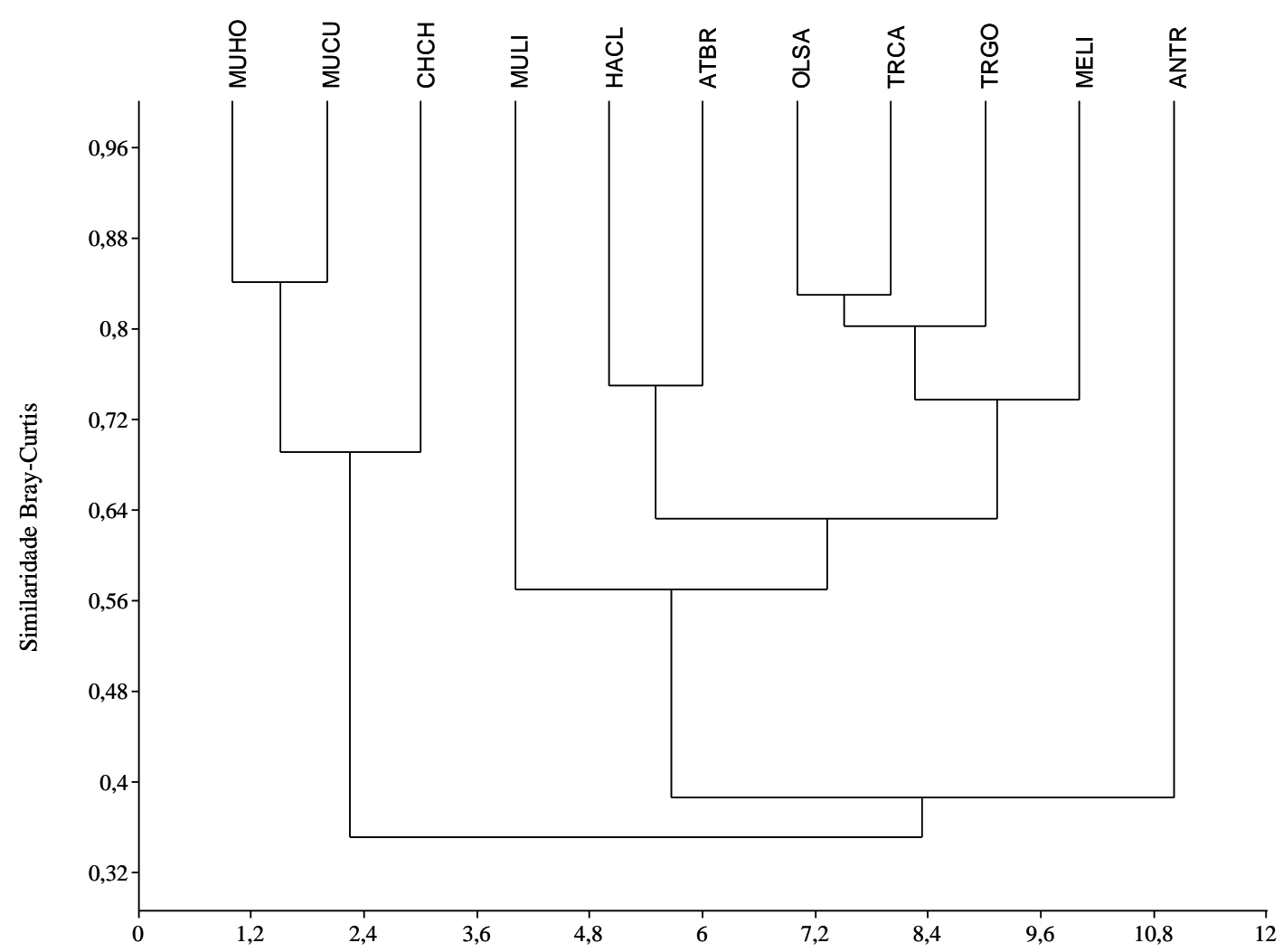

Figura 4.4. Dendograma resultante da análise de agrupamento das espécies realizada com dados de ocorrência numérica mensal, transformados por Hellinger. As siglas utilizadas correspondem às duas primeiras letras do nome genérico e específico, exemplo: $\mathrm{MUCU}=$ Mugil curema. 


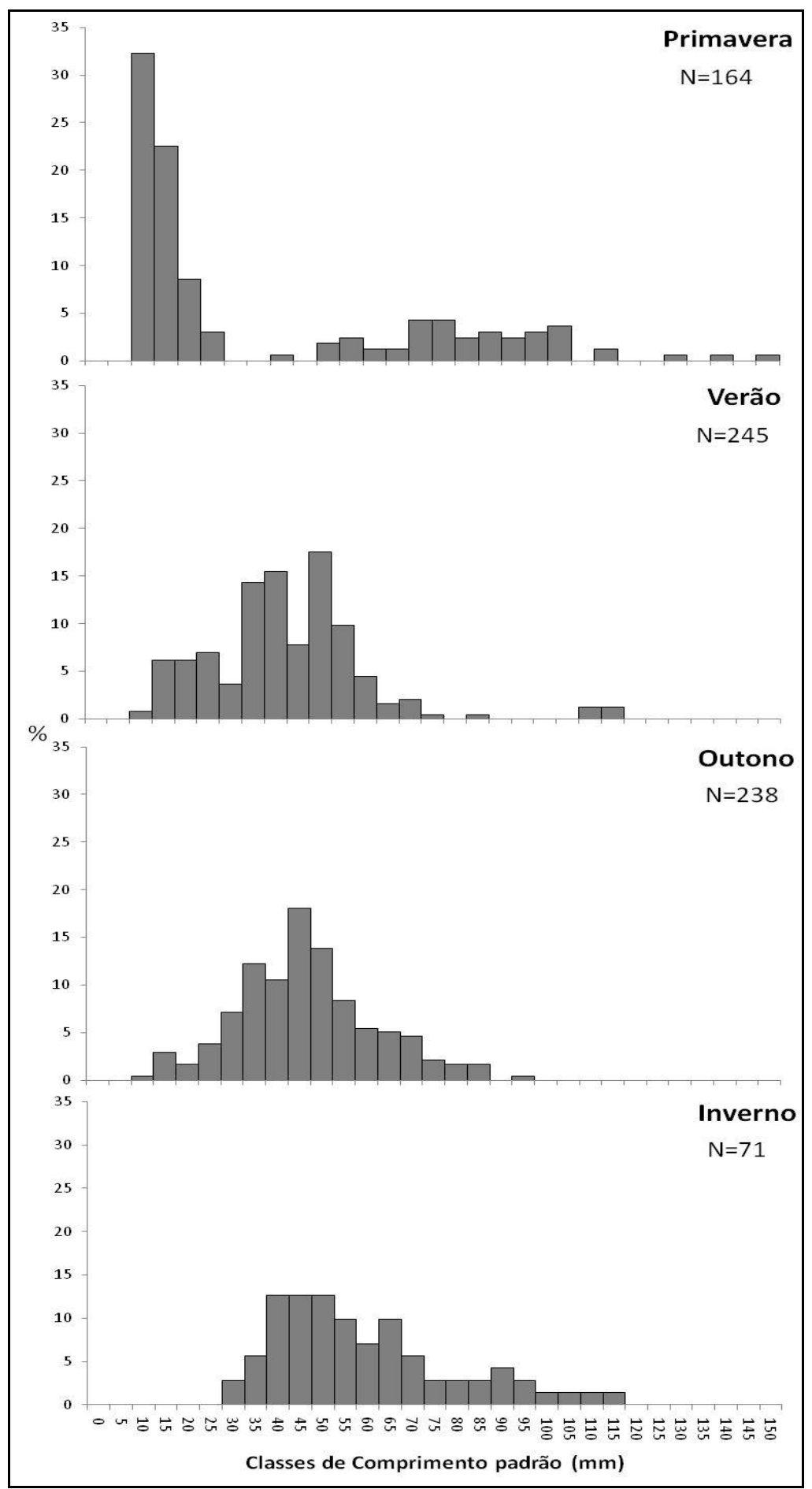

Figura 4.5. Frequência de classes de comprimento padrão para Trachinotus goodei amostrados na zona de surfe de praias arenosas da barra sul do sistema costeiro Cananéia Iguape entre fevereiro de 2009 e janeiro de 2010. 


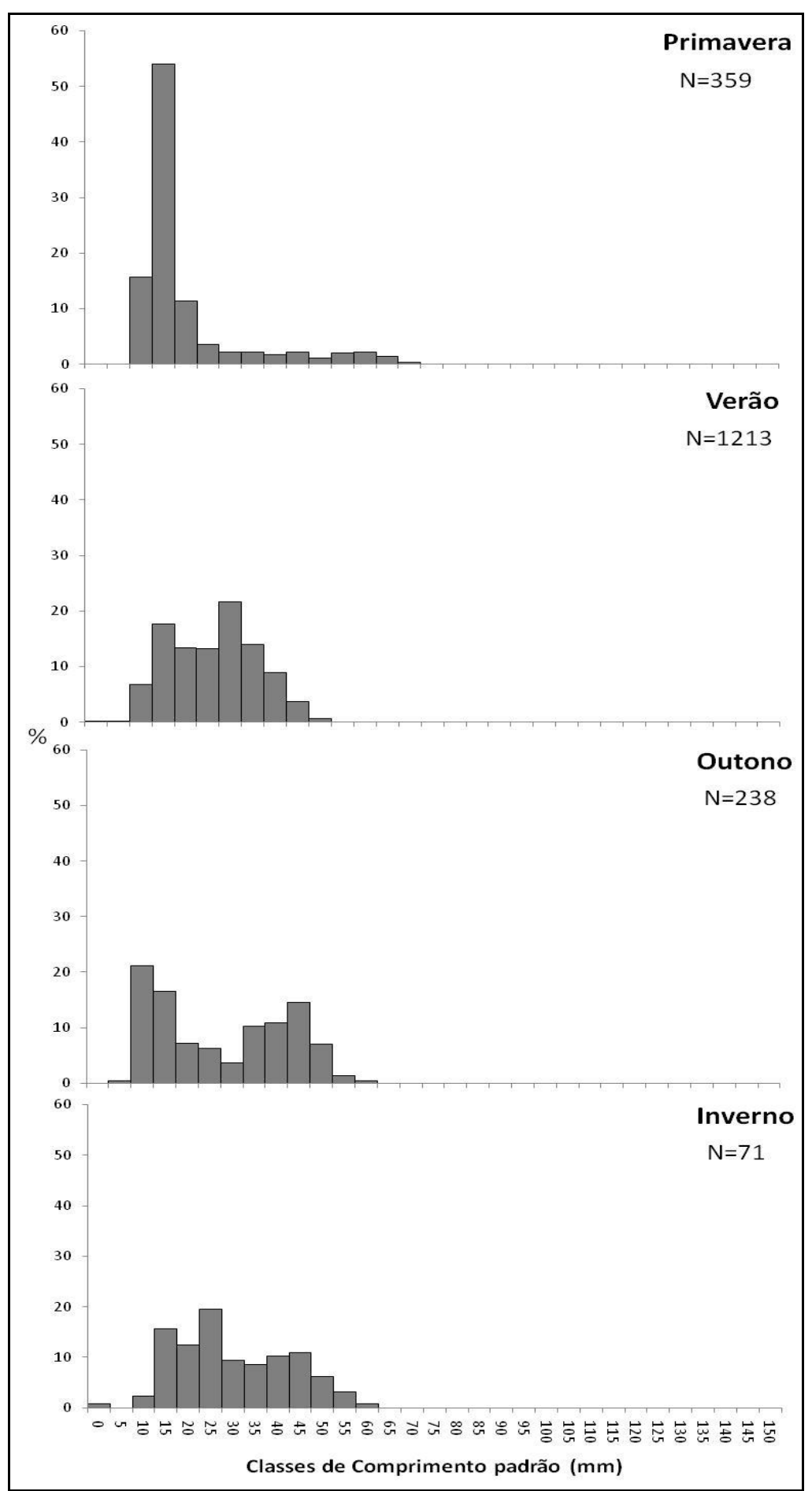

Figura 4.6. Frequência de classes de comprimento padrão para Trachinotus carolinus amostrados na zona de surfe de praias arenosas da barra sul do sistema costeiro Cananéia Iguape entre fevereiro de 2009 e janeiro de 2010. 


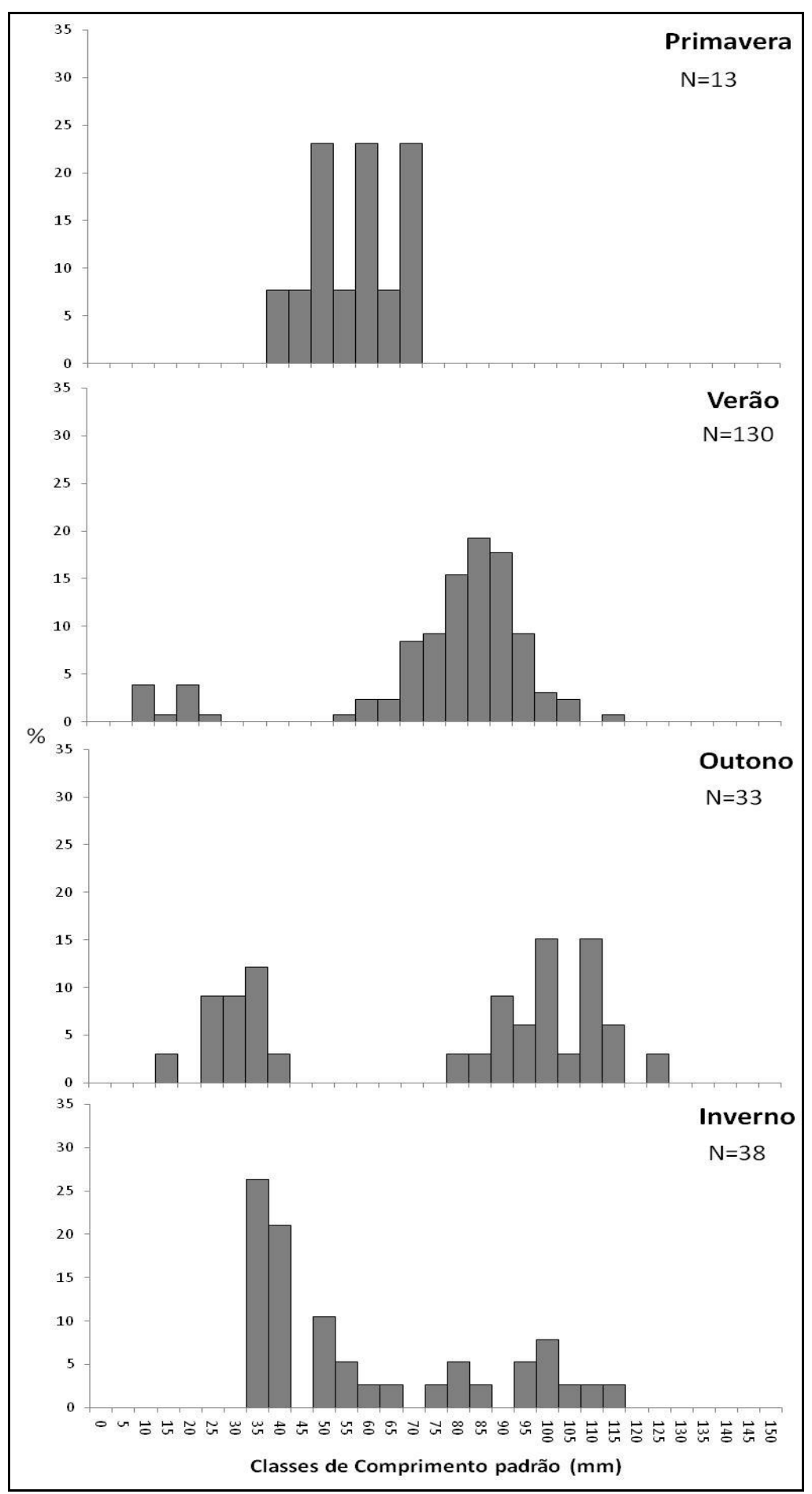

Figura 4.7. Frequência de classes de comprimento padrão para Oligoplites saliens amostrados na zona de surfe de praias arenosas da barra sul do sistema costeiro Cananéia Iguape entre fevereiro de 2009 e janeiro de 2010. 


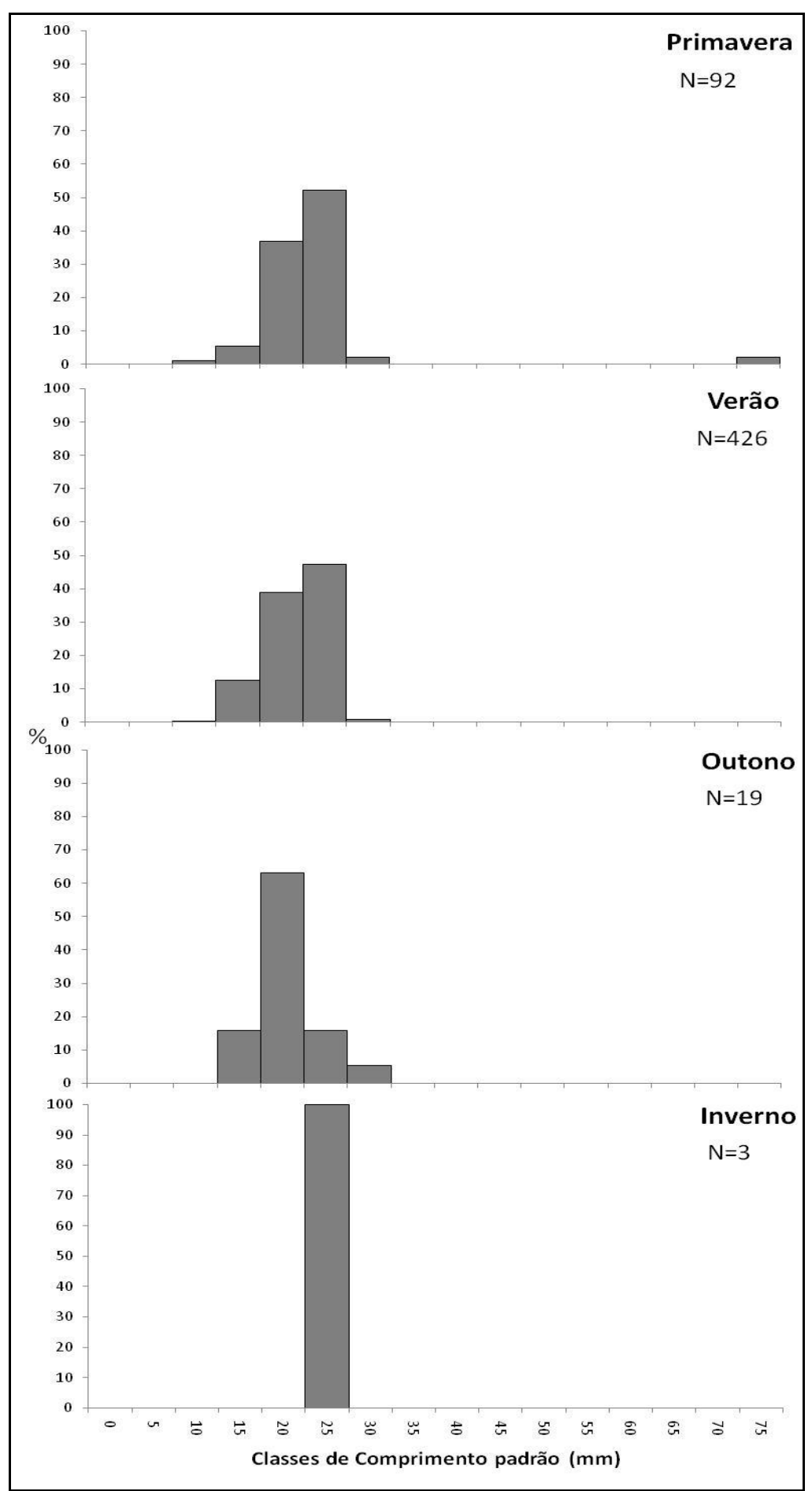

Figura 4.8. Frequência de classes de comprimento padrão para Mugil curema amostrados na zona de surfe de praias arenosas da barra sul do sistema costeiro Cananéia Iguape entre fevereiro de 2009 e janeiro de 2010. 


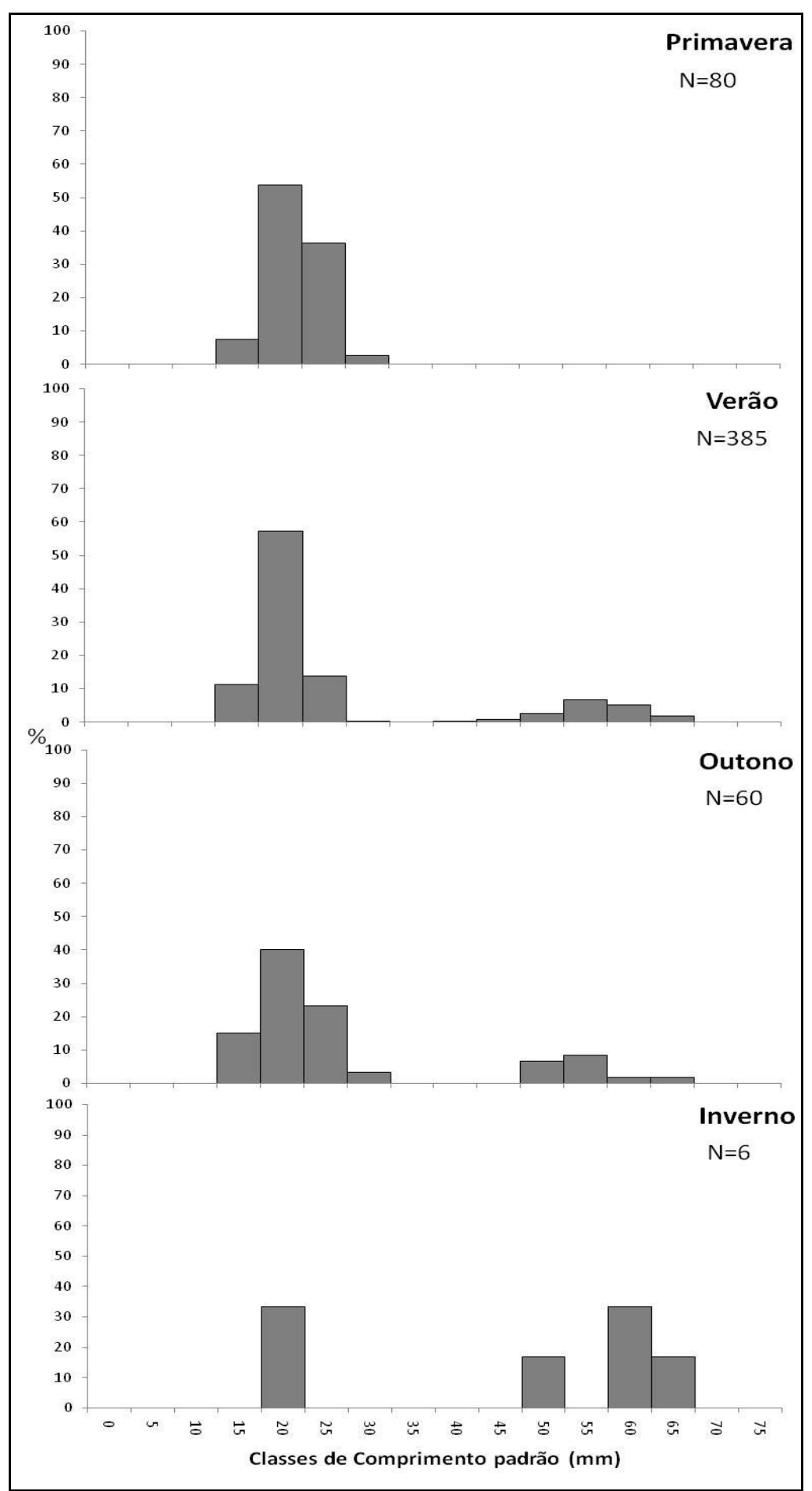

Figura 4.9. Frequência de classes de comprimento padrão para Mugil hospes amostrados na zona de surfe de praias arenosas da barra sul do sistema costeiro Cananéia Iguape entre fevereiro de 2009 e janeiro de 2010. 


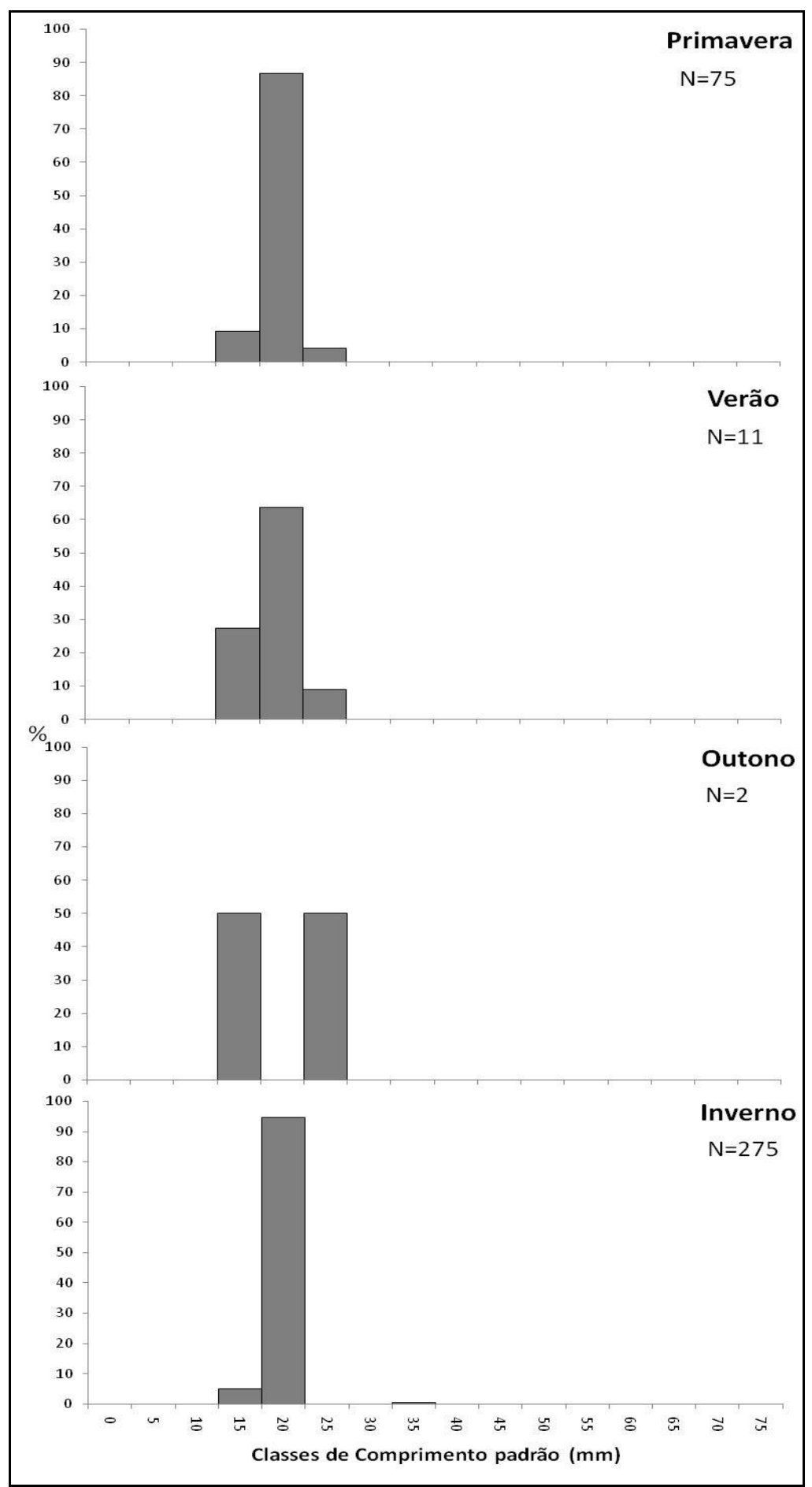

Figura 4.10. Frequência de classes de comprimento padrão para Mugil liza amostrados na zona de surfe de praias arenosas da barra sul do sistema costeiro Cananéia Iguape entre fevereiro de 2009 e janeiro de 2010. 


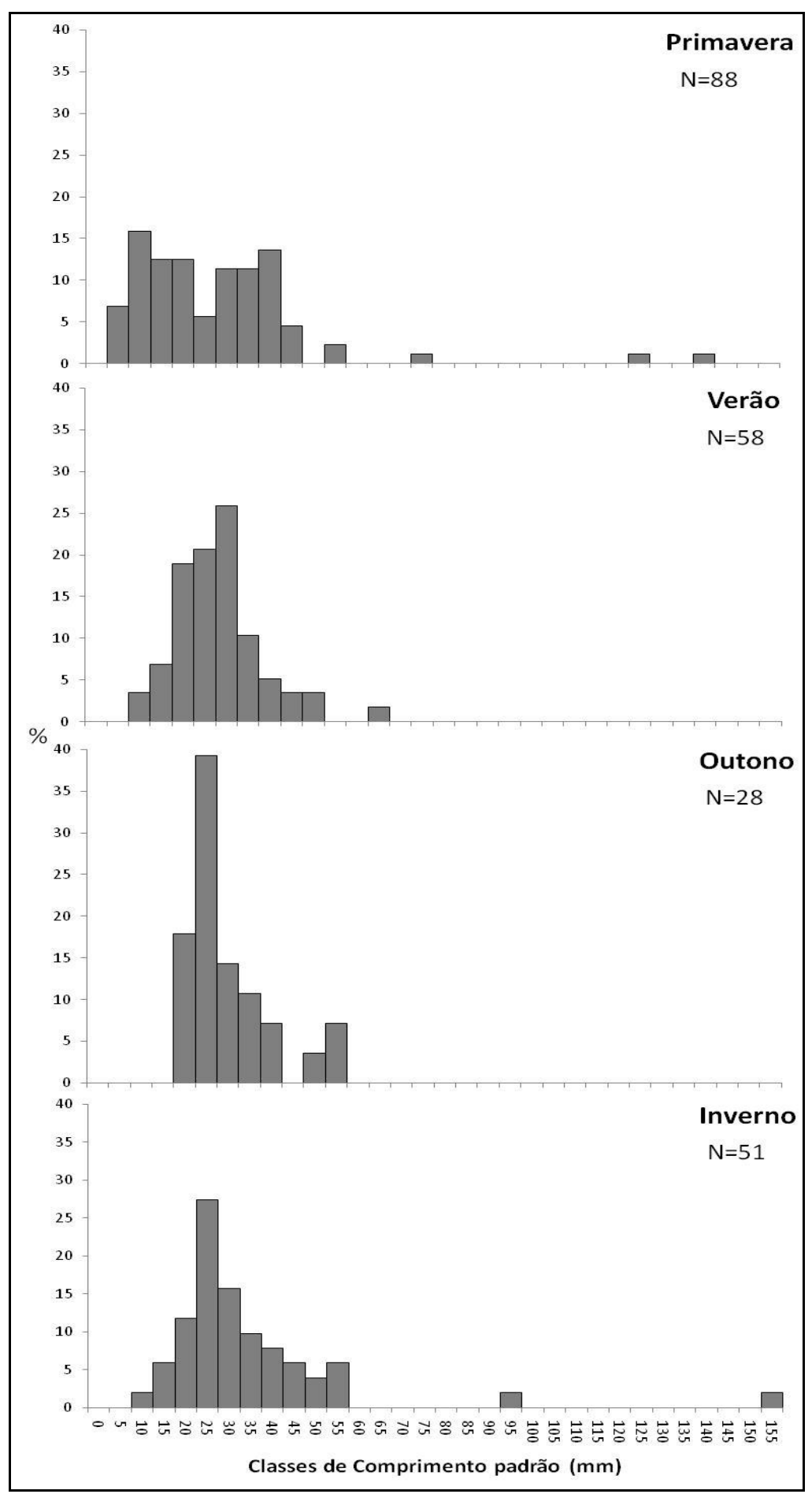

Figura 4.11. Frequência de classes de comprimento padrão para Menticirrhus littoralis amostrados na zona de surfe de praias arenosas da barra sul do sistema costeiro Cananéia Iguape entre fevereiro de 2009 e janeiro de 2010. 


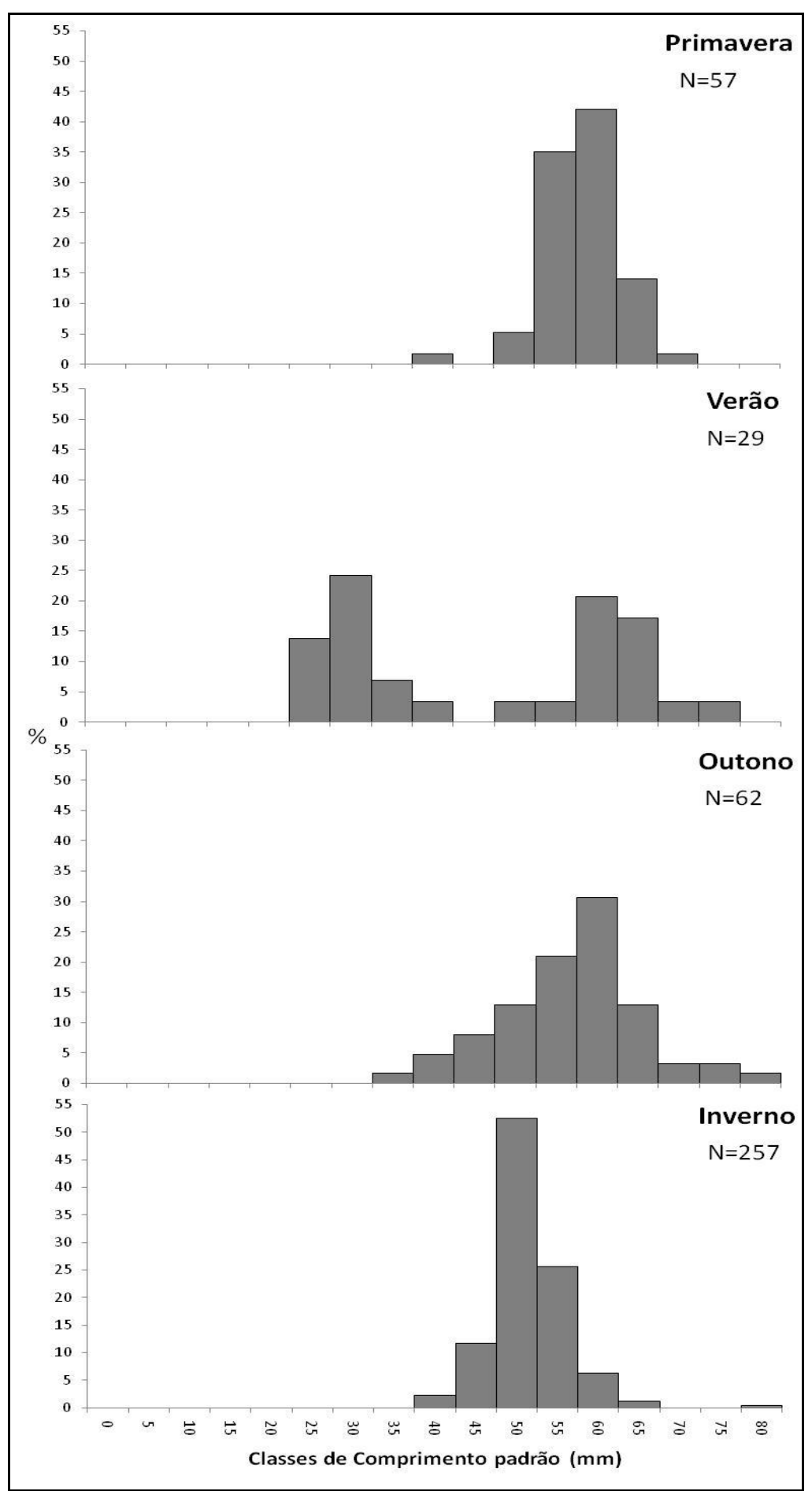

Figura 4.12. Frequência de classes de comprimento padrão para Harengula clupeola amostrados na zona de surfe de praias arenosas da barra sul do sistema costeiro Cananéia Iguape entre fevereiro de 2009 e janeiro de 2010. 


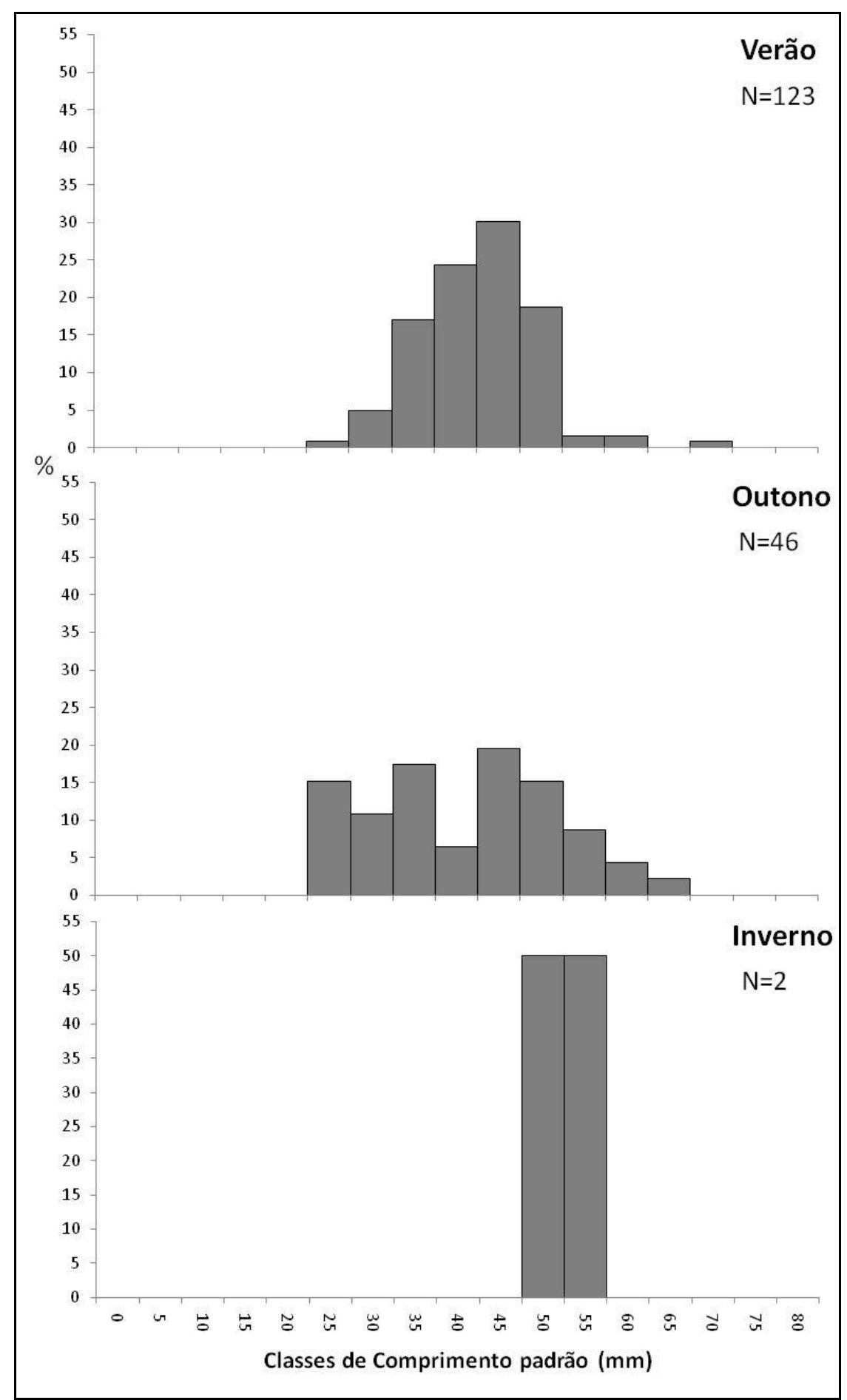

Figura 4.13. Frequência de classes de comprimento padrão para Anchoa tricolor amostrados na zona de surfe de praias arenosas da barra sul do sistema costeiro Cananéia Iguape entre fevereiro de 2009 e janeiro de 2010. 


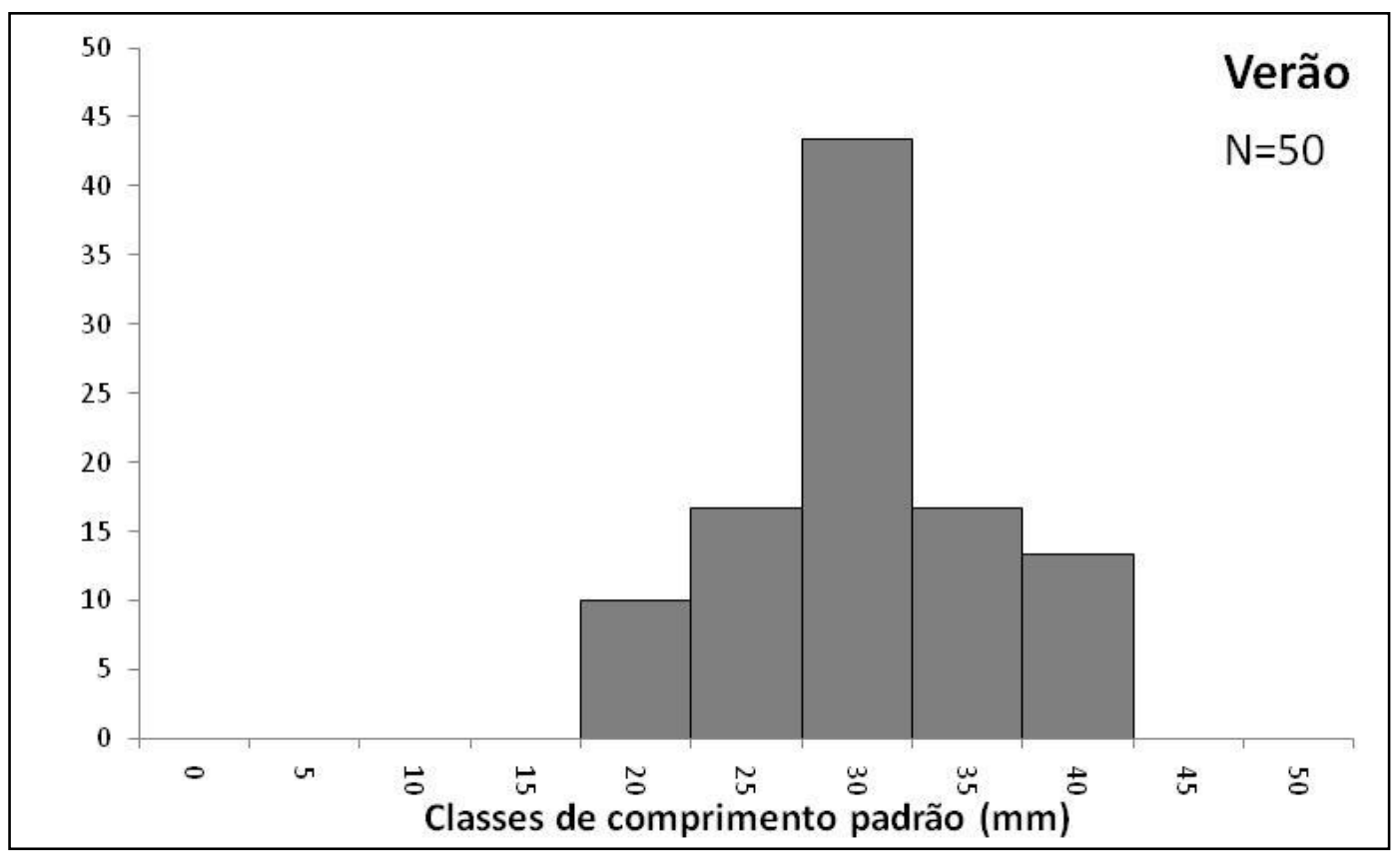

Figura 4.14. Frequência de classes de comprimento padrão para Choloroscombrus chrysurus amostrados na zona de surfe de praias arenosas da barra sul do sistema costeiro Cananéia Iguape em dezembro de 2009. 


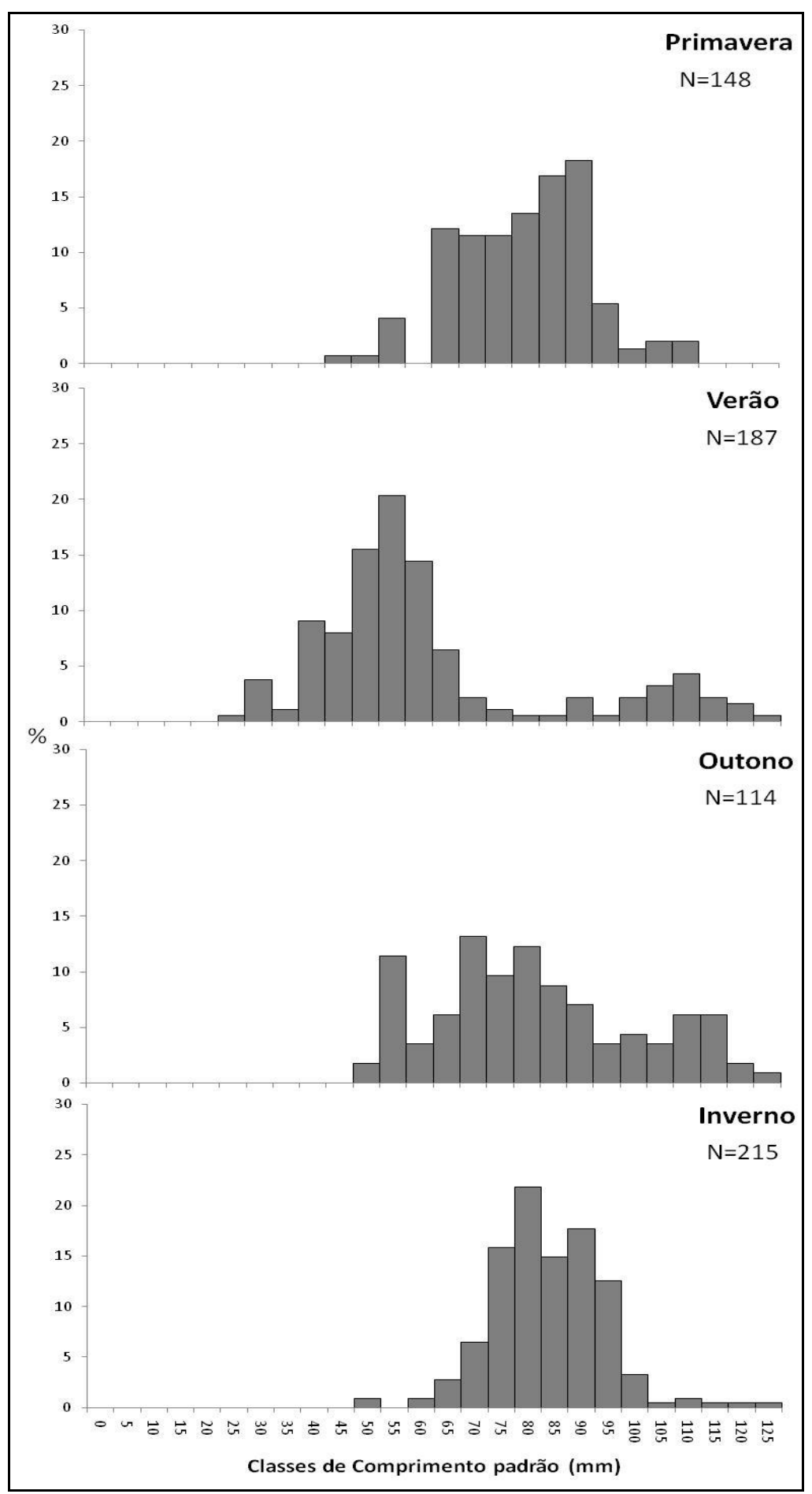

Figura 4.15. Frequência de comprimento padrão para Atherinella brasiliensis amostrados na zona de surfe de praias arenosas da barra sul do sistema costeiro Cananéia Iguape entre fevereiro de 2009 e janeiro de 2010. 


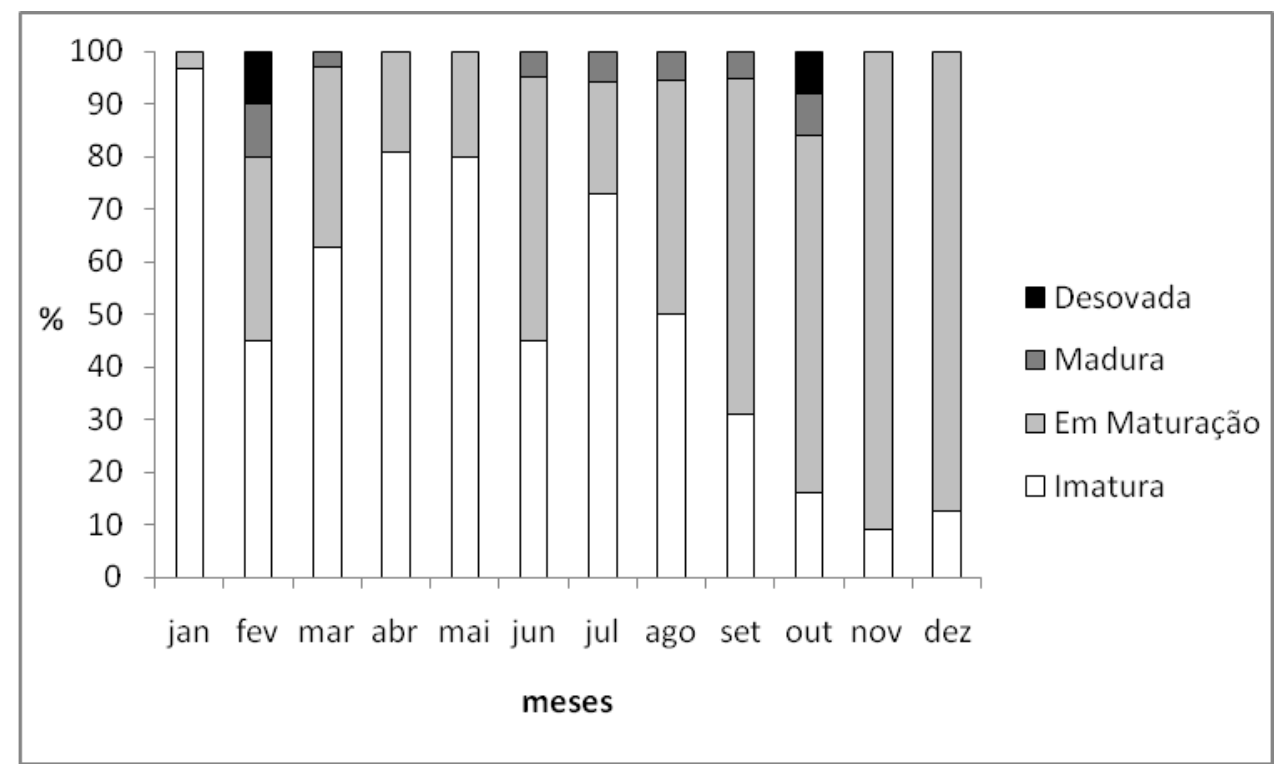

Figura 4.16. Frequência mensal de ocorrência dos estádios de maturação gonadal de Atherinella brasiliensis coletados na zona de surfe de praias arenosas da barra sul do Sistema Costeiro Cananéia Iguape entre fevereiro de 2009. 


\section{SUMÁRIO DOS RESULTADOS OBTIDOS}

Os resultados obtidos nos diferentes estudos aqui realizados podem ser sumarizados como abaixo:

- As principais características das comunidades de peixes da zona de surfe de praias arenosas, como o predomínio de juvenis e um pequeno número de espécies dominantes e constantes, foram observadas nas diferentes escalas temporais estudadas;

- Indivíduos dos gêneros Trachinotus e Mugil foram os mais abundantes tanto na Ilha do Cardoso quanto na Ilha Comprida, em ambas as escalas temporais analisadas, confirmando um padrão existente entre a zona de surfe das praias estudadas e de sistemas costeiros contíguos;

- A praia mais exposta apresentou maior valor de dominância e menores valores de equitatividade, riqueza e diversidade quando comparada com as praias abrigada e intermediária da Ilha Comprida, independentemente da escala temporal;

- Maiores valores de abundância, diversidade e riqueza foram obtidos durante a maré baixa, tanto para as amostragens intensivas de um único mês, quanto para a amostragem mensal;

- A porcentagem de explicação na variabilidade dos dados biológicos pelos dados abióticos foi de aproximadamente $38 \%$ na amostragem de longo prazo, e de $36 \%$ na de curto prazo;

- A influência da temperatura na estruturação da ictiofauna foi significativa apenas nas amostragens mensais ao longo do ano, ressaltando a importância da sazonalidade e do recrutamento na estruturação da comunidade; 
- As variações temporais de curta e longa escala foram as mais representativas, não havendo diferença notável entre a porcentagem de explicação nictemeral;

- Na Ilha Comprida, a porcentagem de explicação das variações espaciais é maior quando realizada a amostragem intensiva em um único mês, provavelmente devido à minimização dos efeitos das variáveis abióticas e biológicas que ocorrem sazonalmente;

- Na zona de surfe das praias amostradas, apenas Atherinella brasiliensis pôde ser classificada como residente;

- Juvenis de Trachinotus carolinus recrutam o ano todo, utilizando a zona de surfe para o seu crescimento, migrando para águas mais profundas com 60$70 \mathrm{~mm}$, enquanto juvenis de Trachinotus goodei e de Menticirrhus littoralis recrutam na zona de surfe das praias estudadas durante a primavera. As últimas espécies são mais abundantes em águas mais salinas e foram amostradas em grande número nas praias mais expostas;

- Os mugilídeos provavelmente utilizam a zona rasa das praias arenosas da barra de Cananéia como rota de migração entre a região oceânica e a estuarina. 


\section{CONCLUSÕES}

Os objetivos parciais enumerados nos três últimos capítulos foram cumpridos. Com relação à descrição da ictiofauna em longa e curta escala temporal, foram reforçadas as principais características gerais das comunidades de peixes da zona de surfe de praias arenosas de outras regiões, como o predomínio de juvenis e um pequeno número de espécies dominantes, constantes e residentes. Os resultados obtidos neste estudo, tanto na Ilha do Cardoso quanto na Ilha Comprida, em ambas as escalas temporais analisadas, confirmaram a presença de um padrão ictiofaunístico existente na zona de surfe das praias de sistemas costeiros contíguos ao sul, em que indivíduos dos gêneros Trachinotus e Mugil são os mais abundantes.

Por outro lado, com relação à influência das variáveis ambientais, foi mostrado que as diferenças na composição e estrutura da ictiofauna foram explicadas pelas variáveis abióticas medidas, tanto na amostragem de longo prazo, quanto na de curto prazo; porém, a influência da temperatura nessa estruturação foi significativa apenas nas amostragens mensais ao longo do ano. As variações sazonais e o recrutamento também foram importantes.

A partir dos resultados deste estudo foi possível responder as hipóteses formuladas no primeiro capítulo. A primeira hipótese, de que as variáveis abióticas influenciariam a composição e a estrutura da comunidade ictíica da zona surfe de praias arenosas de maneiras distintas, quando analisadas em diferentes escalas temporais, foi parcialmente confirmada: à influência das variáveis abióticas se deve incluir as variações sazonais do recrutamento de diferentes espécies como explicadoras, ou seja, também as forçantes bióticas como condicionantes.

A segunda hipótese, de que a zona de surfe de praias arenosas é utilizada como área de crescimento ou como rota de migração para a grande maioria das espécies de actinopterígios encontrados nesse ambiente foi confirmada, pela presença de juvenis de diversas espécies, independente do grau de exposição, local, ou escala temporal considerada. 


\section{SUGESTÕES PARA TRABALHOS FUTUROS}

Seguem algumas sugestões para trabalhos futuros, tendo como base as dificuldades encontradas no presente estudo:

- Utilizar mais de um aparelho de pesca com malhagens e tamanhos diferentes, visando eliminar a seletividade de um único aparelho. A utilização de uma embarcação de pequeno porte motorizada aumentaria a velocidade do arrasto, podendo minimizar a fuga de espécimes de melhor capacidade natatória;

- Classificar corretamente o estado morfodinâmico das praias estudadas, realizando medidas do perfil praial, análise granulométrica e amplitude da zona de surfe, entre outras medidas;

- Avaliar uma maior quantidade de fatores abióticos e bióticos, como altura das ondas, velocidade dos ventos, quantidade de macroalgas e/ou matéria orgânica em decomposição, quantidade de fitoplâncton e de zooplâncton disponível, entre outros.

- Realizar amostragens intensivas mensalmente ao longo de um ano, visando entender a influência das marés de sizígia e quadratura e das diferentes fases lunar na composição e estrutura da comunidade de peixes. Do mesmo modo, realizar coletas nos períodos diurnos e noturnos, para buscar variações de curto prazo não abrangidas no presente trabalho;

- Estudar a taxa de crescimento dos juvenis amostrados na zona de surfe, para então melhor relacionar o período de desova com o de recrutamento. 


\section{BIBLIOGRAFIA}

ABOU-SEEDO, F.; CLAYTON, D.A.; WRIGHT, J.M. 1990. Tidal and turbidity effects on the shallow-water fish assemblage of Kuwait Bay. Mar. ecol., Prog. ser., v. 65 , p. 213-223.

AGUIRRE, A.L.I.; GALLARDO-CABELLO, M. 2004. Reproduction of Mugil cephalus (Pisces: Mugilidae) from a coastal lagoon in the Gulf of México. Bull. mar. sci., v. 75, n. 1, p. 37-49.

ANDRADE-TALMELLI, E.F.A.; ROMAGOSA, E.; NARAHARA, M.Y.; GODINHO, H.M. 1996. Características reprodutivas de Tainha Mugil platanus (Teleostei, Perciformes, Mugilidae), da região Estuarino-Lagunar de Cananéia, São Paulo. Ceres, v. 43, n. 246, p. 165-185.

ARAÚJO, C.C.V.; ROSA, D.M.; FERNANDES, J.M.; RIPOLI, L.V.; KROLING, W. 2008. Composição e estrutura da comunidade de peixes de uma praia arenosa da Ilha do Frade,Vitória, Espírito Santo. Iheringia, Sér. zool., v. 98, n. 1, p. 129-135.

BARLETTA-BERGAN, A.; BARLETTA, M.; SAINT-PAUL, U. 2002. Comunity structure and temporal variability of ichthyoplankton in north Brazilian mangrove creeks. J. fish biol., v. 61, Suppl. 1, p. 33-51.

BARLETTA, M.; BARLETTA-BERGAN, A.; SAINT-PAUL,U.; HUBOLD,G. 2005. The role of salinity in structuring the fish assemblages in a tropical estuary. J. fish boil., v.66, n.1, p. 45-72.

BARRERA-ALBA, J.J. 2004. Dinâmica metabólica e transporte de propriedades no sistema Estuarino-Lagunar de Cananéia-Iguape. 216 f. Tese (Doutorado em Oceanografia Biológica)- Instituto Oceanográfico, Universidade de São Paulo, São Paulo.

BEGON, M.; TOWNSEND, C.R.; HARPER, J.L. 2006. Ecology: from individuals to ecosystem. 4th .edition. Victoria: Blackwell Publishing. 759 p.

BENNETT, B.A. 1989. The fish community of a moderately exposed beach on the southwestern cape coast of South Africa and an assessment of this habitat a nursey for juvenile fish. Estuar., coast. shelf sci., v. 28, n. 3, p. 293-305. 
BÉRGAMO, A. L. 2000. Características da hidrografia, circulação e transporte de sal: barra de Cananéia, sul do Mar de Cananéia, e baía do Trapandé. 254 f. Dissertação (Mestrado em Oceanografia Biológica) - Instituto Oceanográfico, Universidade de São Paulo, São Paulo.

BERNARDES M.E.C., MIRANDA, L.B. 2001. Circulação estacionária e estratificação de sal em canais estuarinos: simulação com modelos analíticos. Rev. bras. Oceanogr., v. 49, n.1/2, p.115-132.

BOMVENTI T.; WAINER, I. E. K. C.; MOITA, D. M. S.; TONELLI, M.; SCHULTZ, C. 2006. Análise dos parâmetros meteorológicos de superfície do município de Cananéia. In: III Simpósio Brasileiro de Oceanografia, São Paulo. Resumos do III Simpósio Brasileiro de Oceanografia. São Paulo: IOUSP. p. 27.

BONETTI-FILHO, J. ; L. B. DE MIRANDA, 1997. Estimativa de descarga de água doce no sistema estuarino-lagunar de Cananéia-Iguape. Bol. Inst. Oceanogr., v.45, n. $1 / 2$, p. 89-94.

BORCARD, D.; LEGENDRE, P.; DRAPEAU, P. 1992. Partialling out the spatial component of ecological variation. Ecology, v. 73, n. 3, p. 1045 -1055.

BRAUN, A.S.; FOUNTOURA, N.F. 2004. Reproductive biology of Menticirrhus littoralis in southern Brazil (Actinopterygii: Perciformes: Sciaenidae). Neotrop. ichthyol., v. 2, n. 1, p. 31-36.

BRICHTA, M. 1999. Biomassa e Produção Autotrófica Planctônica no Complexo Estuarino-Lagunar de Iguape-Cananéia. 93 f. Dissertação (Mestrado em Oceanografia Biológica) - Instituto Oceanográfico, Universidade de São Paulo, São Paulo.

BROWN, A.C.; MCLACHLAN, A. 1990. Ecology of sandy shores. New York: Elsevier. 328 p.

CARPENTER, K. E. (Ed.) 2002. The living marine resource of the western central Atlantic. Volume 3: Bony fishes part 2 (Opistognathidae to Molidae), sea turtles and marine mammals. Rome: Food Agriculture Organization of the United Nations. p. 1375-2127.

CARTER, R.W.G. 1988. Coastal environments. An introduction to physical, ecological and cultural systems of coastlines. London: Academic Press. 617 p. 
CERGOLE, M.C. 1986. Aspectos sobre a biologia de M. curema VALLENCINES, 1836 (Pisces, Mugilidae) no estuário de São Vicente, SP. 272 f. Dissertação (Mestrado em Oceanografia Biológica) - Instituto Oceanográfico, Universidade de São Paulo, São Paulo.

CHANG, C.W.; TZENG, W.N.; LEE, Y.C. 2000. Recruitment and hatching dates of Grey Mullet (Mugil cephalus L.) juveniles in the Tanshui estuary of Northwest Taiwan. Zool. stud., v. 39, n. 2, p. 99-106.

CLARK, B.M.; BENNETT, B.A.; LAMBERT, S.J. 1994. A comparasion of the ichthyofauna of two estuaries and their adjacent surf zones, with an assessment of the effects of beach-seinning on the nursery function of estuaries for fish. S. Afr. J. mar. Sci. v. 14, p. 121-131.

CLARK, B.M.; BENNETT, B.A., LAMBERT, S.J. 1996a. Temporal variations in surf zone fish assemblages from False Bay, South Africa. Mar. ecol., Prog. ser., v. 131, p. 35-47.

CLARK, B.M.; BENNETT, B.A.; LAMBERT, S.J. 1996b. Factors affecting spatial variability in seine net catches of fish in the surf zone of False Bay, South Africa. Mar. ecol., Prog. ser., v. 131, p. 17-34.

CLARK, B.M. 1997. Variation in Surf-zone Fish Community Structure Across a Waveexposure Gradient. Estuar., coast. shelf sci., v. 44, n.6, p. 659-674.

CONTENTE, R.F.; FAVERO, J.M.; VILLAMARIN, B.C.; IMOTO, R.D.; PRADO, A.F.; CORTEZI, M.; DIAS, J.F. 2010a. Riqueza de peixes do Sistema Costeiro Cananéia-Iguape. In: Anais do III Congresso Brasileiro de Oceanografia, Rio Grande. CD-ROOM.

CONTENTE, R.F.; STEFANONI, M.F.; SPACH, H.L. 2010b. Feeding ecology of the Brazilian silverside Atherinella brasiliensis (Atherinopsidae) in a sub-tropical estuarine ecosystem. J. Mar. Biol. Assoc. U.K. In press.

COWLEY, P.D.; WHITFIELD, A.K.; BELL, K.N.I. 2001. The Surf Zone Ichthyoplankton Adjacent to an Intermittently Open Estuary, with Evidence of Recruitment during Marine Overwash Events. Estuar., coast. shelf. Sci., v. 52, p. 339-348.

DAJOZ, R. 1983. Ecologia Geral. 2nd edição. São Paulo: Editora da Universidade de São Paulo. 472 p.

DAY JR., J. W.; HALL, C. A. S.; KEMP, W. M.; YÁÑEZ-ARANCIBIA, A. 1989. Estuarine ecology. New York: John Wiley Sons. 558 p. 
DIAS, J.F.; PERES-RIOS, E.; CHAVES, P.T.C.; ROSSI-WONGTSCHOWSKI, C.L.D.B. 1998. Análise macroscópica dos ovários de teleósteos: problemas de classificação e recomendações de procedimentos. Rev. Brasil. Biol., v. 58, n. 1, p. $55-69$.

ESPER, M.L.P.; MENEZES, M.S.; ESPER, W. 2001. Época reprodutiva de Mugil platanus (Günther, 1880), Pisces Mugilidae da Baia de Paranaguá (Paraná, Brasil). Acta Biol. Par., v. 30, n. 1,2,3,4, p. 5-17.

FÁVARO, L.F.; LOPES, S.C.G.; SPACH, H.L. 2003. Reprodução do peixe, Atherinella brasiliensis (Quoy \& Gaimard) (Atheriniformes, Atherinidae), em uma planície de maré adjacente à gamboa do Baguaçu, Baía de Paranaguá, Paraná, Brasil. Rev. bras. Zool., v. 20, n. 3, p. 501-506.

FÁVARO, L.F.; OLIVEIRA, E.C.; VERANI, N.F. 2007. Estrutura da população e aspectos reprodutivos do peixe-rei Atherinella brasiliensis (Quoy \& Gaimard) (Atheriniformes, Atherinopsidae) em áreas rasas do Complexo Estuarino de Paranaguá, Paraná, Brasil. Rev. bras. Zool., v. 24, n. 4, p. 1150-1156.

FÉLIX, F.C.; SPACH, H.L.; HACKRADT, C.W.; MORO, P.S.; ROCHA, D.C. 2006. Abundância sazonal e a composição da assembléia de peixes em duas praias estuarinas da Baía de Paranaguá, Paraná. Rev. bras. zoociênc., v. 8, n. 1, p. 35-47.

FÉLIX, F.C.; SPACH, H.L.; MORO, P.S.; HACKRADT, C.W.; QUEIROZ, G.M.L.N.; HOSTIM-SILVA, M. 2007a. Icthyofauna composition across a wave - energy gradient on southern Brazil beaches. Braz. j. oceanogr., v. 55, n. 4, p. 281-292.

FÉLIX, F.C.; SPACH, H.L.; MORO, P.S.; SCHWARZ JR. R.; SANTOS, C.; HACKRADT, C.W.; HOSTIM-SILVA, M. 2007b. Utilization pattern of surf zone inhabiting fish from beaches in Southern Brazil. Pan-Am. j. aquat. sci., v. 2, n. 1, p. 27-39.

FERNADEZ, W.S. 2007. Dinâmica populacional de Atherinella brasiliensis (Quoy \& Gaimard, 1824) da Praia de Itamambuca (SP). 144 f. Dissertação (Mestrado em Oceanografia Biológica)- Instituto Oceanográfico, Universidade de São Paulo, São Paulo.

FERREIRA, L.I. 1989. Estudos de aspectos da reprodução de Mugil curema Vallenciennes, 1836 (Pisces, Mugilidae) no estuário de São Vicente, SP. 90 f. Dissertação (Mestrado em Oceanografia Biológica) - Instituto Oceanográfico, Universidade de São Paulo, São Paulo. 
FIELDS, H.M. 1962. Pompanos (Trachinotus spp.) of South Atlantic coast of United States. Fish. Bull., v. 62, p. 189-222.

FIGUEIREDO, J.L.; MENEZES, N.A. 1978. Manual de peixes marinhos do sudeste do Brasil. II. Teleostei (1). São Paulo: Museu de Zoologia da Universidade de São Paulo, 110 p.

FIGUEIREDO, J.L.; MENEZES, N.A. 1980. Manual de peixes marinhos do sudeste do Brasil. III. Teleostei (2). São Paulo: Museu de Zoologia da Universidade de São Paulo, 90 p.

FIGUEIREDO, J.L.; MENEZES, N.A. 2000. Manual de peixes marinhos do sudeste do Brasil. VI. Teleostei (5). São Paulo: Museu de Zoologia da Universidade de São Paulo, 116 p.

GAELZER, L.R.; ZALMON, I.R. 2003. The influence of wave gradient on the ichthyofauna of Southeastern Brazil: Focusing the Community structure in Surf zone. J. coast. res., v. 35, p. 456-462.

GAELZER, L.R.; ZALMON, I.R. 2008a. Diel variation of fish community in sandy beaches of southeastern Brazil. Braz. j. oceanogr., v. 56, n. 1, p. 23-39.

GAELZER, L.R.; ZALMON, I.R. 2008b. Tidal influence on surf zone ichthyofauna structure ate three sandy beaches, Southeastern Brazil. Braz. j. oceanogr., v. 56, n. 3 , p. $165-177$.

GIANNINI, R.; PAIVA FILHO, A.M. 1995. Análise comparativa da ictiofauna da zona de arrebentação de praias arenosas do Estado de São Paulo, Brasil. Bol. Inst. Oceanogr., v. 43, n. 2, p. 141-152.

GIBSON, R.N.; ROBB, L.; BURROWS, M.T.; ANSELL, A.D. 1996. Tidal, diel and longer term changes in the distribution of fishes on a Scottish sandy beach. Mar. ecol., Prog. ser., v. 130, p. 1-17.

GODEFROID, R.S.; HOFSTAETTER, M.; SPACH, H.L. 1998. Moon, tidal and diel influences on catch composition of fishes in the surf zone of Pontal do Sul Beach, Paraná. Rev. Bras. Zool. v. 15, n. 3, p. 697 -701.

GODEFROID, R.S.; SANTOS, C; HOFSTAETTER, M; SPACH, H.L. 2001. Occurrence of Larvae and Juveniles of Eucinostomus argenteus, Eucinostomus gula, Menticirrhus americanus, Menticirrhus littoralis, Umbrina coroides and Micropogonias furnieri at Pontal do Sul beach, Paraná. Braz. arch. biol. technol., v. 44, n. 4 , p. 411-418. 
GODEFROID, R.S.; SPACH, H.L.; SCHWARZ JR, R.; MACLAREN, G. 2003a. A fauna de peixes da praia do Balneário Atami, Paraná, Brasil. Atlântica, v. 25, n. 2, p. $147-161$.

GODEFROID, R.S.; SPACH, H.L.; SCHWARZ JR, R.; QUEIROZ, G.M.L.N.; OLIVEIRA NETO, J.F. 2003b. Efeito da lua e da maré na captura de peixes em uma planície de maré da Baía de Paranaguá, Paraná, Brasil. Bol. Inst. Pesca, v. 29 , n. 1, p. $47-55$.

GODEFROID, R.S.; SPACH, H.L.; SANTOS, C.; MACLAREN, G.; SCHWARZ Jr, R. 2004. Mudanças temporais na abundância e diversidade da fauna de peixes do infralitoral raso de uma praia do sul do Brasil. Iheringia, Sér. Zool., v. 94, n. 1, p. 95:104.

GOMES, M.P.; CUNHA, M.S.; ZALMON, I.R. 2003. Spatial and temporal variations of diurnal ichthyofauna on surf-zone of São Francisco do Itabapoaba Beaches, Rio de Janeiro state, Brazil. Braz. arch. biol. technol., v. 46, n. 4, p. 653-664.

HARDEN JONES, F. R., 1968. Fish migration. London: Edward Arnold. 325 p.

HARRIS, S.A.; CYRUS, D.P. 1996. Larval and Juvenile Fishes in the Surf Zone Adjacent to the St Lucia Estuary Mouth, KwaZulu-Natal, South Africa. Mar. Freshw. res., v. 47, n. 3, p. 465-482.

HJORT, J. 1914. Fluctuations in the great fisheries of northern Europe viewed in the light of biological research. J. Cons. - Cons. perm. int. explor. mer., v. 20, p. 1228.

HUAQUÍM, L.G. 1980. Filamentos coriales en ovócitos y huevos de Basilichthys australis Elgenmann (Osteichthyes: Atherinidae). Arquivos de Biologia y Medicina Experimental, v. 13, n. 1, p. 70.

HUNTER, J. R.; GOLDBERG, S. R. 1980. Spawning incidence and batch fecundity in Northern Anchovy Engraulis mordax. Fish. Bull., v. 77, n. 3, p.641-652.

INOUE, T.; SUDA, Y.; SANO, M. 2008. Surf zone fishes in an exposed sandy beach at Sanrimatsubara, Japan: Does fish assemblage structure differ among microhabitats? Estuar., coast. shelf. sci., v. 77, n. 1, p. 1-11.

IPCC - INTERGOVERNMENTAL PANEL ON CLIMATE CHANGE. Disponível em: <http://www.ipcc.ch/index.htm>. Acesso em 17 dez. 2010.

JENNINGS, S.; KAISER, M.J.; REYNOLDS, J.D. 2001. Marine Fisheries Ecology. USA: Blackwell Science. 417p. 
LASIAK, T.A. 1981. Nursey grounds of juvenile teleosts: evidence from the surf-zone of King's Beach, Port Elizabeth. S. Afric. j. mar. sci., v. 77, p. 388-390.

LASIAK, T.A. 1984a. Structural aspects of the surf-zone fish assemblage at King's Beach, Algoa Bay, South Africa: short term fluctuations. Estuar., coast. shelf. sci., v. 18, n. 3, p. 347-360.

LASIAK, T.A. 1984b. Structural aspects of the surf-zone fish assemblage at King's Beach, Algoa Bay, South Africa: Long-term fluctuations. Estuar., coast. shelf. sci., v. 18 , n. 5 , p. 459-483.

LAYMAN, C.A. 2000. Fish Assemblage Structure of the Shallow Ocean Surf-Zone on the Eastern Shore of Virginia Barrier Islands. Estuar., coast. shelf. sci., v.51, n. 2, p. 201-213.

LEGENDRE, P.; LEGENDRE, L. 1998. Numerical ecology. Amsterdam: Elsevier Science B.V. 870 p.

LEMOS, V.M.; CORDEIRO, G.J.; VIEIRA, J.P. 2010. Recrutamento de Trachinotus marginatus (Cuvier 1832) (Teleostei, Carangidae) na Praia do Cassino, Rio Grande, RS. In: Anais do III Congresso Brasileiro de Oceanografia, Rio Grande. CD-ROOM.

LIMA, M.S.P.; VIEIRA, J.P. 2009. Variação espaço-temporal da ictiofauna da zona de arrebentação da Praia do Cassino, Rio Grande do Sul, Brasil. Zoologia, v. 26, n. 3, p. $499-510$.

LIRA, A.K.F.; TEIXEIRA, S.F. 2008. Ictiofauna da praia de Jaguaribe, Itamaracá, Pernambuco. Iheringia, Sér. Zool., v. 98, n. 4, p. 475-480. 
MACIEL, N.A.L. 2001. Composição, Abundância e distribuição espaço-temporal da ictiofauna do Complexo Estuarino Lagunar de Iguape-Cananéia- São Paulo, Brasil. 252 f. Tese (Doutorado em Oceanografia Biológica)- Instituto Oceanográfico, Universidade de São Paulo, São Paulo.

MARÍN, B.J.; QUINTERO A.; BUSSIÈRE, D.; DODSON, J.J. 2003. Reproduction and recruitment of White Mullet (Mugil curema) to a tropical lagoon (Margarita Island, Venezuela) as revealed by otolith microstrucutre. Fish. Bull., v. 101, n. 4, p. 809-821.

MARÍN, B.M.; DIAZ, O.; BRICEÑO, R. 1995. Aspectos descriptivos de los ovócitos y postlarva de tinicalo Xenomelaniris brasiliensis (Quoy \& Gaimard) (Pisces: Atherinidae). Bol. Inst. Oceanogr., v. 34, n. 1,2, p. 59 - 68.

MARQUEZ, M.R.K.; MAHIQUES, M.M. 2010. Variações morfológicas no prisma praial da Ilha Comprida (Sudeste do Brasil) - Subsídios para uma Gestão Costeira Sustentável. Revista da Gestão Costeira Integrada, v.10, n.3, p.361-379.

MCFARLAND, W.N. 1963. Seasonal change in the number and biomass of fishes from the surf at Mustang Island, Texas. Publ. Inst. Mar. Sci. Univ. v. 9, p. 91-112.

MCHUGH, J. L. 1985. The estuarine ecosystem integrated. In: YÁÑES-ARANCIBA, A. Fish community ecology in estuaries and coastal lagoons: towards an ecosystem integration. Cidade do México: UNAM Press, p. 9-16.

MCLACHALAN A. 1983. Sandy beach ecology - a review. In: MACLACHLAN A.; ERASMUS, T. (eds). Sandy beaches as ecosystems. Junk: The Hague, p. 321380.

MCLACHLAN, A., ERASMUS, T., VAN DER HORST, G., ROSSOUW G., LASIAK, T.A.; MCGMYNNE, L. 1981. Sand beach energetics: an ecosystem approach towards a high energy interface. Estuar., coast. shelf sci., v. 13, n. 1 p. 11-25.

MCLACHLAN, A., ERASMUS, T., VAN DER HORST, G., ROSSOUW G., LASIAK, T.A.; MCGMYNNE, L. 1981. Sand beach energetics: an ecosystem approach towards a high energy interface. Estuar., coast. shelf sci., v. 13, n. 1 p. 11-25.

MEDINA, S.V.; YUNDA, G.A.G. 2008. reporte preliminar de la ictiofauna capturada con chinchorro playero en las playas Salguero y Aeropuerto, Santa Marta, Caribe Colombiano. Arq. Ciên. mar., v. 41, n. 1, p. 58-66.

MENDONÇA, J.T.; KATSURAGAWA, M. 1997. Desembarque da pesca costeira em Cananéia (São Paulo), Brasil, durante 1995 e 1996. Nerítica, v. 11, p.1965-190. 
MENDONÇA, J. T. 1998. A Pesca na região de Cananéia - SP, nos anos de 1995 e 1996. 90 f. Dissertação (Mestrado em Oceanografia Biológica)- Instituto Oceanográfico, Universidade de São Paulo, São Paulo.

MENDONÇA, J.T.; KATSURAGAWA, M. 2001. Caracterização da pesca artesanal no complexo estuarino-lagunar de Cananéia-Iguape, Estado de São Paulo, Brasil (1995-1996). Acta Scientiarium, v.23, n.2, p. 535-547.

MENDONÇA, J.T.; MIRANDA, L.V. 2008. Estatística pesqueira do litoral sul do estado de São Paulo: subsídios para a gestão compartilhada. Pan-Am. j. aquat. sci., v.3, n.3, p.152-173.

MENEZES, N.A.; FIGUEIREDO, J.L. 1980. Manual de peixes marinhos do sudeste do Brasil. IV. Teleostei (3). São Paulo: Museu de Zoologia da Universidade de São Paulo, 1-96p.

MENEZES, N.A.; FIGUEIREDO, J.L. 1985. Manual de peixes marinhos do sudeste do Brasil. V. Teleostei (4). São Paulo: Museu de Zoologia da Universidade de São Paulo, 105p.

MENEZES, N.A.; BUCKUP, P.A.; FIGUEIREDO, J.L.; MOURA, R.L. 2003. Catálogo de peixes marinhos do Brasil. São Paulo: Museu de Zoologia da USP, $159 \mathrm{p}$.

MENEZES, N.A.; OLIVEIRA, C.; NIRCHIO, N. An old taxonomic dilemma: the identity of the western south Atlantic lebranche mullet (Teleostei: Perciformes: Mugilidae). Zootaxa, v. 2519, p.59-68.

MINIUSSI, I. C. 1959. Propagação de maré em torno da Ilha de Cananéia. Contrib. avulsas Inst. Oceanogr., Oceanogr. Fís., v. 2, p. 1-8.

MIRANDA, L. B. de; MESQUITA, A. R. de; FRANÇA, C. A. de S. 1995. Estudo da circulação e dos processos de misturas no extremo sul do mar de Cananéia: condições de dezembro de 1991. Bol. Inst. Oceanogr., v. 43, n. 2, p.101-113.

MIRANDA, L. B. de; CASTRO FILHO, B.M. de. 1996. On the salt transport in the Cananéia Sea during a spring tide experiment. Bol. Inst. Oceanogr., v. 44, n. 2, p. 123-133.

MIRANDA, L.B. de; CASTRO, B.M. ; KJERFVE, B. 2002. Princípios de Oceanografia Física de Estuários. São Paulo: Editora da Universidade de São Paulo. 424 p. 
MISHIMA, M., N YAMANAKA, O. M. PEREIRA, F. DAS C. SOARES, C. SINQUE, S AKABOSHI E O, JACOBSEN, 1985. Hidrografia do complexo estuarinolagunar de Cananéia $\left(25^{\circ} \mathrm{S}\right.$ e $\left.48^{\circ} \mathrm{W}\right)$, São Paulo, Brasil. Bol. Inst. Pesca, v. 12, n. 3, p. 109-121.

MIYAO, S. Y. 1976. Estudo de alguns aspectos da região estuarina de Cananéia. 90 f. Dissertação (Mestrado em Oceanografia Química e Geológica)- Instituto Oceanográfico, Universidade de São Paulo, São Paulo.

MIYAO, S. Y.; NISHIHARA, L. 1989. Estudo preliminar da maré e das correntes de maré na região estuarina de Cananéia $\left(25^{\circ} \mathrm{S}\right.$ e $\left.48^{\circ} \mathrm{W}\right)$. Bol. Inst. Oceanogr., v. 37 , n. 2, p.107-123.

MODDE,T. 1980. Growth and residency of juvenile fishes within a surf zone habitat in the Gulf of México. Gulf res. rep., v. 6, n. 4, p. 377-385.

MONTEIRO NETO, C.; TUBINO, R.A.; MORAES, L.E.S.; MENDONÇA NETO, J. P.; ESTEVES, G.V.; FORTES, W.L. 2008. Associações de peixes na região costeira de Itaipu, Niterói, RJ. Iheringia, Ser. Zool., v.98, n.1, p.50-59.

MORAIS, A. T. de; MORAIS, L. T. de. 1994. The abundance and diversity of larval and juvenile fish in a tropical estuary. Estuaries, v. 17, p. 216-225.

NASCIMENTO, D.R. Jr., 2006. Morfologia e Sedimentologia ao longo do sistema praia-duna frontal de Ilha Comprida, SP. 156 f. Dissertação (Mestrado em Geologia Sedimentar)- Instituto de Geociências, Universidade de São Paulo, São Paulo.

NYBAKKEN, J.M.; BERTNESS, M.D. 2004. Marine Biology: na ecological approach. São Francisco: Pearson, Benjammin Cummings, 579 p.

OLIVEIRA-NETO, J. F.; GODEFROID, R. S.; QUEIROZ, G. M. L. N.; SCHWARZ Jr., R. 2004. Variação diurna na captura de peixes em uma planície de maré da Baía de Paranaguá, PR. Acta Biol. Leopold., v. 26, p. 125- 138.

OLIVEIRA-SILVA, J.T.; PESO-AGUIAR, M.C.; LOPES, P.R.D. 2008. Ictiofauna das praias de Cabuçu e Berlinque: Uma contribuição ao conhecimento das comunidades de peixes na Baía de Todos os Santos - Bahia - Brasil. Biotemas, v. 21, n. 4, p. 105-115.

PAIVA FILHO, A.M.; TOSCANO, A.P. 1987. Estudo comparativo e variação sazonal da ictiofauna na zona entremarés do Mar Casado - Guarujá e Mar Pequeno - São Vicente, SP. Bol. Inst. Oceanogr., v. 35, n. 2, p. 153-165. 
PAIVA FILHO, A. M.; GIANNINI, R. A.; RIBEIRO NETO, F. B.; SCHMIEGELOW, J. M. M. 1987. Ictiofauna do complexo Baía Estuário de Santos e São Vicente, SP, Brasil. Relat. int. Inst. Oceanogr., v. 17, p. 1-10.

PEREIRA, L. E. 1994. Variação diurna e sazonal dos peixes demersais na barra do estuário da Lagoa dos Patos, RS. Atlântica, v.16, p.5-21.

PERES - RIOS, E. 2001. Papel do estuário no ciclo de vida das espécies dominantes da ictiofauna do Complexo Estuarino - Lagunar de Cananéia - Iguape. 128 f. Tese (Doutorado em Oceanografia Biológica)- Instituto Oceanográfico, Universidade de São Paulo, São Paulo.

PERKINS, E. J. 1974. The biology of estuaries and coastal waters. London: Academic Press, 678 p.

PESSANHA, A.L.; ARAÚJO F.G. 2001. Recrutamento do peixe-rei Xenomelaniris brasiliensis (Atheriniformes, Atherinopsidae), na margem continental da Baía de Sepetiba, Rio de Janeiro, Brasil. Rev. bras. Zool., v. 18, n. 4, p. 1265-1274.

PESSANHA, A. L. M. ; ARAÚJO, F. G. 2003. Spatial, temporal and diel variations of fish assemblages at two sandy beaches in the Sepetiba Bay, RJ. Estuar., coast. shelf sci., v. 57, n. 5-6, p. 817 - 828.

PRITCHARD, D. W. 1967. What is an estuary: Physical viewpoint. In: LAUFF, G. H. Estuaries. Washington: Am. Assoc. Adv. Sci., v. 88: 3-5.

RAMOS, E. B.; GALLO, J.; VERRONE, V. M. A. 1980. Áreas da região lagunar de Cananéia-Iguape suscetíveis de exploração pesqueira segundo diversos tipos de tecnologia. I- Pesca com cerco fixo. Bol. Inst. Oceanogr., v. 29, n. 2, p. 329-335.

RAMOS, L.A.; VIEIRA, J.P. 2001. Composição específica e abundância de peixes de zonas rasas dos cinco estuários do Rio Grande do Sul, Brasil. Bol. Inst. Pesca, v. 21, n. 1, p. 109-121.

RICHARDS, W. J. 2006. Early stages of Atlantic Fishes: an identification guide for the Western Central North Atlantic. Boca Raton: CRC Press, 2640 p.

RODRIGUES, F.L.; VIEIRA, J.P.; LOEBMANN, D.; RASEIRA, M.B. 2010. Variações temporais de curto prazo na ictiofauna da zona de arrebentação da Praia do Cassino, Rio Grande do Sul, RS, Brasil. In: Anais do III Congresso Brasileiro de Oceanografia, Rio Grande. CD-ROOM.

ROMER, G.S. 1990. Surf zone fish community and species response to wave energy gradient. J. fish biol., v. 36, p. 279-287 
ROSS, S. W.; MCMICHAEL, R. H., JR; RUPLE, D. L. 1987. Seasonal and diel variation in the standing crop of fishes and macroinvertebrates from a Gulf of Mexico surf zone. Estuar., coast. shelf. sci., v. 25, n. 4, p. 391-412.

RULIFSON, R.A. 1977. Temperature and water velocity effects on the swimming performances of young-of-the-year striped mullet (Mugil cephalus), spot (Leiostomus xanthurus), and pinfish (Lagodon rhomboides). J. Fish. Res. Board Can., v. 34, p. 2316-2322.

SANTANA, F.M.S.; SEVERE, W. 2009. Composição e estrutura da assembléia de peixes da zona de arrebentação da praia de Jaguaribe, Itamaracá (PE). Bioikos, v.23, n.1, p.3-17.

SANTOS, P. J. P. 1994. Environmental characterization of sandy beaches in southern Brasil. Nerítica, v. 8, p. 31-45.

SANTOS, R.S.; NASH, R.D.M. 1995. Seazonal changes in a sandy beach fish assemblage at Porto Pim, Faial, Azores. Estuar., cost. shelf sci., v. 41, n. 6, p. 579-591.

SANTOS-NININ, A. P. 2008. Morfologia e distribuição de peixes da família Sciaenidae no estágio de transformação na costa sul e sudeste do Brasil. 194 f. Tese (Doutorado em Oceanografia Biológica)- Instituto Oceanográfico, Universidade de São Paulo, São Paulo.

SATO, N.; ASAHIDA, T.; TERASHIMA, H.; HURBUNGS, M.D.; IDA, H. 2008. Species composition and dynamics of larval and juvenile fishes in the surf zone of Mauritius. Environ. biol. Fishes, v. 81, n. 2, p. 229-238.

SAUL, A. C.; CUNNINGHAM, P. T. M. 1995. Comunidade ictiofaunística da ilha do Bom Abrigo, Cananéia.Brasil. 2- Lanço. Arq. Biol. Tecnol., v. 38, n. 4, p. 1053 1069.

SCHWINGEL, P.R; OCCHIALINI, D.S. 2007. Descrição e dinâmica de frota de traineiras no porto de Itajaí (SC) entre 1997 e 1999. In: ROSSIWONGTSCHOWSKI, C.L.D.B; BERNARDES, R. A.; CERGOLE, M.C. (ed.) 2007. Dinâmica das frotas pesqueiras comerciais da região sudeste-sul do Brasil. EDUSP, Série documentos REVIZEE, 343 p.

SELLESLAGH, J.; AMARA, R. 2008. Inter-season and interannual variations in fish and macrocrustacean community structure on a eastern English Channel sandy beach: influence of environmental factors. Estuar., cost. shelf sci., v. 77, n.4, p.721-730. 
SILVA, F.M.S. 2007. Biologie, Pêche et Dynamique de la Population de Mulet Blanc (Mugil curema, Valenciennes, 1836) de Pernambuco - Brasil. 260 f. Tese (Doutor em Oceanografia Biológica)- Université de Bretagne Occidentale, França.

SILVA, I. F., 1989. Dados climatológicos de Cananéia e Ubatuba (Estado de São Paulo). Série de 1956-1985. Bol. climatol., v.6, p.1-21.

SOKAL, R.R.; ROHLF, F.J. 1995. Biometry: the principles and practice of statistics in biological research. New York: W.H. Freeman and Co. 887 p.

SPACH, H.L.; GODEFROID, R.S.; SCHWARZ Jr., R.; QUEIROZ, M.L. de. 2004. Temporal variation in fish assemblage composition on a tidal flat. Braz. j. oceanogr., v.52, n.1. p.47-58.

SPINELLI, F.P; GOMES, C.B. 2008. A Ocorrência Alcalina de Cananéia, Litoral Sul do Estado de São Paulo: Geologia e Geocronologia. Geol. USP Sér. Cient., v.8, n.2, p.53-64.

SPRING, V.G.; WOODBUM, K.D. 1960. An ecological study of the fishes of the Tamba Bay area. Prof. pap. ser.- Fla, Mar. Res. Lab., v.1, p.1-104.

STEFANONI, M.F. 2008. Ictiologia e ecologia trófica de peixes em ambientes praias da Ilha das Peças, Complexo Estuarino de Paranaguá, Paraná. 154 f. Dissertação (Mestrado em Zoologia)- Setor de Ciências Biológicas, Universidade Federal do Paraná, Curitiba.

STRYDOM, N.A. 2003. Occurrence of larval and early juvenile fishes in the surf zone adjacent to two intermittently open estuaries, South Africa. Environ. biol. Fishes, v. 66 , n. 3, p. 349-359.

SUDA, Y.; INOUE, T.; UCHIDA, H. 2002. Fish Communities in the Surf Zone of a Protected Sandy Beach at Doigahama, Yamaguchi Prefecture, Japan. Estuar., coast. shelf sci., v. 55, n. 1, p. 81-96.

SUGUIO, K.; TESSLER, M. G. 1992. Depósitos quaternários da planície costeira de Cananéia-Iguape (SP). Publ. espec. Inst. oceanogr., v. 9, p. 1-33.

TEIXEIRA, R.L.; ALMEIDA, G.I. 1998. Composição da ictiofauna de três praias arenosas de Maceió, AL- Brasil. Bol. Mus. Biol. Mello Leitão, v.8, p.21-38.

TESSLER, M.G. 1982. Sedimentação atual na região lagunar de Cananéia-Iguape, estado de São Paulo. 110 f. Dissertação (Mestrado em Geologia)- Instituto de Geociências, Universidade de São Paulo, São Paulo. 
TESSLER, M.G.; SUGUIU, K.; MAHIQUES, M.M. de; FURTADO, V.V. 1990. Evolução temporal e espacial da desembocadura lagunar de Cananéia (SP). Bol. Inst. Oceanogr., v. 38, p. 23-29.

TESSLER, M. G.; DE SOUZA, L. A. P. 1998. Dinâmica sedimentar e feições sedimentares identificadas na superfície de fundo do sistema Cananéia-Iguape, SP. Bol. Inst. Oceanogr., v. 46, p. 69-93.

VASCONCELLOS, R.M.; SANTOS, J.N. DE S.; SILVA, M. DE A.; ARAÚJO, F.G. 2007. Efeito do grau de exposição às ondas sobre a comunidade de peixes juvenis em praias arenosas do Município do Rio de Janeiro, Brasil. Biota neotrop., v. 7, n. 1, p. 93-100.

VAZZOLER, A. E. A. M. 1981. Manual de métodos para estudos biológicos de populações de peixes - reprodução e crescimento. Brasília: CNPq, Programa Nacional de Zoologia, 108p.

VAZZOLER, A.E.A.M. 1996. Biologia da reprodução de peixes teleósteos: Teoria e prática. Maringá: Eduem. 169p.

VIEIRA, J.P. 1991. Juvenile Mullets (Pisces:Mugilidae) in the Estuary of Lagoa dos Patos, RS, Brazil. Copeia, v. 2, p. 409-418.

VIEIRA, J.P.; SCALABRIN, C. 1991. Migração reprodutiva da "Tainha" (Mugil platanus GUNTHER, 1980) no sul do Brasil. Attântica, v. 13, n. 1, p. 131-141.

WARDLE, C.S. 1993. Fish behaviour and fishing gear. In: PITCHER, T. (Ed.) Behaviour of teleost fishes. London: Chapman Hall, $715 \mathrm{p}$.

WATT- PRINGLE, P.; STRYDOM, N.A. 2003. Habitat use by larval fishes in a temperate South African surf zone. Estuar., cost. shelf sci., v. 58, p. 765-774.

WENER, R. G., 2002. Habitat Requeriments. In: FUIMAN, L. A.; WENER, R. G. Fishery Science: The unique contributions of early life history. United Kingdom: Blackwell Science, p.161-182.

WILBER, D.H.; ClARKE, D.G.; BURLAS, M.H.; RUBEN, H. WILL, R.J. 2003. Spatial and temporal variability in surf zone fish assemblages on the coast of northern New Jersey. Estuar., cost. shelf sci., v. 56, n. 1, p. 291-304.

WRIGHT, P.J.; TOBIN, D.; GIBB, F.M.; GIBB, I.M. 2010. Assessing nursery contribution to recruitment: relevance of closed areas to haddock Melanogrammus aeglefinus. Mar. ecol. Prog. ser., v. 400, p. 221-232. 
YÁÑES-ARANCIBA, A. 1985. The estuarine nekton: why and how an ecology monography. In: YÁÑES-ARANCIBA, A. Fish community ecology in estuaries and coastal lagoons: towards an ecosystem integration. Cidade do México: UNAM Press, p. 1-8.

ZANI-TEIXEIRA, M. L., 1983. Contribuição ao conhecimento da ictiofauna da Baía do Trapandé, Complexo Estuarino Lagunar de Cananéia, São Paulo. 254 f. Dissertação (Mestrado em Oceanografia Biológica)- Instituto Oceanográfico, Universidade de São Paulo, São Paulo. 